Florida International University

FIU Digital Commons

6-17-2019

\title{
Topoisomerase and Tyrosyl-DNA-phosphodiesterase Ratio as an Indicator for the Response of Glioblastoma Cancer to Topoisomerase Targeting Anticancer Drugs
}

Wenjie Wang

wwang036@fiu.edu

Follow this and additional works at: https://digitalcommons.fiu.edu/etd

Part of the Biochemistry Commons, Biological Factors Commons, Enzymes and Coenzymes Commons, and the Nervous System Diseases Commons

\section{Recommended Citation}

Wang, Wenjie, "Topoisomerase and Tyrosyl-DNA-phosphodiesterase Ratio as an Indicator for the Response of Glioblastoma Cancer to Topoisomerase Targeting Anticancer Drugs" (2019). FIU Electronic Theses and Dissertations. 4254.

https://digitalcommons.fiu.edu/etd/4254

This work is brought to you for free and open access by the University Graduate School at FIU Digital Commons. It has been accepted for inclusion in FIU Electronic Theses and Dissertations by an authorized administrator of FIU Digital Commons. For more information, please contact dcc@fiu.edu. 


\section{FLORIDA INTERNATIONAL UNIVERSITY}

Miami, Florida

TOPOISOMERASE AND TYROSYL-DNA PHOSPHODIESTERASE RATIO AS AN INDICATOR FOR THE RESPONSE OF GLIOBLASTOMA CANCER TO TOPOISOMERASE TARGETING ANTICANCER DRUGS

A dissertation submitted in partial fulfillment of the requirements for the degree of DOCTOR OF PHILOSOPHY

in

CHEMISTRY

by

Wenjie Wang 
To: Dean Michael R. Heithaus

College of Arts, Sciences and Education

This dissertation, written by Wenjie Wang, and titled Topoisomerase and TyrosylDNA-phosphodiesterase Ratio as an Indicator for the Response of Glioblastoma Cancer to Topoisomerase Targeting Anticancer Drugs, have been approved in respect to style and intellectual content, is referred to you for judgment.

We have read this dissertation and recommend that it be approved

$\begin{array}{r}\text { Alexander Mebel } \\ \hline \text { Jeremy Chambers } \\ \hline \text { Yuatson Lees } \\ \hline \text { Yuk-Ching Tse-Dinh, Major Professor }\end{array}$

Date of Defense: June 17, 2019

The dissertation of Wenjie Wang is approved

Dean Michael R. Heithaus

College of Arts, Sciences and Education

Andrés G. Gil

Vice President for Research and Economic Development and Dean of the University Graduate School

Florida International University, 2019 
(C) Copyright 2019 by Wenjie Wang

All rights reserved 


\section{DEDICATION}

I dedicate this dissertation to my parents and grandparents. Without their patience, understanding, and most of all, love, the completion of this work would not have been possible. 


\section{ACKNOWLEDGMENTS}

I am grateful to every individual that I have met during my Ph.D. period for their unconditional support and generosity toward me. First, I would like to thank my committee members as they have made it possible for me to go this far into my Ph.D. route. A special appreciation goes to my mentor Dr. Yuk-Ching Tse-Dinh, the most generous and understandable professor I have ever met, who provided numerous scientific ideas, taught me how to be a student, a team-worker, a scientist, and most importantly, a person. I also appreciate Dr. Jeremy Chambers and his staff, Dr. Arlet Maria Acanda De La Rocha and Dr. Monica Rodriguez Silva, who have been selflessly helping me with my cell culture work and have been sharing their work area with me. Dr. Chambers's guidance on cancer research allowed me to stay on the right track throughout my project. I would like to appreciate Dr. Yuan Liu and her coworker Dr. Yanhao Lai who have also been generously supporting my work throughout these years. I would also like to thank the advice that our program director, Dr. Watson Lees, provided me with related to my life and work whenever I would search for it. I would also like to thank Dr. Alexander Mebel, who was the first person I spoke with in FIU, with his biggest smile that always makes me feel at home. Secondly, I would like to thank my lab mates. Thanks to Dr. Arasu Annamalai, who is the most helpful person in the lab and always keeping everything running on their right track. Thanks to all the lab members I met. They inspired me and stimulated me to work harder and think more in-depth in the scientific area every single day. Thanks to Maggie Autie, the most fabulous department secretary at FIU, who gave me the most significant 
support during my toughest days. I want to thank all my friends who are supporting me for years and making my life colorful from the very start. Lastly, I am grateful for the generous financial support by FIU as a teaching assistant for years and thanks to the Dissertation Year Fellowship, helping me to accomplish my manuscripts for publication and dissertation on time. 


\title{
ABSTRACT OF THE DISSERTATION \\ TOPOISOMERASE AND TYROSYL-DNA PHOSPHODIESTERASE RATIO AS \\ AN INDICATOR FOR THE RESPONSE OF GLIOBLASTOMA CANCER TO \\ TOPOISOMERASE TARGETING ANTICANCER DRUGS
}

\author{
by \\ Wenjie Wang \\ Florida International University, 2019 \\ Miami, Florida \\ Professor Yuk-Ching, Tse-Dinh, Major Professor
}

Glioblastoma (GBM) patients have an estimated survival of $\sim 15$ months, with the standard of care (surgery, radiation, and chemotherapy) that has only modestly enhanced patient survival. Identifying biomarkers representing vulnerabilities in GBM biology may allow for the selection of effective and safe chemotherapy options. Irinotecan (IRT), a genotoxic compound currently in clinical trials for GBM, targets topoisomerase I (TOP1) by forming an irreversible ternary DNA-TOP1 cleavage complex (TOP1cc) and leads to apoptosis. Tyrosyl-DNA phosphodiesterase 1 (TDP1) is a crucial repair enzyme that rescues TOP1cc and reduces the effectiveness of IRT. In the current study, we evaluate the value of the TDP1/TOP1 activity ratio as a prospective biomarker for the personalized use of IRT on GBM patients.

After analysis of susceptibility of nine GBM cell lines to IRT treatment along with TDP1 and TOP1 expression and activity levels in these cell lines, we found 
that the TDP1/TOP1 activity ratio had the strongest correlation $(R=0.972$, $\mathrm{P}=1.2 \times 10^{-5}$ ) with IRT IC 50 values for a decrease of cell viability following IRT treatment. Increasing the TDP1/TOP1 activity ratio by ectopic expression of wildtype TDP1 increased in IRT IC 50 , while expression of the TDP1 catalytic-null mutant did not alter the susceptibility to IRT. Further, after analyzing GBM patient tumors, TDP/TOP1 activity ratio was found to correlate $(R=-0.707, P=0.03)$ with patient survival significantly. Correlations were also observed between patient age and survival this set of GBM patients $(R=-0.929, P=0.023)$ as well as $G B M$ patients in the TCGA database $\left(R=-0.353, P=7.7 \times 10^{-17}\right)$.

From our results, we suggested that the TDP1/TOP1 activity ratio may be a new predictive indicator for GBM vulnerability to IRT, which may allow for the selection of individual patients for IRT treatment based on risk-benefit. As a predictor, the lower TDP1/TOP1 activity ratio would correspond to higher IRT cytotoxicity. In addition, TDP1/TOP1 activity ratio might be a potential prognostic indicator for GBM patient survival. The lower TDP1/TOP1 ratio would correspond to patients with longer survival probability. Finally, inhibitors of TDP1 may be useful for novel combination therapy with IRT to improve GBM patient responsiveness to genotoxic chemotherapies. 


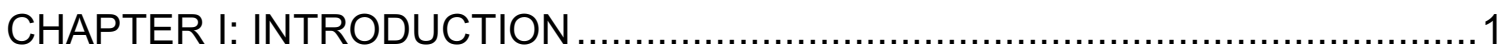

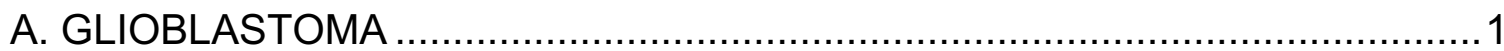

B. HUMAN TOPOISOMERASE I (TOP1) ..............................................

C. HUMAN TYROSYL-DNA PHOSPHODIESTERASE 1 (TDP1) ....................11

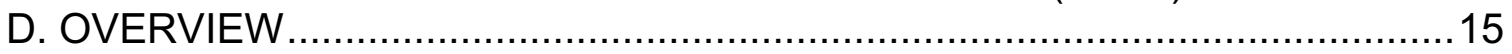

CHAPTER II: TDP1/TOP1 ACTIVITY RATIO AS AN INDICATOR FOR GBM CELL LINE RESPONSE TO IRT TREATMENT ….....................................17

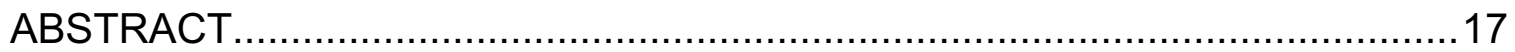

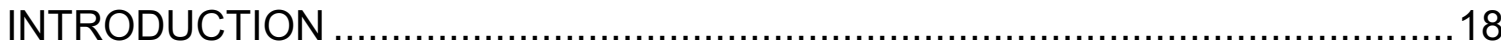

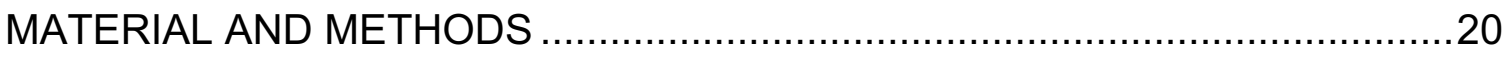

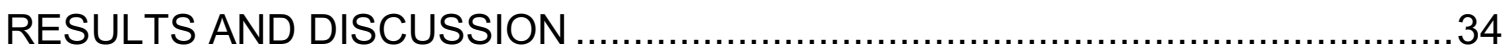

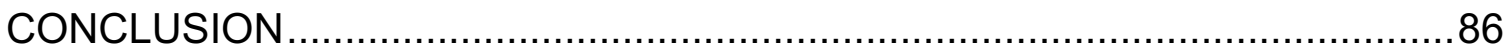

CHAPTER III: STUDY OF TOP1 AND TDP1 IN GBM STEM CELLS AND

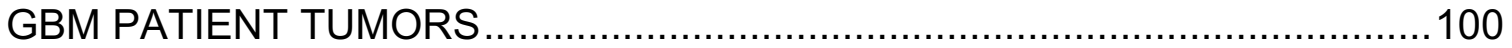

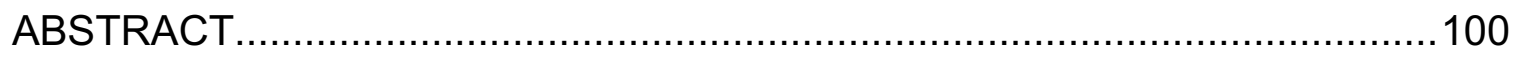

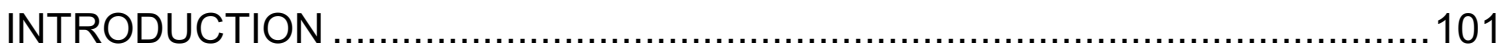

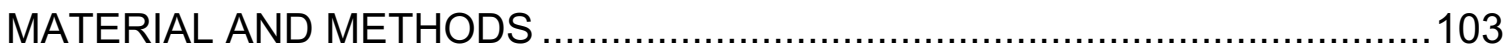

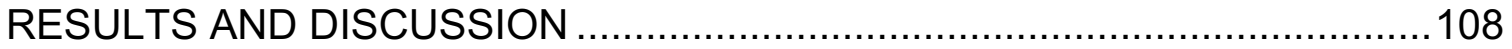

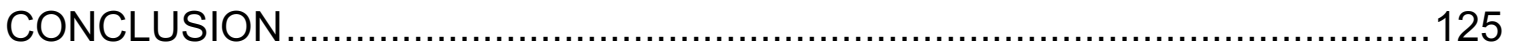

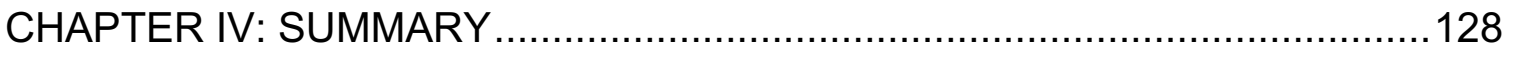

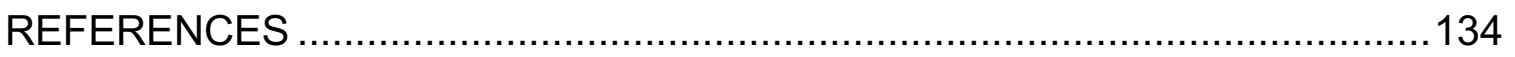

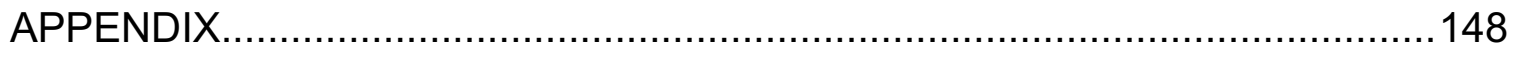

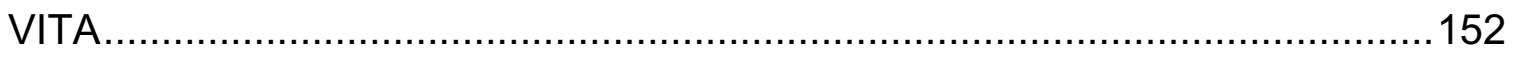




\section{LIST OF TABLES}

CHAPTER

PAGE

CHAPTER II

Table 2.1. Glioblastoma cell line information ..............................................20

Table 2.2. Information of primary and secondary antibody ............................23

Table 2.3. DNA oligo and primers used in this study ...................................27

Table 2.4. Topoisomerase I/II inhibitor sensitivity data for GBM cell lines ..........35

Table 2.5. Relative TOP1 protein expression level of GBM cell lines ................39

Table 2.6. The mRNA expression of TOP1 and TDP1 in GBM cell lines and their IRT IC 50 $_{5}$ available in the CellMinerCDB database

Table 2.7. TOP1 activity and the relative TOP1 activity level of GBM cell lines ..46

Table 2.8. Relative TDP1 protein expression level in GBM cell lines .................54

Table 2.9. TDP1 activity and relative TDP1 activity levels in GBM cell lines.......58

Table 2.10. TDP1 activity and relative TDP1 activity levels in GBM cell lines.....58

Table 2.11. TDP1/TOP1 protein ratio and TDP1/TOP1 activity ratio of GBM cell lines.

Table 2.12. TDP1/TOP1 protein ratio and TDP1/TOP1 activity ratio of GBM cell lines

Table 2.13. Correlation of experimental TOP1, TDP1, and TDP1/TOP1 ratio with experimental IC 50 of IRT in GBM cell lines

Table 2.14. Correlation of experimental TOP1, TDP1, and TDP1/TOP1 ratio with Z-score of IRT in GBM cell lines from CellMiner database

Table 2.15. Correlation of experimental TOP1, TDP1, and TDP1/TOP1 ratio with Z-score of Camptothecin in GBM cell lines from CellMiner database...

Table 2.16. Correlation of experimental TOP1, TDP1, and TDP1/TOP1 ratio with Z-score of Topotecan in GBM cell lines from CellMiner database 
Table 2.17. Correlation of experimental TOP1, TDP1, and TDP1/TOP1 ratio with Z-score of Etoposide in GBM cell lines from CellMiner database .

Table 2.18. Correlation of experimental TOP1, TDP1, and TDP1/TOP1 ratio with Z-score of Doxorubicin in GBM cell lines from CellMiner database

Table 2.19. Correlation of experimental TOP1, TDP1, and TDP1/TOP1 ratio with fold-increase in TOP1cc level at $15 \mathrm{~min}, 30 \mathrm{~min}$, and $60 \mathrm{~min}$ following $15 \mu \mathrm{M}$ IRT treatment of GBM cell lines

Table 2.20. Comparison of TOP1, TDP1, TDP1/TOP1 levels in three sets of experiments and three different database panels

Table 2.21. Correlation of TOP1 level with TDP1 level in GBM cell lines .98

Table 2.22. Comparison of protein level with activity level of TOP1 and TDP1 in GBM cell

Table 2.23. Correlation of protein level with mRNA level in GBM cell lines .99 CHAPTER III

Table 3.1 GBM Patient information 105

Table 3.2 TOP1, TDP1, and TDP1/TOP1 ratio of GSC cell lines 109

Table 3.3. Relative levels of TOP1, TDP1 protein and activity plus TDP1/TOP1 protein and activity ratio in GBM tumors

Table 3.4. Correlations of patient survival and diagnosis age among cancers from TCGA database

Table 3.5. GBM tumor information from TCGA database

Table 3.6. Correlation between TOP1 and TDP1 levels in GBM cell lines, GSC cell lines, and GBM tumors

Table 3.7. Correlation between protein level and activity level of TOP1, TDP1, as well as TDP1/TOP1 ratio in GBM cell lines, GSC cell lines, and GBM tumors.

CHAPTER IV

Table 4.1 Correlations between gel-based assay and fluorescence-based assay for the measurement of TDP1 activity 
Table 4.2. Correlations between TDP1/TOP1 activity ratio and GBM sensitivities to topoisomerase inhibitors treatment. 


\section{LIST OF FIGURES}

CHAPTER

PAGE

CHAPTER I

Figure 1.1. Distribution of different classes of CNS tumors. 1

Figure 1.2. Classes of human topoisomerase and covalent topoisomerase

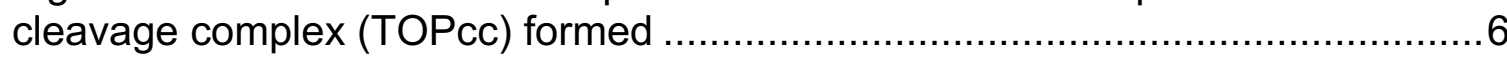

Figure 1.3. Human topoisomerase I inhibitors and TOP1cc ternary complex .......8

Figure 1.4. Human tyrosyl-DNA phosphodiesterase 1 and 2 functions for rescuing topoisomerase cleavage complexes

Figure 1.5. TDP1 and TDP2 catalytic mechanisms ......................................14

Figure 1.6 Diagram of TOP1 and TDP1 functions in GBM with IRT treatment ...16 CHAPTER II

Figure 2.1. Typical color response curves for BSA using the BCA assay .22

Figure 2.2. Dynamic range and sensitivity of the Quant-iT PicoGreen dsDNA assay.

Figure 2.3. Diagram of GBM cell viabilities with serial dilutions of Irinotecan

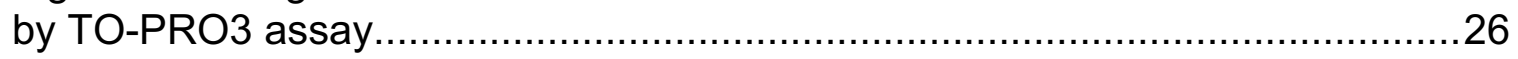

Figure 2.4. Diagram of TOP1 relaxation assay ...........................................29

Figure 2.5. Diagram of gel-based TDP1 activity assay …..............................31

Figure 2.6. Diagram of fluorescence-based TDP1 activity assay .......................32

Figure 2.7. Diagram of CES2 catalytic activity measurement …......................33

Figure 2.8. Comparison of experimental IRT IC $\mathrm{C}_{50}$ S against GBM cell lines to IRT sensitivities from databases.

Figure 2.9. Coomassie blue staining of GBM cell lines

Figure 2.10. Comparison of topoisomerase I protein level in GBM cell lines to assess potential correlation with Irinotecan sensitivities from experiments and databases 
Figure 2.11. Lack of correlation between TOP1 mRNA expression data and Irinotecan $\mathrm{IC}_{50}$ s against $\mathrm{GBM}$ cell lines from CellMinerCDB database.

Figure 2.12. Comparison of TOP1 protein level with TOP1 mRNA level.

Figure 2.13. Topoisomerase I activity from recombinant human TOP1

Figure 2.14. Comparison of TOP1 activity in GBM cell lines to assess potential correlation with Irinotecan sensitivities from experiments and databases

Figure 2.15. Lack of correlation between TOP1 protein levels and TOP1 activity levels.

Figure 2.16. Comparison of TDP1 protein levels in GBM cell lines to assess potential correlation with Irinotecan sensitivities from experiments and databases

Figure 2.17. Comparison of TOP1 level with TDP1 level

Figure 2.18. Comparison of TOP1 mRNA expression and Irinotecan $\mathrm{IC}_{50 \mathrm{~S}}$ against GBM cell lines from CellMinerCDB database

Figure 2.19. Comparison of TDP1 protein level with TDP1 mRNA level

Figure 2.20. Tyrosyl-DNA phosphodiesterase 1 activity from recombinant human TDP1.

Figure 2.21. Comparison of TOP1 activity level with TDP1 activity level 59

Figure 2.22. Comparison of TDP1 activity by gel-based assay in GBM cell lines to assess potential correlation with Irinotecan sensitivities from experiments and databases

Figure 2.23. Comparison of TDP1 activity by fluorescence-based assay in GBM cell lines to assess potential correlation with Irinotecan sensitivities from experiments and databases

Figure 2.24. Comparison of gel-based and fluorescence-based assays for TDP1 activity measurement.

Figure 2.25. Correlation between TDP1 protein levels and TOP1 activity levels.

Figure 2.26. Comparison of TDP1/TOP1 protein ratio in GBM cell lines to assess potential correlation with Irinotecan sensitivities 
Figure 2.27. Comparison of TDP1/TOP1 mRNA ratio in GBM cell lines from CellMinerCDB database to assess potential correlation with Irinotecan sensitivities

Figure 2.28. Comparison of TDP1/TOP1 protein ratio with TDP1/TOP1 mRNA ratio

Figure 2.29. Comparison of gel-based TDP1/TOP1 activity ratio in GBM cell lines to assess potential correlation with Irinotecan sensitivities .73

Figure 2.30. Comparison of fluorescence-based TDP1/TOP1 activity ratio in GBM cell lines to assess potential correlation with Irinotecan sensitivities

Figure 2.31. Correlation between TDP1/TOP1 protein ratios and TDP1/TOP1 activity ratios

Figure 2.32. Comparison of TDP1/TOP1 ratio in GBM cell lines with Irinotecan sensitivities from CancerDR database.

Figure 2.33. Assessment of potential correlation between sensitivities of GBM cell lines to human topoisomerase I/Il poisons and TDP1/TOP1 ratios in GBM cell lines.

Figure 2.34. TOP1cc level in GBM cell lines following IRT treatment ................78

Figure 2.35. No significant changes of TOP1 and TDP1 protein and activity

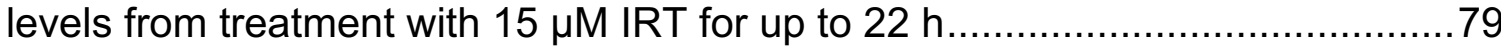

Figure 2.36. Carboxylesterase 2 (CES2) activity in GBM cell lines ...................81

Figure 2.37. Transfection induced increase of TDP1/TOP1 activity ratio in $\mathrm{H} 4$ GBM cell line results in a higher Irinotecan IC50.

Figure 2.38. Time effects on post-transfection of TDP1 in H4 cell line. 85

Figure 2.39. Protein expression level and activity level of TOP1 and TDP1 from all three sets of GBM cell line experiments

CHAPTER III

Figure 3.1. Analysis of WCE of glioblastoma stem cells

Figure 3.2. Comparison of TOP1, TDP1, and TD1P/TOP1 ratio levels in GSC cell lines with Irinotecan sensitivities

Figure 3.3.TOP1 and TDP1 levels in GBM and GSC cell lines 
Figure 3.4. Analysis of TOP1 protein expression and activity levels of GBM

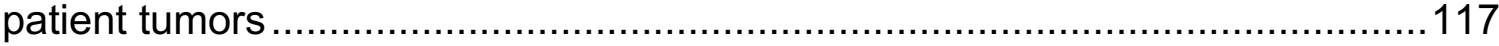

Figure 3.5. Analysis of TDP1 protein expression and activity levels of GBM

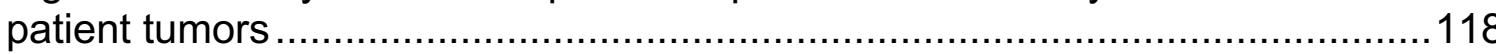

Figure 3.6. Analysis of TDP1/TOP1 ratios of GBM patient tumors ..................118

Figure 3.7. Correlations between patient age and survivals..........................119

Figure 3.8. Correlations between TOP1, TDP1, TDP1/TOP1 ratio in GBM

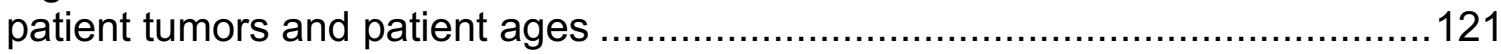

CHAPTER IV

Figure 4.1. TDP1/TOP1 activity ratios of GBM cell lines and patient tumors ....133 


\section{ABBREVIATION AND ACRONYMS}

\begin{tabular}{|c|c|}
\hline APS & ammonium persulfate \\
\hline AP site (abasic site) & Apurinic/apyrimidinic site \\
\hline ASD & autism spectrum disorder \\
\hline ATCC & American Type Culture Collection \\
\hline ATM & ataxia-telangiectasia mutated \\
\hline ATP & adenosine triphosphate \\
\hline ATR & ataxia telangiectasia and Rad3-related protein \\
\hline BBB & blood-brain barrier \\
\hline $\mathrm{BHQ}$ & Black Hole Quencher \\
\hline BRD4 & bromodomain-containing protein 4 \\
\hline BSA & bovine serum albumin \\
\hline CancerDR & Cancer Drug Resistance \\
\hline CCEL & Broad Institution Cancer Cell Lines Encyclopedia \\
\hline CellMinerCDB & CellMiner Cross Database \\
\hline CES2 & carboxylesterase 2 \\
\hline CPT & Camptothecin \\
\hline CNS & central neural system \\
\hline $\csc$ & cancer stem cells \\
\hline CTRP & Cancer Therapeutics Response Portal \\
\hline DC & vaccine: dendritic cell vaccine \\
\hline DCTD & $\begin{array}{l}\text { National Cancer Institution Division of Cancer } \\
\text { Treatment and Diagnosis }\end{array}$ \\
\hline
\end{tabular}




\begin{tabular}{|c|c|}
\hline DDIA & DNA damage-induced apoptosis \\
\hline DDR & DNA damage response \\
\hline DMEM & Dulbecco's Modified Eagle's medium \\
\hline DMSO & dimethyl sulfoxide \\
\hline DNA & deoxyribonucleic acid \\
\hline DOX & doxorubicin \\
\hline DPCC & DNA-protein covalent complexes \\
\hline DSB & double-strand break \\
\hline dsDNA & double-stranded DNA \\
\hline DSHB & Developmental Studies Hybridoma Bank \\
\hline DTT & dithiothreitol \\
\hline E. coli & Escherichia coli \\
\hline EDTA & ethylenediaminetetraacetic acid \\
\hline EGFR & epidermal growth factor receptor \\
\hline EMT & epithelial to mesenchymal transition \\
\hline $\mathrm{EtBr}$ & ethidium bromide \\
\hline ETO & etoposide \\
\hline FBS & fetal bovine serum \\
\hline FDA & Food and Drug Administration \\
\hline FPKM & $\begin{array}{l}\text { fragments per kilobase of exon model per million reads } \\
\text { mapped }\end{array}$ \\
\hline GBM & glioblastoma \\
\hline GDC & Genomic Data Commons \\
\hline
\end{tabular}




\begin{tabular}{|c|c|}
\hline GDSC & Genomics of Drug Sensitivity in Cancer \\
\hline GSARC & Gliosarcoma \\
\hline GSC & glioblastoma stem cell \\
\hline HRP & horse-radish peroxidase \\
\hline $\mathrm{IC}_{50}$ & The half maximal inhibitory concentration \\
\hline IDH & isocitrate dehydrogenase \\
\hline IRT & Irinotecan \\
\hline $\mathrm{h}$ & hour \\
\hline hTOP1 & recombinant human topoisomerase I \\
\hline hTDP1 & recombinant human tyrosyl-DNA phosphodiesterase 1 \\
\hline $\mathrm{kDa}$ & kilodalton \\
\hline kDNA & Kinetoplast DNA \\
\hline LBN & $\mathrm{NaCl}$ - lysogeny broth \\
\hline LOP & loperamide \\
\hline mAMSA & amsacrine \\
\hline $\mathrm{mCRC}$ & metastatic colorectal cancer \\
\hline MGMT & methylguanine methyltransferase \\
\hline $\min$ & minute \\
\hline MIT & Massachusetts Institute of Technology \\
\hline mRNA & Messenger RNA \\
\hline Mtb & Mycobacterium tuberculosis \\
\hline $\mathrm{NaOH}$ & sodium hydroxide \\
\hline $\mathrm{NCl}$ & National Cancer Institute \\
\hline
\end{tabular}


nt

NEB

NHA

$\mathrm{NIH}$

NSCLC

NTD

PARP

PBS

PCR

PDB

PenStrep

PFA

PFS

PI

PMSF

PNKP

p-NP

p-NPA

PTM

RADAR

RIPA

RNA

RNAPII nucleotide

New England Biolab

normal human astrocyte

national institute of health

non-small cell lung cancer

$\mathrm{N}$-terminal domain

poly(ADP-ribose) polymerase

phosphate-buffered saline

polymerase chain reaction

protein-linked DNA break

penicillin/streptomycin

paraformaldehyde/PBS

progression-free survival

Isoelectric point

phenylmethaneasulfonyl fluoride

polynucleotide kinase phosphatase

para-nitrophenol

4-nitrophenyl acetate

post-translational modification

rapid approach to DNA adduct recovery

radioimmunoprecipitation assay buffer

ribonucleic acid

RNA polymerase II 


\begin{tabular}{|c|c|}
\hline ROS & reactive oxygen species \\
\hline RPPA & reverse-phase protein array \\
\hline RT & room temperature \\
\hline s: & second \\
\hline SCAN1 & spinocerebellar ataxia with axonal neuropathy \\
\hline SCLC & small cell lung cancer \\
\hline SDM & site-directed Mutagenesis \\
\hline SDS-PAGE & $\begin{array}{l}\text { sodium dodecyl sulfate-polyacrylamide gel } \\
\text { electrophoresis }\end{array}$ \\
\hline SNP & single nucleotide polymorphism \\
\hline SSB & single-strand break \\
\hline SWATH-MS & $\begin{array}{l}\text { sequential window acquisition of all theoretical mass } \\
\text { spectra }\end{array}$ \\
\hline TBS & tris-buffered saline \\
\hline TBST & $1 \%$ Tween20 in TBS \\
\hline TCGA & the cancer genome atlas \\
\hline TDP1 & tyrosyl-DNA phosphodiesterase 1 \\
\hline TDP2 & tyrosyl-DNA phosphodiesterase 2 \\
\hline TEMED & $\mathrm{N}, \mathrm{N}, \mathrm{N}, \mathrm{N}$ ', N'-tertramethylethylenediaine \\
\hline TMZ & temozolomide \\
\hline TOP1 & topoisomerase \\
\hline TOP1mt & mitochondria topoisomerase I \\
\hline TOP2A & DNA topoisomerase II alpha \\
\hline TOP1cc & topoisomerase I cleavage complexes \\
\hline
\end{tabular}




$\begin{array}{ll}\text { TPT } & \text { topotecan } \\ \text { TRAIL } & \begin{array}{l}\text { Tumor necrosis factor-related apoptosis-inducing } \\ \text { ligand }\end{array} \\ \text { UPP } & \text { Ubiquitin-proteasome pathway } \\ \text { VEGF } & \text { Vascular endothelial growth factor } \\ \text { WCE } & \text { whole cell extract } \\ \text { WHO } & \text { World Health Organization } \\ \text { WT } & \text { wide-type }\end{array}$




\section{CHAPTER I: INTRODUCTION}

\section{A. GLIOBLASTOMA}

Glioblastoma (GBM), accounting for $50 \%$ of all malignant central nervous system (CNS) tumors in adults (Figure 1.1), is the most deadly primary brain cancer with a 14.6-month median survival and a median diagnosis age around 64 (1-3). GBM is defined as grade IV gliomas, which has the highest malignancy designated by the World Health Organization (WHO). GBM, with elusively pathophysiologic mechanism, is histologically derived from astrocytes which are essential for nutrients support of nervous tissues. Even with maximal surgical excision followed by radiotherapy, the invasive nature of GBM is most likely leading to an inexorable relapse, which results in poor clinical outcomes indicated by a $\sim 5.5 \%$ survival after five years. Thus, there is an urgent need for effective therapy to treat patients (4).

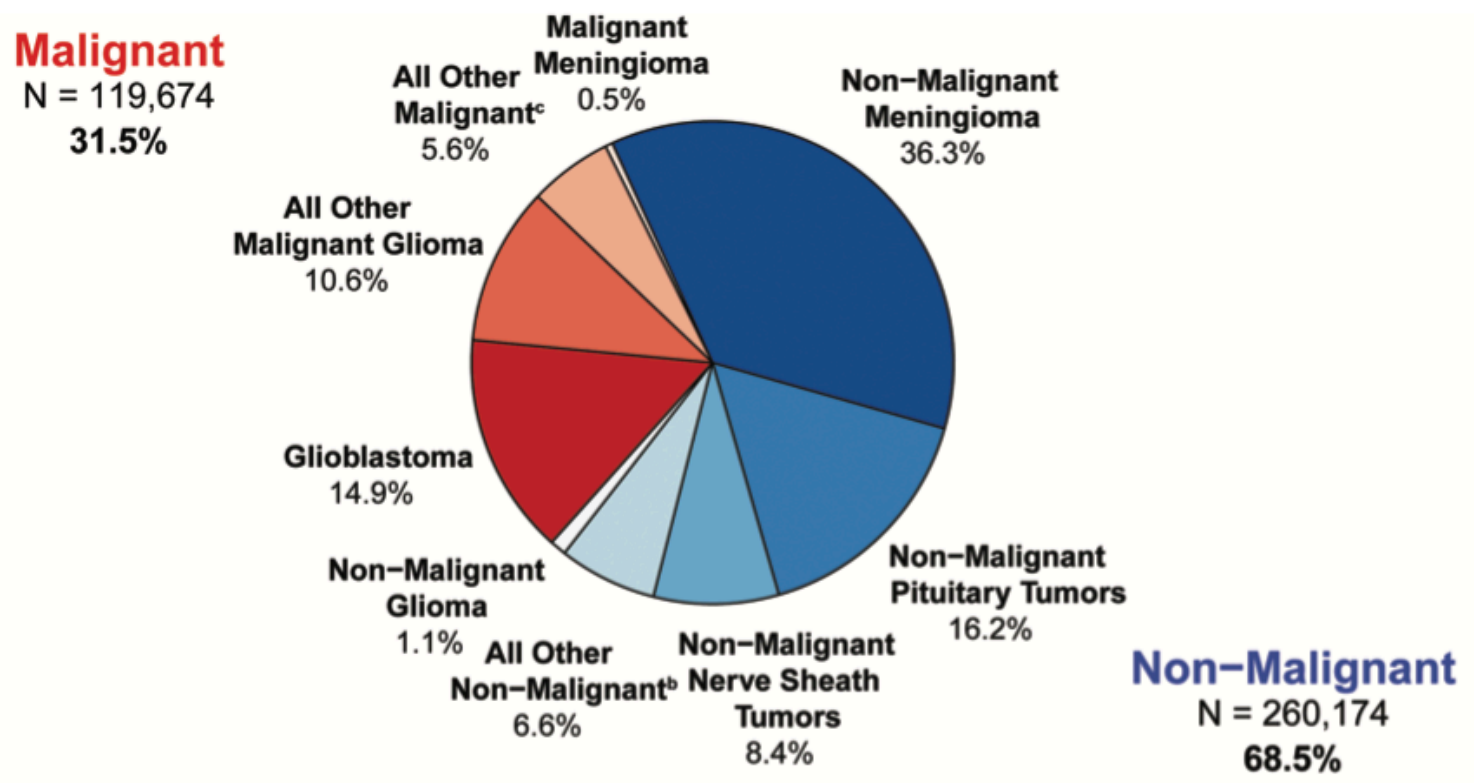

Figure 1.1. Distribution of different classes of CNS tumors (2) 
With the GBM diagnostic incidence gradually rising over the past decades, however, the standard-of-care treatment for newly diagnosed glioblastoma has remained the same since the 1990s, which is typically surgery followed by radiotherapy and maintenance by temozolomide chemotherapy $(3,5,6)$. Temozolomide (TMZ), an alkylating agent with the ability to cross the blood-brain barrier (BBB), has been proven by clinical results to help prolong the survival of patients who have silenced methylguanine methyltransferase (MGMT) gene. The MGMT gene silencing via promoter methylation has been found in more than $1 / 3$ of newly diagnosed GBM patients $(7,8)$. It has been reported that cancer cells lacking MGMT enzyme fail to remove the methyl group added by TMZ onto DNA which then leads to cytotoxicity. Temozolomide has been shown to be effective for certain cases of GBM. However, the positive clinical outcomes are selective and lead to a merely 2-3 months improvement on median overall survival. Also, the cumulative toxicity of TMZ during extensive cycles of usage illustrates the need for other chemotherapy treatment options.

There are numerous obstacles facing chemotherapy as either first-line or second-line treatments for GBM (9). Histologically, GBM tumors are highly heterogeneous, which diminish the efficacy of molecular-targeting chemotherapy $(10,11)$. The blood-brain barrier (BBB), working as a highly selective barrier, significantly reduces the drug delivery efficiency to brain tumors and limits the usage of chemotherapeutic drugs (12). Cancer cells survive from the initial chemotherapeutic treatment may finally induced tumor recurrence (13). In addition, the side-effects from chemotherapeutic medications may also put patient survival 
on edge (14). Therefore, finding predictive biomarkers from studying the GBM tumors from individual patients may improve the molecular-targeting chemotherapy efficacy for patients who might benefit from the specific chemotherapeutic treatment and prevent unnecessary side-effects for patients who might not respond to the treatment.

Genomic and proteomic studies have been applied to identify promising biomarkers which could predict the response of GBM to chemotherapies. Thousands of new cases of CNS tumors are diagnosed each year, and the expanded database system has allowed scientists to access the genomic and proteomic analyses to attempt identifying mechanisms and potential biomarkers for GBM drug resistance $(1,15)$. The Cancer Genome Atlas (TCGA) is a valuable cancer genomic analysis database of clinical patients' tumors $(16,17)$. The CellMiner Cross Database (CellMinerCDB) enables exploration and analysis of cancer cell lines pharmacogenomic data across different cancer types (18). Previous studies have shown that by correlating gene of interests with patient survival provided from databases, scientists were able to identify 20 genes which express proteins that might be potential targets for GBM treatment $(11,19)$. Besides meta-analysis, proteomic analysis of protein expressions in GBM has been conducted, and inhibitors targeting the overexpressed biomarkers, which correlated with GBM aggressiveness have been investigated $(20,21)$. The epidermal growth factor receptor (EGFR) is upregulated in more than $40 \%$ of GBM tumors. However, treatment targeting EGFR has not shown any survival improvement on the basis of randomized trials $(22,23)$. Vascular endothelial 
growth factor (VEGF) expression in GBM is necessary for angiogenesis and tumor proliferation. Bevacizumab (Avaglio) with anti-VEGF activity had been tested on GBM patients with promising response rate in randomized clinical trials $(23,24)$. However, no overall survival benefit had been found on expanded Phase III trials with Avaglio treatment alone $(25,26)$. Improved effective treatment outcome was observed with a combination treatment of bevacizumab and Irinotecan, a topoisomerase I inhibitor which is able to cross BBB, in Phase II studies, although the underlying mechanism is not clear (27). There is also much interest in testing immunotherapy in clinical trials for GBM because of the immunosuppressive feature of GBM tumors (28). Although immune checkpoint inhibitors have been successfully applied in treatment of non-small cell lung cancer (NSCLC) patients, the inhibitors have failed in GBM treatment trials, and the biomarkers for the response of GBM to checkpoint inhibitors treatment remain elusive (29). Tumor antigen vaccines have been a promising approach for GBM treatment by targeting the biomarkers, which are expressed by tumors (30). Customized vaccines have been studied for over a decade and some impressive reports have been published recently, whereas additional clinical evidence is still needed to be confirmed $(31,32)$. Besides, the BBB acting as a tightly surrounding armor of the brain requires drugs with penetrating abilities. Promising nano-scaled drug delivery methods have been investigated for GBM treatment. However, the outcomes are still insufficient (33). Therefore, more efficient GBM treatments using promising new biomarkers are still urgently needed. 
To date, the deadliest brain cancer, GBM, remains one of the most significant challenges in cancer treatment (34). New strategies of chemotherapy treatment of GBM tumor are urgently required. Novel biomarkers, which can enhance the likelihood for the response to the drugs that are able to cross the BBB are much needed. Research conducted in this study is focusing on these aspects of GBM treatment needs.

\section{B. HUMAN TOPOISOMERASE I (TOP1)}

Topoisomerases are ubiquitous enzymes that present in all kingdoms of life. As a result of the intertwined nature of the DNA duplex, complex topological structures can be generated during gene transcription, replication, recombination, and chromatin compactions. Accumulation of negatively supercoiled DNA behind and the positively supercoiled DNA ahead of RNA polymerase or replication fork presents topological challenges for transcription and replication processes which are critical for cell proliferation. The elimination of these topological barriers from DNA is required for the maintenance and proper function of the genome. Topoisomerases are essential enzymes that can resolve DNA topological problems during both transcription and replication. In brief, topoisomerases relax the accumulated supercoiled tensions from DNA through DNA cleavage and rapid resealing processes (35). 


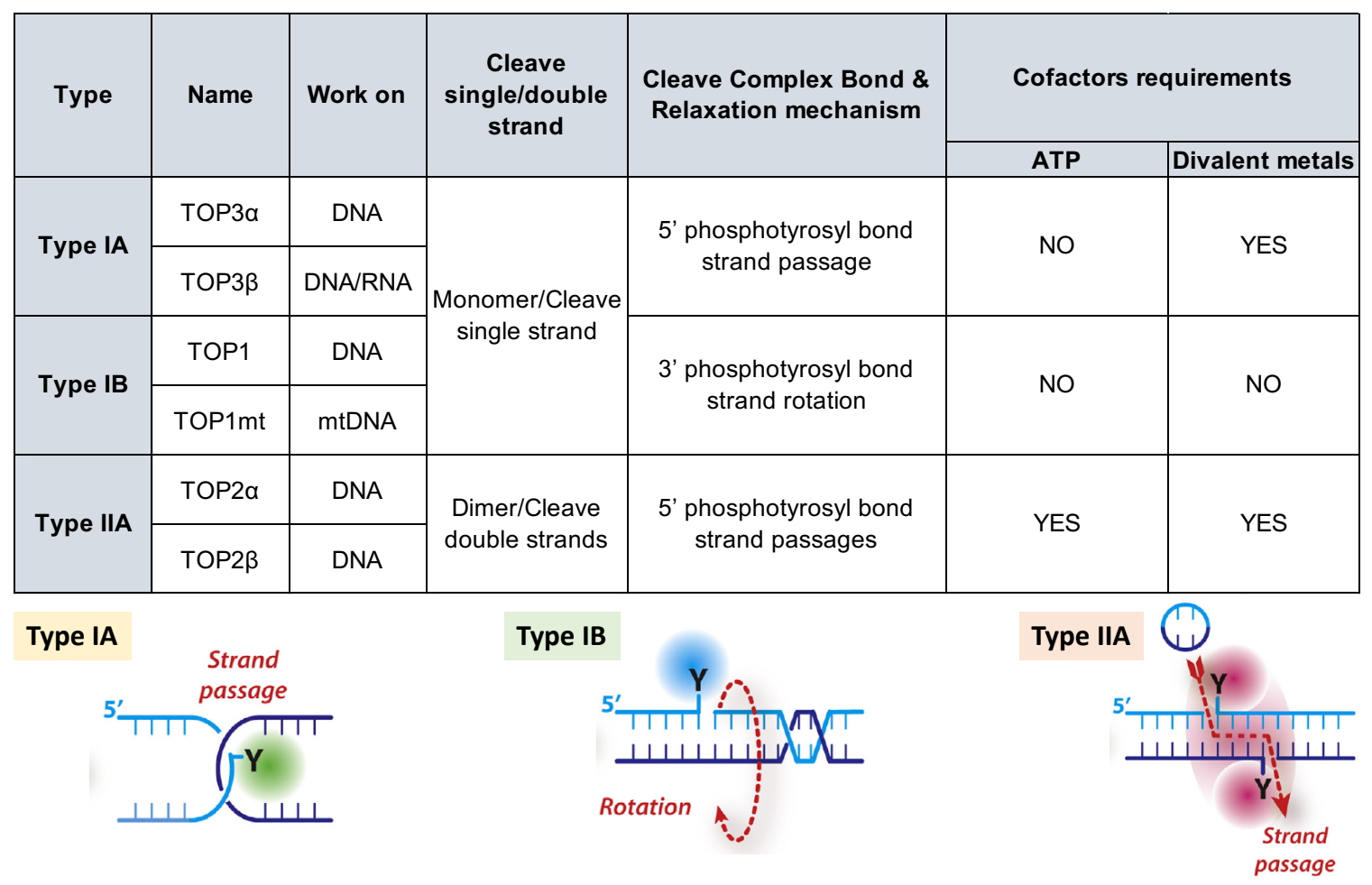

Figure 1.2. Classes of human topoisomerase and covalent topoisomerase cleavage complex (TOPcc) formed

(36). (Left) Type IA topoisomerase includes topoisomerase IIIa (TOP3a) and topoisomerase III $\beta$ (TOP3 $\beta$ ) which cut single-strand of DNA and relax the DNA tension by passing the intact-strand through the nick. (Middle) Type IB topoisomerase includes topoisomerase I (TOP1) and mitochondria topoisomerase I (mtTOP1) which cut single-strand of DNA and relax the DNA tension by rotating the broken strand around the other strand of DNA. (Right) Type IIA topoisomerase includes topoisomerase Ila (TOP2 $\alpha$ ) and topoisomerase $\| \beta$ (TOP2 $\beta$ ) which cut double-strand of DNA and relax the DNA tension by passing the other doublestrand through the break.

In human cells, there are three types of topoisomerases, type IA (TOP3 $\alpha$ and TOP3 $\beta$ ), type IB (TOP1 and mitochondria TOP1), and type IIA (TOP2 $\alpha$ and TOP2 $\beta$ ), involving six different functioning enzymes (Figure 1.2). Topoisomerases cleave and re-ligate single strand (type I) or double (type II) strands of the DNA by forming a transient covalent intermediate. Topoisomerases use tyrosine residue(s) at the active site and relax the tension of DNA by passing the intact-strand(s) 
through the broken strand(s) (type IA, IIA) or rotating the broken strand around the intact strand (type IB). Type IA and type IIA topoisomerases generate phosphotyrosyl-bond at the 5' end of the cleavage site and also free 3'-OH group(s), while type IB topoisomerases generate a phosphotyrosyl-bond at the 3' end of the cleavage site and a free 5'-OH group $(37,38)$. Divalent ions are required for catalysis of type IA and type IIA topoisomerases. No cofactors are required for human type IA or type IB topoisomerases to be functional, while adenosine triphosphate (ATP) is necessary for type IIA TOP2 $\alpha$ and TOP2 $\beta$ enzymes to perform (36). During topoisomerase relaxation processes, the transient covalent complexes of DNA with topoisomerase are termed as TOPcc (topoisomerase cleavage complexes) (Figure 1.2) (39). Under normal conditions, TOPcc remains at a low level and the religation process is favored over the cleavage process (40).

Eukaryotic topoisomerase $\mathrm{I}$ is essential for the survival of multicellular organisms and relaxes both negatively and positively supercoiled DNA without any energy or cofactor (Figure 1.2). Previous studies have shown that the deficiency of topoisomerase I in mice induced an embryonic lethality at the 8-cell stage and aberrant topoisomerase I function in human cells might be associated with autism spectrum disorder (ASD), a life-long neurodevelopmental disorder concomitant with behavior deficiency $(41,42)$. However, topoisomerases can also induce harmful DNA lesions in association with endogenous and exogenous genomic threats. Studies have shown that DNA apurinic/apyrimidinic (AP) sites, single base mismatches, reactive oxygen species (ROS), UV lesions, alkylating agents, as well as topoisomerase poisons, can trigger the generation and stabilization of TOP1cc 
(43-47). Failure to release topoisomerase I from DNA in TOP1cc will result in protein-linked DNA breaks (PDBs). Protein-linked DNA breaks can be rescued by activating cell cycle checkpoint and cellular repair pathways, while the accumulation of PDBs may finally result in DNA damage-induced apoptosis (DDIA). Insufficient DNA repair of TOP1cc or defective cell apoptosis might eventually induce the loss of genomic stability and tumorigenesis (48).
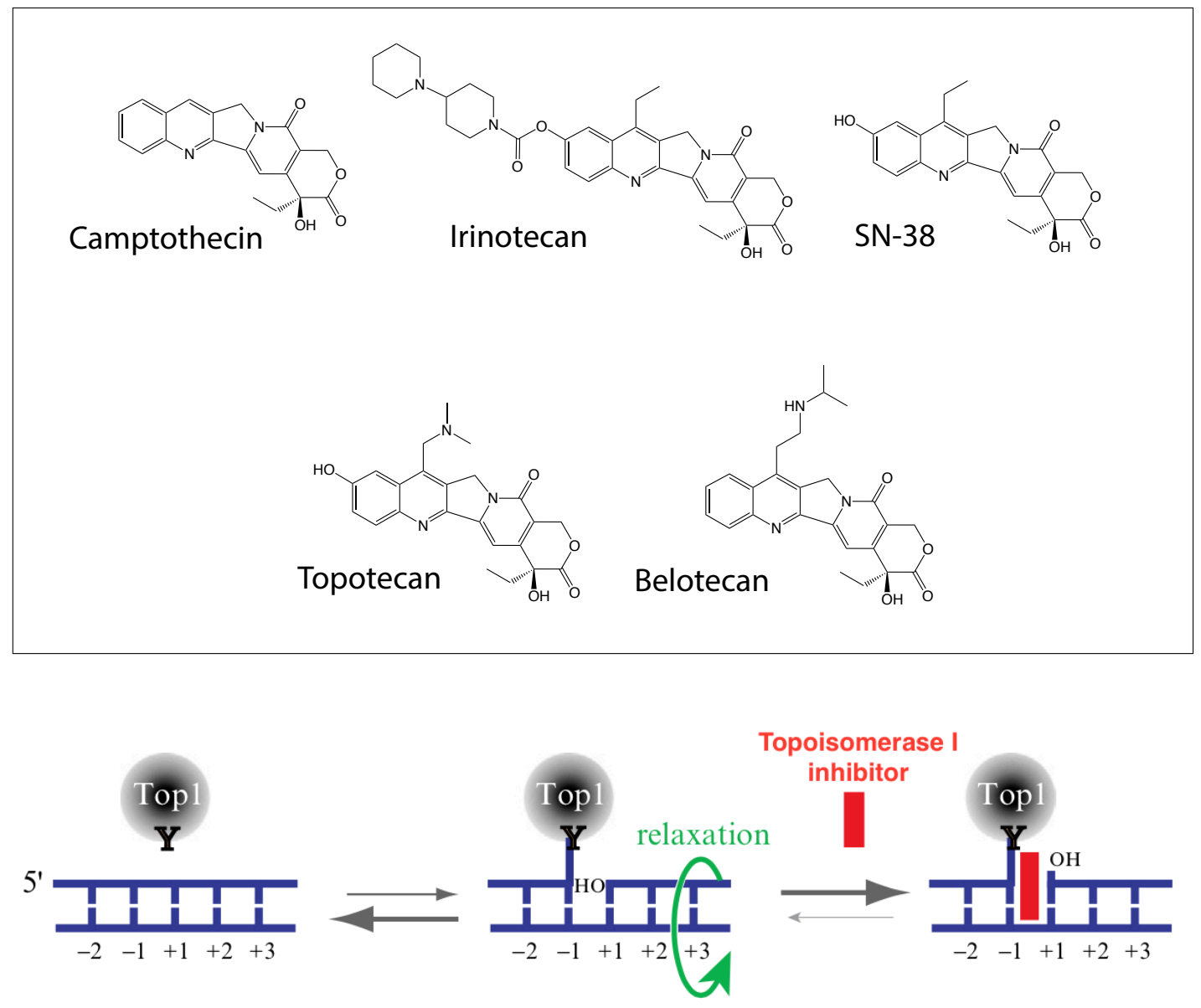

Figure 1.3. Human topoisomerase I inhibitors and TOP1cc ternary complex (49) (Above) Human topoisomerase I inhibitor structures: Camptothecin (CPT), Irinotecan (IRT), active metabolite of IRT (SN-38), Topotecan (TPT), and Belotecan. (Bottom) Human topoisomerase I inhibitors insert at the interface of DNA and TOP1 by forming the irreversible cleavage complexes. 
With the lethal feature of TOP1cc described above, human topoisomerase I has been shown as a promising chemotherapy target for decades, and topoisomerase poisons which lead to accumulation of its cleavage complexes are widely used for cancer therapies (Figure 1.3) (50-52). Irinotecan (IRT), its active metabolite SN-38, and topotecan (TPT) are chemotherapeutic camptothecin derivatives (CPTs) which are widely applied in cancer therapy as TOP1 poisons and have been approved by Food and Drug Administration (FDA) since the mid1990s (53-55). Topotecan is now routinely utilized to treat ovarian cancer $(56,57)$ and small cell lung cancer (SCLC) $(58,59)$. Irinotecan is routinely used for the treatment of colorectal cancer $(60,61)$. It has been demonstrated that these topoisomerase poisons target the interface of TOP1/DNA complex and stabilize TOP1cc with hydrogen bonds as well as hydrophobic interactions resulting in a stable ternary complex which prevents the religation of DNA and the release of TOP1, thus inducing cell apoptosis $(44,49)$.

However, resistance to TOP1 poisons has become one of the toughest tasks for cancer therapy. Studies have suggested that the endogenous repair systems, such as DNA damage response (DDR), existing in cells may result in the drug resistance and rescue cells from apoptosis $(62,63)$. It has been reported that poly(ADP-ribose) polymerase (PARP) inhibitor, veliparib, targeting PARP, the critical enzyme for adenosyl ribosylation of TOP1 in the DDR pathway, in combination with topoisomerase I inhibitor topotecan was able to modulate TOP1cc mediated DNA damages in lymphomas (64). Ataxia telangiectasia and Rad3-related protein (ATR) inhibitor, M6620, targeting ATR, the main transducer 
of replication stress, in combination with TPT was found to produce response from platinum-refractory SCLC which usually would not respond to topotecan alone (65). On the other hand, studies have shown the cell resistance to drug treatment could also be modulated by post-translational modifications (PTMs) and epigenetic modifications. It has been reported that the ubiquitin-proteasome pathway results in an elevated CPT resistance in cancer cells $(62,63)$. Besides, histone deacetylase (HDAC) inhibitors could overcome colorectal cancer (CRC) cells resistance to IRT treatment by inhibiting H4K16 deacetylation (66). Therefore, to attain a better cancer cell response from chemotherapeutic treatment with topoisomerase poisons, combination treatment with inhibitors of enzymes in the DDR, PTM, or epigenetic pathways has become a promising approach (67). 


\section{HUMAN TYROSYL-DNA PHOSPHODIESTERASE 1 (TDP1)}

Tyrosyl-DNA phosphodiesterase1 (TDP1) and tyrosyl-DNA phosphodiesterase 2 (TDP2) are unique repair enzymes found in eukaryotes and are able to rescue covalent complexes, which are stabilized by either endogenous DNA lesions or exogenous inhibitors, formed by topoisomerases on DNA termini (Figure 1.4) $(51,53)$. Human TDP1 is a member of the phospholipase D (PLD) superfamily (68). Following proteasome-dependent degradation of TOP1cc, TDP1 rescues cells from the lethal DNA damage by hydrolyzing the phosphotyrosyl-bond of TOP1 peptide from the 3' end of DNA single-strand breaks (SSBs) and covalently form a TDP1-DNA intermediate through $\mathrm{H} 263$ at its active site $(36,69)$. Tyrosyl-DNA phosphodiesterase1 covalent complex (TDP1cc) is further rescued by hydrolysis of the phosphotyrosyl-bond of TDP1 by H493 in its active pocket followed by 3'-OH generation through the polynucleotide kinase phosphatase (PNKP) activity (Figure 1.5A). On the other hand, human TDP2, a member of $\mathrm{Mg}^{2+/} \mathrm{Mn}^{2+}$-dependent phosphodiesterases superfamily, releases TOP2 peptides from the $5^{\prime}$ terminus of DNA without the formation of the TDP2cc (Figure 1.5B). Minor overlap in repairing TOP1cc and TOP2cc have been observed between TDP1 and TDP2 based on published studies $(68,70)$. 


\begin{tabular}{|c|c|c|c|c|c|}
\hline \multirow{2}{*}{ Name } & \multirow{2}{*}{ Function } & \multirow{2}{*}{ Product } & \multirow{2}{*}{ Removal of DNA adducts } & \multicolumn{2}{|c|}{ Cofactor requirement } \\
\hline & & & & ATP & Divalent metals \\
\hline TDP1 & 3' phosphodiesterase & 3' phosphate & $\begin{array}{l}\text { 3' blocking DNA (RNA) lesions } \\
\text { (3' phosphotyrosyl bond, 3' abasic site, 3' } \\
\text { phosphoglycolate, 3' BHQ, 3' 6-FAM) }\end{array}$ & NO & NO \\
\hline TDP2 & 5' phosphodiesterase & 5' phosphate & $\begin{array}{c}\text { 5'-phosphotyrosyl DNA (RNA) } \\
\text { lesions }\end{array}$ & NO & YES \\
\hline
\end{tabular}
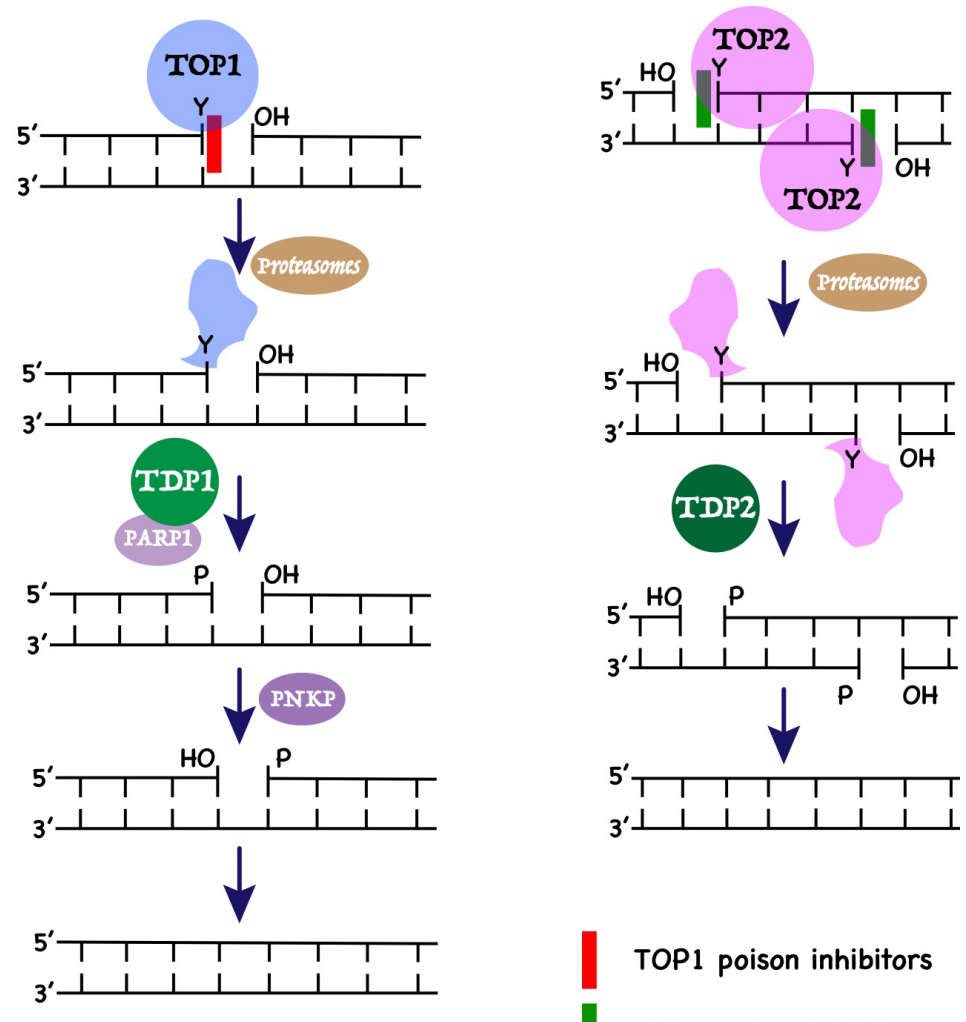

TOP1 poison inhibitors

TOP2 poison inhibitors

Figure 1.4. Human tyrosyl-DNA phosphodiesterase 1 and 2 functions for rescuing topoisomerase cleavage complexes

(67) (Left) TDP1 hydrolyzes phosphotyrosyl-bond of TOP1 peptide from 3' end of DNA. (Right) TDP2 hydrolyzes phosphotyrosyl-bond of TOP2 peptides from 5'-end of DNA.

Tyrosyl-DNA phosphodiesterase1, a ubiquitous and highly conserved repair enzyme, is also able to resolve various 3' blocked termini of DNA, such as 3'phosphotyrosyl, 3'-abasic site, 3'-non-phosphorylated nucleotide, and 3'phosphoglycolate with no cofactor requirement (71). Post-translational 
modifications regulate TDP1 acting as a crucial enzyme in SSB and double-strand break (DSB) repairs. Studies have shown that TDP1 PTMs are substantially associated with its N-terminal domain (NTD, residues 1-148), a dispensable domain for TDP1 catalytic activity. Phosphorylation, SUMOylation, and PARylation at NTD stabilize TDP1 and promote the recruitment of TDP1 and other repair enzymes on DNA damage site without interfering with TDP1 activity (72-75). It has been reported that DSBs or CPT-induced TDP1 phosphorylation at serine 81 by ataxia-telangiectasia mutated (ATM) kinase increases the recruitment of TDP1 on DNA damage sites and also enhanced the protein-protein interaction with XRCC1 and ligase III which are crucial for PNKP recruitment $(73,74)$. In addition, SUMOylation of TDP1 at lysine 111, which is independent from DNA damage, is able to accumulate TDP1 at TOP1cc site for further repair (75). Moreover, PARylations of the TDP1 on its N-terminus could stabilize TDP1 recruitment on TOP1cc damage sites without interfering its activities and also helped to recruit XRCC1 for further PNKP participation in the DNA repair pathways (72). On the other hand, PTM associated with TDP1 C-terminal domain was also reported. A recent study highlighted that the methylation of R261 and R586 of TDP1 on its catalytic domain (149-608), enhancing TDP1 activity as well as XRCC1 association with TDP1, promotes cancer cell survival in response to CPT treatment (76). As TDP1 is involved in multiple DNA-damage-induced repair pathways, the deficiency of TDP1 function may induce chaos in the cells. Studies have shown that homozygous H493R mutation on TDP1 is associated with familial spinocerebellar ataxia with axonal neuropathy (SCAN1) disease, which results in 
mental retardation and immunodeficiencies $(77,78)$. The lymphoblastoid cells derived from SCAN1 patients are hypersensitive to CPTs owing to the 25 -fold reduction in TDP1 activity (79).

A
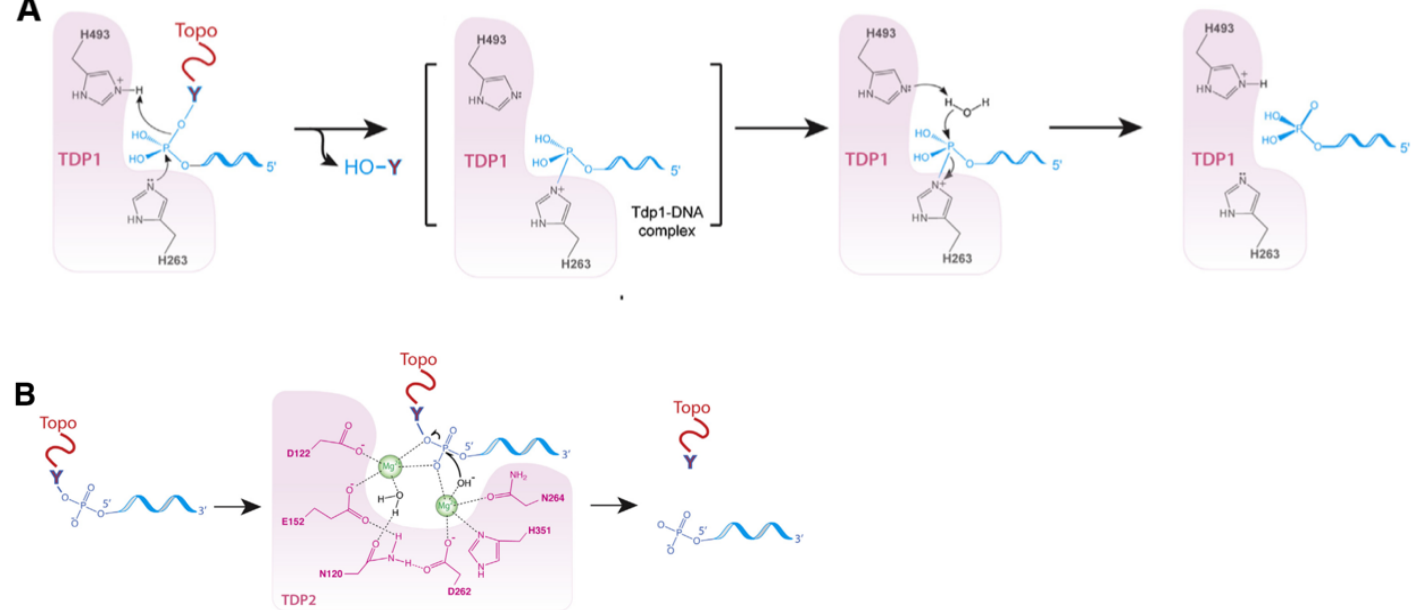

Figure 1.5. TDP1 and TDP2 catalytic mechanisms

(36). (A) TDP1 cleaves TOP1 peptide from DNA by nucleophilic attack of phosphodiester backbone by $\mathrm{H} 263$ residue and subsequently releases from DNA by a second nucleophilic attack by $\mathrm{H} 493$ residue. (B) TDP2 cleaves TOP2 peptide from DNA by nucleophilic attack of its catalytic residues which are coordinated with two magnesium ions.

As described above, TDP1 is performing as an essential enzyme on TOP1cc repair pathways, thus targeting TDP1 in cells has become one of the promising approaches for cancer treatment. Although no FDA-approved TDP1 inhibitor has been published, inhibitors targeting TDP1-associated repair enzymes PARP in combination with TOP1 inhibitor IRT have yielded responses from lymphomas (64). Moreover, TDP1 protein deficiency in TDP1 knockdown cells confers a higher cytotoxic response to CPT treatment, whereas further depletion of TOP1 rescues cells from CPT-induced apoptosis (80). Additionally, TDP1 phosphorylation at serine 81 (pS81) could protect cells from CPT induced accumulated DNA damages 
and deficiency of XRCC1, which closely interacts with TDP1, could cause hypersensitivity of cells to CPT treatment (74). With TDP1 acting as a broadspectrum 3'-end DNA lesion repair enzyme that crucially associates with cell functions, combination treatments of TDP1 inhibitors with reagents contributing to harmful DNA lesions, such as TOP1 inhibitors, alkylating agents, and other repair enzyme inhibitors are promising for anti-cancer therapies in the future treatment. Therefore, research focusing on finding effective TDP1 inhibitors has become a compelling task.

\section{OVERVIEW}

Currently, new biomarkers for the treatment of the most aggressive brain tumor, GBM, are urgently needed to enhance the likelihood of patient response. Topoisomerases I inhibitors have been proven as a powerful chemotherapeutic tool in multiple anti-cancer regimens. Irinotecan possessing the ability to cross the BBB has been used for the treatment of GBM in clinical trials. Monotherapy of Irinotecan and the combination treatment with TMZ on GBM have yielded encouraging results and comparable with $\mathrm{TMZ}$ treatment alone $(81,82)$. However, inconsistent responses from GBM to Irinotecan treatment has remained elusive in previous clinical trials, and the overall survival rate is still not showing significant increase over the past two decades $(83,84)$. Tyrosyl DNA phosphodiesterase 1 (TDP1) is a ubiquitous and highly conserved repair enzyme in eukaryotes which can resolve various 3' blocking termini of DNA lesions including 3'-phosphotyrosylbond from TOP1cc induced by TOP1 inhibitors (71). The lack of TDP1 in cells may finally induce cancer cell apoptosis (Figure 1.6). Therefore, in this dissertation 
project, we tested the hypothesis that TDP1/TOP1 ratio might be a new predictive biomarker for GBM response to Irinotecan treatment. Both cell lines and patient tumors were analyzed in our research.

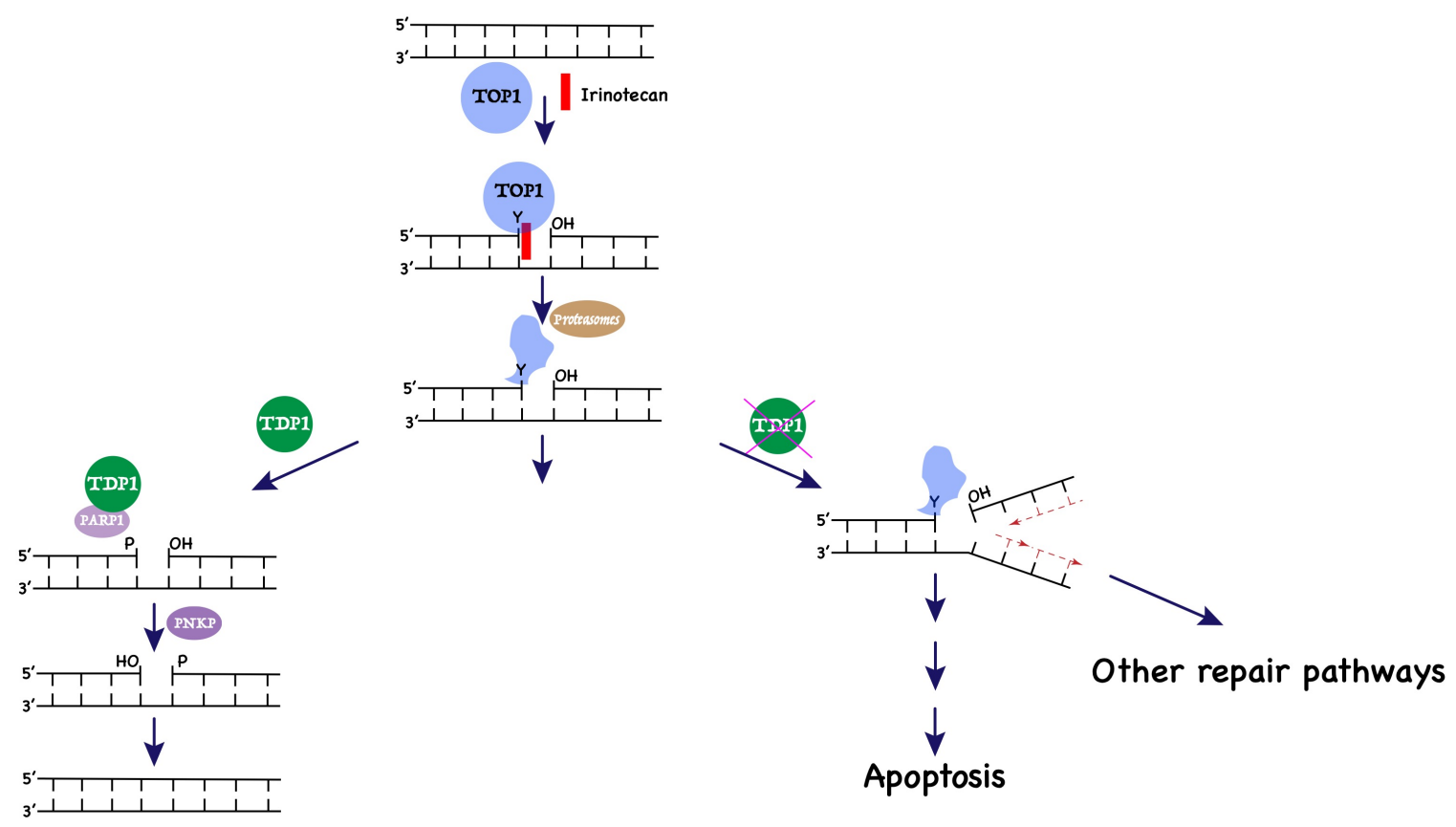

Figure 1.6 Diagram of TOP1 and TDP1 functions in GBM with IRT treatment 


\section{CHAPTER II: TDP1/TOP1 ACTIVITY RATIO AS AN INDICATOR FOR GBM CELL LINE RESPONSE TO IRT TREATMENT}

\section{ABSTRACT}

To select cancer chemotherapy for individual patients, the essentiality to identify predictive biomarkers, which would predict the response of the patient's cancer cells to chemotherapeutic drug treatment, is significant. Topoisomerase I (TOP1) is an essential enzyme that modulates the topological structure of chromosome DNA during replication and transcription by concerted DNA cleavage and rejoining steps. Irinotecan (IRT), working as a TOP1 poison inhibitor, targets the interface of TOP1 and DNA and stabilizes an irreversible TOP1 cleavage complex (TOP1cc) which induces cancer cell death by apoptosis. Tyrosyl-DNA phosphodiesterase 1 (TDP1) is a crucial repair enzyme that efficiently removes the TOP1 peptide from the lethal TOP1cc. Irinotecan has been demonstrated to have anti-cancer activity against glioblastoma (GBM), the most aggressive primary brain tumor according to world health organization (WHO). The present study shows that TOP1 or TDP1 expression level alone does not correlate with IRT efficacy. We demonstrate that the TDP1/TOP1 activity ratio has the strongest correlation with the TOP1cc level as well as IRT sensitivities in comparison with the TDP1 or TOP1 activity level alone, suggesting that both TDP1 and TOP1 activities in GBM cells play critical roles in the outcome of IRT treatment. 


\section{INTRODUCTION}

Glioblastoma (GBM) is a devastating disease with poor prognosis and lack of predictive biomarkers (20). Irinotecan (IRT), a topoisomerase I (TOP1) poison specifically stabilizing and accumulating the lethal TOP1cc in cells, has been found in GBM clinical trials to have inconsistent efficacy. However, the explanation of the poor prognosis is remaining elusive (82). Therefore, our study evaluated the roles of TOP1 and tyrosyl-DNA phosphodiesterase 1 (TDP1), in the response of GBM to IRT treatment, in order to identify rational predictive biomarkers that may improve the chemotherapeutic outcomes. Furthermore, cytotoxicity induced by IRT had been evaluated by cell viability assay on nine GBM cell lines. Cytotoxicity data had also been gathered from Cancer Drug Resistance (CancerDR) database and CellMiner databases which are widely used to compare the effectiveness of anti-cancer drugs against well-established cancer cell lines (85-87). Also, TOP1cc level was measured to confirm further the DNA damage induced by IRT treatment.

Previous studies have shown that protein expression levels of TOP1 or TDP1 are factors that can alter cell cytotoxicity induced by TOP1 poisons. Meisenberg et al. proposed the TDP1/TOP1 protein expression ratio as a promising indicator for the cytotoxicity of small cell lung cancer to treatment with the TOP1 poison topotecan (TPT) (88). Other studies have shown that camptothecin (CPT) and related drugs induced degradation of TOP1 protein, via SUMOylation and Ubiquitin-proteasome pathway (UPP), results in elevated drug resistance in cells $(62,63)$. The overexpression of TDP1 in human embryonic kidney cells counteracted with CPT-induced DNA lesions (89). Thus, we assayed protein 
expression level of both TDP1 and TOP1 with Western blot to determine if there is any correlation with cell response to IRT treatment in GBM cell lines.

In addition to the variation of TOP1 and TDP1 protein expression level, the modulation of TOP1 and TDP1 enzyme activities could also affect cell responses to drug treatment. It has been reported that the increased TOP1 activity level could sensitize the human glioma cells to IRT treatment following Delta-24 infections (90). Additionally, activity increase of TOP1 from phosphorylation at Thr268 and Ser506 sites sensitized cancer cells to cytotoxicity from CPT treatment $(91,92)$. A previous study has also suggested that the increased expression and activity of TDP1 along with DNA repair endonucleases XPF might contribute to CPT resistance in small cell lung cancer (NSCLC) cells (93). Therefore, in the present study, TOP1 activity and TDP1 activity were measured and analyzed for correlation with the responses to IRT treatment. In our study, we overexpressed recombinant wild-type WT-TDP1 and mutant H263A-TDP1 in GBM cells and the resulting TDP1 activity variations were correlated with cell cytotoxicity from IRT treatment.

Human carboxylesterase 2 (CES2), belonging to serine hydrolase superfamily, has been reported as a critical enzyme that efficiently converts prodrug IRT to its active metabolite $\mathrm{SN}-38$ in cancer cells as a result of its preference for esters with a relatively large alcohol group and a small acyl group as hydrolysis substrates (94). It has been reported that two GBM cell lines, U87 and U251, can effectively convert IRT into SN-38 in vitro (95). In addition, a small scale clinical research study showed that patients with overexpression of CES-2 and TOP1 were positively correlated with both progression-free survival (PFS) and 
overall survival (OS) in metastatic colorectal cancer (mCRC) suggesting that patients with high CES-2 levels might benefit from IRT-based therapy (96). Therefore, CES2 levels were also measured for the GBM cell lines included in our study to determine if there is significant variation in the CES2 levels that might affect the cytotoxicity resulting from IRT treatment (97).

\section{MATERIAL AND METHODS}

All buffer compositions and preparation protocols are listed in Appendix I.

\section{Glioblastoma cell culture}

Table 2.1. Glioblastoma cell line information

\begin{tabular}{|c|c|c|c|c|c|}
\hline Cell lines & Source & Age & Gender & Disease & Morphology \\
\hline SF539 & NCI & 34 & female & glioblastoma & \\
\hline SF295 & NCl & 67 & female & glioblastoma & \\
\hline H4 & ATCC & 37 & male & neuroglioma & epithelial \\
\hline SF268 & NCl & 24 & female & ana plastic astrocytoma & \\
\hline SNB19 & NCI & 47 & male & glioblastoma & \\
\hline U251 & NCl & 75 & male & glioblastoma & \\
\hline A172 & ATCC & 53 & male & glioblastoma & \\
\hline SNB75 & NCI & & female & astrocytoma & \\
\hline U87 & ATCC & 44 & male & glioblastoma & epithelial \\
\hline
\end{tabular}

Three out of nine GBM cell lines (U87, A172, and H4) were received from the American Type Culture Collection (ATCC). The other six cell lines (SF295, SF268, SF539, SNB75, SNB19, and U251) were received from the National Cancer Institute, Division of Cancer Treatment and Diagnosis (NCl, DCTD). All nine GBM cell lines used in the current study are listed in Table 2.1. Cell lines were cultured 
and maintained in Dulbecco's Modified Eagle's medium (DMEM, Corning) supplemented with 10\% heat-inactivated Fetal Bovine Serum (FBS, Hyclone), 1\% Penicillin/Streptomycin (PenStrep, Gibco), and $0.1 \%$ prophylactic (InvivoGen). Cells were grown at $37^{\circ} \mathrm{C}$ in a humidified incubator with $5 \% \mathrm{CO}_{2}$.

\section{Glioblastoma cell extract preparation}

Cells were seeded in a density of $4 \times 10^{5}$ cells/well in $60-\mathrm{mm}$ dishes and cultured until reaching $80 \%$ confluency. Next, cells were washed twice in phosphate-buffered saline (PBS, Gibco) and lysed in radioimmunoprecipitation assay buffer (RIPA, $50 \mathrm{mM}$ Tris-HCl, pH 7.4, $150 \mathrm{mM} \mathrm{NaCl}, 5 \mathrm{mM}$ EDTA, $1 \mathrm{mM}$ EGTA. 1\% NP-40, 0.1\% SDS and 0.5\% sodium deoxycholate) supplemented with $1 \mathrm{mM}$ phenylmethanesulfonyl fluoride (PMSF), $1 \%(\mathrm{v} / \mathrm{v})$ of Halt Protease inhibitor cocktails (Thermo Fisher), and 1\% (v/v) Halt Phosphatase inhibitor cocktails (Thermo Fisher). Cells were incubated with lysis buffer on ice for 5 min and then transferred to a sterile microcentrifuge tube followed by sonication at $30 \%$ amplitude for 30 seconds (120 W, FB120, Fisher Scientific). The cell debris was removed by centrifugation at $15000 \times \mathrm{g}$ at $4^{\circ} \mathrm{C}$ for $15 \mathrm{~min}$. The protein concentration of the supernatant was measured using the Pierce BCA Assay Kit (Thermo Fisher) according to the manufacturer's protocol. Bovine serum albumin (BSA) in concentrations from $31.25 \mathrm{ng} / \mu \mathrm{L}$ to $2 \mu \mathrm{g} / \mu \mathrm{L}$ was used to generate a standard curve (Figure 2.1) for determination of the GBM cell extract protein concentration. The isolated proteins from the whole cell extracts were aliquoted and stored at $-80^{\circ} \mathrm{C}$ for further analysis. 


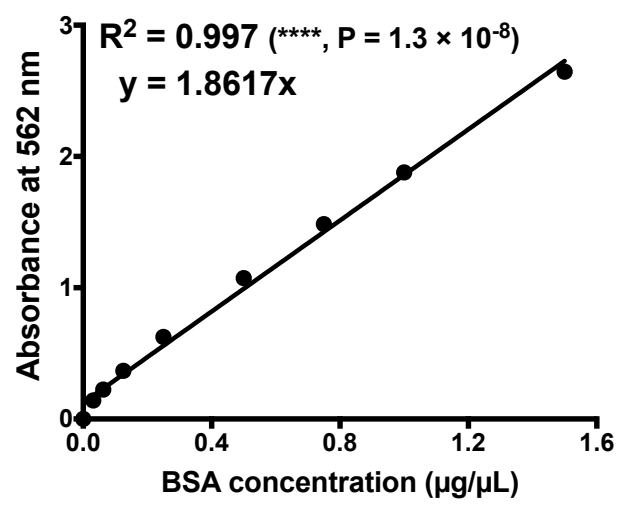

Figure 2.1. Typical color response curves for BSA using the BCA assay

\section{Western blot analysis}

The protein expression level was measured using Western blot analysis. Briefly, protein from whole cell extract (WCE) was first separated by $7.5 \%$ SDSPAGE and then transferred onto a nitrocellulose membrane with transfer buffer (48 $\mathrm{mM}$ Tris, $39 \mathrm{mM}$ glycine, $0.4 \%$ SDS, $20 \% \mathrm{v} / \mathrm{v}$ methanol) for $1 \mathrm{~h}$ at $100 \mathrm{~V}, 4^{\circ} \mathrm{C}$ by the Mini-PROTEAN Tetra vertical electrophoresis system (Bio-Rad). The membrane was blocked with 5\% BSA diluted in Tris-buffered saline (TBS) at room temperature $(\mathrm{RT})$ for one hour followed by incubation of 1:1000 $(\mathrm{v} / \mathrm{v})$ primary antibody diluted in $1 \%$ Tween 20 of TBS (TBST) at $4^{\circ} \mathrm{C}$ for $18 \mathrm{~h}$. The membrane was then washed three times for $5 \mathrm{~min}(3 \times 5 \mathrm{~min})$ with TBST buffer before incubation with the horse-radish peroxidase (HRP) conjugated secondary antibody diluted 1:5000 (v/v) in TBST at RT for additional one hour. The membrane was washed $3 \times 5$ min before the expression level of the protein of interest was developed with the SuperSignal West Pico Plus Chemiluminescent Substrate (Thermo Fisher) for 5 min in the dark. The images were obtained with the C-DiGit 
Blot scanner (LI-COR) and the band density corresponding to the protein expression level was analyzed using the ImageStudio software (LI-COR). The standard deviation was calculated using at least three individual experiments. All the primary and secondary antibodies used in the study are listed in Table 2.2.

Table 2.2. Information of primary and secondary antibody

\begin{tabular}{|c|c|c|c|c|c|c|c|}
\hline Cell lines & Antibody & Size & PI & Dilutions & Method & Source & Incubation \\
\hline \multirow{4}{*}{$\begin{array}{c}\text { Primary } \\
\text { antibody }\end{array}$} & \multirow{2}{*}{ Anti-TOP1 } & \multirow{2}{*}{$91 \mathrm{kD}$} & \multirow{2}{*}{9.3} & $1: 500$ & Slot blot & \multirow{2}{*}{ DSHB-CPTC-Top1-2-s } & \multirow{2}{*}{ Overnight $/ 4^{\circ} \mathrm{C}$} \\
\hline & & & & $1: 1000$ & \multirow{5}{*}{$\begin{array}{c}\text { Western } \\
\text { blot }\end{array}$} & & \\
\hline & Anti-TDP1 & $68 \mathrm{kD}$ & 7.3 & $1: 1000$ & & Bethyl, A301-618A-M & Overnight $/ 4^{\circ} \mathrm{C}$ \\
\hline & Anti-actin & $42 \mathrm{kD}$ & 5.2 & $1: 5000$ & & Abcam, ab3280 & Overnight $/ 4^{\circ} \mathrm{C}$ \\
\hline \multirow{2}{*}{$\begin{array}{l}\text { Secondary } \\
\text { antibody }\end{array}$} & Anti-mouse & & & $1: 5000$ & & Santa Cruz, sc-516102 & $1 \mathrm{~h} / \mathrm{RT}$ \\
\hline & Anti-rabbit & & & $1: 5000$ & & Santa Cruz, sc-2054 & $1 \mathrm{~h} / \mathrm{RT}$ \\
\hline
\end{tabular}

\section{DNA-protein covalent complexes isolation}

Cells were first plated at a density of $2 \times 10^{5}$ cells/well in $35-\mathrm{mm}$ dishes and cultured until $70-80 \%$ confluence. A stock solution of Irinotecan (148 mM) in dimethyl sulfoxide (DMSO) was first diluted to $15 \mu \mathrm{M}$ with freshly prepared culture media. Following the addition of IRT diluted in culture media, cells were incubated further for $15 \mathrm{~min}, 30 \mathrm{~min}$, and $60 \mathrm{~min}$. The DPCCs were then harvested (98). Briefly, cells were collected and lysed with $1 \mathrm{~mL}$ of lysis buffer $(6 \mathrm{M}$ guanidinium isothiocyanate, $10 \mathrm{mM}$ Tris- $\mathrm{HCl}, \mathrm{pH}$ 6.5, $20 \mathrm{mM}$ EDTA, 4\% TritonX-100, 1\% Sarkosyl, and $1 \%$ dithiothreitol) at RT for 5 min without any wash step, followed by addition of $0.5 \mathrm{~mL}$ of $100 \%$ ice-cold ethanol. DNA-protein covalent complexes were precipitated at $-20^{\circ} \mathrm{C}$ for $30 \mathrm{~min}$ and collected by centrifugation at $20000 \times \mathrm{g}$ at $4^{\circ} \mathrm{C}$ 
for $15 \mathrm{~min}$. The precipitate was then washed twice with $75 \%$ ice-cold ethanol and dissolved in freshly prepared $8 \mathrm{mM} \mathrm{NaOH}$. The DNA concentration was measured using the Quant-iT PicoGreen dsDNA Assay Kit (Invitrogen) according to the manufacturer's instruction (Figure 2.2). The isolated DNA-protein covalent complexes (DPCCs) from GBM cell lines were aliquoted and stored at $-80^{\circ} \mathrm{C}$ for further analysis.

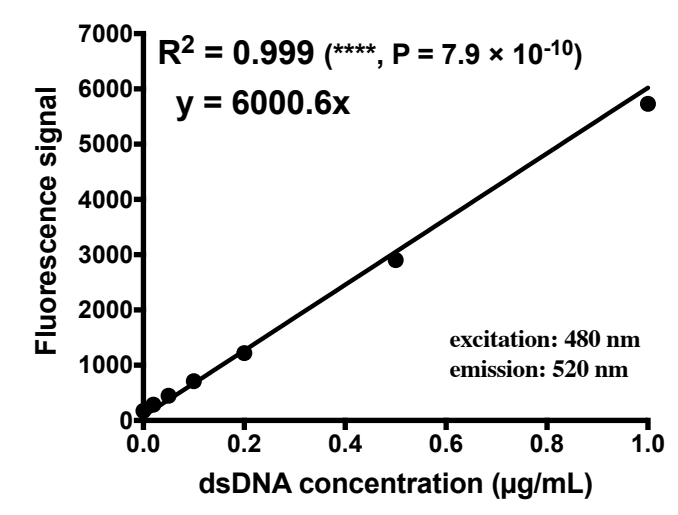

Figure 2.2. Dynamic range and sensitivity of the Quant-iT PicoGreen dsDNA assay.

\section{Slot blot analysis of TOP1cc in DPCC}

The topoisomerase I cleavage complex (TOP1cc) in DPCC was detected using slot blot analysis (98). Briefly, $80 \mathrm{ng}$ of DPCC was diluted in $200 \mu \mathrm{L}$ of TBS and loaded onto a TBS pre-soaked nitrocellulose membrane in the 48-well Bio-Dot SF microfiltration unit (Bio-Rad) with vacuum applied. The membrane was then blocked with $0.5 \%$ alkali-soluble casein (Novagen) in TBS at RT for one hour followed by incubation with 1:500 (v/v) diluted human TOP1 antibody purchased from Developmental Studies Hybridoma Bank (DSHB, CPTC-TOP1-2) at $4^{\circ} \mathrm{C}$ for $18 \mathrm{~h}$. The membrane was then washed $3 \times 5$ min and incubated at RT with 1:5000 
(v/v) diluted goat anti-mouse secondary antibody (Santa Cruz, sc-516102) for an additional one hour. The membrane was washed $3 \times 5 \mathrm{~min}$ before the TOP1cc signal was developed with the SuperSignal West Pico Plus Chemiluminescent Substrate (Thermo Fisher) for 5 min in the dark. The images were obtained with the C-DiGit Blot scanner (LI-COR) and the TOP1 density from the TOP1cc was analyzed using the ImageStudio software (LI-COR).

\section{$\mathrm{IC}_{50}$ measurement for Irinotecan treatment of GBM cell lines}

Cells were first plated at a density range of $5-8.5 \times 10^{3}$ cells/well in a 96-well plate and cultured until $70-80 \%$ confluence. Serial dilutions (0.05 to $15 \mu \mathrm{M})$ from a stock solution of Irinotecan dissolved in DMSO were made in freshly prepared culture media and used for $72 \mathrm{~h}$ incubation treatment of the cells. The cell viabilities were then assayed with TO-PRO3 reagent (Thermo Fisher) according to the manufacturer's protocol (Figure 2.3). Briefly, cells were fixed using $100 \mu \mathrm{L} /$ well of 4\% paraformaldehyde in PBS (PFA) for 20 min at RT before permeated with $0.2 \%$ TritonX-100/PBS for 30 min with rocking. Cells were then treated with blocking buffer (LI-COR) for $30 \mathrm{~min}$ and stained by adding 1:1000 (v/v) diluted TO-PRO3 reagent in blocking buffer for an additional one hour with rocking. Cells were rinsed four times with $0.1 \%$ Tween/PBS before reading of the fluorescence signal. The far-red fluorescence signal from TO-PRO3 reagent bound to double-stranded DNA was detected using the Odyssey CLx Imaging System (LI-COR) and analyzed using the ImageStudio system (LI-COR). IC ${ }_{50}$ is determined as the concentration 
of Irinotecan which results in 50\% reduction of cell viability compared to the DMSO control.

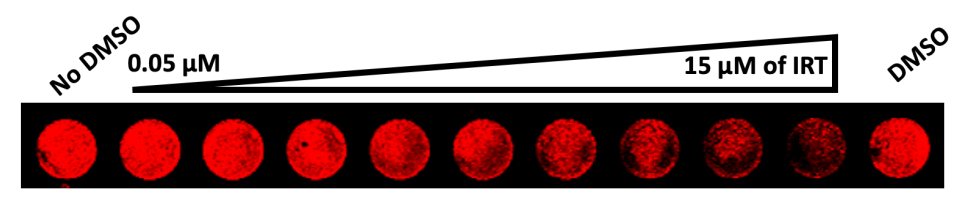

Figure 2.3. Diagram of GBM cell viabilities with serial dilutions of Irinotecan by TO-PRO3 assay

\section{Site-Directed Mutagenesis}

Human TDP1 cDNA clone with expression under the control of the CMV promoter in PCMV6-XL4 vector was obtained from OriGene. Site-directed mutagenesis for $\mathrm{H} 263 \mathrm{~A}$ (histidine to alanine) substitution was performed by polymerase chain reaction (PCR) using the Q5 Site-Directed Mutagenesis Kit from New England Biolabs. Forward (5'-TGG AAC ACA CGC CAC GAA AAT GAT G3') and reverse (5'-AAC GCA ATA TCC AAC TTT G-3') primers were used to generate a mutant TDP1 clone with null catalytic activity (99). The complete TDP1 coding sequences in wild-type (WT) and H263A mutant clones were verified by DNA sequencing. Primers used for sequencing are listed in Table 2.3. The DNA concentration was measured using PicoGreen dsDNA Assay Kit (Invitrogen) and DNA was stored at $-20^{\circ} \mathrm{C}$ for further usage. 
Table 2.3. DNA oligo and primers used in this study

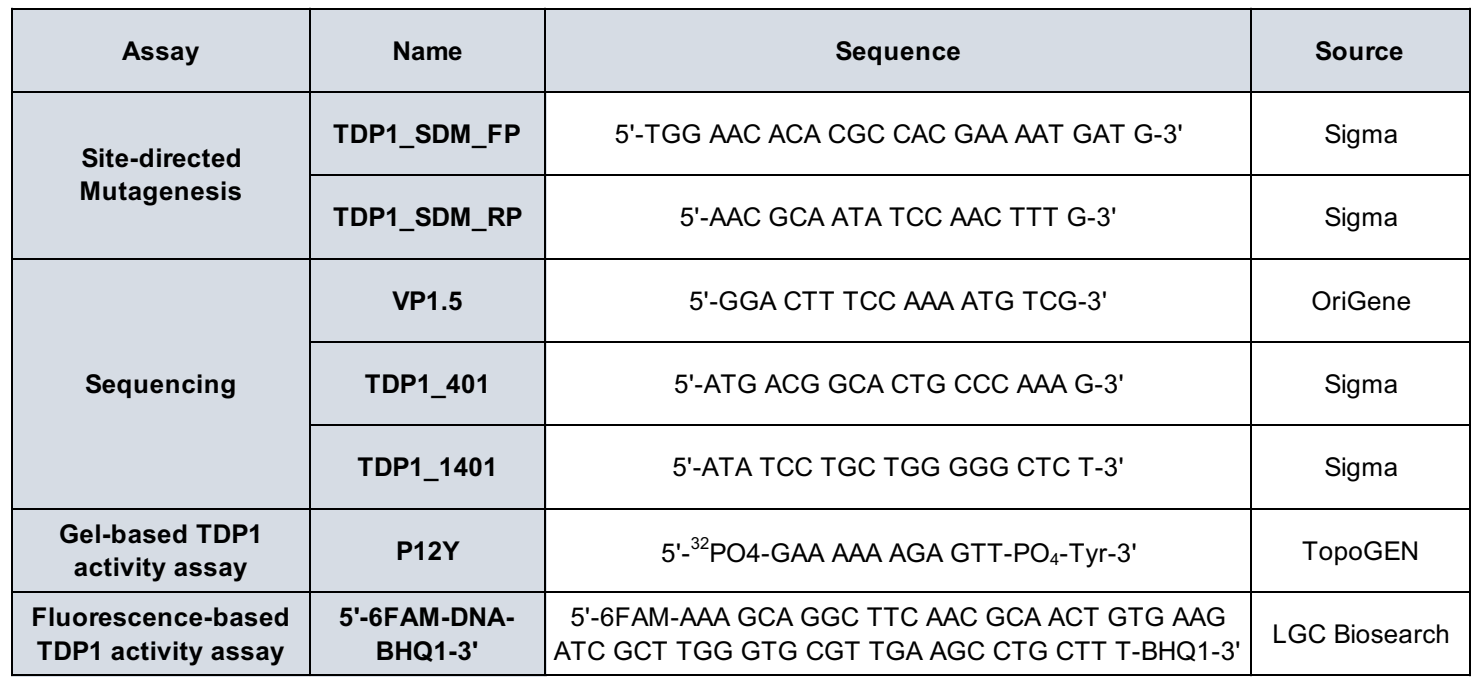

\section{Cell transfection with TDP1 cDNA clones}

The transient transfection of GBM cell line H4, with WT-TDP1 and H263ATDP1 clones, were performed by using Lipofectamine 3000 (Invitrogen) according to its manufacturer's protocol. Briefly, cells were first seeded at a density of $1.8 \times 10^{5}$ cells/well in 35-mm dishes and cultured for $24 \mathrm{~h}$ until $60 \%$ confluence. The DNA in the amount of $500 \mathrm{ng}$ was mixed with Lipofectamine 3000 at a ratio of $1: 2(w / v)$ in $250 \mu \mathrm{L}$ of Opti-MEM Medium (Gibco) for $20 \mathrm{~min}$ at RT and added to cells for $24 \mathrm{~h}$ further incubation. The WCEs were then prepared with RIPA buffer and analyzed as described above.

For the measurement of Irinotecan $\mathrm{IC}_{50}$ following transfection, $\mathrm{H} 4$ cells were plated at a density of $6.5 \times 10^{3}$ cells/well in a 96-well plate and cultured $24 \mathrm{~h}$ until $60 \%$ confluence. The DNA (18 ng) was mixed with Lipofectamine 3000 at a ratio of $1: 2(w / v)$ in $10 \mu \mathrm{L}$ of Opti-MEM Medium for $20 \mathrm{~min}$ at RT and incubated with 
cells for additional $24 \mathrm{~h}$. Cells were then incubated with serial dilutions of IRT for $72 \mathrm{~h}$ and cell viabilities were measured with the TO-PRO3 assay as described above.

\section{Human TOP1 activity measurement by gel relaxation assay}

Human topoisomerase I activity measurement by relaxation assay was carried out in a final reaction volume of $20 \mu \mathrm{L}$. Negatively supercoiled pBAD/Thio DNA (240 ng) was relaxed with serial diluted recombinant human topoisomerase (hTOP1) enzyme (TopoGEN) at $37^{\circ} \mathrm{C}$ for $30 \mathrm{~min}$ in relaxation buffer (10 mM Tris$\mathrm{HCl}, \mathrm{pH}$ 7.9, $1 \mathrm{mM}$ EDTA, $150 \mathrm{mM} \mathrm{NaCl}, 0.1 \%$ BSA, $0.1 \mathrm{mM}$ spermidine, 5\% glycerol). The reaction was stopped by adding $6 \mu \mathrm{L}$ of $4 \times$ SDS stop solution ( $6 \%$ SDS, $0.3 \%$ bromophenol blue, $30 \%$ glycerol) and the supercoiled DNA and relaxed DNA were then separated by electrophoresis in $1 \%$ agarose gel based on the mobility differences (Figure 2.4). The DNA molecules in the gel were stained with $1 \mu \mathrm{g} / \mathrm{mL}$ of ethidium bromide (EtBr) solution and photographed over UV light. AlphaView SA (ProteinSimple) was used to analyze the fraction of supercoiled DNA substrate converted into relaxed DNA at the end of each reaction. Serial dilutions of the recombinant hTOP1 enzyme were used to generate a reference standard curve for the fraction of supercoiled DNA converted to relaxed DNA by units $(U)$ of hTOP1 as defined by the supplier. The TOP1 activity in whole cell extracts (WCEs) was assayed under the same conditions. Serial dilutions of WCEs were assayed to identify amount needed to relax $50 \%$ of the supercoiled DNA substrate and calculate the TOP1 activity present in each WCE using the standard curve as $\mathrm{U} / \mu \mathrm{g}$ of total WCE protein. The relative TOP1 activity levels present in 
the cell lines were normalized to the TOP1 activity level in fetal normal human astrocyte (NHA).

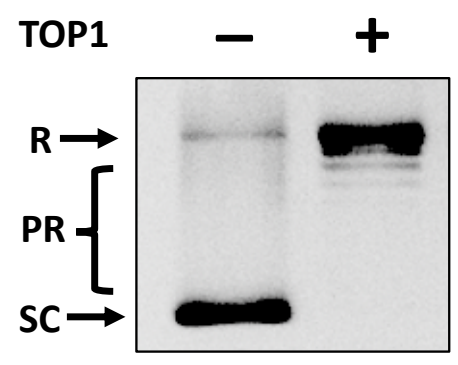

Figure 2.4. Diagram of TOP1 relaxation assay

\section{5'-end labeling of oligonucleotide P12Y}

The 12-base long oligonucleotide substrate $\mathrm{OH} 12 \mathrm{Y}$ linked to tyrosine at the 3'-end (OH12Y, 5'-OH-GAA AAA AGA GTT-PO4-Tyr-3') was obtained from TopoGEN. Radionucleotides [Y-32P] ATP $(10 \mu \mathrm{Ci} / \mu \mathrm{L})$ was purchased from Perkin Elmer Inc. The 5'-end labeling reaction was carried out in a final reaction volume of $20 \mu \mathrm{L}$. The $\mathrm{OH} 12 \mathrm{Y}$ oligonucleotide ( $800 \mathrm{ng}$ ) was incubated with $25 \mu \mathrm{Ci}$ of $\left[\mathrm{Y}^{-}{ }^{32} \mathrm{P}\right]$ ATP in the presence of $10 \mathrm{U}$ of T4 DNA ligase (NEB) at $37^{\circ} \mathrm{C}$ for $30 \mathrm{~min}$ in reaction buffer (70 mM Tris- $\mathrm{HCl}, \mathrm{pH} 7.6,10 \mathrm{mM} \mathrm{MgCl} 2,5 \mathrm{mM}$ DTT). The reaction was terminated by heating at $75^{\circ} \mathrm{C}$ for $15 \mathrm{~min}$. The $5^{\prime}$-labeled oligonucleotide $(\mathrm{P} 12 \mathrm{Y}$, 5'-32PO4-GAA AAA AGA GTT-PO4-Tyr-3') was then purified by centrifugation through a $1.5 \mathrm{~mL}$ Sephadex $\mathrm{G} 15$ column and stored in $10 \mathrm{mM}$ Tris- $\mathrm{HCl}(\mathrm{pH} 7.5)$ at $-20^{\circ} \mathrm{C}$ until further use. 


\section{Human TDP1 activity measurement by Gel-based assay}

Human tyrosyl-DNA phosphodiesterase 1 activity measurement by gel-based assay was carried out in a final reaction volume of $5 \mu \mathrm{L}$. The recombinant human TDP1 (hTDP1) was received as a gift from Dr. Yves Pommier at the National Institute of Health $(\mathrm{NIH})(100)$. The P12Y oligo (4 ng) was cleaved with serial dilutions of recombinant hTDP1 at $37^{\circ} \mathrm{C}$ for $30 \mathrm{~min}$ in gel-based assay reaction buffer (20 mM Tris-HCl, pH 7.5, $100 \mathrm{mM} \mathrm{KCl,} 10 \mathrm{mM}$ EDTA, $1 \mathrm{mM}$ DTT). The reaction was stopped by adding $5 \mu \mathrm{L}$ of $2 \times$ stop solution ( $96 \%$ formamide, $20 \mathrm{mM}$ EDTA, $0.03 \%$ xylene cyanol and $0.03 \%$ bromophenol blue) followed by heating at $95^{\circ} \mathrm{C}$ for $5 \mathrm{~min}$. The oligonucleotide substrate and product were separated by electrophoresis in $20 \%$ urea-denaturing sequencing gel (SequaGel, National

Diagnostics) using the mobility differences between $\mathrm{P} 12 \mathrm{Y}$ substrate and $\mathrm{P} 12$ product (5'-32 $\mathrm{PO}_{4}-\mathrm{GAA}$ AAA AGA GTT-PO 4 -3') with 3'-tyrosine removed (Figure 2.5). The intensity of the labeled oligonucleotides was analyzed with the BiorRad PharoFX Plus Phosphorimager. The correlation between hTDP1 activity represented as fmol, and the fraction of $\mathrm{P} 12$ formed from $\mathrm{P} 12 \mathrm{Y}$ is plotted as a standard linear curve. The TDP1 activity assay from WCE was carried out under the same condition with $2 \mu \mathrm{g}$ of WCE added to each reaction. The TDP1 activity present in each microgram of WCE was calculated using the standard curve as $\mathrm{fmol} / \mu \mathrm{g}$. The TDP1 activities in the GBM cell lines were then normalized by TDP1 activity in WCE of NHA. 


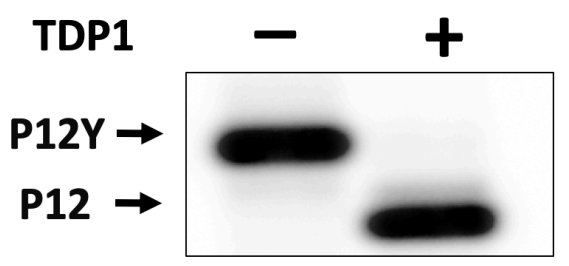

Figure 2.5. Diagram of gel-based TDP1 activity assay

\section{Human TDP1 activity measurement by fluorescence-based assay}

The TDP1 activity was also carried out using a fluorescence-based assay (101). The 55 nucleotide (nt) long 5'FAM-DNA-BHQ1-3' oligonucleotide substrate (5’-6-FAM-AAA GCA GGC TTC AAC GCA ACT GTG AAG ATC GCT TGG GTG CGT TGA AGC CTG CTT T-BHQ1-3', purchased from LGC BioSearch) has 5' phosphorothioate bond linked 6-FAM fluorophore and 3' phosphodiester bond linked black hole quencher 1 (BHQ1) modifications. It forms a blunt-ended hair-pin DNA structure with 6-FAM fluorescence quenched by BHQ1 (Figure 2.6). Briefly, 25 pmol of 5'FAM-DNA-BHQ1-3' was incubated with serial dilutions of hTDP1 at $37^{\circ} \mathrm{C}$ in reaction buffer of $20 \mathrm{mM}$ Tris- $\mathrm{HCl}, \mathrm{pH} 8.0,100 \mathrm{mM} \mathrm{KCl}, 10 \mathrm{mM}$ EDTA, 10 mM DTT, $0.05 \%$ TritonX-100 in a final volume of $25 \mu \mathrm{L}$. Fluorescence signal from each reaction was measured every 30 s for 500 min using the CFX96 Touch RealTime PCR Detection System (Bio-Rad, excitation 490 nm, emission 520 nm). The correlation between the amount of hTDP1 utilized, represent as fmol, and the initial linear slope (0-125 $\mathrm{min})$ of fluorescence signal increase from each reaction is plotted as a standard curve. The TDP1 activity present in $2 \mu \mathrm{g}$ of WCE was assayed under the same experimental conditions and calculated using the 
standard curve as fmol/ $\mathrm{\mu g}$. The relative TDP1 activity level in each cell line was normalized by the TDP1 activity level in NHA.

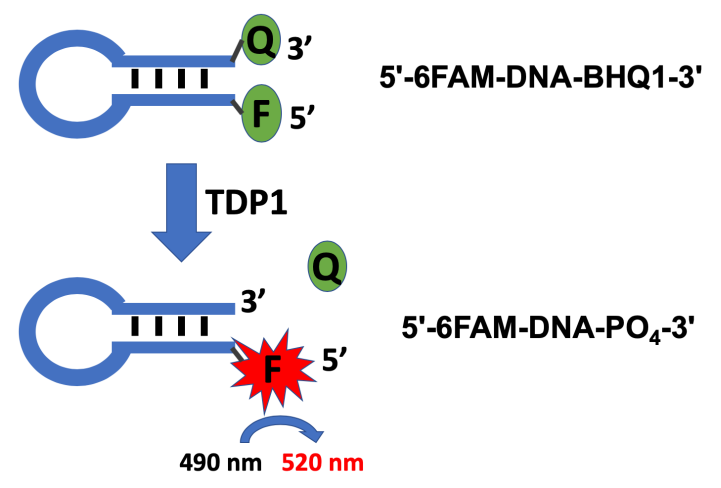

Figure 2.6. Diagram of fluorescence-based TDP1 activity assay

\section{Carboxylesterase 2 activity measurement}

The assay of carboxylesterase 2 (CES2) activity in GBM WCE was carried out as described (97). Briefly, $6.7 \mu \mathrm{g}$ of WCE from each cell line were preincubated in 96 -well plates at $37^{\circ} \mathrm{C}$ for $10 \mathrm{~min}$ in a total volume of $20 \mu \mathrm{L}$ of reaction buffer (100 mM Tris-HCl, $\mathrm{pH} 7.4$ ) in presence or absence of $300 \mu \mathrm{M}$ of CES2 inhibitor loperamide (LOP, Sigma). The reaction was initiated by adding $200 \mu \mathrm{L}$ of $1.5 \mathrm{mM}$ 4-nitrophenyl acetate (p-NPA, Sigma) in reaction buffer and incubated at $37^{\circ} \mathrm{C}$. Absorbance at $405 \mathrm{~nm}$ was recorded at $0,5,10,20,30,40,50$, and $60 \mathrm{~min}$. The amount of the reaction product para-nitrophenol ( $\mathrm{p}-\mathrm{NP}$ ) formed was calculated using the standard curve generated with serial dilutions of p-NP (Sigma). The carboxylesterase activity from each microgram of WCE was represented as $\mathrm{pmol} / \mathrm{min} / \mathrm{\mu g}$. The difference in activity obtained in the presence and absence of LOP was considered as CES2 activity (Figure 2.7). 


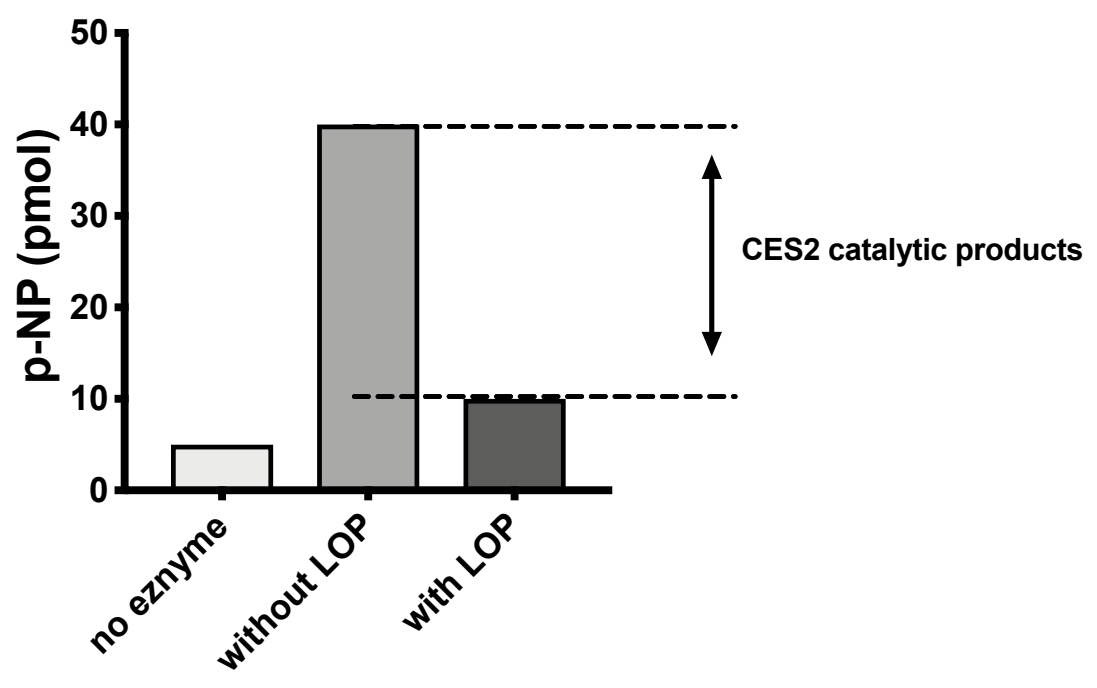

Figure 2.7. Diagram of CES2 catalytic activity measurement

\section{Statistical analysis}

Degree of correlations between two parameters tested in this study is determined by using the Pearson correlation coefficient value $(R)$ and considered as significant for $P<0.05$. GraphPad Prism version 8.0 was used to carry out the data analysis. 


\section{RESULTS AND DISCUSSION}

\section{Variation of Irinotecan sensitivity among GBM cell lines}

Nine different commercially available glioblastoma (GBM) cell lines (Table 2.1) were treated with serial diluted Irinotecan (IRT) and the cell viabilities were measured with the TO-PRO3 assay (Figure 2.8A). The $\mathrm{IC}_{50}$ values, defined as the concentration that induces $50 \%$ loss of viability, are listed in Table 2.4 , column 1 . Cells with the higher IC $\mathrm{C}_{50}$, such as SNB75 (IRT IC $\left.50=10.02 \mu \mathrm{M}\right)$, are more resistant to drug treatment, whereas the cells with lower $\mathrm{IC}_{50}$ S, such as SF539 (IRT $\left.I_{50}=1.91 \mu \mathrm{M}\right)$, are more likely to respond to IRT treatment. Drug sensitivities data (Z-score) from the $\mathrm{NCl}-60$ panel provided on CellMiner database (https://discover.nci.nih.gov/cellminer/) and the $\mathrm{IC}_{50}$ S from Cancer Cell Line Encyclopedia (CCLE) panel provided on the CancerDR database (http://crdd.osdd.net/raghava/cancerdr/) are also listed in Table 2.4, column 3 and column 2, respectively. A higher Z-score indicates the cells are more sensitive to the drug treatment, such as SF539 (IRT, Z-score $=0.9367)$, while the lower Zscore indicates that the cell lines are more resistant, such as SNB75 (IRT, Z-score

$=0.1333)$. The significant correlation between experimental IRT $I C_{50}$ and database-gathered IRT sensitivities demonstrates that the viability assay we used based on TO-PRO3 reagent is reliable (Figure 2.8, panels $\mathrm{B}, \mathrm{C}$ ).

The TOP1 expression level was first analyzed in the following section to identify biomarkers correlated with the variation of IRT sensitivities among GBM cell lines, 
Table 2.4. Topoisomerase I/II inhibitors sensitivity data for GBM cell lines

\begin{tabular}{|c|c|c|c|c|c|c|c|}
\hline \multirow{3}{*}{ Cell lines } & \multirow{3}{*}{$\begin{array}{c}\text { Experimental } \\
\text { results } \\
{ }^{* 1} \\
\text { rinotecan } \\
\mathrm{IC}_{50}(\mu \mathrm{M}) \\
\end{array}$} & \multirow{3}{*}{$\begin{array}{c}\begin{array}{c}\text { CancerDR } \\
\text { database }^{* 2}\end{array} \\
\text { Irinotecan } \\
I_{50}(\mu \mathrm{M})\end{array}$} & \multicolumn{5}{|c|}{ CellMiner databased $^{* 3}$} \\
\hline & & & \multicolumn{3}{|c|}{ Topoisomerase I inhibitors } & \multicolumn{2}{|c|}{ Topoisomerase II inhibitors } \\
\hline & & & $\begin{array}{c}\text { Irinotecan } \\
\text { activity Z-score }\end{array}$ & $\begin{array}{l}\text { Camptothecin } \\
\text { activity Z-score }\end{array}$ & $\begin{array}{c}\text { Topotecan } \\
\text { activity Z-score }\end{array}$ & $\begin{array}{c}\text { Etoposide } \\
\text { activity Z-score }\end{array}$ & $\begin{array}{c}\text { Doxorubicin } \\
\text { activity Z-score }\end{array}$ \\
\hline SF539 & 1.91 & $\mathrm{~N} / \mathrm{A}$ & 0.91 & 0.76 & 0.88 & 0.55 & 0.41 \\
\hline SF295 & 2.83 & 0.197 & 0.74 & 0.96 & 0.88 & 0.46 & 0.46 \\
\hline H4 & 2.98 & N/A & $N / A^{* 2}$ & $\mathrm{~N} / \mathrm{A}$ & $\mathrm{N} / \mathrm{A}$ & $\mathrm{N} / \mathrm{A}$ & $\mathrm{N} / \mathrm{A}$ \\
\hline SF268 & 3.66 & $\mathrm{~N} / \mathrm{A}$ & 0.81 & 0.97 & 0.88 & 0.05 & 0.02 \\
\hline SNB19 & 3.68 & $\mathrm{~N} / \mathrm{A}$ & 0.64 & 0.77 & 0.71 & 0.35 & 0.79 \\
\hline U251 & 5.15 & $\mathrm{~N} / \mathrm{A}$ & 0.78 & 0.98 & 0.88 & 0.51 & 0.8 \\
\hline A172 & 8.42 & 0.509 & $\mathrm{~N} / \mathrm{A}$ & $\mathrm{N} / \mathrm{A}$ & $\mathrm{N} / \mathrm{A}$ & $\mathrm{N} / \mathrm{A}$ & $\mathrm{N} / \mathrm{A}$ \\
\hline SNB75 & 10.02 & $\mathrm{~N} / \mathrm{A}$ & 0.24 & 0.12 & 0.5 & 0.08 & 0.53 \\
\hline U87 & 10.5 & 0.792 & $\mathrm{~N} / \mathrm{A}$ & $\mathrm{N} / \mathrm{A}$ & $\mathrm{N} / \mathrm{A}$ & $\mathrm{N} / \mathrm{A}$ & $\mathrm{N} / \mathrm{A}$ \\
\hline
\end{tabular}

${ }^{* 1}$ Drug $\mathrm{IC}_{50}$ based on experimental results

${ }^{* 2}$ Drug $\mathrm{IC}_{50}$ based on CancerDR Database

${ }^{*}$ Drug activity Z-score based on CellMiner Database

N/A: not available
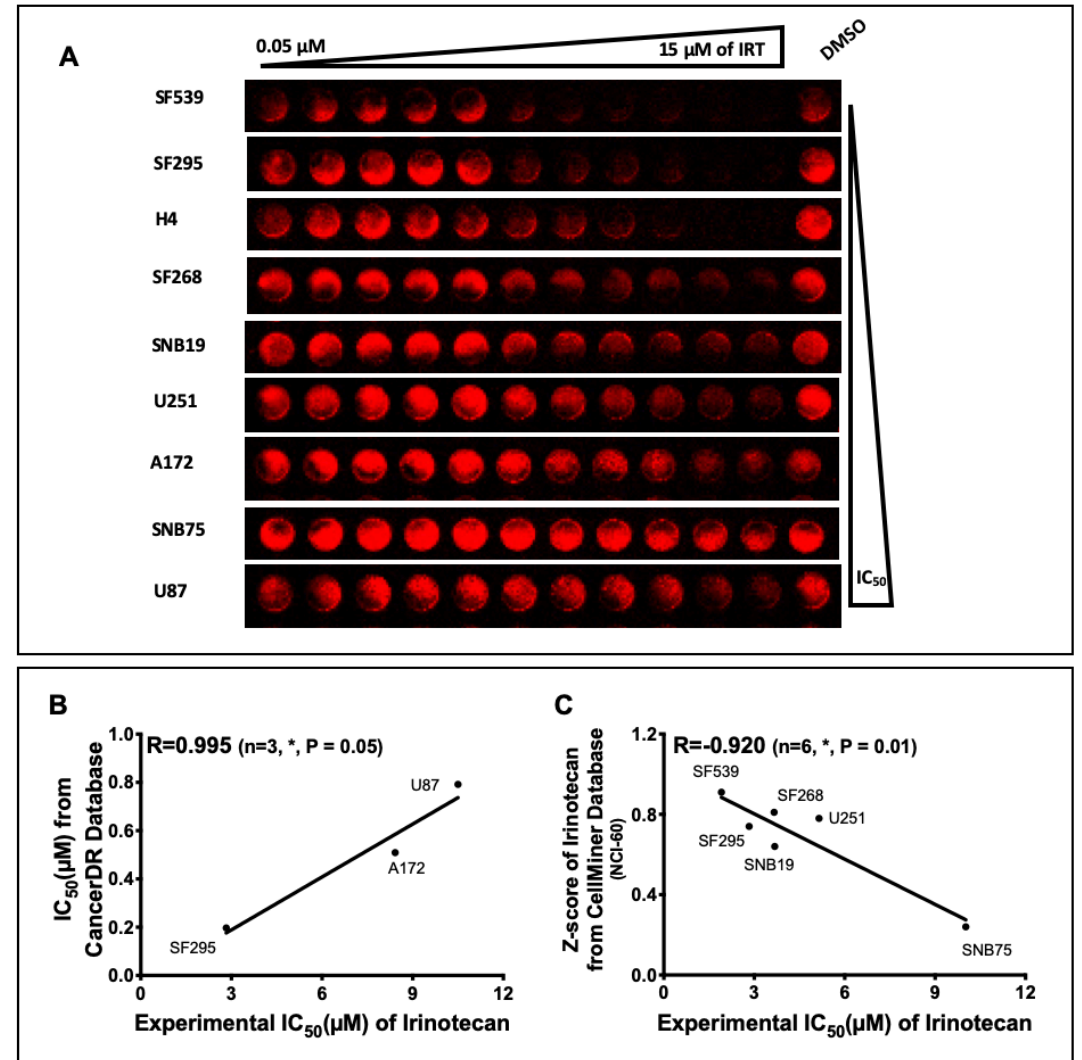

Figure 2.8. Comparison of experimental IRT IC ${ }_{50}$ S against GBM cell lines to IRT sensitivities from databases

(A) The cell viabilities of GBM cell lines were measured by TO-PRO3 assay after $72 \mathrm{~h}$ treatment with serial dilutions of IRT $(0.05 \mu \mathrm{M}$ to $15 \mu \mathrm{M})$. DMSO treatment was used as control. The $\mathrm{IC}_{50}$ values used for the correlation analysis are the average values of data collected from three individual experiments. (B) Experimental $\mathrm{IC}_{50}$ is significantly correlated with $\mathrm{IC}_{50}$ for CCLE panel provided on 
CancerDR database. (C) Experimental $\mathrm{IC}_{50}$ is significantly correlated with IRT sensitivity Z-score for $\mathrm{NCl}-60$ panel from CellMiner database.

\section{TOP1 expression level is not correlated with GBM cell line sensitivities to Irinotecan}

On the basis of the Coomassie blue staining following SDS-PAGE, total proteins found in $10 \mu \mathrm{g}$ of whole cell extracts (WCEs) prepared from the GBM cell lines are comparable (Figure 2.9), which indicates that the expression level of individual proteins of interests among GBM cell lines can be compared by Western blot analysis of the WCEs. Cells were collected from three independent sets of cultures (set \#1, set \#2, set \#3) along with fetal NHA (Normal Human Astrocyte). The TOP1 protein level in $10 \mu \mathrm{g}$ of WCEs was measured by Western blotting (Figure 2.10, panels A1, B1, C1). The signal intensity was first normalized to actin signal to correct for loading, then divided by the NHA signal intensity for comparison. The data from each set were collected from at least three individual experiments. The TOP1 expression variations observed among the GBM cell lines are shown in Table 2.5. Results from GBM set \#1 (Fig 2.10, panel A2) revealed that the GBM cell lines tested mostly had higher level of TOP1 protein expression than NHA (relative ratios $\geq 1$ ). The TOP1 protein expression showed up to 2 -fold variation (relative ratio from 0.98 to 1.96). Similar results were also observed in set \#2 (Figure 2.10, panel B2) and set \#3 GBM cell cultures (Figure 2.10, panel C2). The TOP1 relative expression levels measured ranged from 1.34 to 2.46 in the set \#2 experiments, and from 1.16 to 2.20 in the set \#3 experiments. The expression of TOP1 calculated from averaging the results of set \#1, \#2, and \#3 (Figure 2.10, 
panel D1), ranged from 1.14 to 1.97. According to our data, TOP1 expression level is comparable throughout experiments set \#1, \#2, and \#3 which indicates the stability of cells cultured from three individual aliquots of cryopreserved GBM cells. In addition, elevated expression of TOP1 in GBM cell lines in comparison to NHA suggests that TOP1 is required for GBM proliferation and increased TOP1 target level might enhance the cytotoxicity from IRT treatment. However, no significant correlation $(R=-0.254$, Figure 2.10, panel $A 3)$ was observed between the TOP1 protein level in GBM set \#1 with experimental $I_{50}$ s. The lack of correlation between TOP1 protein level and IRT IC 50 S was also observed for data set \#2 $(R=$ 0.189, Figure 2.10, panel B3), set \#3 $(R=-0.291$, Figure 2.10, panel $C 3)$, as well as the average of TOP1 protein levels $(R=-0.139$, Figure 2.10 , panel D2). Furthermore, the TOP1 protein levels measured here also showed no significant correlation with IRT sensitivities reported in databases (Figure 2.10, panel A4, B4, C4, D3).

An extensive analysis of TOP1 mRNA expression levels in GBM cell lines available from various cancer cell databases was conducted next to determine if there is any correlation with IRT IC $\mathrm{C}_{50}$ S. The CellMiner Cross Database (CellMinerCDB) (https://discover.nci.nih.gov/cellminercdb/) is a robust platform which provides pharmacogenomic data of cancer cell lines across different sources (18). We analyzed the TOP1 mRNA expression of GBM cell lines included in three separate panels (CCLE, NCl-60, and Genomics of Drug Sensitivity in Cancer (GDSC)) of CellMinerCDB. The mRNA expression level of TOP1 is available for 45 GBM cell lines included in the CCLE panel, 41 GBM cell lines 
included in the GDSC panel, and 5 GBM cell lines included in the $\mathrm{NCl}-60$ panel (Table 2.6). The TOP1 mRNA expression data from both CCLE and GDSC were analyzed against the $\mathrm{IC}_{50}$ S provided in the CCLE database since no IRT drug sensitivity data is available in GDSC. Additionally, the mRNA expression from cell lines in the $\mathrm{NCl}-60$ panel was compared with its Z-score provided by CellMiner database. Analysis of the TOP1 mRNA expression level and IRT drug sensitivities revealed that there is no significant correlation (Figure 2.11) as expected from our previous results which no correlation was obtained between TOP1 protein level and IRT IC ${ }_{50}$ S. In addition, TOP1 protein level is not comparable with TOP1 mRNA expression level (Figure 2.12).

It can be concluded that TOP1 expression levels in GBM cell lines, measured for both protein and mRNA, do not correlate with IRT sensitivities. The TOP1 protein needs to bind and cleave the DNA substrate before the TOP1cc can be trapped by inhibition of DNA rejoining by IRT. Therefore, GBM sensitivity to IRT may not only depend on the amount of TOP1 existing in cells but is more dependent on TOP1 activities. To further support our hypotheses about TOP1 activity playing a more significant role in IRT drug sensitivity, TOP1 relaxation assay was conducted and the results will be discussed in the following section 


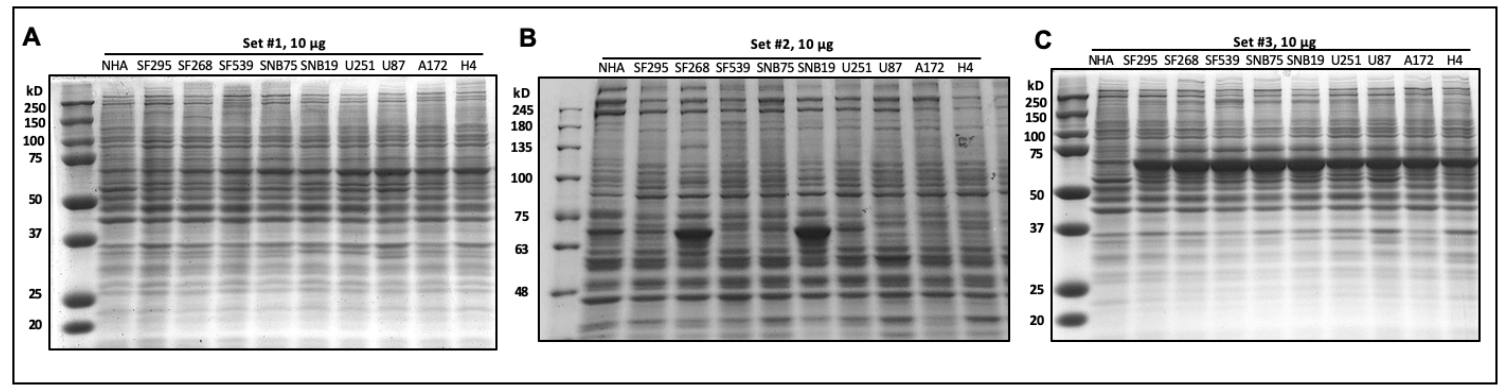

Figure 2.9. Coomassie blue staining of GBM cell lines

(A) For set \#1 collection, the total proteins in $10 \mu \mathrm{g}$ of WCEs of nine glioblastoma cell lines (SF295, SF269, SF539, SNB75, SNB19, U251, U87, A172, H4) as well as normal human astrocyte (NHA) were visualized by Coomassie blue staining following SDS PAGE. For (B) set \#2 and (C) set \#3 collections, the WCE proteins were also visualized by Coomassie blue staining.

Table 2.5. Relative TOP1 protein expression level of GBM cell lines

\begin{tabular}{|c|c|c|c|c|}
\hline \multicolumn{5}{|c|}{ Experimental TOP1 protein levels } \\
\hline Cell lines & Set \#1, GBM & Set \#2, GBM & Set \#3, GBM & Average of Set \#1, 2, 3, GBM \\
\hline SF539 & $1.259 \pm 0.227$ & $1.698 \pm 0.548$ & $1.886 \pm 0.199$ & $1.501 \pm 0.415$ \\
\hline SF295 & $1.387 \pm 0.346$ & $1.838 \pm 0.226$ & $1.501 \pm 0.376$ & $1.448 \pm 0.360$ \\
\hline H4 & $1.956 \pm 0.277$ & $2.125 \pm 0.446$ & $1.860 \pm 0.186$ & $1.974 \pm 0.299$ \\
\hline SF268 & $1.095 \pm 0.248$ & $1.489 \pm 0.399$ & $2.056 \pm 0.435$ & $1.374 \pm 0.483$ \\
\hline SNB19 & $1.652 \pm 0.333$ & $1.394 \pm 0.441$ & $2.198 \pm 0.960$ & $1.681 \pm 0.500$ \\
\hline U251 & $1.610 \pm 0.362$ & $1.738 \pm 0.213$ & $1.545 \pm 0.366$ & $1.623 \pm 0.332$ \\
\hline A172 & $0.977 \pm 0.281$ & $1.742 \pm 0.144$ & $1.563 \pm 0.278$ & $1.321 \pm 0.430$ \\
\hline SNB75 & $1.037 \pm 0.253$ & $1.340 \pm 0.494$ & $1.162 \pm 0.344$ & $1.136 \pm 0.340$ \\
\hline U87 & $1.686 \pm 0.301$ & $2.450 \pm 0.681$ & $2.134 \pm 0.557$ & $1.961 \pm 0.546$ \\
\hline
\end{tabular}




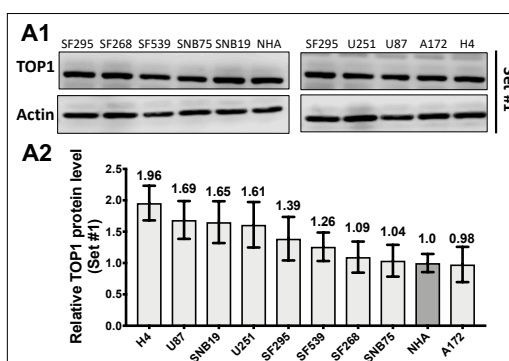

A3

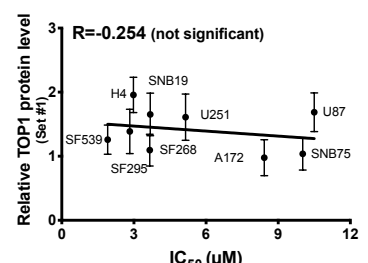

A4

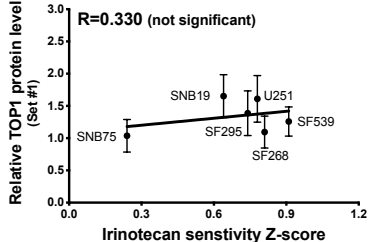

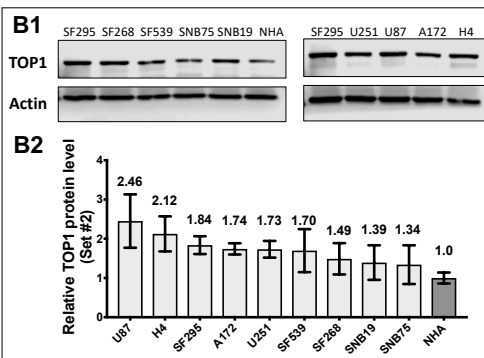

B3

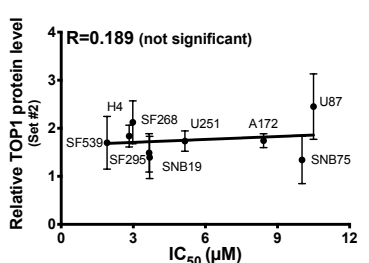

B4

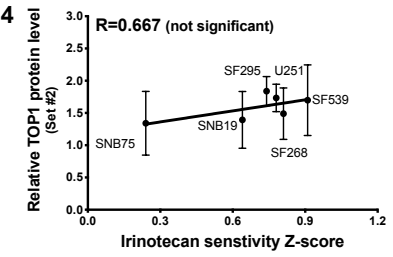

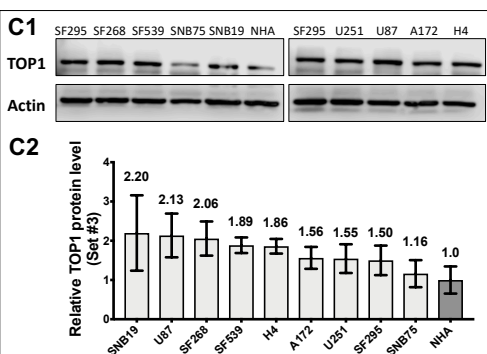

C3
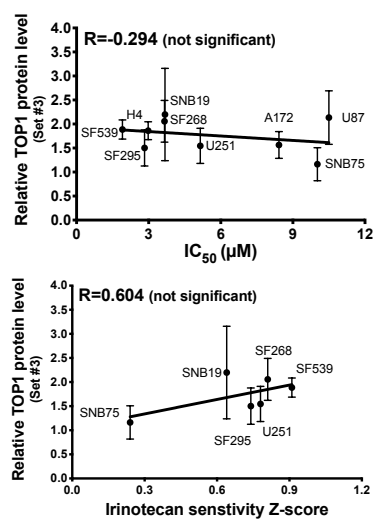

D1

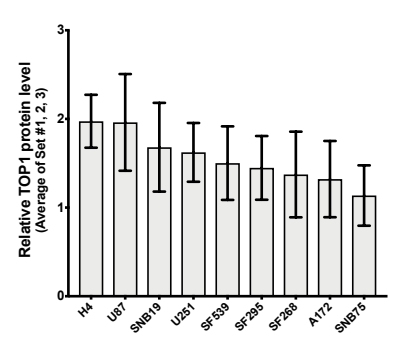

D2
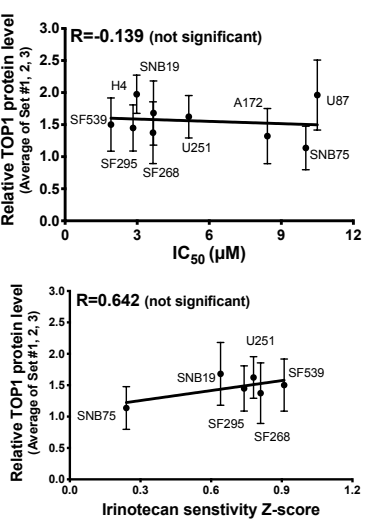

Figure 2.10. Comparison of topoisomerase I protein level in GBM cell lines to assess potential correlation with Irinotecan sensitivities from experiments and databases

(A1) The relative levels of TOP1 protein expression from set \#1 GBM cell lines were measured by western blotting and normalized against NHA. The signal from actin was used to control the loading of $10 \mu \mathrm{g}$ of WCE. For (B1) set \#2 (C1) set \#3, TOP1 protein expression levels were also detected by western blotting. (A2) TOP1 protein levels from set \#1 collection were higher than NHA (gray bar) (relative ratios >1). For (B2) set \#2, (C2) set \#3, and (D1) the average of TOP1 protein expression level, TOP1 protein expression in GBM cell lines was also observed to be higher than NHA. (A3) The relative TOP1 protein level from set \#1 does not correlate with Irinotecan $I C_{50}$. For (B3) set \#2, (C3) set \#3, (D2) and the average of TOP1 protein expression level from the 3 sets of experiments, the same insignificant correlations were observed. The (A4) set \#1, (B4) set \#2, (C4) set \#3, and (D3) the average of TOP1 protein expression levels do not correlate with IRT Z-score from NCl-60 panel on the CellMiner database. 
Table 2.6. The mRNA expression of TOP1 and TDP1 in GBM cell lines and their IRT IC ${ }_{50}$ S available in the CellMinerCDB database

\begin{tabular}{|c|c|c|c|c|c|c|c|c|c|c|}
\hline \multicolumn{10}{|c|}{ Data from CellMinerCDB database } & \multirow{3}{*}{\begin{tabular}{|c}
$\begin{array}{c}\text { Cellminer } \\
\text { database }\end{array}$ \\
z-score
\end{tabular}} \\
\hline \multicolumn{4}{|c|}{ CCLE panel } & \multicolumn{3}{|c|}{$\begin{array}{c}\text { GDSC panel } \\
\end{array}$} & \multicolumn{3}{|c|}{$\mathrm{NCl}-60$ panel } & \\
\hline Cell Line & mRNA TOP1 & mRNA TDP1 & $\begin{array}{l}\log \left(\mid I_{50}\right) \text { of } \\
\text { Irinotecan }\end{array}$ & Cell Line & mRNA TOP1 & mRNA TDP1 & Cell Line & mRNA TOP1 & mRNA TDP1 & \\
\hline & & & & SF539 & 9.347 & 7.136 & & & & \\
\hline SF-295 & 10.256 & 5.600 & 6.706 & SF295 & 9.410 & 5.574 & CNS:SF-295 & 8.460 & 6.992 & 0.740 \\
\hline \multirow[t]{2}{*}{$\mathrm{H} 4$} & 9.362 & 5.681 & & $\mathrm{H} 4$ & 9.298 & 6.920 & & & & \\
\hline & & & & SF268 & 9.681 & 8.242 & CNS:SF-268 & 8.708 & 8.238 & 0.810 \\
\hline SNB-19 & 9.937 & 5.676 & & & & & CNS:SNB-19 & 8.269 & 7.501 & 0.64 \\
\hline U-251 MG & 9.027 & 5.660 & & U251 & 9.361 & 7.700 & CNS:U251 & 7.877 & 7.649 & 0.780 \\
\hline \multirow[t]{2}{*}{ A172 } & 9.716 & 6.127 & 6.294 & A172 & 9.361 & 7.392 & & & & \\
\hline & & & & SNB75 & 8.785 & 7.406 & CNS:SNB-75 & 8.079 & 7.897 & 0.240 \\
\hline U-87 MG & 10.004 & 6.073 & 6.101 & U-87-MG & 8.823 & 7.620 & & & & \\
\hline 42-MG-BA & 10.238 & 6.218 & & 42-MG-BA & 9.221 & 7.633 & & & & \\
\hline 8-MG-BA & 10.347 & 5.211 & & 8-MG-BA & 9.774 & 6.758 & & & & \\
\hline AM-38 & 10.224 & 6.451 & & AM-38 & 9.805 & 8.615 & & & & \\
\hline Becker & 9.694 & 6.053 & & Becker & 9.359 & 6.126 & & & & \\
\hline CAS-1 & 10.798 & 5.747 & 6.109 & CAS-1 & 9.839 & 7.755 & & & & \\
\hline CCF-STTG1 & 9.279 & 5.961 & & CCF-STTG1 & 10.516 & 7.212 & & & & \\
\hline DBTRG-05MG & 11.059 & 5.701 & 7.070 & DBTRG-05MG & 10.879 & 6.703 & & & & \\
\hline DK-MG & 9.793 & 5.117 & 6.233 & DK-MG & 9.202 & 6.627 & & & & \\
\hline GB-1 & 9.906 & 6.126 & 7.104 & GB-1 & 9.556 & 7.539 & & & & \\
\hline Gl-1 & 10.360 & 6.021 & & Gl-1 & 10.026 & 7.200 & & & & \\
\hline GMS-10 & 10.675 & 6.063 & 5.553 & GMS-10 & 9.990 & 7.889 & & & & \\
\hline KNS-81 & 9.595 & 5.358 & 6.660 & KNS-81-FD & 9.465 & 6.324 & & & & \\
\hline KS-1 & 9.716 & 6.087 & & KS-1 & 8.679 & 7.038 & & & & \\
\hline LN-18 & 10.481 & 5.877 & 6.125 & LN-18 & 9.738 & 8.313 & & & & \\
\hline LN-229 & 10.124 & 5.895 & & LN-229 & 9.990 & 7.839 & & & & \\
\hline SF126 & 9.742 & 6.132 & 6.902 & SF126 & 9.851 & 7.980 & & & & \\
\hline SW 1088 & 10.108 & 5.817 & & SW1088 & 10.297 & 7.507 & & & & \\
\hline T98G & 10.456 & 5.509 & 6.023 & T98G & 9.274 & 7.013 & & & & \\
\hline U-118 MG & $\begin{array}{l}9.849 \\
\end{array}$ & 5.516 & 6.719 & U-118-MG & 8.582 & 7.038 & & & & \\
\hline YH-13 & 9.435 & 5.650 & & YH-13 & 8.709 & 7.158 & & & & \\
\hline \multirow[t]{13}{*}{ YKG1 } & 10.640 & 5.557 & 5.766 & YKG-1 & 9.261 & 5.912 & & & & \\
\hline & & & & D-247MG & 9.783 & 7.912 & & & & \\
\hline & & & & D-263MG & 9.608 & 8.006 & & & & \\
\hline & & & & D-392MG & 9.465 & 7.087 & & & & \\
\hline & & & & D-423MG & 9.849 & 7.842 & & & & \\
\hline & & & & D-542MG & 8.618 & 7.263 & & & & \\
\hline & & & & D-566MG & 9.968 & 8.242 & & & & \\
\hline & & & & LN-405 & 10.338 & 7.883 & & & & \\
\hline & & & & LNZTA3WT4 & 9.125 & 7.786 & & & & \\
\hline & & & & M059J & 10.105 & 7.403 & & & & \\
\hline & & & & MOG-G-CCM & 9.821 & 7.677 & & & & \\
\hline & & & & MOG-G-UVW & 9.231 & 6.447 & & & & \\
\hline & & & & SK-MG-1 & 9.130 & 7.949 & & & & \\
\hline KG-1-C & 10.719 & 5.253 & & & & & & & & \\
\hline KNS-60 & 9.502 & 6.078 & 6.360 & & & & & & & \\
\hline LN-235 & 10.158 & 5.894 & & & & & & & & \\
\hline LN-319 & 9.932 & 6.317 & & & & & & & & \\
\hline LN-340 & 10.475 & 5.741 & & & & & & & & \\
\hline LN-443 & 10.638 & 6.597 & & & & & & & & \\
\hline LN382 & 10.487 & 5.587 & & & & & & & & \\
\hline LNZ308 & 9.648 & 5.919 & & & & & & & & \\
\hline M059K & 10.289 & 6.203 & & & & & & & & \\
\hline SF-172 & 10.905 & 6.276 & & & & & & & & \\
\hline SNU-1105 & 9.359 & 6.191 & & & & & & & & \\
\hline SNU-201 & 9.286 & 5.464 & & & & & & & & \\
\hline SNU-466 & 9.192 & 5.783 & & & & & & & & \\
\hline SNU-489 & 9.417 & 5.664 & & & & & & & & \\
\hline SNU-626 & 9.742 & 5.160 & & & & & & & & \\
\hline U-138 MG & 9.629 & 5.447 & & & & & & & & \\
\hline U-178 & 9.304 & 6.100 & & & & & & & & \\
\hline U343 & 10.283 & 5.641 & & & & & & & & \\
\hline
\end{tabular}


A1

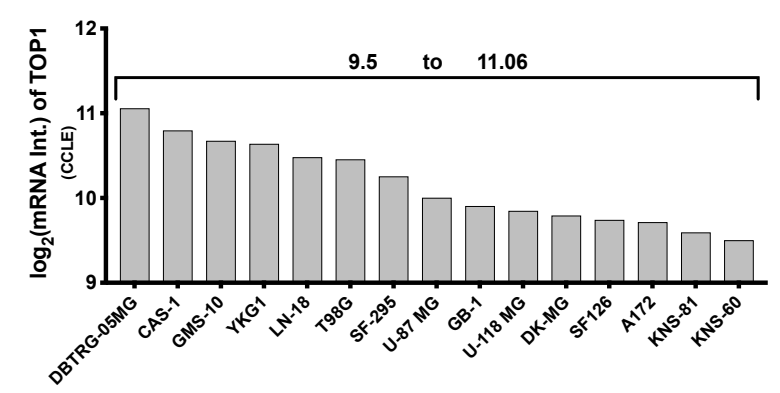

A2

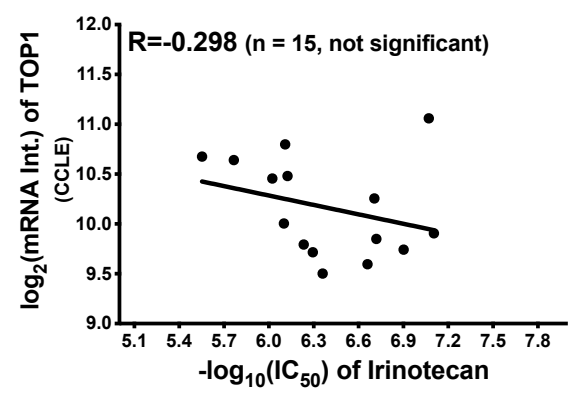

B1

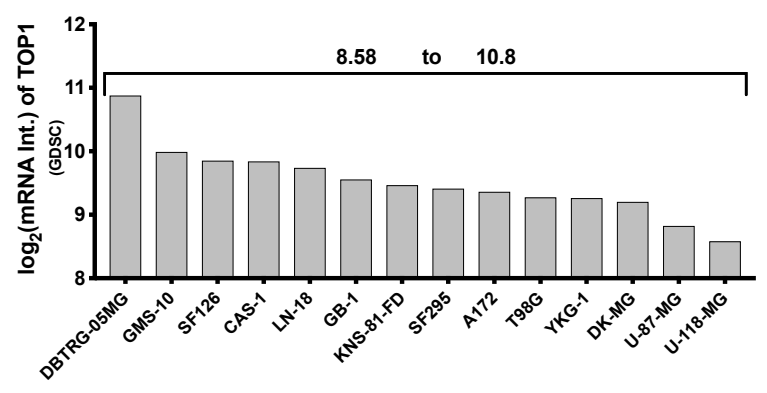

B2

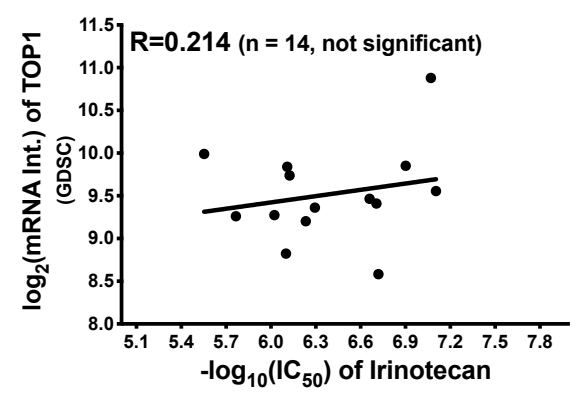

C1

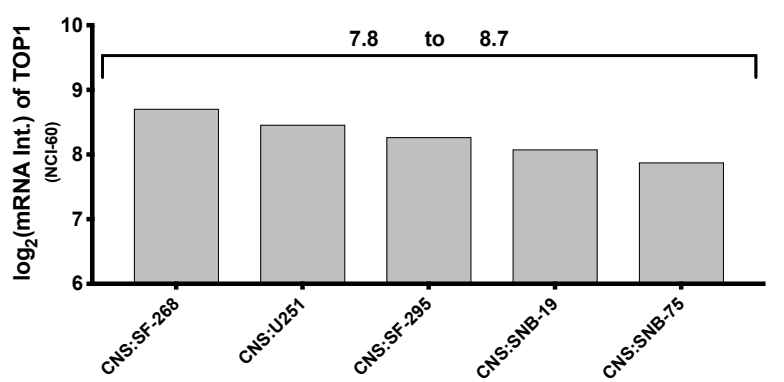

C2

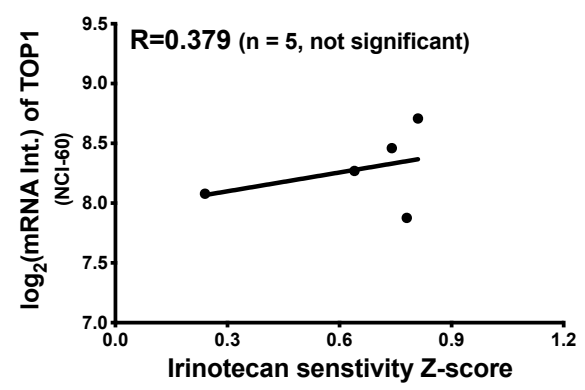

Figure 2.11. Lack of correlation between TOP1 mRNA expression data and Irinotecan $\mathrm{IC}_{50}$ S against $\mathrm{GBM}$ cell lines from CellMinerCDB database.

(A) The TOP1 mRNA expression in GBM cell lines $(n=15)$ does not correlate with IRT IC 50 s from the CCLE panel. (B) The TOP1 mRNA expression of GBM cell lines $(n=14)$ does not correlate with IRT IC ${ }_{50}$ s from the GDSC panel. (C) The TOP1 mRNA expression of GBM cell lines $(n=5)$ does not correspond with IRT IC ${ }_{50}$ S from the $\mathrm{NCl}-60$ panel. 

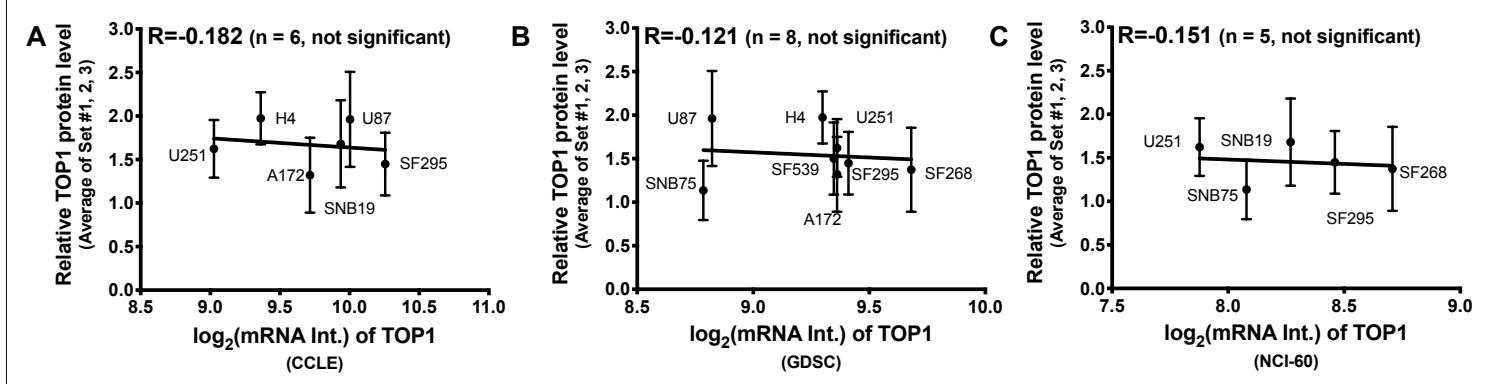

Figure 2.12. Comparison of TOP1 protein level with TOP1 mRNA level. The average of TOP1 protein levels are not correlated with mRNA levels on (A) CCLE panel, (B) GDSC panel, and (C) NCl-60 panel. 
TOP1 activity level in GBM cell lines does not correlate with Irinotecan sensitivities

The TOP1 catalytic activity present in WCE of GBM cell lines was assayed using negatively (-) supercoiled plasmid DNA as substrate. Human TOP1 belongs to the type IB topoisomerase family that does not require ATP or divalent metal ions for its catalytic activity (35). Therefore, cells were collected and lysed in RIPA buffer containing EDTA and EGTA to chelate the metal ions required for endogenous nuclease activities. In addition, EDTA was also included in the TOP1 reaction buffer to suppress the activities from the metal ion-dependent type IA and type IIA topoisomerase activities present in WCE. The TOP1 relaxation activity from each GBM cell line was assayed with serial dilutions of WCE (from $5 \mathrm{ng}$ to 750 ng, Figure 2.14, panels A1, B1, C1). Recombinant human TOP1 (hTOP1) was used to generate a standard linear curve of the increase in the fraction of relaxed DNA with increasing level of TOP1 activity (Figure 2.13). The TOP1 activities were calculated using the standard curve. The relative activity levels were normalized to the TOP1 activity present in NHA. Both activity and relative activity levels of TOP1 are listed in Table 2.7.

The TOP1 activity measured in set \#1 experiments (Fig 2.14, panel A2) showed that the majority of GBM cell lines tested had a higher level of TOP1 activity than NHA (ranging from 0.79 to 1.57). Similar trends were observed in set $\# 2$ and \#3, but the TOP1 activity measured in set \#2 experiments (Figure 2.14, panel B2) has a broader range (relative activity levels from 0.21 to 2.83 ) than the TOP1 relative activity levels measured in set \#3 experiments (Figure 2.14, panel 
C2, from 1.06 to 3.09). The average of TOP1 activity level was calculated using the three sets of data (Figure 2.14, panel D2, ranging from 0.74 to 2.43). On the basis of these results, there is a more significant variation of TOP1 activity level among the three sets of data, despite the observed similarity in TOP1 protein expression levels. The TOP1 activity levels from set \#1, \#2, \#3, and the average of TOP1 activity level (Figure 2.15) do not correlate with TOP1 protein levels, suggesting TOP1 activity in GBM is most likely to be modulated by posttranslational modifications as previously reported $(92,102,103)$. There is also a lack of significant correlation between the TOP1 activity level and IRT IC ${ }_{50}$ S (Figure 2.14, panels A3, B3, C3, D3). Besides, the examination of TOP1 activity level against IRT sensitivities available from databases also showed that there was no significant correlation (Figure 2.14, panels A4, B4, C4, D4).

To sum up, the TOP1 activity level is not significantly correlated with Irinotecan sensitivities of GBM cell lines. However, it might be a better predictor of Irinotecan response than TOP1 protein level, due to TOP1 activity level is negatively correlated with $\mathrm{IC}_{50}$ s throughout all sets of data.

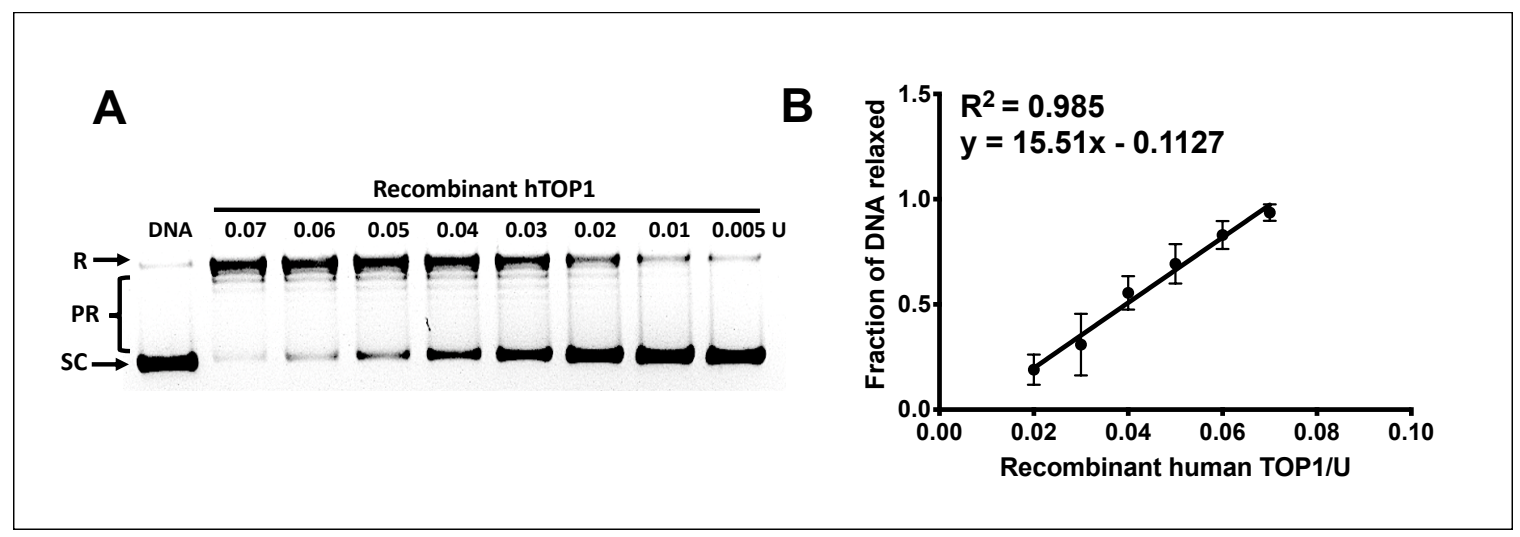

Figure 2.13. Topoisomerase I activity from recombinant human TOP1 
(A) Negatively supercoiled plasmid DNA was relaxed with serial dilutions of recombinant hTOP1 (TopoGEN) and separated by electrophoresis in $1 \%$ agarose gel. SC: supercoiled DNA; R: relaxed DNA; PR: partially relaxed DNA. (B) The standard linear curve generated by quantitation of fraction of DNA relaxed by hTOP1 activity (U).

Table 2.7. TOP1 activity and the relative TOP1 activity level of GBM cell lines

\begin{tabular}{|c|c|c|c|c|c|c|c|c|}
\hline \multicolumn{9}{|c|}{ Experimental TOP1 activity levels } \\
\hline \multirow{2}{*}{$\begin{array}{c}\text { Cell } \\
\text { lines }\end{array}$} & $\begin{array}{c}\text { SeP1 activity } \\
(\mathbf{U} / \mathbf{\mu g})\end{array}$ & $\begin{array}{c}\text { Relative TOP1 } \\
\text { activity }\end{array}$ & $\begin{array}{c}\text { TOP1 activity } \\
(\mathbf{U} / \mathbf{\mu g})\end{array}$ & $\begin{array}{c}\text { Relative TOP1 } \\
\text { activity }\end{array}$ & $\begin{array}{c}\text { TOP1 activity } \\
(\mathbf{U} / \mathbf{\mu g})\end{array}$ & $\begin{array}{c}\text { Relative TOP1 } \\
\text { activity }\end{array}$ & $\begin{array}{c}\text { TOP1 activity } \\
(\mathbf{U} / \boldsymbol{\mu g})\end{array}$ & $\begin{array}{c}\text { Relative TOP1 } \\
\text { activity }\end{array}$ \\
\hline SF539 & $0.661 \pm 0.021$ & $0.787 \pm 0.026$ & $1.739 \pm 0.118$ & $2.071 \pm 0.141$ & $1.941 \pm 0.052$ & $2.313 \pm 0.063$ & $1.402 \pm 0.618$ & $1.670 \pm 0.736$ \\
\hline SF295 & $1.021 \pm 0.100$ & $1.217 \pm 0.119$ & $2.380 \pm 0.254$ & $2.835 \pm 0.303$ & $2.590 \pm 0.151$ & $3.086 \pm 0.180$ & $2.037 \pm 0.698$ & $2.427 \pm 0.831$ \\
\hline H4 & $1.320 \pm 0.104$ & $1.572 \pm 0.125$ & $2.172 \pm 0.131$ & $2.587 \pm 0.157$ & $2.154 \pm 0.202$ & $2.566 \pm 0.241$ & $1.837 \pm 0.449$ & $2.189 \pm 0.534$ \\
\hline SF268 & $1.070 \pm 0.106$ & $1.275 \pm 0.127$ & $0.189 \pm 0.015$ & $0.226 \pm 0.017$ & $1.124 \pm 0.110$ & $1.340 \pm 0.130$ & $0.888 \pm 0.409$ & $1.058 \pm 0.487$ \\
\hline SNB19 & $1.239 \pm 0.090$ & $1.476 \pm 0.107$ & $1.887 \pm 0.200$ & $2.249 \pm 0.238$ & $2.451 \pm 0.098$ & $2.920 \pm 0.117$ & $1.905 \pm 0.536$ & $2.269 \pm 0.639$ \\
\hline U251 & $1.077 \pm 0.112$ & $1.283 \pm 0.134$ & $0.963 \pm 0.147$ & $1.147 \pm 0.175$ & $1.903 \pm 0.204$ & $2.267 \pm 0.243$ & $1.359 \pm 0.474$ & $1.620 \pm 0.564$ \\
\hline A172 & $0.878 \pm 0.081$ & $1.046 \pm 0.096$ & $1.250 \pm 0.196$ & $1.489 \pm 0.233$ & $1.778 \pm 0.158$ & $2.118 \pm 0.189$ & $1.256 \pm 0.383$ & $1.499 \pm 0.456$ \\
\hline SNB75 & $0.742 \pm 0.018$ & $0.884 \pm 0.022$ & $0.179 \pm 0.007$ & $0.214 \pm 0.009$ & $0.886 \pm 0.022$ & $1.056 \pm 0.026$ & $0.624 \pm 0.315$ & $0.744 \pm 0.376$ \\
\hline U87 & $0.832 \pm 0.076$ & $0.991 \pm 0.091$ & $0.535 \pm 0.095$ & $0.637 \pm 0.113$ & $1.966 \pm 0.196$ & $2.342 \pm 0.234$ & $1.050 \pm 0.626$ & $1.251 \pm 0.746$ \\
\hline
\end{tabular}




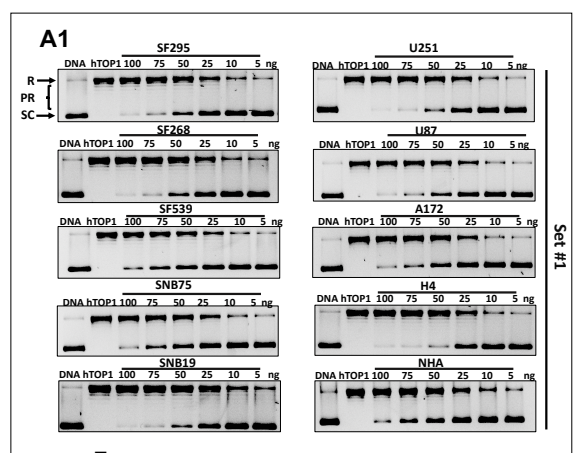

A2

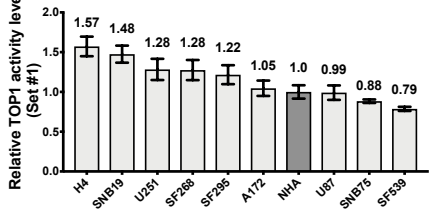

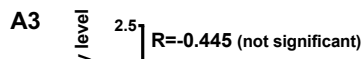

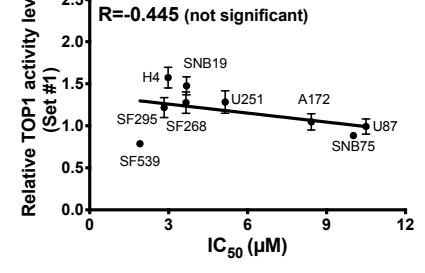

A4

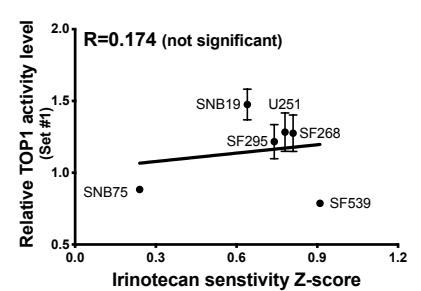

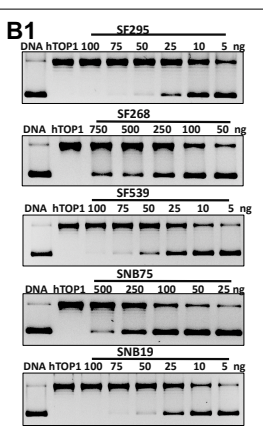

B2 $\stackrel{\overline{\mathrm{g}}}{\mathrm{\alpha}}$

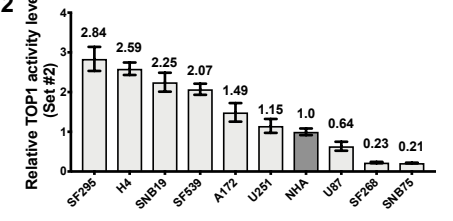

B3

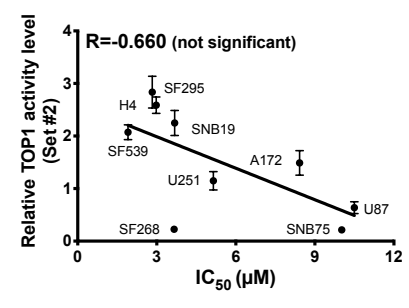

B4

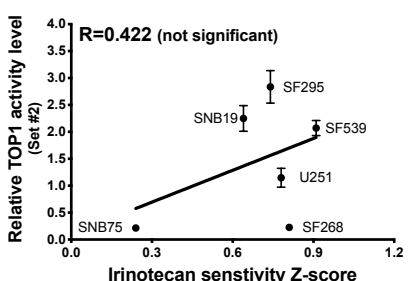

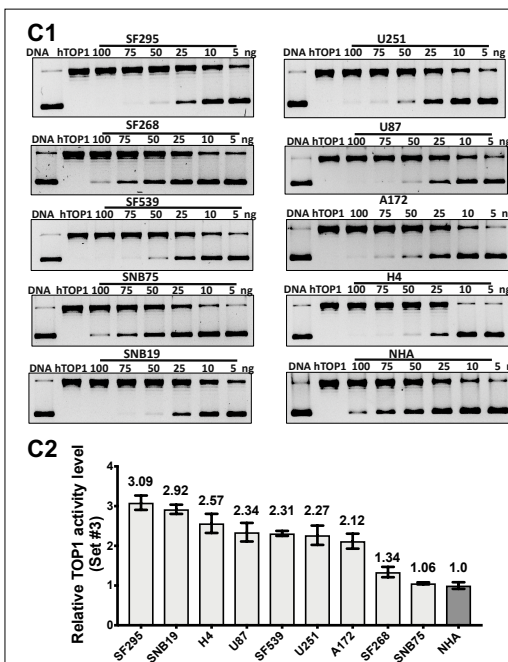

C3
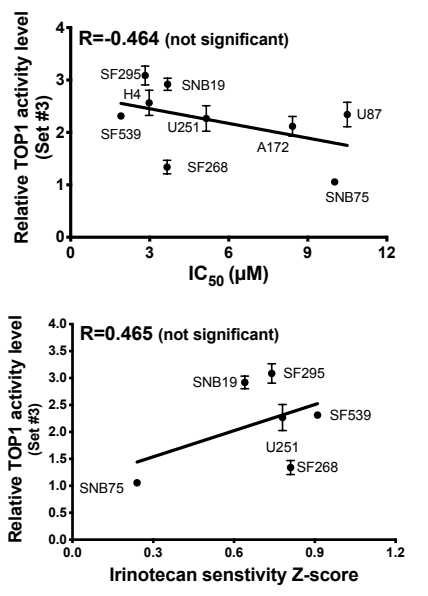

D1

D2

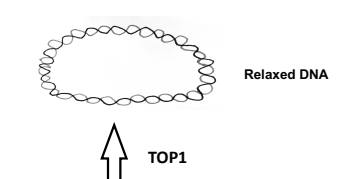

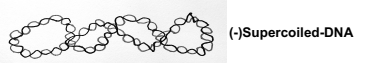

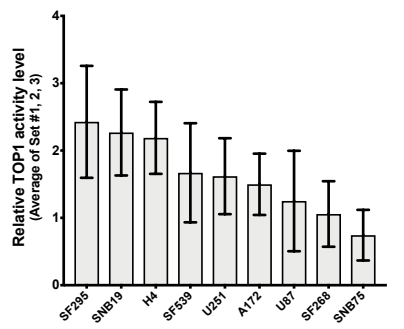

D3

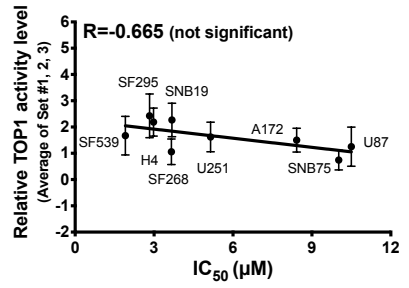

D4

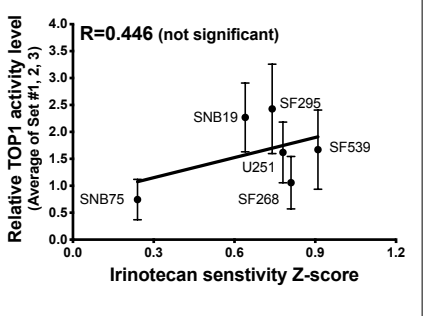

Figure 2.14. Comparison of TOP1 activity in GBM cell lines to assess potential correlation with Irinotecan sensitivities from experiments and databases

(A1) Negatively supercoiled plasmid DNA was relaxed by serial dilutions of WCE from GBM cells set \#1 and separated by electrophoresis in $1 \%$ agarose gel. SC: supercoiled DNA, R: relaxed DNA, PR: partially relaxed DNA. For (B1) set 
\#2, and (C1) set \#3 experiments, TOP1 activity was also measured by relaxation assay. (D1) Diagram of DNA relaxation by TOP1. (A2) TOP1 activity levels in the majority of set \#1 GBM cell lines are higher than TOP1 protein level in NHA (grey bar) (relative ratios $>1$ ). (B2) Set \#2, (C2) set \#3, and (D2) the average of TOP1 activity from three sets have similar trends as in set \#1. The (A3) set \#1, (B3) set \#2, (C3) set \#3, and (D3) the average of TOP1 activity levels do not correlate with IRT IC 50 values. The results shown for each set of data represent the average from three replicated measurements. The (A4) set \#1, (B4) set \#2, (C4) set \#3, and (D4) the average of TOP1 activity expression levels do not correlate IRT Z-score from NCl-60 panel on CellMiner database.
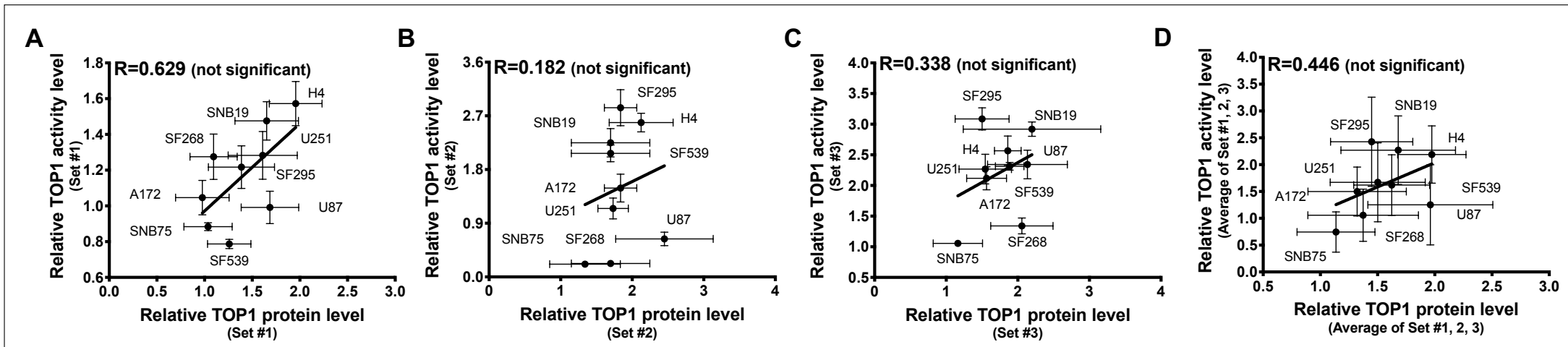

Figure 2.15. Lack of correlation between TOP1 protein levels and TOP1 activity levels

The relative TOP1 protein level does not correlate with TOP1 activity level in (A) set \#1, (B), set \#2, (C) set \#3, and (D) the average levels. 


\section{TDP1 expression level is moderately correlated with Irinotecan sensitivities among GBM cell lines}

The TDP1 expression level in $10 \mu \mathrm{g}$ of WCE was also measured by Western blotting to determine the expression variations (Figure 2.16, panels A1, B1, C1). The TDP1 protein expression level from set \#1 (Fig 2.16, panel A2) revealed that, in contrary to TOP1 expression level, the majority of GBM cell lines had lower TDP1 expression level than NHA (relative ratios <1) (ranging from 0.57 to 1.10 ). Similar results were observed from experiments set \#2 (Figure 2.16, panel B2) and set \#3 (Figure 2.16, panel C2) with relative TDP1 expression level ranging from 0.39 to 1.07 in set \#2, and from 0.48 to 1.23 in set \#3. The average of relative TDP1 protein expression level is calculated using the three sets of data (Figure 2.16, panel D1) and ranges from 0.53 to 1.12 . According to these data, the TDP1 protein expression levels determined in each set of experiments are quite similar, indicating once again that the reproducibility of results from three individual aliquot of cryopreserved cells as described above. The relative protein level of TDP1 from three sets of GBM experiments are listed in Table 2.8.

Interestingly, the TDP1 expression level observed in the three sets of experiments showed significant and mostly moderate correlation with experimental $I_{50}$ S (Figure 2.16, panels A3, B3, C3, D2). The down-regulated TDP1 protein expression level in GBM cell lines in comparison with NHA suggests that the GBM cell lines may benefit from IRT treatment. However, there is no consistent correlation between the TDP1 protein level and the IRT sensitivities available in the databases (Figure 2.16, panel A4, B4, C4, D4). In addition, TDP1 protein level 
is not consistently comparable with TDP1 mRNA expression level (Figure 2.19) and no significant correlation was observed between TDP1 mRNA expressions and IRT sensitivities in GBM cell lines from CCLE (Figure 2.18, panel A), GDSC (Figure 2.18, panel B), as well as the $\mathrm{NCl}-60$ (Figure 2.18, panel C) collections. We also concluded that there is no inherent correlation between TOP1 expression and TDP1 expression in both protein and mRNA levels (Figure 2.17).

In summary, the TDP1 expression is moderately correlated with $\mathrm{IC}_{50} \mathrm{~s}$ in GBM cell lines and most likely to be a better predictor of Irinotecan response than TOP1 expression or activity, as the TDP1 protein level associated significantly with $\mathrm{IC}_{50} \mathrm{~S}$ throughout all three sets of experiments with GBM cell lines. A lower level of the TDP1 repair activity is expected to result in a higher degree of TOP1cc-induced cytotoxicity following IRT treatment. However, the inconsistency of the correlation between TDP1 expression level with IRT sensitivity results in the databases indicated that TDP1 expression level might not be a reliable biomarker of GBM for IRT treatment. To further explore other potential biomarkers, TDP1 activities were measured in the following section. 


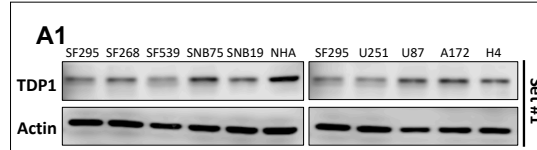

A2

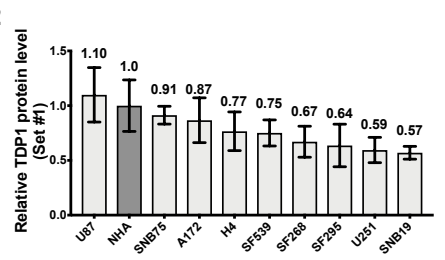

A3
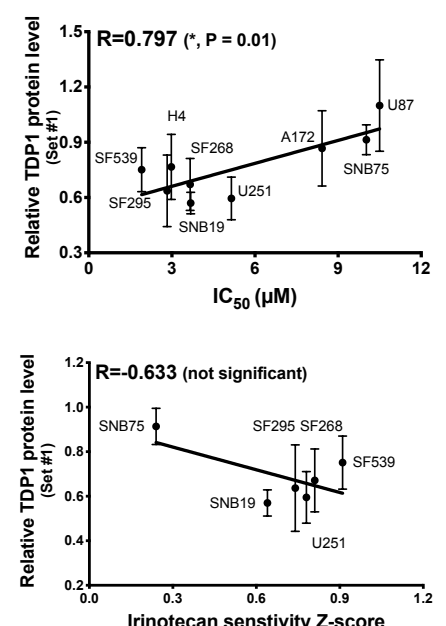

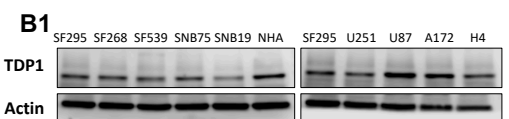

B2

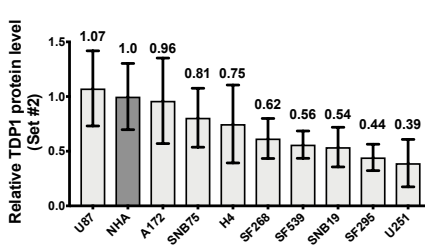

B3

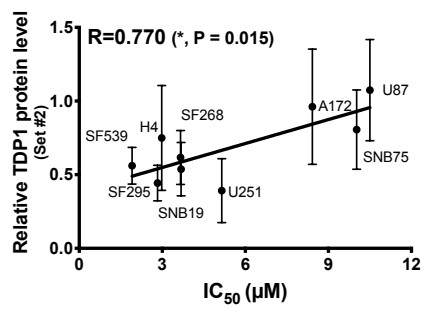

B4

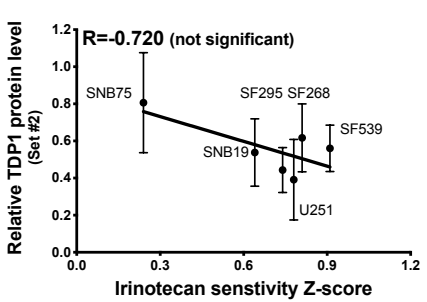

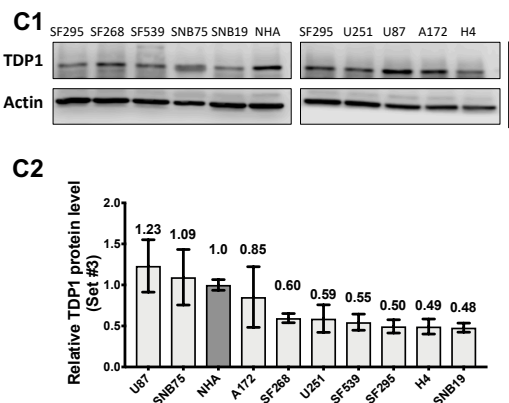

C3

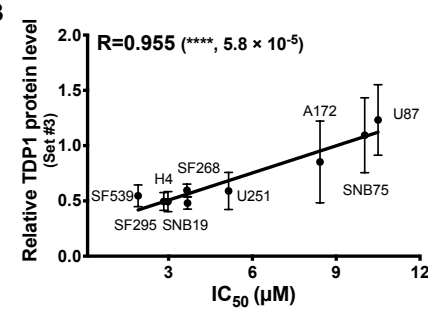

C4

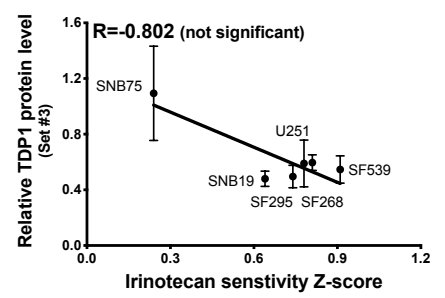

D1
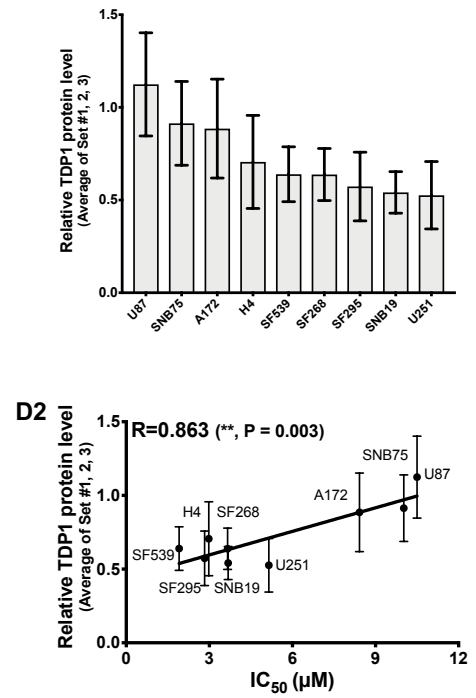

D3

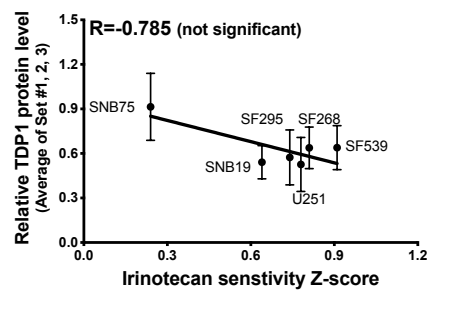

Figure 2.16. Comparison of TDP1 protein levels in GBM cell lines to assess potential correlation with Irinotecan sensitivities from experiments and databases

TDP1 protein expression from (A) set \#1, (B) set \#2, and (C) set \#3 experiments on GBM cell lines were compared against NHA. Signal from actin was used to control loading of $10 \mu \mathrm{g}$ of WCE. The majority of TDP1 protein levels from (A2) set \#1, (B2) set \#2, (C2) set \#3, and (D1) the average of TDP1 protein expression are lower than TDP1 protein level in NHA (grey bar) (relative ratios <1). TDP1 protein level from (A3) set \#1, (B3) set \#2, and (D3) the relative TDP1 
protein levels have moderate correlations with Irinotecan $I_{50}$. TDP1 protein levels from (C3) set \#3 has a relatively strong correlation with Irinotecan $\mathrm{IC}_{50}$ S The TDP1 protein levels reported for each data set represent the average of at least triplicated measurements. TDP1 protein level from (A3) set \#1, (B3) set \#2, and (D3) the relative TDP1 protein levels do not correlate with Irinotecan z-score from CellMiner database. TDP1 protein level from (C3) set \#3 is correlated with and z-score from CellMiner database.

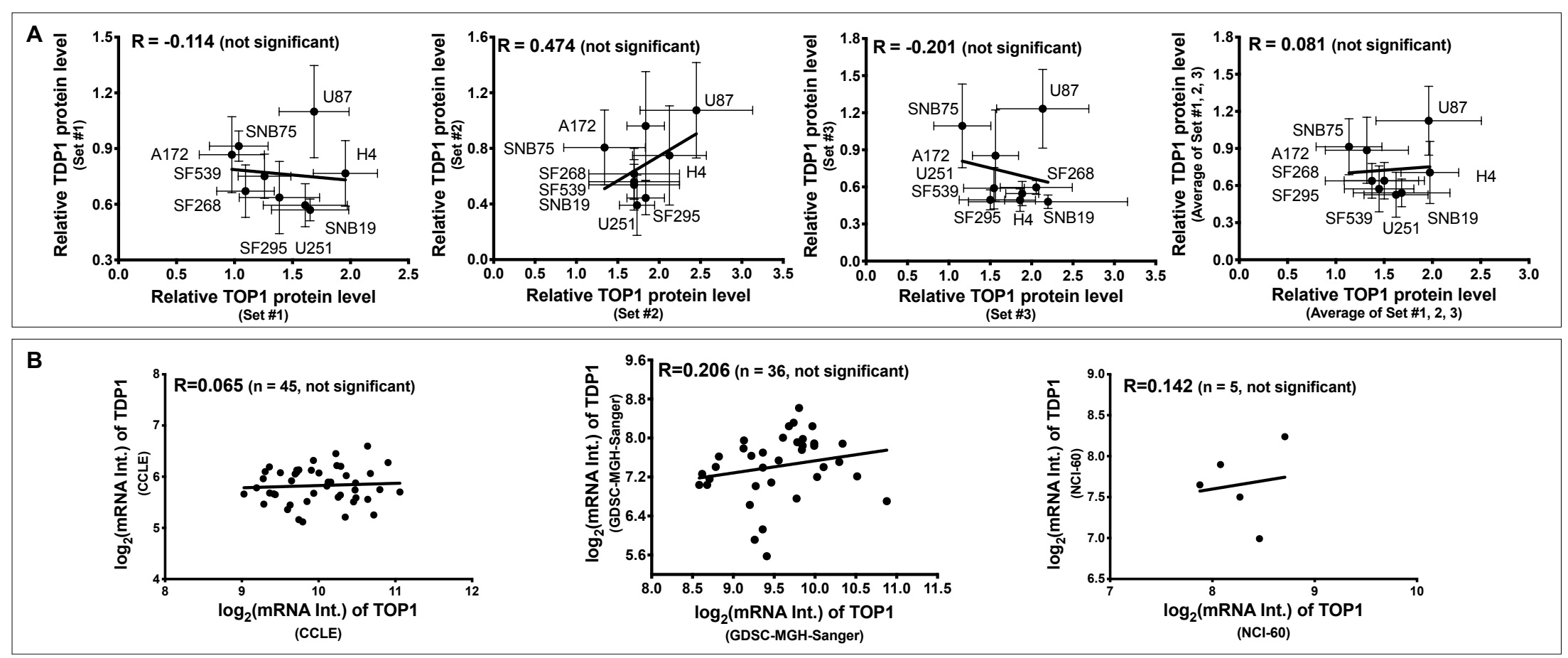

Figure 2.17. Comparison of TOP1 level with TDP1 level

(A) The average of TOP1 protein level is not associated with the average of TDP1 protein level. (B) On CCLE panel, TOP1 mRNA expression level is not associated with TDP1 mRNA expression level. (EC On GDSC panel, TOP1 mRNA expression level is not associated with TDP1 mRNA expression level. (D) On NCl-60 panel, TOP1 mRNA expression level is not associated with TDP1 mRNA expression level. 

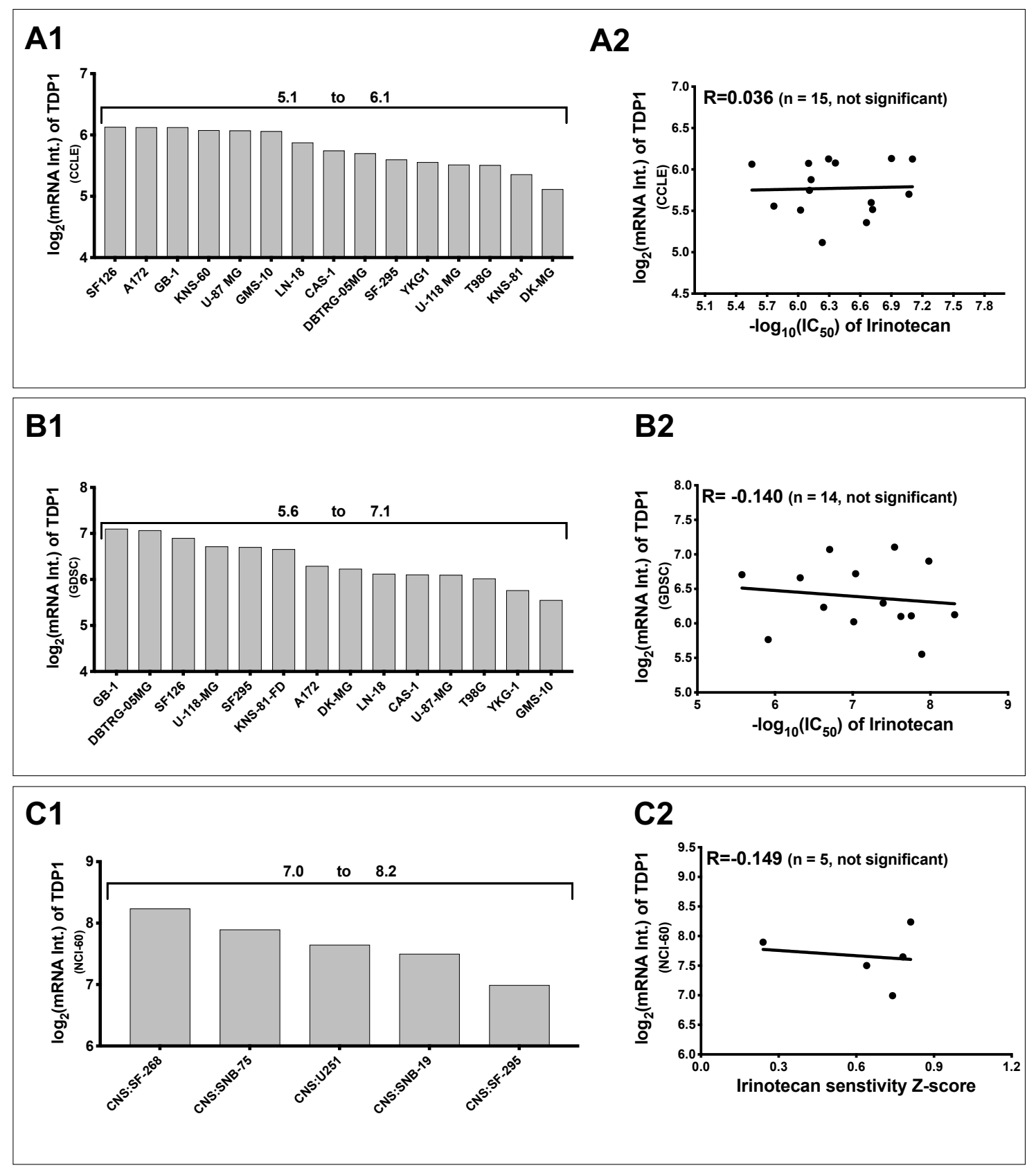

Figure 2.18. Comparison of TOP1 mRNA expression and Irinotecan IC $\mathrm{C}_{50} \mathrm{~S}$ against GBM cell lines from CellMinerCDB database

(A) The TOP1 mRNA expression of GBM cell lines $(n=15)$ is not correlated with IRT IC 50 s from CCLE panel. (B) The TOP1 mRNA expression of GBM cell lines ( $\mathrm{n}$ $=14$ ) is not correlated with IRT IC 50 s from GDSC panel. (C) The TOP1 mRNA expression of GBM cell lines $(n=5)$ is not correlated with IRT IC 50 s from NCl-60 panel. 
Table 2.8. Relative TDP1 protein expression level in GBM cell lines

\begin{tabular}{|c|c|c|c|c|}
\hline \multicolumn{5}{|c|}{ Experimental TDP1 protein levels } \\
\hline Cell lines & Set \#1, GBM & Set \#2, GBM & Set \#3, GBM & Average of Set \#1, 2, 3, GBM \\
\hline SF539 & $0.751 \pm 0.119$ & $0.560 \pm 0.125$ & $0.547 \pm 0.098$ & $0.639 \pm 0.148$ \\
\hline SF295 & $0.636 \pm 0.194$ & $0.443 \pm 0.121$ & $0.495 \pm 0.081$ & $0.573 \pm 0.185$ \\
\hline H4 & $0.766 \pm 0.177$ & $0.749 \pm 0.356$ & $0.493 \pm 0.091$ & $0.706 \pm 0.251$ \\
\hline SF268 & $0.671 \pm 0.141$ & $0.617 \pm 0.183$ & $0.596 \pm 0.056$ & $0.638 \pm 0.140$ \\
\hline SNB19 & $0.570 \pm 0.059$ & $0.538 \pm 0.182$ & $0.480 \pm 0.055$ & $0.541 \pm 0.112$ \\
\hline U251 & $0.595 \pm 0.116$ & $0.391 \pm 0.217$ & $0.590 \pm 0.168$ & $0.526 \pm 0.182$ \\
\hline A172 & $0.867 \pm 0.204$ & $0.961 \pm 0.319$ & $0.853 \pm 0.370$ & $0.885 \pm 0.267$ \\
\hline SNB75 & $0.913 \pm 0.081$ & $0.806 \pm 0.270$ & $1.094 \pm 0.339$ & $0.914 \pm 0.226$ \\
\hline U87 & $1.099 \pm 0.248$ & $1.074 \pm 0.343$ & $1.232 \pm 0.319$ & $1.124 \pm 0.278$ \\
\hline
\end{tabular}

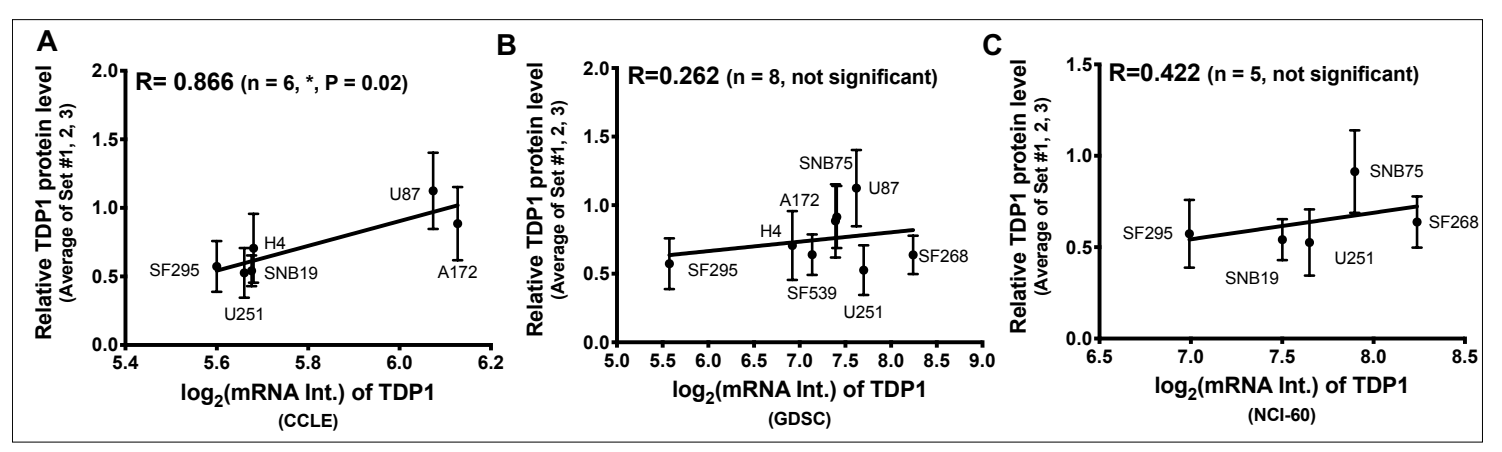

Figure 2.19. Comparison of TDP1 protein level with TDP1 mRNA level

The average of TDP1 protein level is not associated with mRNA levels on (B) GDSC and (C) NCl-60 panels. The average of TDP1 protein level is significantly correlated with mRNA levels on (A) CCLE panel. 


\section{TDP1 activity level is moderately correlated with Irinotecan sensitivities among GBM cell lines}

Two approaches were applied to measure TDP1 catalytic activity in WCEs of GBM cell lines. Previous studies have demonstrated that human TDP1 is an ATPand divalent ion-independent enzyme that can hydrolyze the phosphotyrosyllinkage at the 3' end of DNA (69). Therefore, both RIPA lysis buffer and TDP1 reaction buffers were supplemented with EDTA to suppress the activities from metal ion-dependent exonucleases present. In addition, TDP1 can act as a broadspectrum 3' exonuclease which is able to hydrolyze various phosphodiester linkages at the 3' ends of DNA and its activity is efficient on single-stranded or blunt-ended oligonucleotides without sequence specificity $(36,69,104)$. Thus, we conducted a traditional gel-based assay that utilizes a $5^{\prime}-{ }^{32} \mathrm{P}$ labeled singlestranded oligonucleotide with a 3' tyrosine modification (P12Y) as substrate (Fig 2.22, panel D1) and also an alternative fluorescence-based assay using a bluntended oligonucleotide with a 5' fluorophore (6FAM) and a 3' quencher (BHQ1) modifications as a substrate (Fig 2.23, panel D1) (101). The fluorescence signal is suppressed as a result of the hairpin structure formed by this oligonucleotide substrate. Recombinant human TDP1 (hTDP1) was used to generate the standard linear curve for the increase in fraction of cleaved DNA (P12) with increasing level of TDP1 activity measured by the gel-based assay (Figure 2.20, panels A, B), and also for the increase in fluorescence signal $(\Delta \mathrm{F} / \mathrm{min})$ measured by the

fluorescence-based assay (Figure 2.20, panels C, D). The TDP1 activities in the GBM cell lines WCEs were calculated using standard curves and the TDP1 
activities measured by both assays were normalized by the TDP1 activity level in NHA. The activity and relative activity of TDP1 from the gel-based assay and the fluorescence-based assay are listed in Table 2.9 and 2.10, respectively.

The two assays showed outstanding correlations with each other in results from set \#1 experiments $\left(R=0.968, P=4.7 \times 10^{-6}\right)$, set \#2 experiments $(R=0.914$, $P=0.0002)$, set $\# 3$ experiments $(R=0.897, P=0.0004)$, as well as the average of TDP1 activities from all three set of experiments $\left(R=0.943, P=4.4 \times 10^{-5}\right)$, demonstrating the similar capabilities of the two assays for measuring TDP1 activities in vitro (Figure 2.24). In addition, the activities of TDP1 from gel-based and fluorescence-based assay have an approximate 1:1 ratio in set \#1 $(\mathrm{y}=$ $0.9854 x)$, set \#2 $(y=0.9059 x)$, set \#3 $(y=0.9405 x)$, as well as average of TDP1 activities $(y=0.9333 x)$, further demonstrating that the two assays produce comparable results for TDP1 activity measurements (Figure 2.24). The fluorescence-based assay has the advantage of not requiring the handling of radioactive material and can also be easily adapted for high throughput measurements.

The results from set \#1 experiments showed that the GBM cell lines had a lower level of TDP1 activity than NHA, with relative TDP1 activity levels from the fluorescence-based assay ranging from 0.23 to 0.71 (Figure 2.23, panel A2) while the relative TDP1 levels from the gel-based assay ranged from 0.21 to 0.80 (Figure 2.22, panel A2). The relative TDP activity levels in set \#2 experiments measured by the fluorescence-based assay ranged from 0.22 to 0.96 (Figure 2.23, panel B2), 
and ranged from 0.11 to 1.26 in the gel-based assay (Figure 2.22, panel B2). The relative TDP1 activity levels measured in set \#3 experiments by the gel-based assay ranged from 0.42 to 1.19 (Figure 2.22, panel C2), and ranged from 0.20 to 1.17 in the gel-based assay (Figure 2.23, panel C2). The average TDP1 activity level for each cell line is calculated using the three individual sets of experiments and ranged from 0.36 to 0.99 and from 0.38 to 0.87 (Figure 2.22, panel D2; Figure 2.23, panel D2). On the basis of our data, TDP1 activity levels correlate moderately with TDP1 protein levels measured (Figure 2.25, panels A1, C2, D2). However, inconsistent correlations between TDP1 activities and protein expressions were also observed (Figure 2.18, panels A2, B1, B2, C1, D1), suggesting that TDP1 protein level might not always represent the TDP1 activity in cells. We also concluded that there is no inherent correlation between TOP1 and TDP1 activities in GBM cell lines, suggesting TDP1 activity level, acting differently from TOP1 activity level, is worth to compare with IRT sensitivities (Figure 2.21). We then assessed if there is any correlation between TDP1 activities and IRT sensitivities. We found that although set \#1 TDP1 activity levels from gel-based assay (Figure 2.22, panel A3) and the majority of TDP1 activity levels from fluorescence-based assay (Figure 2.23, panels A3, C3, D3) could correlate significantly with experimental $I_{50}$, insignificant correlations were sometimes observed (Figure 2.22, panels B3, C3, D3, Figure 2.23, panel B3). Moreover, the significant correlations between TDP1 activities and IRT sensitivity values in the databases were not consistently observed (Figure 2.22 and 2.23 , panels A4, B4, C4, D4). 
In summary, similar to the relative TDP1 protein levels, the relative TDP1 activity levels in GBM cell lines also show moderate correlation with Irinotecan sensitivities. Still, TDP1 activity level might not be a consistent biomarker for prediction of IRT sensitivity. Therefore, we started to incorporate both TOP1 and TDP1 as contributing factor which modulates the IRT response in GBM cell lines.

Table 2.9. TDP1 activity and relative TDP1 activity levels in GBM cell lines

\begin{tabular}{|c|c|c|c|c|c|c|c|c|}
\hline \multicolumn{9}{|c|}{ Experimental TDP1 activity level by gel-based assay } \\
\hline \multirow{2}{*}{$\begin{array}{l}\text { Cell } \\
\text { lines }\end{array}$} & \multicolumn{2}{|c|}{ Set \#1, GBM } & \multicolumn{2}{|c|}{ Set \#2, GBM } & \multicolumn{2}{|c|}{ Set \#3, GBM } & \multicolumn{2}{|c|}{ Average of Set \#1, 2, 3, GBM } \\
\hline & $\begin{array}{l}\text { TDP1 activity } \\
\text { (fmol/ } / \mu \mathrm{g})\end{array}$ & $\begin{array}{c}\text { Relative TDP1 } \\
\text { activity }\end{array}$ & $\begin{array}{l}\text { TDP1 activity } \\
\text { (fmol/ } / \mu \mathrm{g})\end{array}$ & $\begin{array}{l}\text { Relative TDP1 } \\
\text { activity }\end{array}$ & $\begin{array}{l}\text { TDP1 activity } \\
\text { (fmol/ } / \mu \mathrm{g})\end{array}$ & $\begin{array}{c}\text { Relative TDP1 } \\
\text { activity }\end{array}$ & $\begin{array}{l}\text { TDP1 activity } \\
\text { (fmol/ } / \mu \mathrm{g})\end{array}$ & $\begin{array}{c}\text { Relative TDP1 } \\
\text { activity }\end{array}$ \\
\hline SF539 & $0.441 \pm 0.144$ & $0.215 \pm 0.070$ & $1.084 \pm 0.170$ & $0.529 \pm 0.083$ & $0.985 \pm 0.112$ & $0.481 \pm 0.054$ & $0.780 \pm 0.335$ & $0.381 \pm 0.163$ \\
\hline SF295 & $0.917 \pm 0.067$ & $0.447 \pm 0.032$ & $1.344 \pm 0.151$ & $0.656 \pm 0.074$ & $1.261 \pm 0.133$ & $0.615 \pm 0.065$ & $1.137 \pm 0.227$ & $0.555 \pm 0.111$ \\
\hline H4 & $1.426 \pm 0.655$ & $0.696 \pm 0.320$ & $1.409 \pm 0.235$ & $0.688 \pm 0.115$ & $1.401 \pm 0.115$ & $0.684 \pm 0.056$ & $1.413 \pm 0.400$ & $0.690 \pm 0.195$ \\
\hline SF268 & $0.970 \pm 0.303$ & $0.473 \pm 0.148$ & $0.235 \pm 0.044$ & $0.114 \pm 0.022$ & $0.858 \pm 0.130$ & $0.419 \pm 0.063$ & $0.728 \pm 0.383$ & $0.355 \pm 0.187$ \\
\hline SNB19 & $0.908 \pm 0.116$ & $0.443 \pm 0.056$ & $1.010 \pm 0.172$ & $0.493 \pm 0.084$ & $1.017 \pm 0.134$ & $0.496 \pm 0.066$ & $0.985 \pm 0.139$ & $0.481 \pm 0.068$ \\
\hline U251 & $0.794 \pm 0.125$ & $0.388 \pm 0.061$ & $1.363 \pm 0.216$ & $0.666 \pm 0.106$ & $1.310 \pm 0.184$ & $0.637 \pm 0.090$ & $1.187 \pm 0.302$ & $0.579 \pm 0.148$ \\
\hline A172 & $1.273 \pm 0.397$ & $0.621 \pm 0.194$ & $2.589 \pm 0.251$ & $1.264 \pm 0.123$ & $2.431 \pm 0.272$ & $1.187 \pm 0.133$ & $2.034 \pm 0.695$ & $0.993 \pm 0.339$ \\
\hline SNB75 & $1.248 \pm 0.133$ & $0.609 \pm 0.065$ & $0.785 \pm 0.146$ & $0.383 \pm 0.071$ & $0.877 \pm 0.141$ & $0.428 \pm 0.069$ & $0.945 \pm 0.236$ & $0.461 \pm 0.115$ \\
\hline U87 & $1.638 \pm 0.359$ & $0.800 \pm 0.175$ & $1.792 \pm 0.256$ & $0.875 \pm 0.125$ & $2.331 \pm 0.310$ & $1.138 \pm 0.151$ & $1.899 \pm 0.422$ & $0.927 \pm 0.206$ \\
\hline
\end{tabular}

Table 2.10. TDP1 activity and relative TDP1 activity levels in GBM cell lines

\begin{tabular}{|c|c|c|c|c|c|c|c|c|}
\hline \multicolumn{9}{|c|}{ Experimental TDP1 activity level by fluorescence-based assay } \\
\hline \multirow{2}{*}{$\begin{array}{l}\text { Cell } \\
\text { lines }\end{array}$} & \multicolumn{2}{|c|}{ Set \#1, GBM } & \multicolumn{2}{|c|}{ Set \#2, GBM } & \multicolumn{2}{|c|}{ Set \#3, GBM } & \multicolumn{2}{|c|}{ Average of Set \#1, 2, 3, GBM } \\
\hline & $\begin{array}{l}\text { TDP1 activity } \\
\text { (fmol/ } / \mathrm{gg})\end{array}$ & $\begin{array}{l}\text { Relative TDP1 } \\
\text { activity }\end{array}$ & $\begin{array}{l}\text { TDP1 activity } \\
\text { (fmol/ } / \mu \mathrm{g})\end{array}$ & $\begin{array}{c}\text { Relative TDP1 } \\
\text { activity }\end{array}$ & $\begin{array}{l}\text { TDP1 activity } \\
\text { (fmol/ } / \mu \mathrm{g})\end{array}$ & $\begin{array}{c}\text { Relative TDP1 } \\
\text { activity }\end{array}$ & $\begin{array}{l}\text { TDP1 activity } \\
\text { (fmol/ } \mu \mathrm{g})\end{array}$ & $\begin{array}{c}\text { Relative TDP1 } \\
\text { activity }\end{array}$ \\
\hline SF539 & $0.564 \pm 0.130$ & $0.234 \pm 0.054$ & $1.501 \pm 0.111$ & $0.622 \pm 0.046$ & $0.907 \pm 0.018$ & $0.376 \pm 0.007$ & $0.948 \pm 0.420$ & $0.393 \pm 0.174$ \\
\hline SF295 & $1.067 \pm 0.053$ & $0.442 \pm 0.022$ & $1.315 \pm 0.090$ & $0.545 \pm 0.037$ & $1.010 \pm 0.011$ & $0.419 \pm 0.005$ & $1.114 \pm 0.134$ & $0.462 \pm 0.056$ \\
\hline H4 & $1.452 \pm 0.135$ & $0.602 \pm 0.056$ & $1.091 \pm 0.067$ & $0.453 \pm 0.028$ & $1.025 \pm 0.082$ & $0.425 \pm 0.034$ & $1.255 \pm 0.231$ & $0.520 \pm 0.096$ \\
\hline SF268 & $1.340 \pm 0.052$ & $0.556 \pm 0.022$ & $0.530 \pm 0.054$ & $0.220 \pm 0.022$ & $0.491 \pm 0.017$ & $0.204 \pm 0.007$ & $0.925 \pm 0.435$ & $0.384 \pm 0.180$ \\
\hline SNB19 & $1.092 \pm 0.113$ & $0.453 \pm 0.047$ & $1.236 \pm 0.047$ & $0.512 \pm 0.020$ & $0.990 \pm 0.049$ & $0.411 \pm 0.020$ & $1.102 \pm 0.122$ & $0.457 \pm 0.051$ \\
\hline U251 & $0.904 \pm 0.059$ & $0.375 \pm 0.025$ & $1.745 \pm 0.141$ & $0.724 \pm 0.059$ & $1.676 \pm 0.059$ & $0.695 \pm 0.025$ & $1.308 \pm 0.429$ & $0.542 \pm 0.178$ \\
\hline A172 & $1.659 \pm 0.208$ & $0.688 \pm 0.086$ & $2.315 \pm 0.075$ & $0.960 \pm 0.031$ & $2.755 \pm 0.097$ & $1.142 \pm 0.040$ & $2.097 \pm 0.508$ & $0.869 \pm 0.211$ \\
\hline SNB75 & $1.492 \pm 0.085$ & $0.618 \pm 0.035$ & $1.016 \pm 0.145$ & $0.421 \pm 0.060$ & $1.662 \pm 0.107$ & $0.689 \pm 0.045$ & $1.415 \pm 0.269$ & $0.587 \pm 0.112$ \\
\hline U87 & $1.701 \pm 0.094$ & $0.705 \pm 0.039$ & $2.076 \pm 0.143$ & $0.861 \pm 0.059$ & $2.830 \pm 0.032$ & $1.174 \pm 0.013$ & $2.077 \pm 0.490$ & $0.862 \pm 0.203$ \\
\hline
\end{tabular}




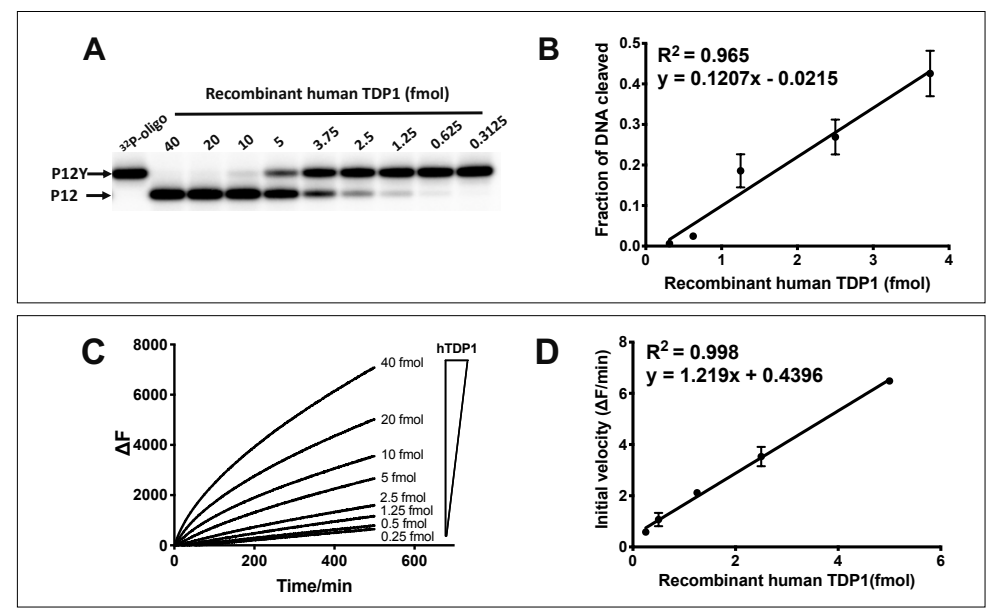

Figure 2.20. Tyrosyl-DNA phosphodiesterase 1 activity from recombinant human TDP1

(A) Gel-based assay for the conversion of radiolabeled P12Y DNA substrate into P12 product under serial dilutions of recombinant hTDP1 (B) The standard curve for fraction of DNA substrate cleaved by increasing amounts of TDP1. (C) Fluorescence-based assay for the increase in FL-signal under serial dilutions of recombinant hTDP1. (D) The standard curve generated using the initial velocity of fluorescence increase.

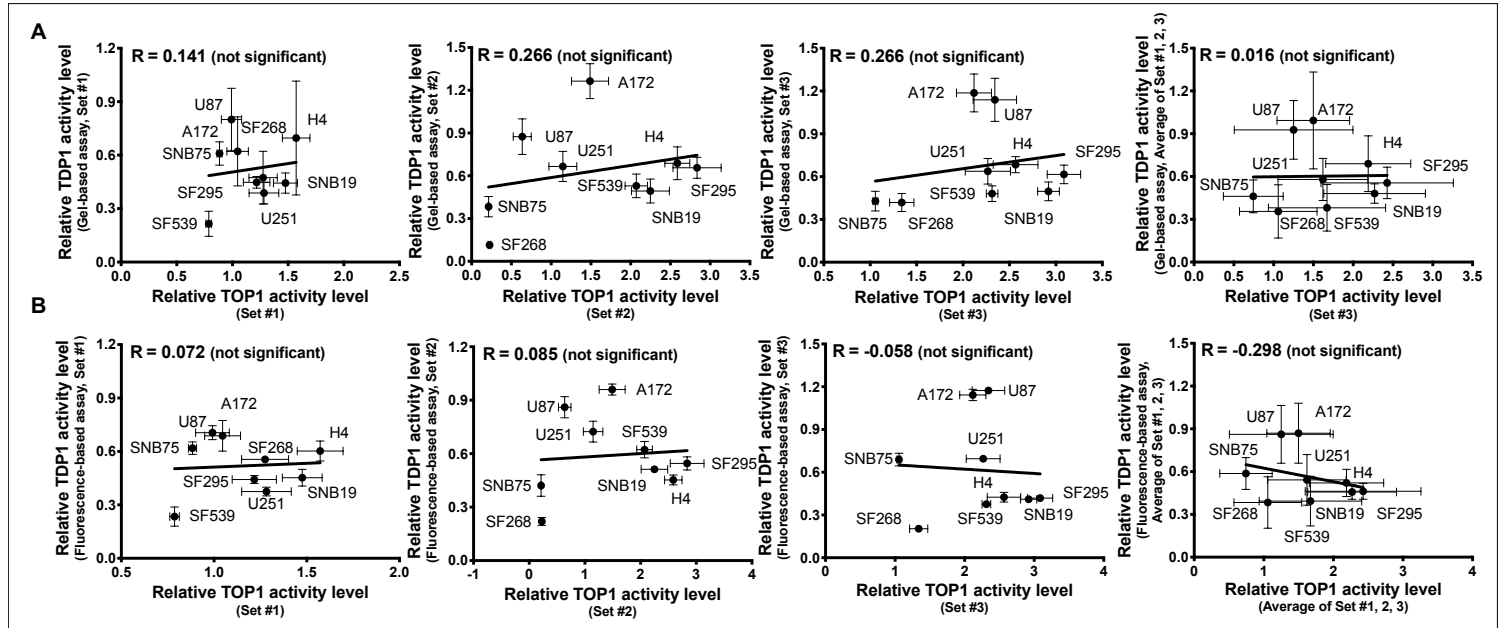

Figure 2.21. Comparison of TOP1 activity level with TDP1 activity level The average of relative TOP1 activity level is not associated with TDP1 activity by both (A) gel-based and (B) fluorescence-based assays. 

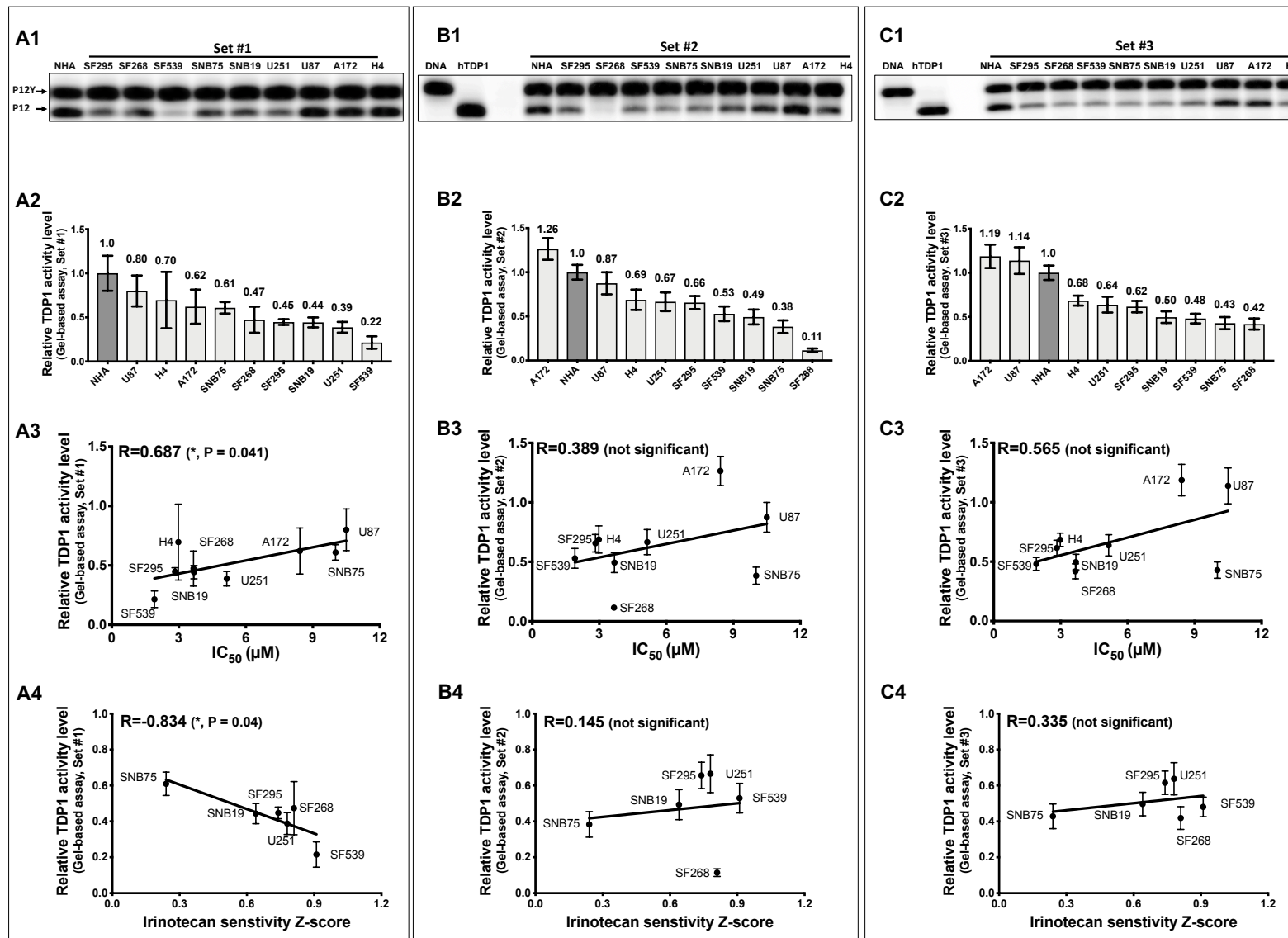

B4
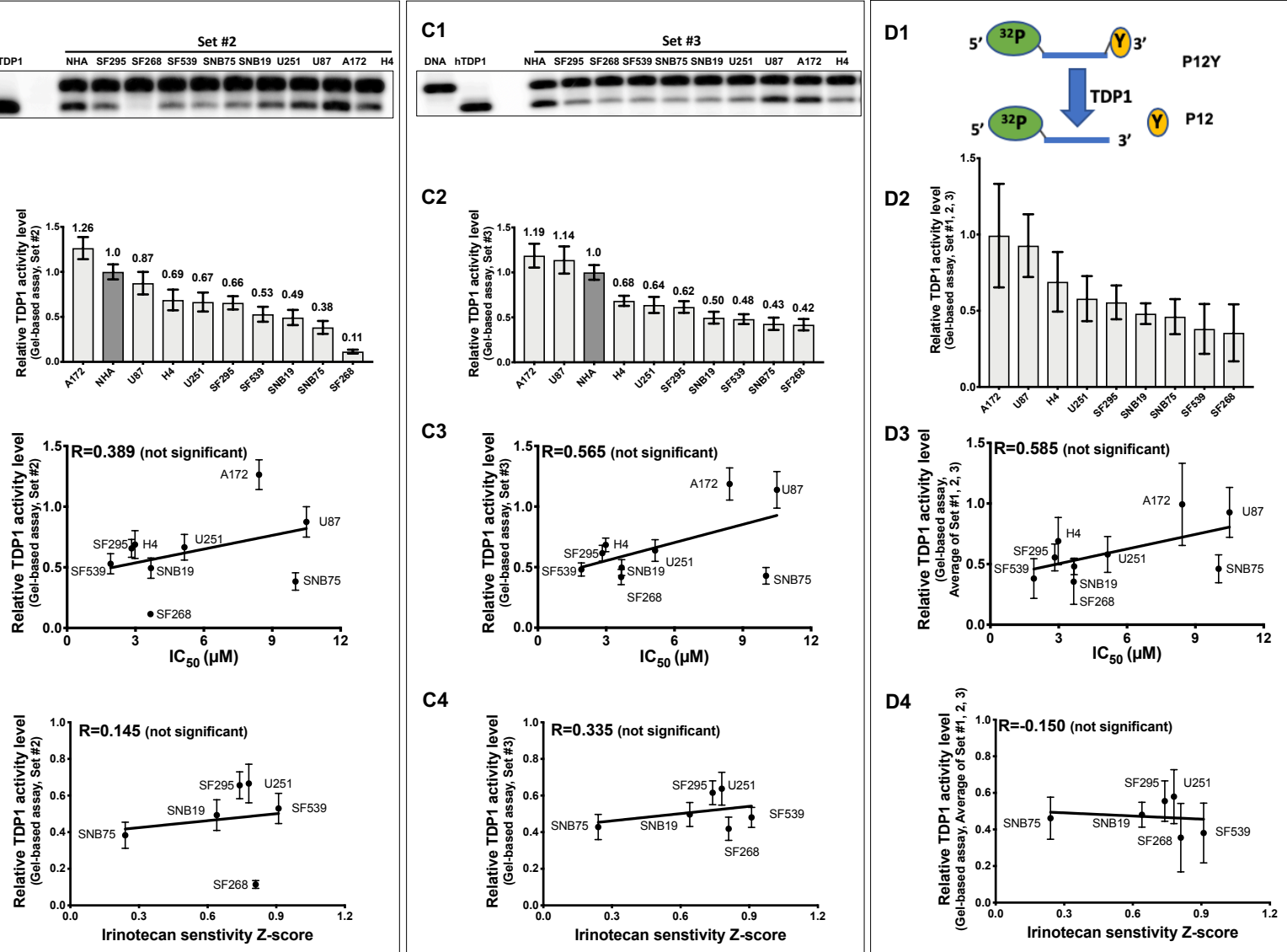

C4

D4

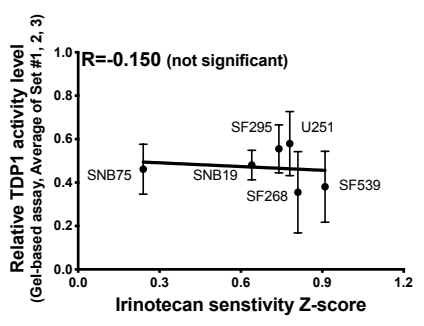

Figure 2.22. Comparison of TDP1 activity by gel-based assay in GBM cell lines to assess potential correlation with Irinotecan sensitivities from experiments and databases

TDP1 activity levels from $2 \mu \mathrm{g}$ of GBM WCE from (A1) set \#1, (B1) set \#2, and (C1) set \#3 experiments were conducted by gel-based assay. P12Y: radiolabeled DNA substrate (5'-32P-GAA AAA AGA GTT-PO4-Tyr-3'); P12: product by TDP1 (5'-32P -GAA AAA AGA GTT-OH-3'). (D1) Diagram of TDP1 activity measurement by gel-based assay. (A2) TDP1 activity levels in set \#1 GBM cell lines are all lower than TDP1 activity level in NHA (grey bar) (relative ratios <1). The (B2) set \#2, (C2) set \#3, and (D2) the average of TDP1 activity from three sets have similar trends as in set \#1. TDP1 activity 
level from (B3) set \#2, (C3) set \#3, and (D3) the relative TDP1 activity levels do not correlate with Irinotecan IC 50. TDP1 protein levels from (A3) set \#1 has a moderate correlation with Irinotecan $I_{50}$. TDP1 protein level from (B3) set \#2, (C3) set \#3, and (D3) the average of relative TDP1 activity levels do not correlate with Z-score from CellMiner database.TDP1 protein levels from (A3) set \#1 has a moderate correlation with Z-score from CellMiner database.
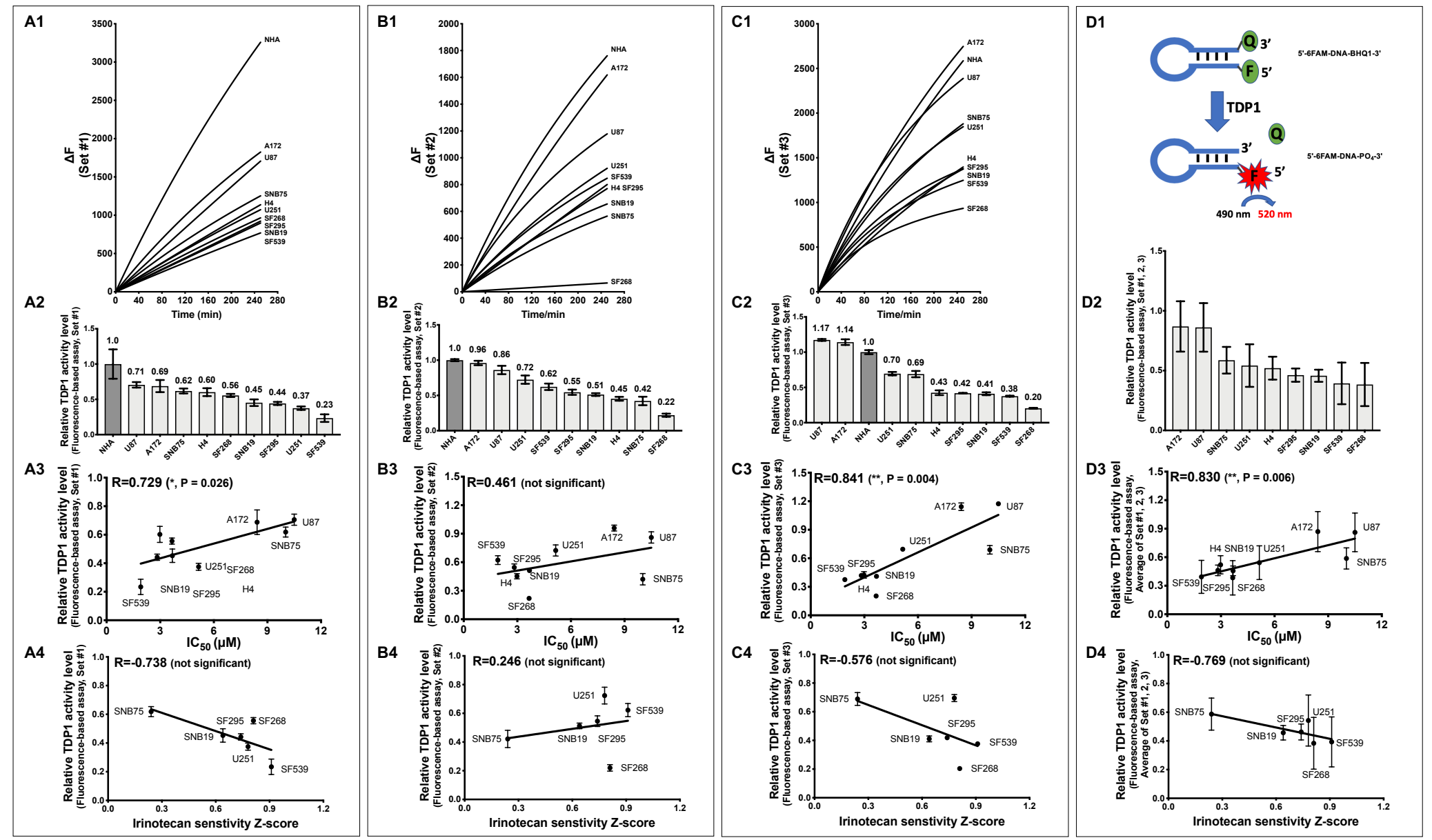
Figure 2.23. Comparison of TDP1 activity by fluorescence-based assay in GBM cell lines to assess potential correlation with Irinotecan sensitivities from experiments and databases

TDP1 activity levels from $2 \mu \mathrm{g}$ of GBM WCE from (A1) set \#1, (B1) set \#2, and (C1) set \#3 experiments were conducted by fluorescence-based assay. (D1) Diagram of TDP1 activity measurement by fluorescence-based assay. (A2) TDP1 activity levels in set \#1 GBM cell lines are all lower than TDP1 activity level in NHA (grey bar) (relative ratios <1). The (B2) set \#2, (C2) set \#3, and (D2) the average of TDP1 activity from three sets have similar trends as in set \#1. TDP1 activity level from (A3) set \#1, (C3) set \#3, and (D3) the relative TDP1 activity levels do not correlate with Irinotecan IC 50. TDP1 protein levels from (B3) set \#2 has a moderate correlation with Irinotecan I $_{50}$ S. TDP1 protein level from (A3) set \#1, (B3) set \#2, (C3) set \#3, and (D3) the average of relative TDP1 activity levels do not correlate with Z-score from CellMiner database.
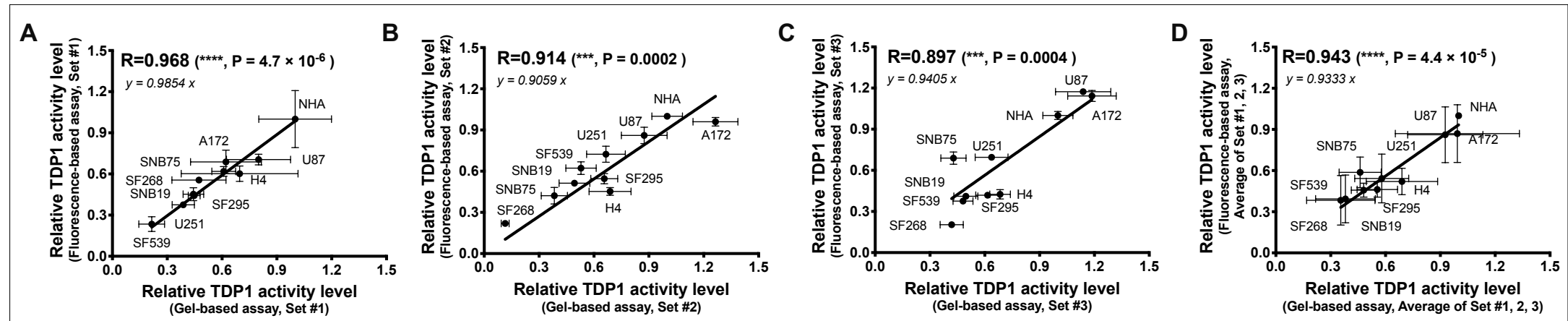

Figure 2.24. Comparison of gel-based and fluorescence-based assays for TDP1 activity measurement

Strong correlations of TDP1 activity level in GBM WCE were observed from (A) set \#1, (B) set \#2, (C) set \#3, and (D3) the average of relative TDP1 activity levels measured by gel-based and fluorescence-based assay protocols. 


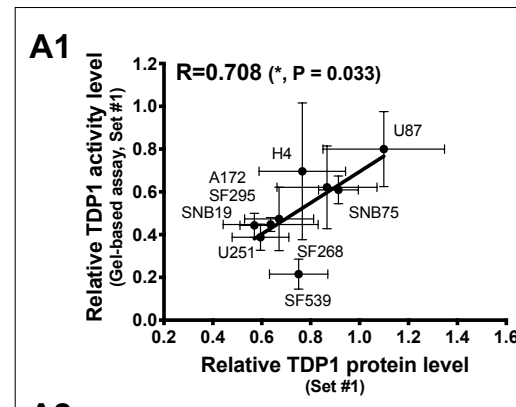

A2

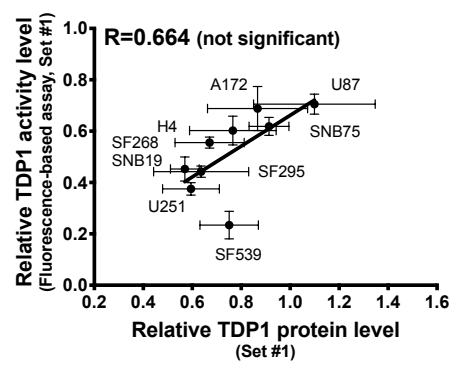

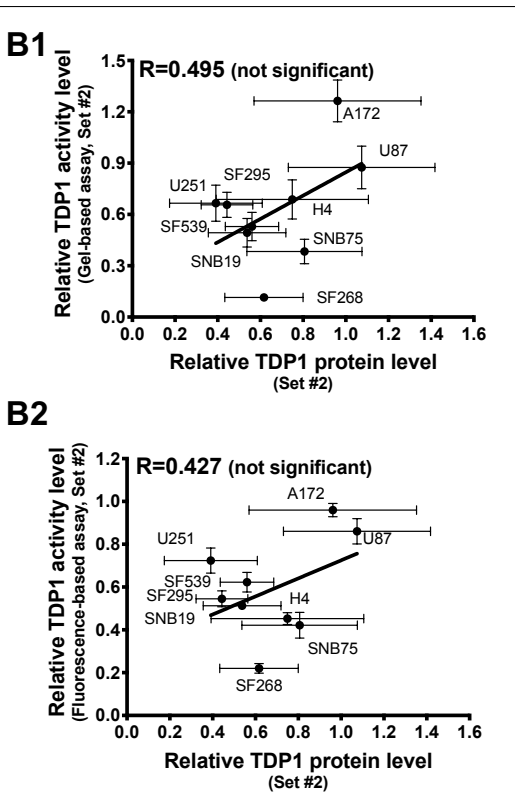

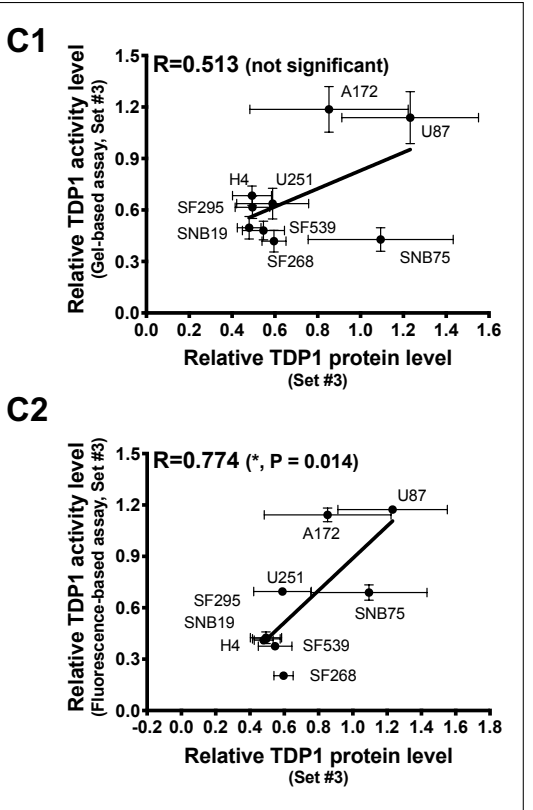

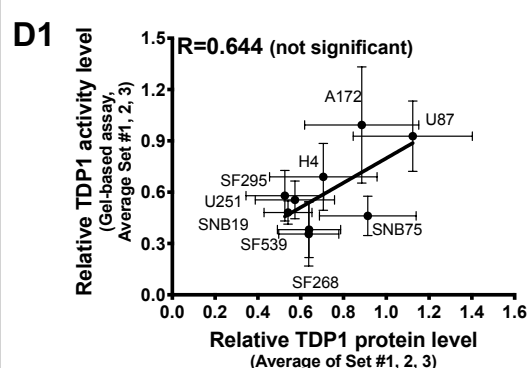

D2

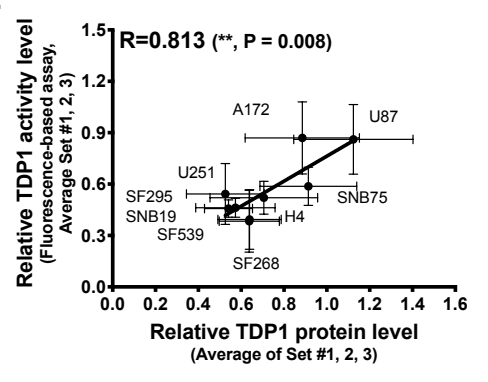

Figure 2.25. Correlation between TDP1 protein levels and TOP1 activity levels

The relative TDP1 protein level does not correlate with gel-based TDP1 activity level in (B1) set \#2, (C1), set \#3, and (D1) the average of relative TDP1 activity levels, and fluorescence-based TDP1 activity in (A2) set \#1 and (B2) set \#2. The relative TDP1 protein level is moderately correlated with gel-based TDP1 activity level in (A1) set \#1, and fluorescence-based TDP1 activity in (C2) set \#3 and (D2) the average of relative TDP1 activity levels. 


\section{TDP1/TOP1 activity ratio has the strongest correlation with Irinotecan sensitivities in GBM cell lines}

Our studies above have demonstrated that protein expression level, mRNA level, and activity level of TOP1 and TDP1 alone does not function consistently as a predictor of the sensitivity of GBM cell lines to Irinotecan treatment. To further identify more promising predictive indicators, we calculated the TDP1/TOP1 protein ratio and activity ratio from each set of experiments conducted with the GBM cell lines (Table 2.11). The TDP1/TOP1 mRNA ratio available for GBM cell lines was extracted from the databases (Table 2.12).

Variations in TDP1/TOP1 protein ratio were observed among the GBM cell lines (Figure 2.26). The results revealed that the GBM cell lines tested all had lower level of TDP1/TOP1 protein ratio than NHA (relative ratios <1). The TDP1/TOP1 protein ratio ranged from 0.36 to 0.93 in set \#1 experiments (Figure 2.26, panel A1), from 0.23 to 0.67 in set \#2 experiments (Figure 2.26, panel B1), from 0.26 to 1.01 in set \#3 experiments (Figure 2.26, panel C1), and from 0.36 to 0.88 for the average from all three sets of experiments (Figure 2.26, panel D1). According to our results, TDP1/TOP1 protein expression ratios are comparable among the different sets of cultured GBM cells. The experimental $\mathrm{IC}_{50}$ S for Irinotecan showed significant correlation with the TDP1/TOP1 protein ratios from set \#1 experiments $(R=0.696, P=0.037$, Figure 2.26, panel $A 2)$, set $\# 2$ experiments $(R=0.698, P=$ 0.037, Figure 2.26, panel $B 2)$, set $\# 3$ experiments $(R=0.862, P=0.003$, Figure 2.26, panel C2), as well as the average of TDP1/TOP1 protein ratios from all three sets of experiments $(R=0.744, P=0.02$, Figure 2.26, panel D2). However, the 
correlation of TDP1/TOP1 protein ratio with Irinotecan sensitivities available in the database is still inconsistent (Figure 2.26, panels A3, B3, C3, D3; Figure 2.32, panel A).

We continued our analysis on TDP1/TOP1 mRNA expression ratio in GBM cell lines to assess potential correlation with Irinotecan sensitivities against GBM cell lines from information available in CellMinerCDB databases which provide results from three different cancer cell panels (CCLE, GDSC, and $\mathrm{NCl}-60)$ ). The TDP1/TOP1 mRNA ratio ranged from 0.49 to 0.66 in CCLE (Figure 2.27, panel A1), from 0.59 to 0.88 in GDSC (Figure 2.27, panel B1), from 0.83 to 0.98 in $\mathrm{NCl}$ 60 (Figure 2.27, panel C1), revealing the TDP1/TOP1 mRNA ratio has much lower variations among GBM cell lines in comparison to TDP1/TOP1 protein ratio. In addition, TDP1/TOP1 mRNA ratio is not comparable with TDP1/TOP1 protein ratio (Figure 2.28) and no significant correlation was observed between TDP1/TOP1 mRNA ratio and IRT sensitivities in GBM cell lines from CCLE (Figure 2.27, panel A2), GDSC (Figure 2.27, panel B2), and the $\mathrm{NCl}-60$ (Figure 2.27, panel C2) collections.

Next, we focused on gel-based TDP1/TOP1 activity ratio. Variations in the activity ratio were observed among the GBM cell lines (Figure 2.29). Similar to TDP1/TOP1 protein ratio, the majority of GBM cell lines tested had a lower relative activity ratio than $\mathrm{NHA}$ (relative ratios $<1$ ). The gel-based TDP1/TOP1 activity ratio ranged from 0.30 to 0.72 in set \#1 experiments (Figure 2.29, panel A1), from 0.18 to 1.98 in set \#2 experiments (Figure 2.29, panel B1), from 0.14 to 0.65 in set \#3 
experiments (Figure 2.29, panel C1), from 0.22 to 0.94 for the average from all three set of experiments (Figure 2.29, panel D1). Although the gel-based TDP1/TOP1 activity ratio had relatively large variations among different sets of GBM cell experiments in comparison to TDP1/TOP1 protein ratio, the majority of TDP1/TOP1 activity ratios are moderately correlated with TDP1/TOP1 protein ratios (Figure 2.31, panels A1, D1). In addition, TDP1/TOP1 activity ratios in each set of experiment maintain significant correlations with the measured Irinotecan $I_{50}$ S. Very strong correlations were observed in set \#1 $(R=0.917, P=0.0005$, Figure 2.29, panel A2), set $\# 2(R=0.940, P=0.0002$, Figure 2.29, panel $B 2)$, set $\# 3(R=0.860, P=0.003$, Figure 2.29 , panel $C 2)$, and the average of activity ratio from all three sets of experiments $\left(R=0.972, P=1.2 \times 10^{-5}\right.$, Figure 2.29, panel $\left.D 2\right)$. Strikingly, the majority of gel-based TDP1/TOP1 activity ratio also correlates consistently with Irinotecan sensitivities found in the databases (Figure 2.29, panels A3, B3, D3; Figure 2.32, panel B).

The fluorescence-based TDP1/TOP1 activity ratio showed similar variations among the GBM cell lines as the gel-based assay described above. The activity ratio ranged from 0.30 to 0.72 in set $\# 1$ experiments (Figure 2.30, panel A1), from 0.18 to 1.98 in set \#2 experiments (Figure 2.30, panel B1), from 0.14 to 0.65 in set \#3 experiments (Figure 2.30, panel C1), and from 0.24 to 0.99 for the average activity ratio of TDP1/TOP1 based on all three sets of experiments (Figure 2.30, panel D1). Although the fluorescence-based TDP1/TOP1 activity ratio had relatively large variations between different sets of GBM cell experiments in comparison to TDP1/TOP1 protein ratio, all of the TDP1/TOP1 activity ratios are 
significantly correlated with TDP1/TOP1 protein ratios (Figure 2.31, panels A2, B2, C2, D2). Besides, the fluorescence-based activity ratios measured in all three sets could correlate significantly with experimental $\mathrm{IC}_{50} \mathrm{~S}$ as gel-based activity ratios. Strong correlations were observed in set \#1 $(R=0.922, P=0.0004$, Figure 2.30, panel $A 2)$, set \#2 $(R=0.827, P=0.006$, Figure 2.30, panel $B 2)$, set $\# 3(R=0.953$, $P=6.8 \times 10^{-5}$, Figure 2.30 , panel $\left.C 2\right)$, and the average of activity ratio $(R=0.952$, $P=7.7 \times 10^{-5}$, Figure 2.30. panel D2). In addition, both the fluorescence-based TDP1/TOP1 activity ratios also correlate with Irinotecan sensitivities from databases (Figure 2.30, panels A3, C3, D3; Figure 2.32, panel C).

In summary, the TDP1/TOP1 mRNA ratio is not a useful biomarker for predicting GBM cell lines sensitivity to Irinotecan treatment. Both the TDP1/TOP1 protein ratio and TDP1/TOP1 activity ratio correlate significantly and consistently with Irinotecan sensitivities, whereas TDP1/TOP1 activity ratio has a stronger correlation compared to the TDP1/TOP1 protein ratio.

The relatively lower TDP1/TOP1 activity ratio in GBM cell lines in comparison with TDP1/TOP1 activity ratio in NHA demonstrated that GBM has a lower capacity to counter the toxicity induced by TOP1 poison inhibitors. Consequently, TOP1 inhibitor treatment is more likely to result in a stronger cytotoxic effect on GBM cancer cells compared to normal astrocyte cells. To further explore this, we assessed the correlation between TDP1/TOP1 activity ratio with the Z-scores of GBM treatment with two other TOP1 poisons, camptothecin (CPT) and topotecan (TPT) (Table 4, column 4 and 5). Topoisomerase II inhibitors, etoposide (ETP) and doxorubicin (DOX) (Table 4, column 6 and 7), were used as negative controls. 
Interestingly, significant correlations between TDP1/TOP1 activity ratio and Zscores for GBM cancers were observed for both CPT and TPT (Figure 2.33A and B), whereas no such correlation was observed for topoisomerase II inhibitors (Figure 2.33C and D). These observations furthered supported our finding that the outcome of GBM cell lines treatment by topoisomerase I poison is influenced significantly by the TDP1/TOP1 activity ratio. The results suggested that TOP1 poisons may be promising for the treatment of certain GBM cancers, and the development of TDP1 inhibitors might help improve the efficacy of GBM treatment.

In conclusion, TDP1/TOP1 activity ratio might be a useful predictive biomarker for GBM treatment with Irinotecan. To further support our finding, increase in TOP1cc level following IRT treatment were measured and correlated with TDP1/TOP1 ratios in the following section. 
Table 2.11. TDP1/TOP1 protein ratio and TDP1/TOP1 activity ratio of GBM cell lines

\begin{tabular}{|c|c|c|c|c|c|c|}
\hline \multicolumn{7}{|c|}{ Experimental TDP1/TOP1 ratio } \\
\hline \multirow{3}{*}{ Cell lines } & \multicolumn{3}{|c|}{ Set \#1, GBM } & \multicolumn{3}{|c|}{ Set \#2, GBM } \\
\hline & \multirow{2}{*}{$\begin{array}{c}\begin{array}{c}\text { TDP1/TOP1 } \\
\text { protein ratio }\end{array} \\
\text { Western blotting }\end{array}$} & \multicolumn{2}{|c|}{ TDP1/TOP1 activity ratio } & \multirow{2}{*}{$\begin{array}{c}\begin{array}{c}\text { TDP1/TOP1 } \\
\text { protein ratio }\end{array} \\
\text { Western blotting }\end{array}$} & \multicolumn{2}{|c|}{ TDP1/TOP1 activity ratio } \\
\hline & & Gel-based assay & FL-based assay & & Gel-based assay & FL-based assay \\
\hline SF539 & $0.614 \pm 0.138$ & $0.273 \pm 0.084$ & $0.297 \pm 0.062$ & $0.367 \pm 0.161$ & $0.256 \pm 0.039$ & $0.301 \pm 0.026$ \\
\hline SF295 & $0.493 \pm 0.209$ & $0.370 \pm 0.040$ & $0.366 \pm 0.035$ & $0.244 \pm 0.068$ & $0.234 \pm 0.034$ & $0.194 \pm 0.024$ \\
\hline $\mathrm{H} 4$ & $0.399 \pm 0.101$ & $0.445 \pm 0.189$ & $0.385 \pm 0.042$ & $0.364 \pm 0.174$ & $0.267 \pm 0.042$ & $0.174 \pm 0.013$ \\
\hline SF268 & $0.641 \pm 0.178$ & $0.374 \pm 0.115$ & $0.439 \pm 0.045$ & $0.433 \pm 0.148$ & $0.510 \pm 0.093$ & $0.978 \pm 0.107$ \\
\hline SNB19 & $0.360 \pm 0.087$ & $0.302 \pm 0.038$ & $0.308 \pm 0.036$ & $0.415 \pm 0.175$ & $0.221 \pm 0.041$ & $0.230 \pm 0.025$ \\
\hline U251 & $0.388 \pm 0.113$ & $0.305 \pm 0.050$ & $0.295 \pm 0.033$ & $0.228 \pm 0.120$ & $0.590 \pm 0.113$ & $0.641 \pm 0.094$ \\
\hline A172 & $0.954 \pm 0.343$ & $0.597 \pm 0.178$ & $0.662 \pm 0.093$ & $0.555 \pm 0.197$ & $0.867 \pm 0.155$ & $0.658 \pm 0.105$ \\
\hline SNB75 & $0.929 \pm 0.234$ & $0.690 \pm 0.065$ & $0.700 \pm 0.040$ & $0.673 \pm 0.317$ & $1.797 \pm 0.307$ & $1.975 \pm 0.252$ \\
\hline U87 & $0.677 \pm 0.205$ & $0.812 \pm 0.176$ & $0.716 \pm 0.070$ & $0.459 \pm 0.162$ & $1.413 \pm 0.319$ & $1.390 \pm 0.273$ \\
\hline \multirow{3}{*}{ Cell lines } & \multicolumn{3}{|c|}{ Set \#3, GBM } & \multicolumn{3}{|c|}{ Average of Set \#1, 2, 3, GBM } \\
\hline & $\begin{array}{l}\text { TDP1/TOP1 } \\
\text { protein ratio }\end{array}$ & \multicolumn{2}{|c|}{ TDP1/TOP1 activity ratio } & $\begin{array}{l}\text { TDP1/TOP1 } \\
\text { protein ratio }\end{array}$ & \multicolumn{2}{|c|}{ TDP1/TOP1 activity ratio } \\
\hline & Western blotting & Gel-based assay & FL-based assay & Western blotting & Gel-based assay & FL-based assay \\
\hline SF539 & $0.292 \pm 0.053$ & $0.208 \pm 0.0215$ & $0.163 \pm 0.005$ & $0.512 \pm 0.191$ & $0.249 \pm 0.068$ & $0.253 \pm 0.078$ \\
\hline SF295 & $0.343 \pm 0.084$ & $0.200 \pm 0.022$ & $0.136 \pm 0.007$ & $0.478 \pm 0.210$ & $0.279 \pm 0.080$ & $0.261 \pm 0.101$ \\
\hline $\mathrm{H} 4$ & $0.267 \pm 0.049$ & $0.268 \pm 0.030$ & $0.167 \pm 0.018$ & $0.385 \pm 0.117$ & $0.345 \pm 0.154$ & $0.289 \pm 0.113$ \\
\hline SF268 & $0.300 \pm 0.065$ & $0.315 \pm 0.051$ & $0.153 \pm 0.014$ & $0.563 \pm 0.210$ & $0.381 \pm 0.116$ & $0.450 \pm 0.274$ \\
\hline SNB19 & $0.259 \pm 0.127$ & $0.170 \pm 0.021$ & $0.141 \pm 0.008$ & $0.361 \pm 0.113$ & $0.220 \pm 0.062$ & $0.240 \pm 0.077$ \\
\hline U251 & $0.397 \pm 0.133$ & $0.284 \pm 0.045$ & $0.309 \pm 0.032$ & $0.365 \pm 0.128$ & $0.391 \pm 0.160$ & $0.380 \pm 0.155$ \\
\hline A172 & $0.558 \pm 0.230$ & $0.563 \pm 0.071$ & $0.542 \pm 0.044$ & $0.835 \pm 0.360$ & $0.693 \pm 0.203$ & $0.638 \pm 0.100$ \\
\hline SNB75 & $1.013 \pm 0.422$ & $0.406 \pm 0.059$ & $0.653 \pm 0.039$ & $0.881 \pm 0.295$ & $0.940 \pm 0.648$ & $0.986 \pm 0.568$ \\
\hline U87 & $0.607 \pm 0.206$ & $0.490 \pm 0.075$ & $0.505 \pm 0.050$ & $0.618 \pm 0.215$ & $0.926 \pm 0.426$ & $0.849 \pm 0.367$ \\
\hline
\end{tabular}


Table 2.12. TDP1/TOP1 protein ratio and TDP1/TOP1 activity ratio of GBM cell lines

\begin{tabular}{|c|c|c|c|c|c|}
\hline \multicolumn{6}{|c|}{ Data from CellMinerCDB database } \\
\hline \multicolumn{2}{|c|}{ CCLE panel } & \multicolumn{2}{|c|}{ GDSC panel } & \multicolumn{2}{|c|}{$\mathrm{NCl}-60$ panel } \\
\hline Cell Line & TDP1/TOP1 & Cell Line & TDP1/TOP1 & Cell Line & TDP1/TOP1 \\
\hline & & SF539 & 0.763 & & \\
\hline SF-295 & 0.546 & SF295 & 0.592 & CNS:SF-295 & 0.826 \\
\hline \multirow{2}{*}{$\mathrm{H} 4$} & 0.607 & H4 & 0.744 & & \\
\hline & & SF268 & 0.851 & CNS:SF-268 & 0.946 \\
\hline SNB-19 & 0.571 & & & CNS:SNB-19 & 0.907 \\
\hline U-251 MG & 0.627 & U251 & 0.823 & CNS:U251 & 0.971 \\
\hline \multirow[t]{2}{*}{ A172 } & 0.631 & A172 & 0.790 & & \\
\hline & & SNB75 & 0.843 & CNS:SNB-75 & 0.977 \\
\hline U-87 MG & 0.607 & U-87-MG & 0.864 & & \\
\hline 42-MG-BA & 0.607 & 42-MG-BA & 0.828 & & \\
\hline 8-MG-BA & 0.504 & 8-MG-BA & 0.691 & & \\
\hline AM-38 & 0.631 & AM-38 & 0.879 & & \\
\hline Becker & 0.624 & Becker & 0.655 & & \\
\hline CAS-1 & 0.532 & CAS-1 & 0.788 & & \\
\hline CCF-STTG1 & 0.642 & CCF-STTG1 & 0.686 & & \\
\hline DBTRG-05MG & 0.515 & DBTRG-05MG & 0.616 & & \\
\hline DK-MG & 0.523 & DK-MG & 0.720 & & \\
\hline GB-1 & 0.618 & GB-1 & 0.789 & & \\
\hline GI-1 & 0.581 & Gl-1 & 0.718 & & \\
\hline GMS-10 & 0.568 & GMS-10 & 0.790 & & \\
\hline KNS-81 & 0.558 & KNS-81-FD & 0.668 & & \\
\hline KS-1 & 0.626 & KS-1 & 0.811 & & \\
\hline LN-18 & 0.561 & LN-18 & 0.854 & & \\
\hline LN-229 & 0.582 & LN-229 & 0.785 & & \\
\hline SF126 & 0.629 & SF126 & 0.810 & & \\
\hline SW 1088 & 0.575 & SW1088 & 0.729 & & \\
\hline T98G & 0.527 & T98G & 0.756 & & \\
\hline U-118 MG & 0.560 & U-118-MG & 0.820 & & \\
\hline YH-13 & 0.599 & YH-13 & 0.822 & & \\
\hline \multirow[t]{13}{*}{ YKG1 } & 0.522 & YKG-1 & 0.638 & & \\
\hline & & D-247MG & 0.809 & & \\
\hline & & D-263MG & 0.833 & & \\
\hline & & D-392MG & 0.749 & & \\
\hline & & D-423MG & 0.796 & & \\
\hline & & D-542MG & 0.843 & & \\
\hline & & D-566MG & 0.827 & & \\
\hline & & LN-405 & 0.763 & & \\
\hline & & LNZTA3WT4 & 0.853 & & \\
\hline & & M059J & 0.733 & & \\
\hline & & MOG-G-CCM & 0.782 & & \\
\hline & & MOG-G-UVW & 0.698 & & \\
\hline & & SK-MG-1 & 0.871 & & \\
\hline KG-1-C & 0.490 & & & & \\
\hline KNS-60 & 0.640 & & & & \\
\hline LN-235 & 0.580 & & & & \\
\hline LN-319 & 0.636 & & & & \\
\hline LN-340 & 0.548 & & & & \\
\hline LN-443 & 0.620 & & & & \\
\hline LN382 & 0.533 & & & & \\
\hline LNZ308 & 0.613 & & & & \\
\hline M059K & 0.603 & & & & \\
\hline SF-172 & 0.576 & & & & \\
\hline SNU-1105 & 0.661 & & & & \\
\hline SNU-201 & 0.588 & & & & \\
\hline SNU-466 & 0.629 & & & & \\
\hline SNU-489 & 0.601 & & & & \\
\hline SNU-626 & 0.530 & & & & \\
\hline U-138 MG & 0.566 & & & & \\
\hline U-178 & 0.656 & & & & \\
\hline U343 & 0.549 & & & & \\
\hline
\end{tabular}



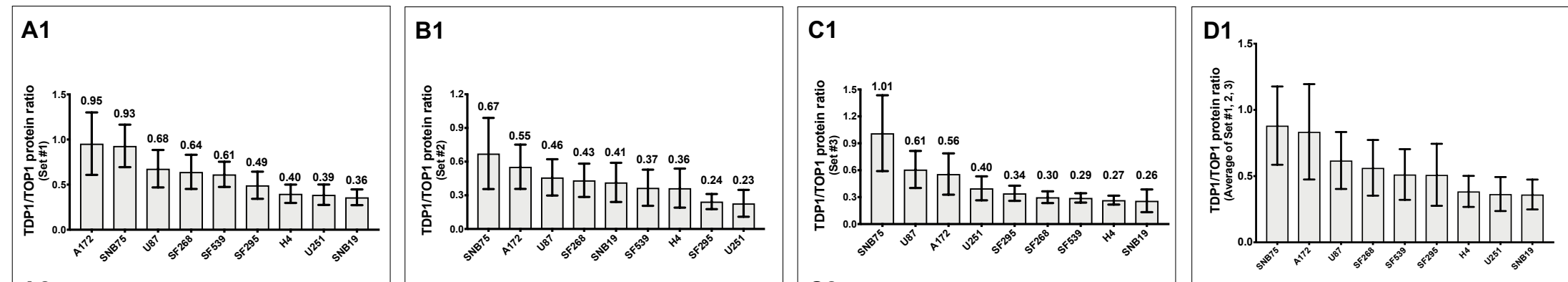

A2

B2

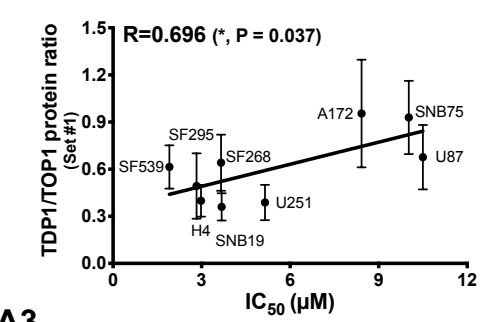

A3

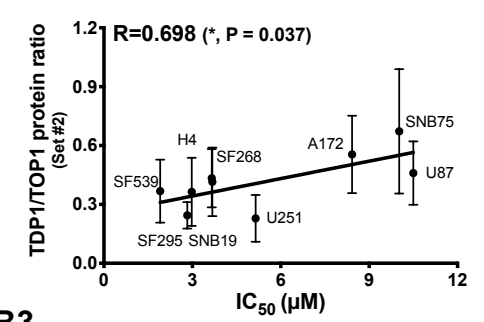

B3

C2

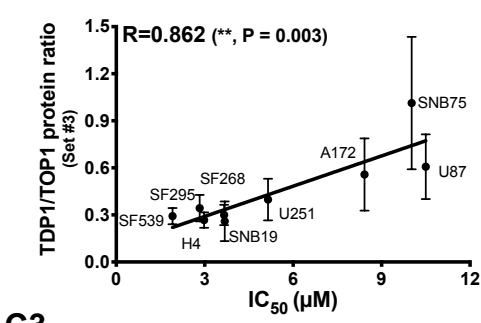

C3
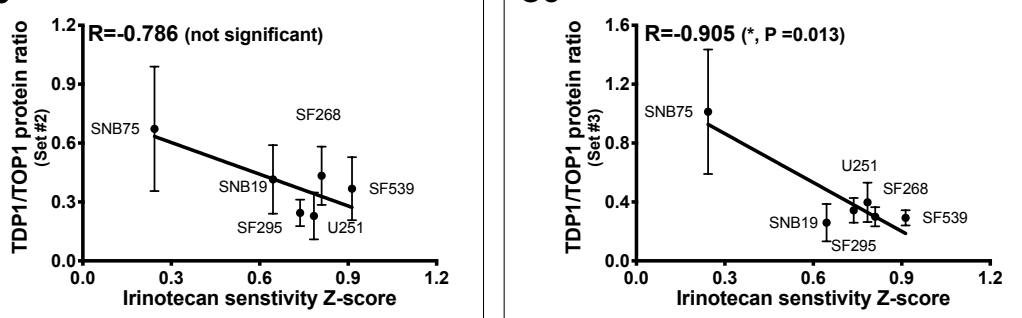

D2
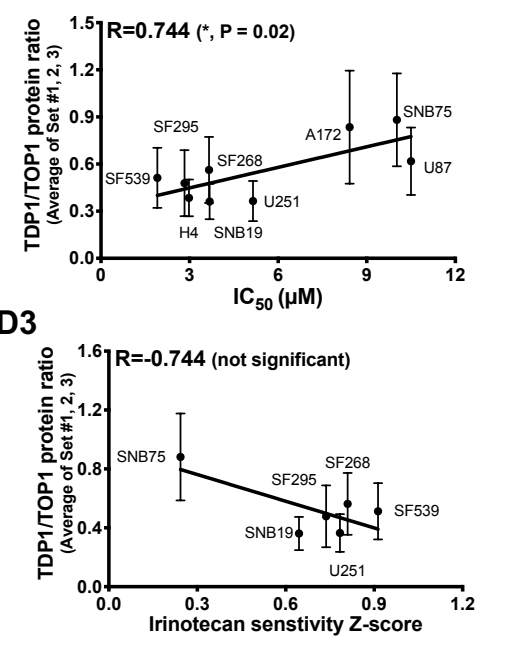

Figure 2.26. Comparison of TDP1/TOP1 protein ratio in GBM cell lines to assess potential correlation with Irinotecan sensitivities

The TDP1/TOP1 protein ratio from (A1) set \#1, (B1) set \#2, (C1) set \#3, and the (D1) average of TDP1/TOP1 protein ratio are all lower than the ratio in NHA (grey bar) (relative ratios <1). The TDP1/TOP1 protein ratio from (A2) set \#1, (B2) set \#2, (C2) set \#3, and (D2) the average of TDP1/TOP1 protein ratio significantly correlate with Irinotecan IC 50 S. The TDP1/TOP1 protein ratio from (C3) set \#3 and (D3) the average of TDP1/OPT1 protein ratio are significantly correlated with Z-scores from CellMiner database, whereas (A3) set \#1 and (B3) set \#2 do not. 


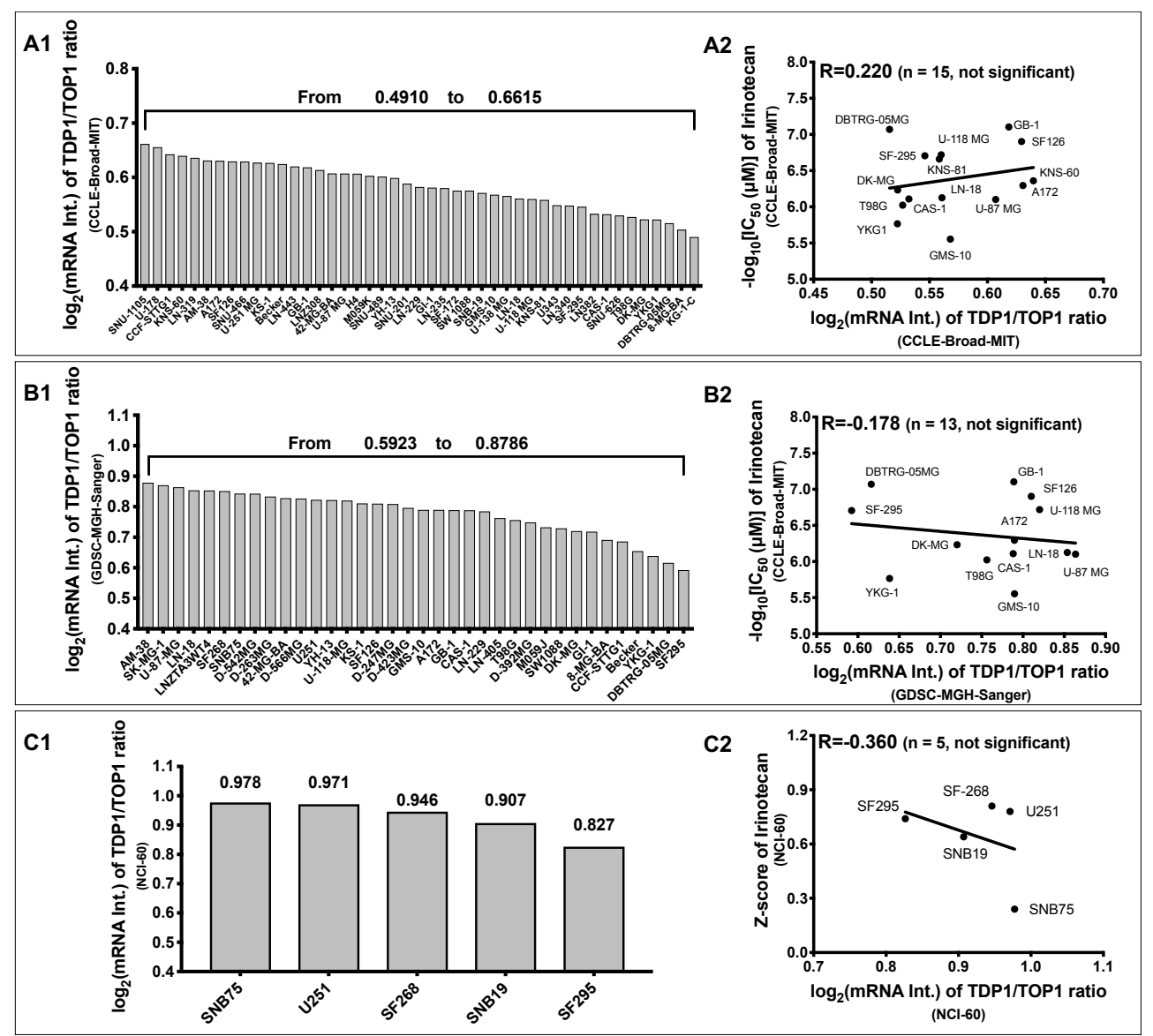

Figure 2.27. Comparison of TDP1/TOP1 mRNA ratio in GBM cell lines from CellMinerCDB database to assess potential correlation with Irinotecan sensitivities

The TDP1/TOP1 mRNA ratio from (A) CCLE, (B) GDSC, and (C) NCl-60 panels do not correlate with Irinotecan sensitivities.

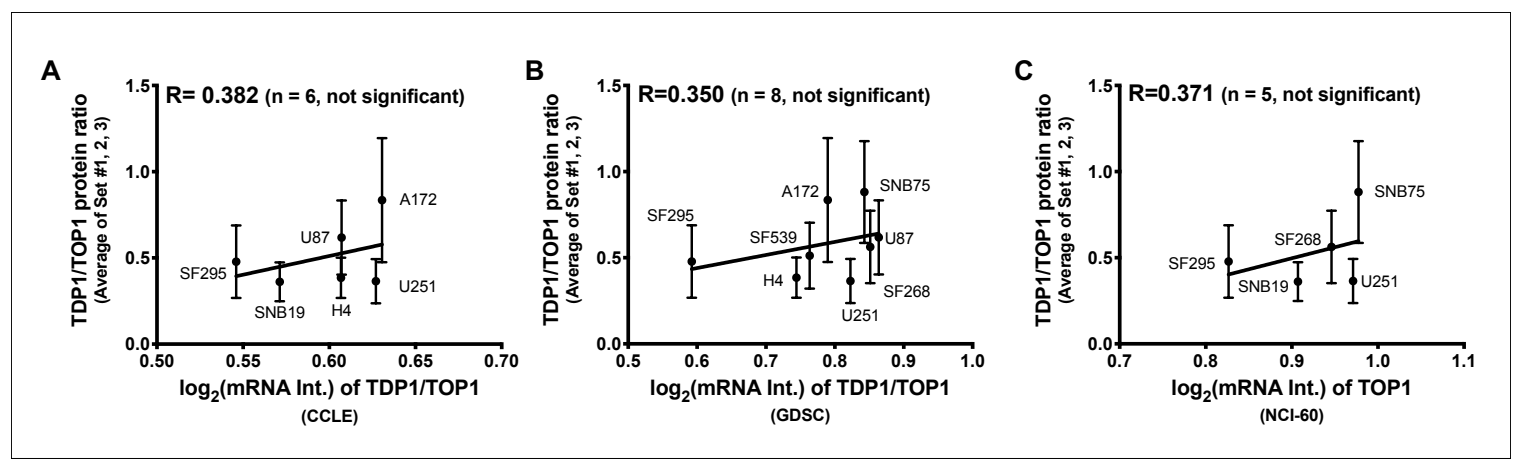

Figure 2.28. Comparison of TDP1/TOP1 protein ratio with TDP1/TOP1 mRNA ratio

The average of TDP1/TOP1 protein ratio is not correlated with mRNA ratio on (A) CCLE, (B) GDSC, and (C) NCl-60 panels. 

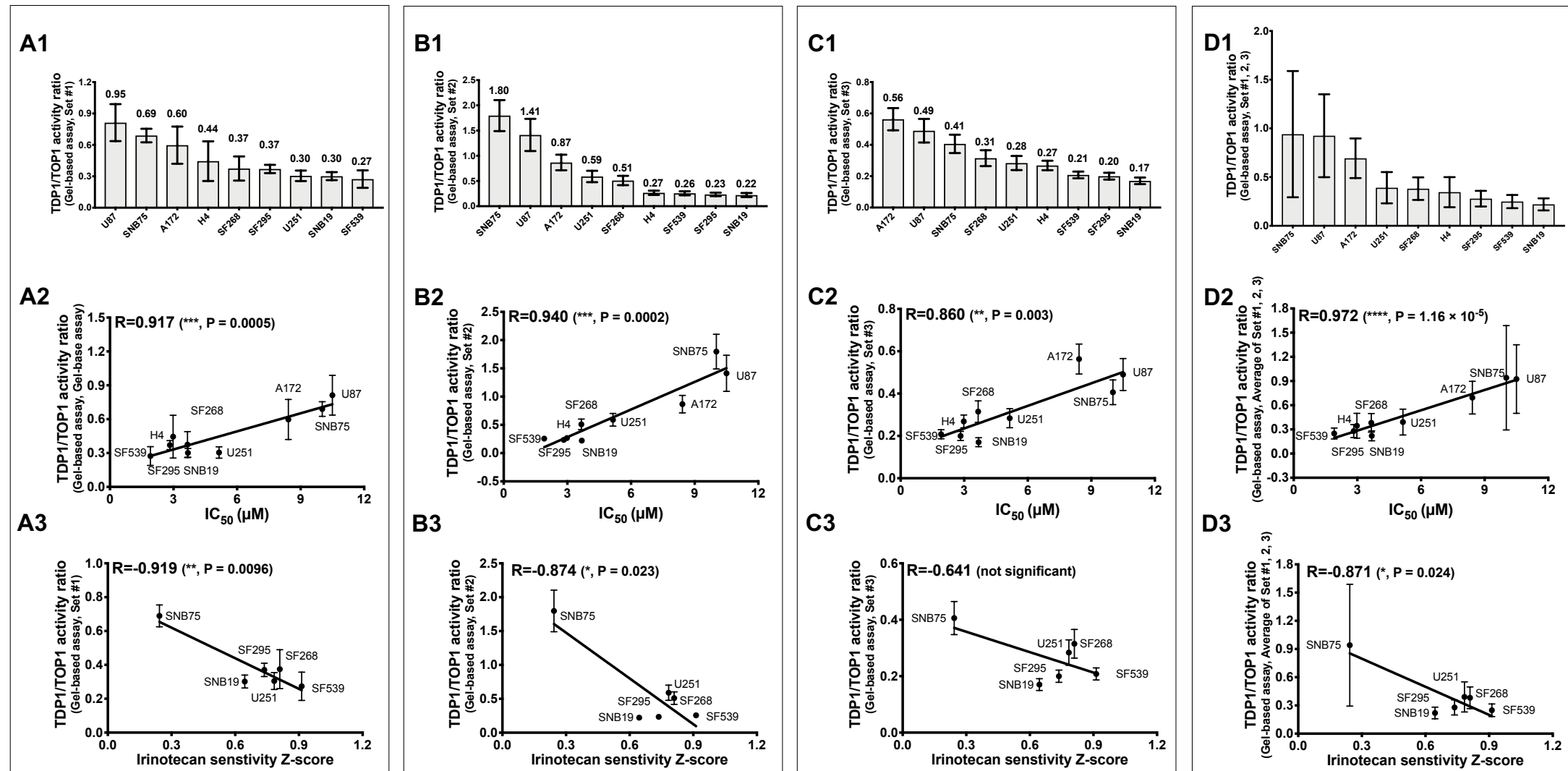

C3
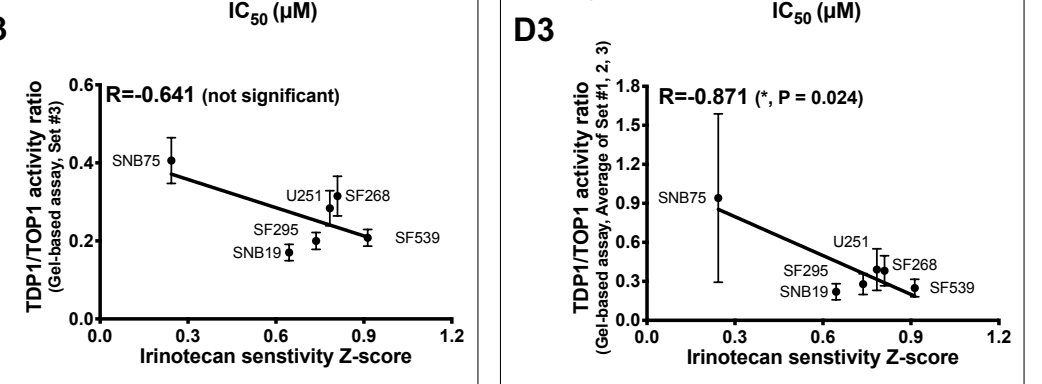

Figure 2.29. Comparison of gel-based TDP1/TOP1 activity ratio in GBM cell lines to assess potential correlation with Irinotecan sensitivities

The majority of TDP1/TOP1 activity ratios from GBM cells measured in (A1) set \#1, (B1) set \#2, (C1) set \#3, and (D1) the average of all three sets of experiments, are lower than the TDP1/TOP1 ratio in NHA (grey bar) (relative ratios <1). The TDP1/TOP1 activity ratio from (A2) set \#1, (B2) set \#2, (C2) set \#3, and (D2) the average of TDP1/TOP1 protein ratio correlate significantly with Irinotecan $I_{50}$ s. The TDP1/TOP1 activity ratio from (A3) set \#1, (B3) set \#2, and (D3) the average of TDP1/TOP1 activity ratios correlate significantly with Irinotecan sensitivities from the CellMiner database, except set \#3 (C3). 

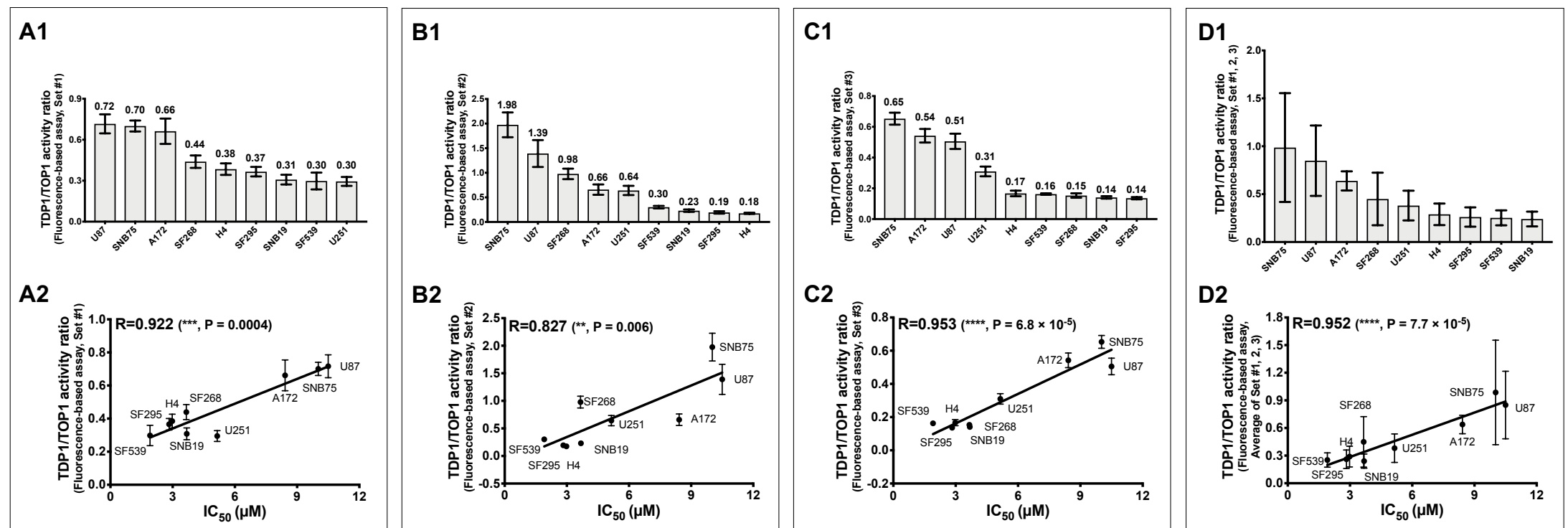

D2

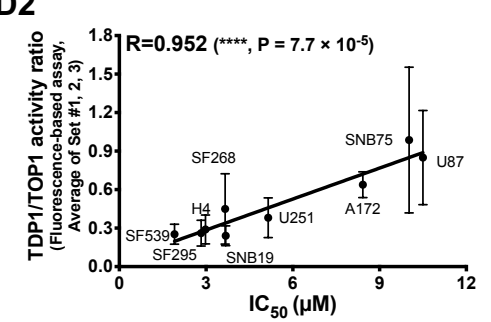

B3

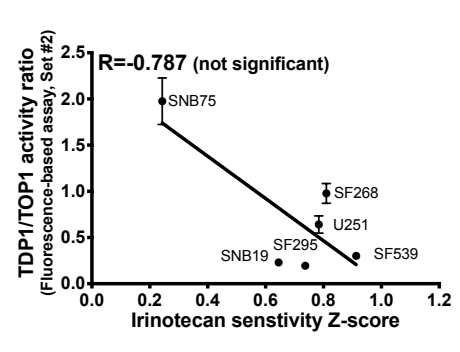

C3

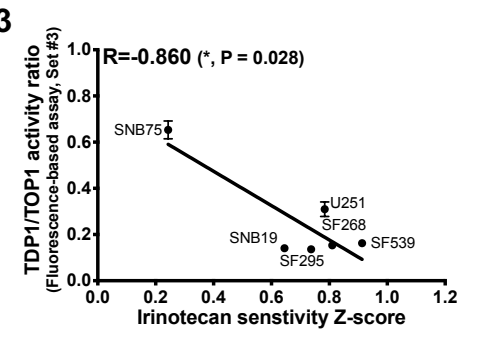

D3
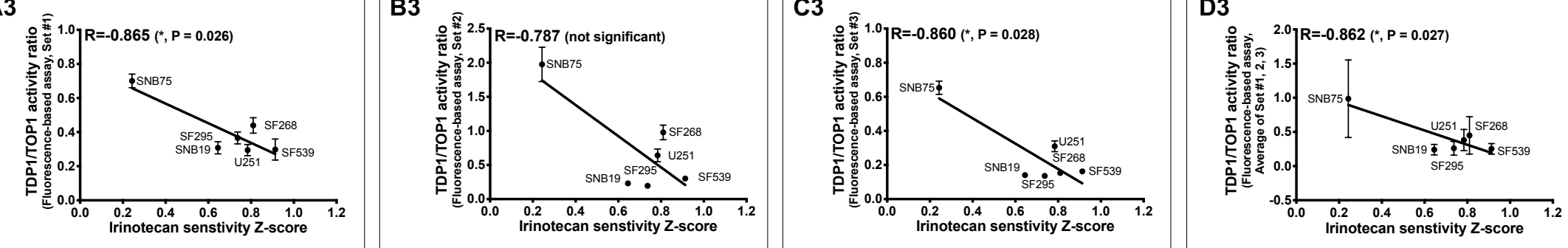

Figure 2.30. Comparison of fluorescence-based TDP1/TOP1 activity ratio in GBM cell lines to assess potential correlation with Irinotecan sensitivities

The majority of TDP1/TOP1 activity ratios from (A1) set\#1, (B1) set \#2, (C1) set \#3, and (D1) the average of TDP1/TOP1 activity ratio are lower than the ratio in NHA (grey bar) (relative ratios $<1$ ). The TDP1/TOP1 activity ratio from (A2) set \#1, (B2) set \#2, (C2) set \#3, and (D2) the average of TDP1/TOP1 activity ratio correlate significantly with Irinotecan $I_{50}$ S. The TDP1/TOP1 activity ratio from (A3) set \#1, (C3) set \#3, and (D3) the average of TDP1/TOP1 activity ratios correlate significantly with Irinotecan sensitivities from the CellMiner database, except for \#2 (B3). 


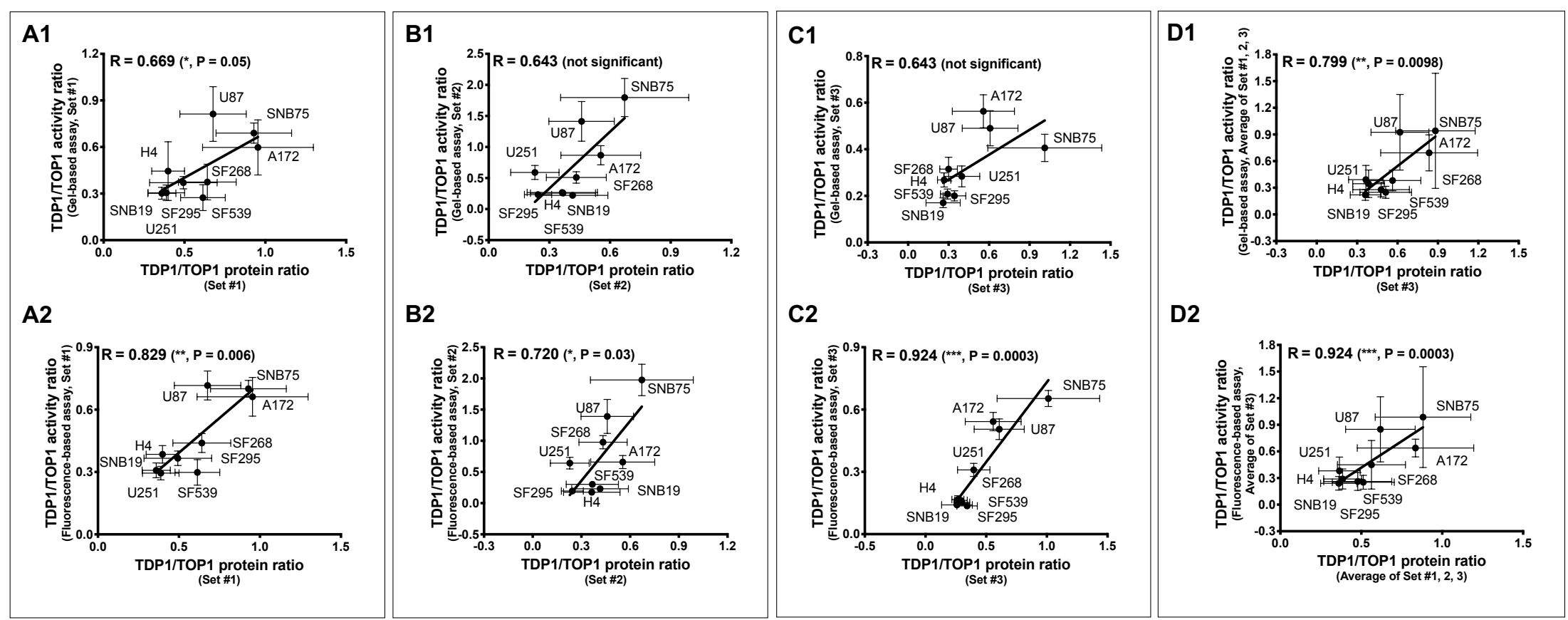

Figure 2.31. Correlation between TDP1/TOP1 protein ratios and TDP1/TOP1 activity ratios

The relative TDP1/TOP1 protein ratios significantly correlate with gel-based TDP1/TOP1 activity ratios in (A1) set \#1, (B1) set \#2, and (D1) the average of the relative TDP1/TOP1 activity ratios, with the exception of set \#3 (B1). The relative TDP1/TOP1 protein ratios significantly correlate with fluorescence-based TDP1/TOP1 activity ratios in (A2) set \#1, (B2) set \#2, (C2) set \#3, and (D2) the average of the relative TDP1/TOP1 activity ratios. 


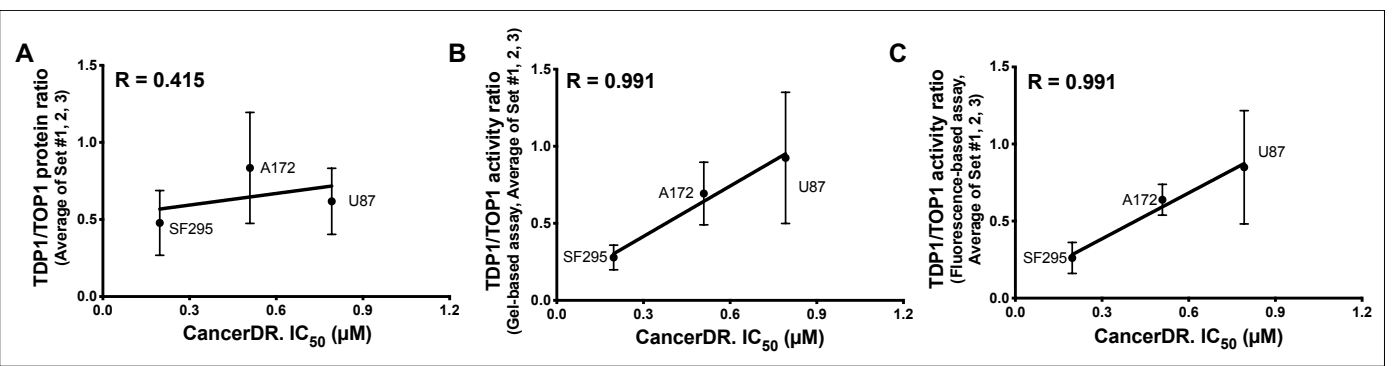

Figure 2.32. Comparison of TDP1/TOP1 ratio in GBM cell lines with Irinotecan sensitivities from CancerDR database

The average of TDP1/TOP1 protein ratio is weakly correlated with $I C_{50}$ s from CancerDR database. The average of the gel-based and fluorescence-based TDP1/TOP1 activity ratios are highly correlated with $\mathrm{IC}_{50} \mathrm{~S}$ from CancerDR database.
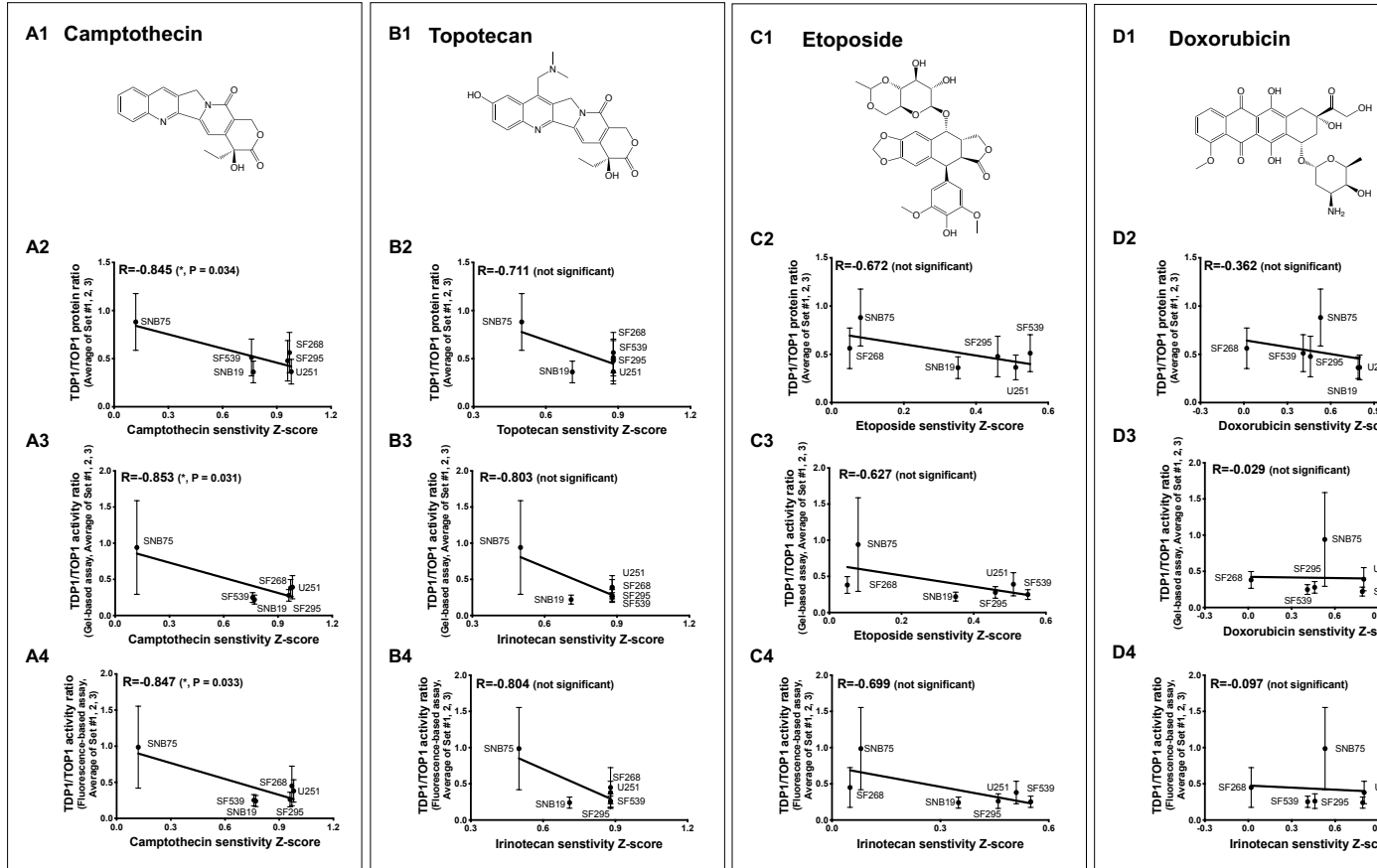

D2

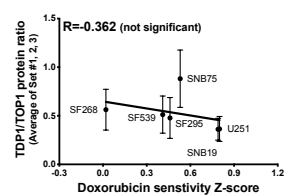

D3

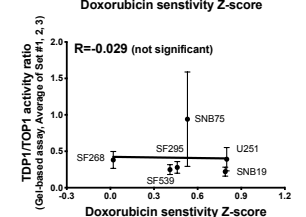

D4

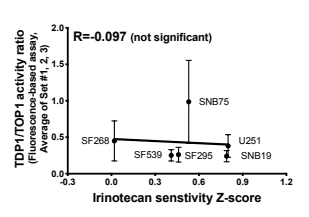

Figure 2.33. Assessment of potential correlation between sensitivities of GBM cell lines to human topoisomerase I/II poisons and TDP1/TOP1 ratios in GBM cell lines

Structure of human topoisomerase I poisons (A1) Camptothecin, (B1) Topotecan, (C1) Etoposide, and (D1) Doxorubicin. The average of TDP1/TOP1 protein ratio from three sets of experiments on GBM cell lines is significantly correlated with both Z-scores of (A2) Camptothecin, while not correlated with (B2) Topotecan, (C2) Etoposide, and (D2) Doxorubicin from CellMiner database. The average of TDP1/TOP1 activity ratio from three sets of experiments on GBM cell lines is significantly correlated with both Z-scores of $(\mathbf{A} 3, \mathbf{A} 4)$ Camptothecin, while not correlated with (B3, B4) Topotecan, (C3, C4) Etoposide, and (D3, D4) Doxorubicin from CellMiner database. 
Irinotecan resistance for GBM cells with higher TDP1/TOP1 activity ratio is linked to lower level of IRT-induced TOP1cc

Three relatively sensitive GBM cell lines (SNB19, H4, and SF295), and two relatively resistant cell lines (A172 and SNB75) were chosen for analysis of TOP1cc level following IRT treatment. The level of topoisomerase I cleavage complexes (TOP1cc) was measured using the RADAR assay (98). Cells were treated with $15 \mu \mathrm{M}$ of IRT and the accumulated TOP1cc levels were compared among these different cell lines (Figure 2.34, panel A). The decrease of accumulated TOP1cc level at 15 min after addition of IRT is most likely because of the proteolysis of the DNA bound TOP1 polypeptide from cellular response instead of IRT-induced cytotoxicity, because there were no significant changes in the overall TOP1 and TDP1 protein levels as well as their activity levels after up to $22 \mathrm{~h}$ of IRT treatment (Figure 2.35). The fold-increase in TOP1cc level (relative to no drug treatment) at $15 \mathrm{~min}$ after treatment with $15 \mu \mathrm{M}$ of IRT showed a significant correlation $(R=-0.892, P=0.042$, Figure 2.34, panel $B)$ with $I R T I C_{50} S$, as well as with the potential predictor, TDP1/TOP1 activity ratio from both gel-based assay $(R=-0.932, P=0.02$, Figure 2.34, panel $D 1)$ and fluorescence-based assay $(R=-$ 0.885, $\mathrm{P}=0.046$, Figure 2.34, panel $\mathrm{E} 1)$. We demonstrated that a lower TDP1/TOP1 activity ratio leads to increased TOP1cc accumulations as well as a higher degree of IRT sensitivity (i.e., lower $I C_{50}$ ). However, there is no significant correlation between the fold-increase in TOP1cc level and TDP1/TOP1 protein ratio (Figure 2.34, panel $B$ ) which is in agreement with the earlier results that the TDP1/TOP1 activity ratio is a better predictor of IRT sensitivity than the 
TDP1/TOP1 protein ratio. The correlation between TOP1cc and TDP1/TOP1 activity ratio became less significant at $60 \mathrm{~min}$ (Figure 2.34, panels D3, E3) following IRT treatment, when TOP1cc might already be proteolyzed and the TOP1 antibody signal is no longer an indicator of the cytotoxic effect from IRT-induced TOP1cc accumulation.

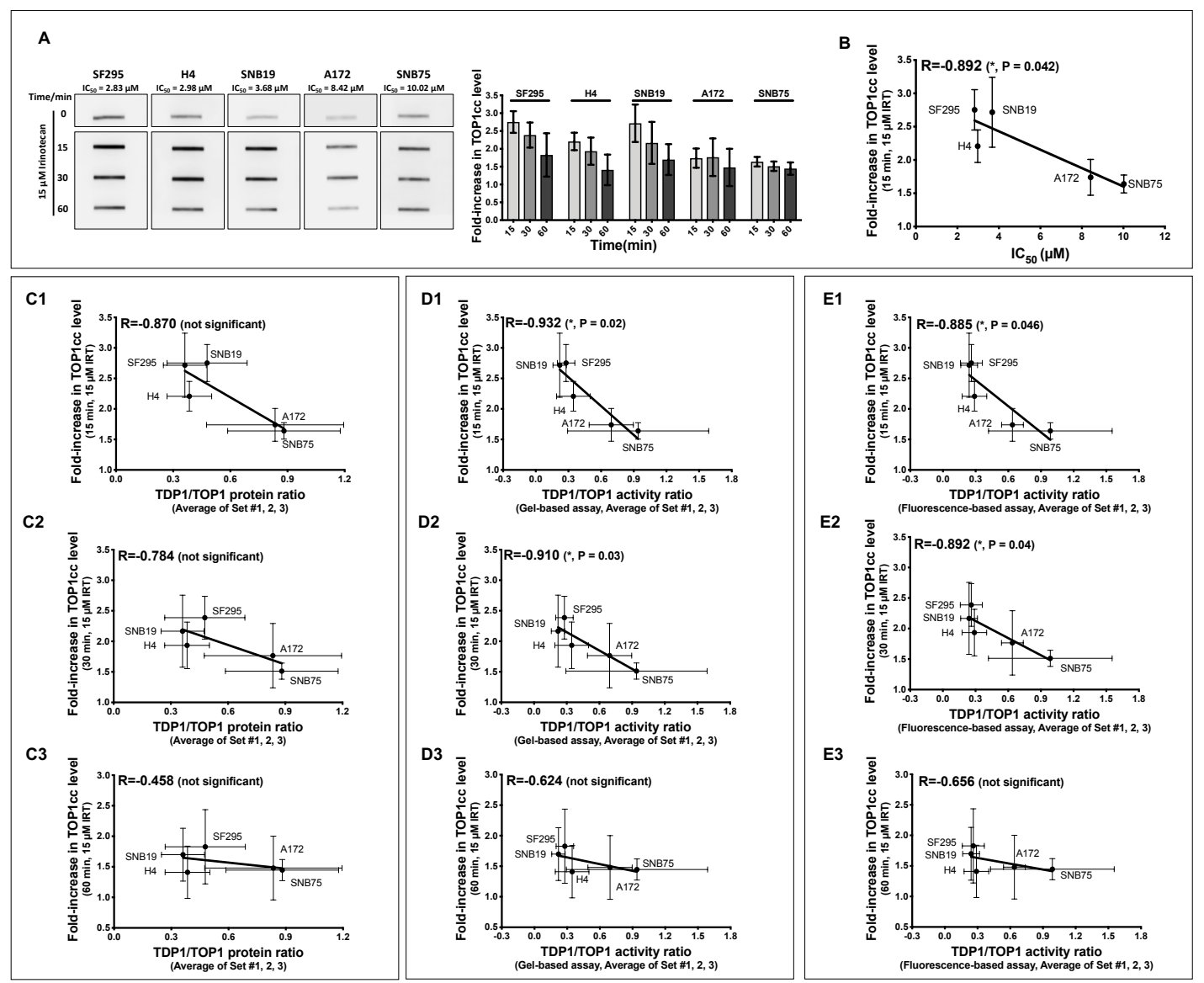

Figure 2.34. TOP1cc level in GBM cell lines following IRT treatment (A1) Immunoblotting of TOP1cc isolated on chromosomal DNA using the RADAR protocol following treatment with $15 \mu \mathrm{M} \mathrm{IRT}$ for $15 \mathrm{~min}, 30 \mathrm{~min}$, and $60 \mathrm{~min}$ in three relatively sensitivity cell lines (SF295, H4, SNB19) and two relatively resistant cell lines (A172, SNB75). (B) The fold-increase in TOP1cc level from $15 \mathrm{~min}, 15 \mu \mathrm{M}$ IRT treatment is significantly correlated with Irinotecan $\mathrm{IC}_{50} \mathrm{~S}$. The average of TDP1/TOP1 protein ratio does not correlate with the fold-increase in TOP1cc level at (C1) $15 \mathrm{~min}$, (C2) $30 \mathrm{~min}$, and (C3) $60 \mathrm{~min}$. The average of TDP1/TOP1 activity ratio is significantly correlated with the fold-increase in TOP1cc level at (D1, E1) $15 \mathrm{~min}$, (D2, E2) $30 \mathrm{~min}$, while not significantly correlated with TOP1cc level at (D3, E3) $60 \mathrm{~min}$. 

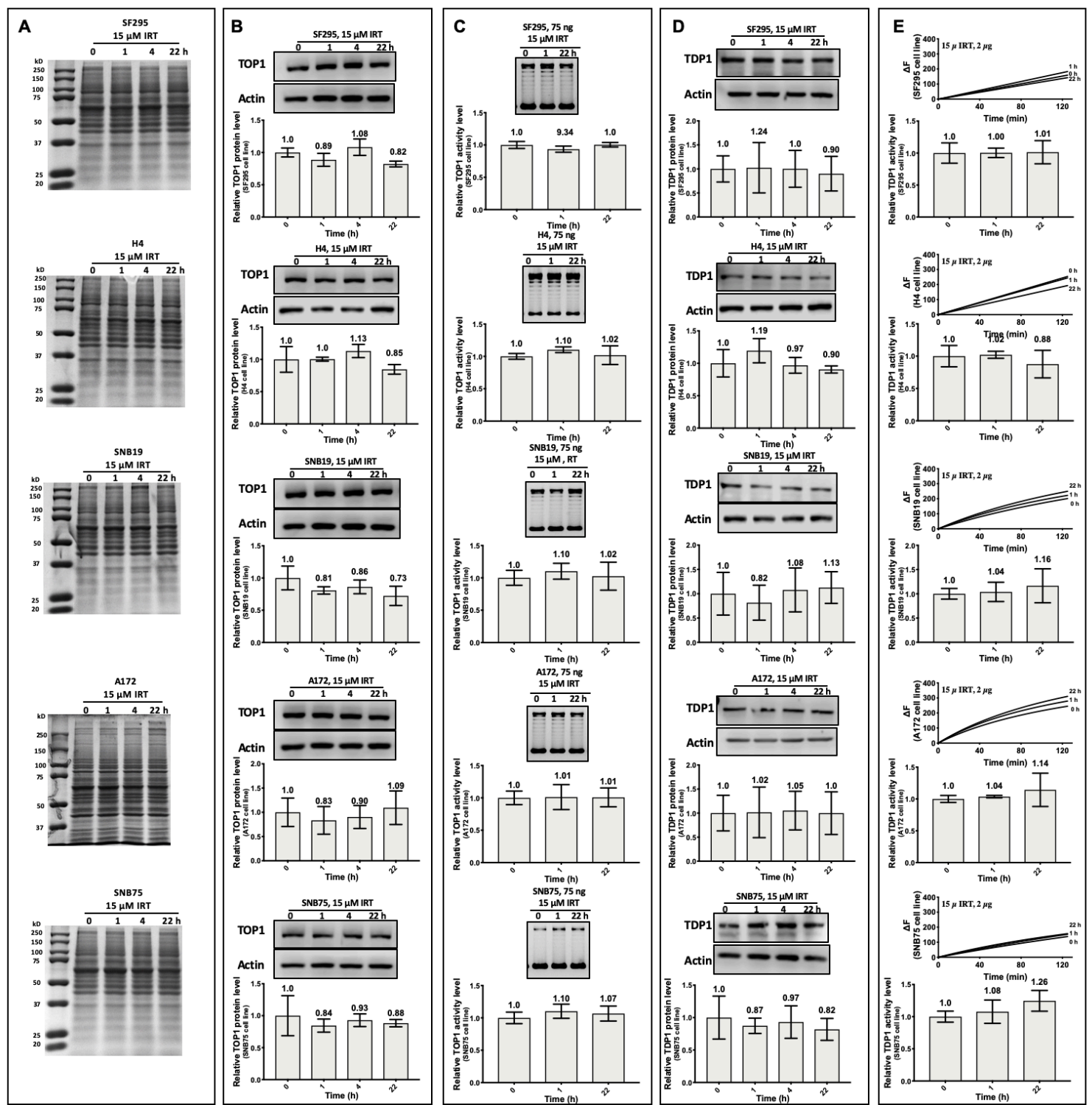

Figure 2.35. No significant changes of TOP1 and TDP1 protein and activity levels from treatment with $15 \mu \mathrm{M}$ IRT for up to $22 \mathrm{~h}$

(A) Total proteins present in $10 \mu \mathrm{g}$ of WCEs of GBM cell lines (SF295, SNB75, SNB19, A172, H4) following treatment with $15 \mu \mathrm{M} I R T$ for $0,1,4$ and $22 \mathrm{~h}$ were visualized by Coomassie blue staining after SDS PAGE. (B) TOP1 and (D) TDP1 expressed in $10 \mu \mathrm{g}$ of WCEs of GBM cell lines treated with $15 \mu \mathrm{M}$ IRT for $0,1,4$, and $22 \mathrm{~h}$ were measured by western blots. (C) TOP1 activity level in $75 \mathrm{ng}$ of WCEs of GBM cell lines treated with $15 \mu \mathrm{M}$ IRT for 0,1 , and $22 \mathrm{~h}$ were measured by agarose gel relaxation assay. (E) TDP1 activity level in $2 \mu \mathrm{g}$ of WCEs of GBM cell lines treated with $15 \mu \mathrm{M} \mathrm{IRT}$ for 0,1 , and $22 \mathrm{~h}$ were measured by fluorescencebased assay. The data shown here is the average of results from two individual experiments. 


\section{IRT resistance for GBM is not due to lack of carboxylesterase CES2 activity}

The human carboxylesterase 2 (CES2) activity converts IRT into a more active metabolite SN-38 (Figure 2.36, panel A). To demonstrate that IRT resistance observed in GBM cell lines was not the result of a lack of CES2 activity, we conducted the CES2 activity assay by using p-NPA as a substrate which will produces a yellow colored p-NP product following esterase catalysis in the presence and absence of $300 \mu \mathrm{M}$ Loperamide (LOP) (Figure 2.36, panel B). The LOP is an anti-diarrhea drug which strongly inhibits CES2 and has been widely used in obtaining the ability of cells on converting IRT into SN-38 $(105,106)$. The activity of CES2 was calculated using the picomolar of product produced in $1 \mathrm{~min}$ with $1 \mu \mathrm{g}$ of WCE $(\Delta \mathrm{pmol} / \mathrm{min} / \mu \mathrm{g})$. The reaction curves are shown in Figure 2.36, panel C and CES2 activity was calculated (Figure 2.36, panel D). There is only 1.3-fold variation of CES2 activity (from 3.58 to $4.64(\Delta \mathrm{pmol} / \mathrm{min} / \mu \mathrm{g}$ ) among all the GBM cell lines studied here, and only 1.06 -fold CES2 protein expression level (from 4.26 to 4.51 ) for the $\mathrm{NCl}-60$ GBM cells in the CellMinerCDB database (Figure 2.36, panel E). Therefore, variation in expression and activity level of CES2 among the GBM cell lines is unlikely to play a role in IRT sensitivities and no significant correlations were observed (Figure 2.38, panel F). Furthermore, there is no significant correlation between CES2 activity level and the fold-increase in TOP1cC level at $15 \mathrm{~min}$.

In summary, the metabolic conversion of IRT to SN-38 would be a significant factor for IRT treatment efficacy in vivo. Nevertheless, there is little variation of 
CES2 activity among the GBM cell lines studied here. The observation made from our experiments that GBM cell lines with lower TDP1/TOP1 activity ratio are more sensitive to TOP1 poisons and induces more TOP1cc, remains valid after the GBM CES activity data is taken into consideration.

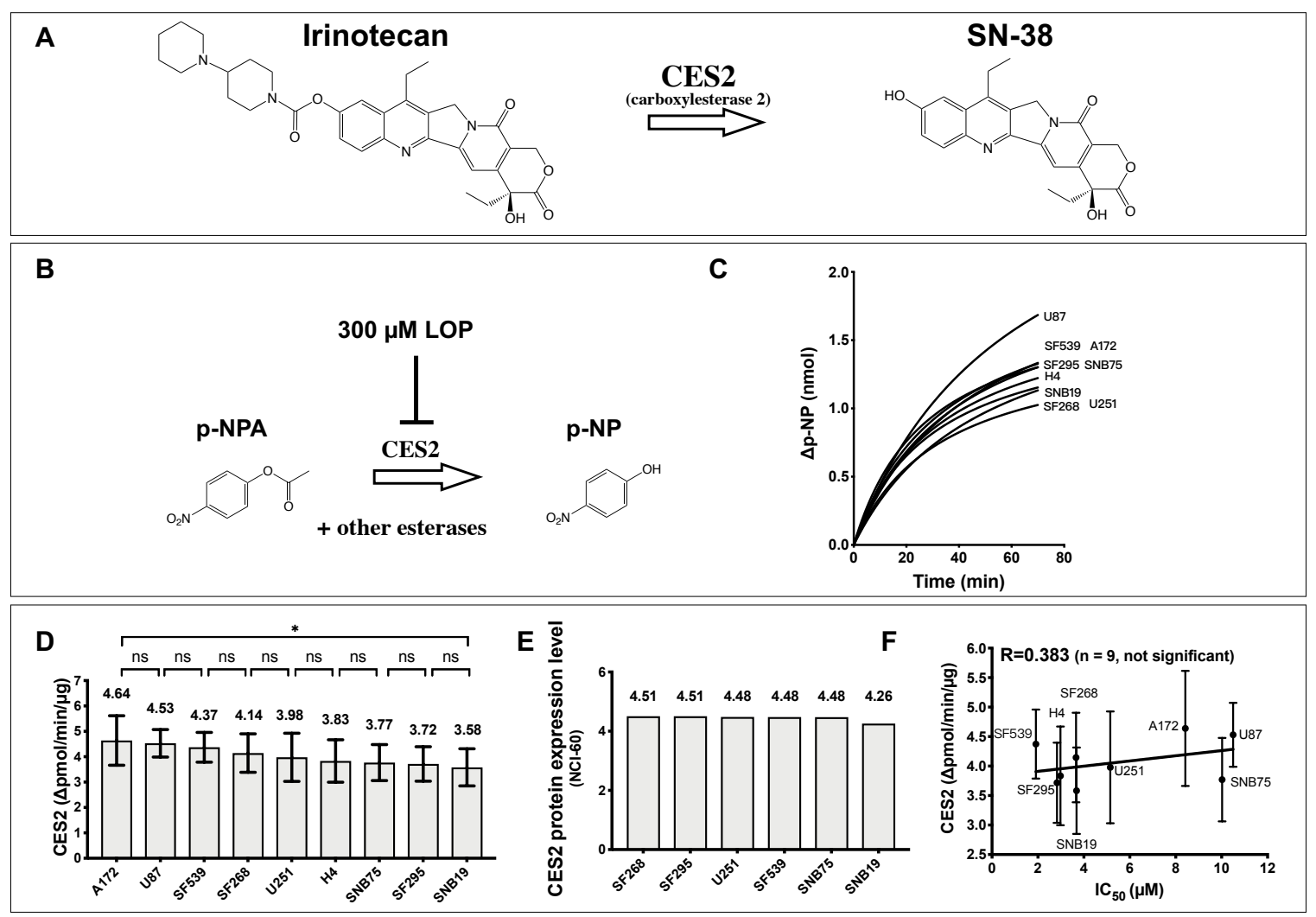

Figure 2.36. Carboxylesterase 2 (CES2) activity in GBM cell lines

(A) CES2 converts IRT to its active form SN-38. (B) p-NPA is used as the esterase substrate to produce p-NP. CES2 activity from other esterases found in the WCE is subtracted based on $p-N P$ produced in the presence of LOP, a specific inhibitor for CES2. (C) The time course of $p$-NP production corrected with results obtained in the presence of $300 \mu \mathrm{M}$ LOP. (D) The variation of CES2 activity among the nine different GBM cell lines measured in the initial 20 min reaction. (E) The variation of CES2 expression in NCl-60 GBM cells from the CellMinerCDB database. (F) CES2 activity does not correlate with experimental IRT IC ${ }_{50}$ S. 
Transfection of recombinant TDP1 led to increased resistance of GBM to Irinotecan treatment

We conclude that the TDP1/TOP1 activity ratio in GBM correlates strongly with IRT sensitivities. In order to find further evidence that IRT sensitivity is dependent on TDP1/TOP1 activity ratio, we transfected H4 GBM cell line with wildtype TDP1 (WT-TDP1) clone and null activity mutant H263-TDP1 clone. The overexpression of TDP1 protein following transfections with both clones was detected, and similar expression levels were observed (Figure 2.37, panel C). The TDP1 catalytic activity increased 4-fold following transfection with WT-TDP1, whereas $\mathrm{H} 4$ cells transfection with mutant H263-TDP1 exhibited TDP1 activity similar to control (Figure 2.37, panel D). The TOP1 protein expression (Figure 2.37, panel A) and activity (Figure 2.37, panel B) remained unchanged following transfections. The resulting increase in TDP1/TOP1 activity ratio for $\mathrm{H} 4$ cells transfected with WT-TDP1 led to a significantly higher IRT IC 50 than $\mathrm{H} 4$ cells transfected with $\mathrm{H} 236 \mathrm{~A}-\mathrm{TDP} 1$ clone $(\mathrm{P}=0.0096$, Fig 2.37, panel E). The $\mathrm{H} 4$ cells transfected with null-activity mutant TDP1 protein exhibited a similar $\mathrm{IC}_{50}(3.2 \mu \mathrm{M})$ as non-transfected cells $(2.98 \mu \mathrm{M}$, Table 2.4$)$. Therefore, the $\mathrm{IC}_{50}$ increase was a result of elevated TDP1/TOP1 activity ratio and not caused by the increase in TDP1/TOP1 protein ratio or TDP1 protein expression alone. Our result further demonstrated that TDP1 activity plays a vital role in GBM cell lines for IRT treatment outcome.

However, the fold-increase in TDP1/TOP1 activity level (4.45-fold) does not correspond to fold-increase in $I C_{50}$ (1.56-fold) at 1:1 ratio. Expression level of TDP1 
changes over time following transfection. We observed the highest TDP1 expression level at $24 \mathrm{~h}$ (Figure 2.38) and a decreased TDP1 expression at $48 \mathrm{~h}$ post-transfection. Therefore, the small magnitude of $\mathrm{IC}_{50}$ increase following transfection of WT-TDP1 clone might because of the decrease of TDP1 activity over time following transfection. It is also possible that other cellular determinants limit the magnitude of increase in drug sensitivity from increase in TDP1/TOP1 activity ratio. 


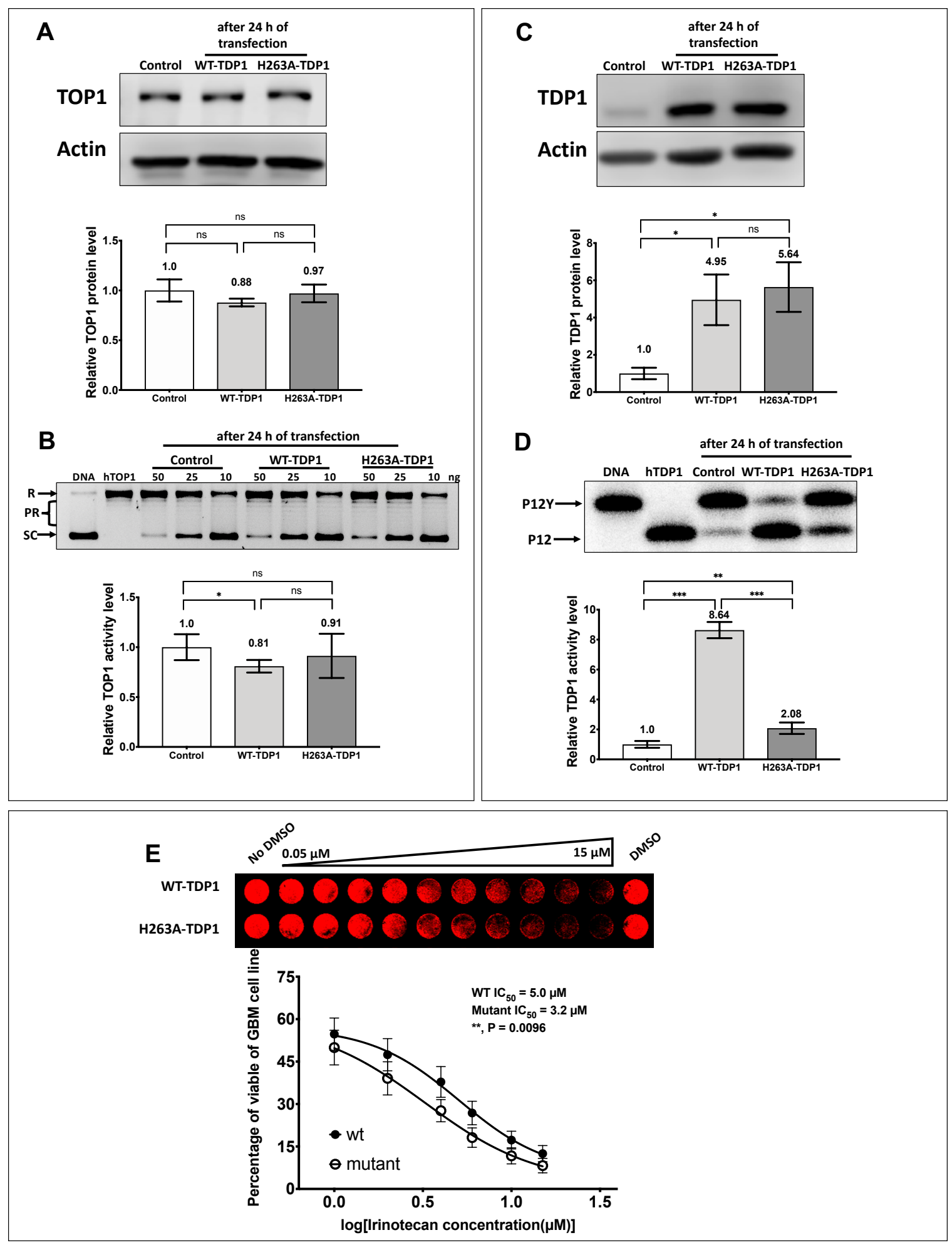

Figure 2.37. Transfection induced increase of TDP1/TOP1 activity ratio in H4 GBM cell line results in a higher Irinotecan IC50.

(A) TOP1 protein level based on western-blot and (B) activity level based on relaxation assay were not affected after transfection with wild-type (WT-TDP1) or 
mutant (H263-TDP1) clones. (C) TDP1 protein level and (D) activity level measured by gel-based assay after transfection with WT-TDP1 or H263-TDP1 clones showed that both clones increased theTDP1 protein level, but only the WT clone resulted in elevated TDP1 activity. (E) A significantly higher IRT IC 50 for $\mathrm{H} 4$ cells transfected with WT-TDP1 clone versus H263 mutant TDP1 clone $(n=7$, $\mathrm{P}=0.0096$ ).

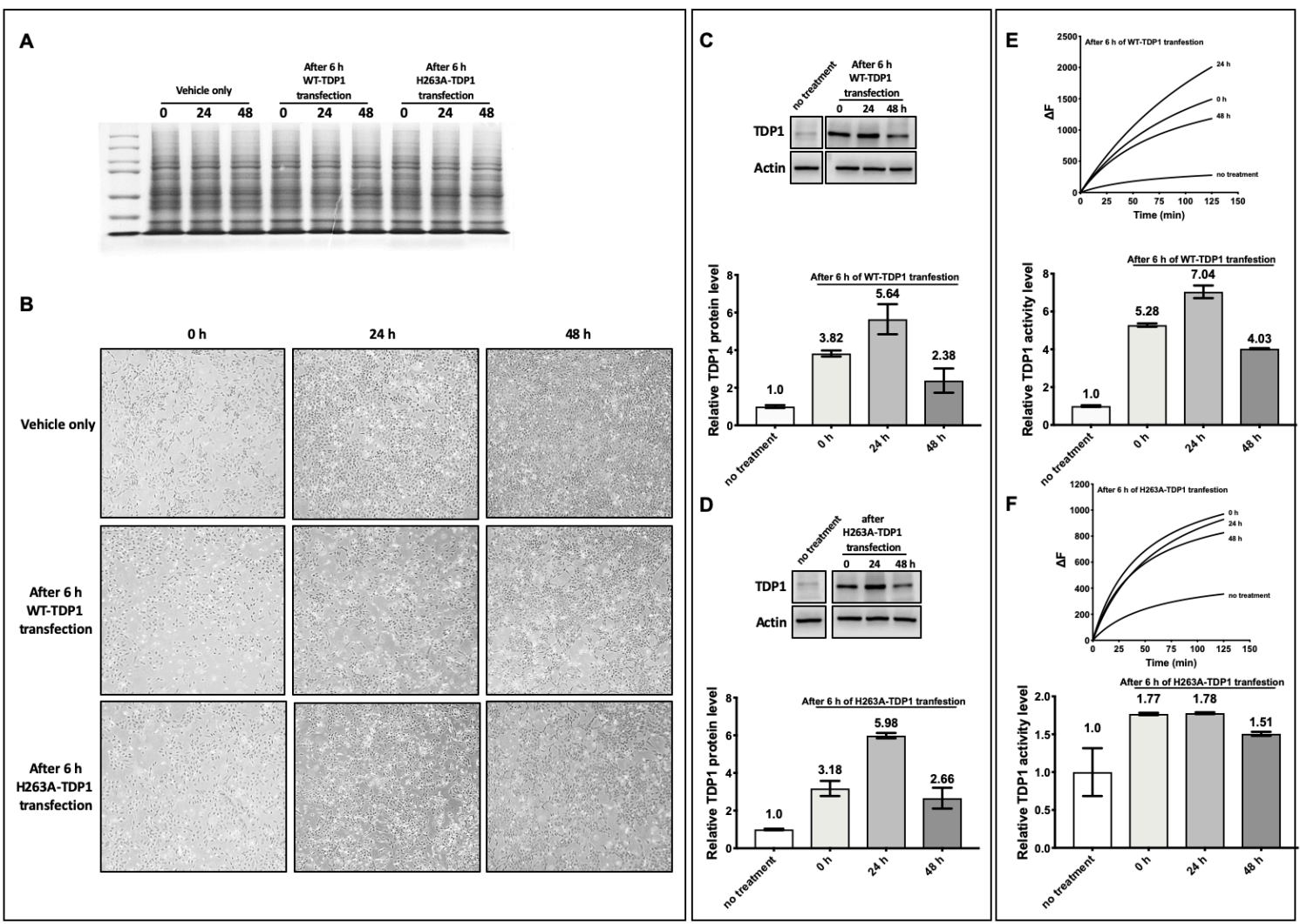

Figure 2.38. Time effects on post-transfection of TDP1 in $\mathrm{H} 4$ cell line

(A) Total protein expression level from $10 \mu \mathrm{g}$ of $\mathrm{H} 4$ cell line at 0,24 , and $48 \mathrm{~h}$ posttransfection with WT-TDP1 or mutant H263-TDP1 clones. (B) Microscopy images of $\mathrm{H} 4$ cells under $40 \times$ magnification at 0,24 , and $48 \mathrm{~h}$ post-transfection with lipid vehicle only, WT-TDP1 or mutant H263-TDP1 clones. The TDP1 protein expression from $10 \mu \mathrm{g}$ of $\mathrm{H} 4$ cell line at 0,24 , and $48 \mathrm{~h}$ post-transfection with (C) WT-TDP1 or (D) mutant H263-TDP1 clones. The TDP1 activity level from $1 \mathrm{\mu g}$ of $\mathrm{H} 4$ cell line at 0,24 , and $48 \mathrm{~h}$ post-transfection with (E) WT-TDP1 or (F) mutant H263-TDP1 clones. 


\section{CONCLUSION}

Glioblastoma is the most aggressive primary brain cancer with a poor prognosis and lack of predictive biomarkers for chemotherapeutic treatments (20). Investigations focusing on the improvement of GBM treatment outcomes by chemotherapy that employs topoisomerase I inhibitors, as well as other anticancer drugs, have been attempted in preclinical and clinical studies for decades. However, the basis of inconsistency in the observation of modest efficacy remains unclear. Irinotecan (IRT) acts as a prodrug of the active metabolite SN-38, which functions as a topoisomerase I poison stabilizing TOP1cc on chromosomal DNA to induce cell toxicity. With its ability to cross the blood-brain barrier (BBB), IRT is the focus of our study to find potential predictive biomarkers for GBM. Biomarkers in cancer cells have been sought for improving the diagnosis, prognosis, as well as predicting chemotherapeutic efficacy of cancer treatment. Genomics and proteomics are two main approaches for discovering promising biomarker and the overexpression of epidermal growth factor receptor (EGFR), promoter methylation on MGMT gene, and isocitrate dehydrogenase $(I D H)$ gene mutations, have been routinely tested as predictive biomarkers for clinical treatment of GBM $(107,108)$ with limitations. Different targets based on genetics, epigenetics, protein overexpression, and cellular subpopulations have been broadly explored to identify predictive biomarkers in GBM cancer treatment research (109).

Carboxylesterase 2 (CES2) is the primary enzyme responsible for converting IRT to its active form SN-38 and might also contribute to the efficacy in cancer treatment by IRT. From our study, we found that activity variation of CES2 in the 
GBM cell lines studied is relatively small and does not correlate with IRT sensitivities. The lack of CES2 expression variation in GBM cell lines was also further confirmed by the constant CES2 expression level in results available in the database for $\mathrm{NCl}-60 \mathrm{GBM}$ cancer cells. It has been reported that CPTs-induced degradation of TOP1, via SUMOylation and the ubiquitin-proteasome pathway (UPP), results in elevated drug resistance in cancer cells $(62,63)$. Although the degradation of TOP1cc is necessary for exposure of the phosphodiester linkage to TDP1 hydrolysis, the overall TOP1 proteolysis may reduce the TOP1 poison efficacy in cancer treatment (110). The mechanism of proteolytic processing of DNA-protein crosslinks (DPCs) in human cells is still not fully elucidated (111). We conducted experiments to measure the TOP1 protein expression and activity levels after IRT treatment. We observed no significant decrease of overall TOP1 levels and a consistent TOP1 activity level in GBM with $15 \mu \mathrm{M}$ IRT treatment for up to 22 hours (Figure 2.35), whereas the signal from TOP1cc trapped on the chromosome started to decrease within 30 minutes (Figure 2.34). The invariant CES2 activity level and lack of significant IRT-induced degradation of TOP1 protein pool, suggest that the TOP1cc repair activities need to be further investigated as determinants of IRT sensitivity in GBM.

Studies have reported the apoptotic TOP1cc can be stimulated by a wide range of exogenous factors, such as physiological ligands tumor necrosis factor related apoptosis-inducing ligand (TRAIL), reactive oxygen species (ROS), and TOP1 poisons $(43,112-114)$. The cytotoxicity from apoptotic TOP1cc induced by TOP1 poison IRT is closely associated with TOP1 and TDP1 levels. A study has 
proven that the overexpression of TDP1 or the depletion of TOP1 in colorectal cancer cell lines increased resistance to IRT treatment (115). Three out of nine clinical colorectal patients tumors with the highest TOP1 expression levels responded to IRT treatment in a preliminary study (116). Additionally, TOP1 activity increment by adenovirus Delta-24 infection of GBM cell lines enhanced the antiglioma effect of IRT treatment (90). As described above, TDP1 and TOP1 are expected to have opposite effects on IRT treatment outcome and numerous efforts have been devoted to demonstrating TDP1 or TOP1 level alone as potential biomarkers for cancer treatment. However, little effort has been spent on enzyme ratio or activity analysis for predictive biomarker discovery $(88,117)$. Meisenberg et al. reported that TDP1/TOP1 protein expression ratio correlated with IRT sensitivities in 8 out of 10 small cell lung cancer (SCLC) cell lines (88). Proszek et al. suggested that the combined measurement of TDP1 and TOP1 activity might be able to predict the CPT response on colorectal cancer cells (117). According to our data, the higher expression and activity level of TOP1 in comparison with NHA may indicate the significant role of TOP1 in GBM cell proliferation, the lower expression and activity level of TDP1 may reflect repair pathway deficiencies in cancer development which make GBM cancer cells more sensitive to IRT than NHA (Figure 2.39). Therefore, we evaluated the correlation of TOP1, TDP1, as well as TDP1/TOP1 ratio in protein, mRNA, and activity levels, with the variation of IRT cytotoxicity for GBM. The potential role of TDP1/TOP1 activity ratio has been highlighted for the first time in our study to find promising predictors of GBM response to IRT treatment. 
Remarkably, we found that both TDP1/TOP1 protein ratio and TDP1/TOP1 activity ratio correlate significantly with experimental $\mathrm{IC}_{50} \mathrm{~S}$, IRT sensitivities in databases, as well as fold-increase in TOP1cc levels with $15 \mathrm{~min}, 15 \mu \mathrm{M}$ IRT treatment in GBM cell lines (Table 2.13, 2.14, 2.19). In addition, by correlating TOP1/TOP1 protein ratios and activity ratios with GBM sensitivities to FDAapproved TOP1 poisons (CPT and TPT) (Table 2.15, 2.16) and TOP2 poisons (ETP and DOX) (Table 2.17, 2.18), the ratios are strongly correlated with TOP1 poisons whereas not with TOP2 poisons, suggesting TDP1/TOP1 ratios could specifically predict TOP1 poison induced cytotoxicity in GBM cell lines. The TDP1/TOP1 activity ratio has the strongest correlation in comparison to TDP1/TOP1 protein ratio, indicating TDP1/TOP1 activity ratio might be a promising predictive biomarker of GBM response to IRT treatment.

CellMinerCDB is a pharmacological and genomic analysis website which provides a wide range of information on cancer cell lines and has been used to identify genomic signatures for topoisomerase poisons (18). TDP1/TOP1 mRNA ratios, TDP1/TOP1 protein ratio and TDP1/TOP1 activity ratio are all comparable among different experimental sets (Table 2.20). However, neither TOP1, TDP1 mRNA alone, nor TDP1/TOP1 mRNA ratio, could correlate with Irinotecan sensitivities in GBM cell lines according to our analysis of the database information. The result might be explained by the lack of correlation between mRNA level and protein expression level of TOP1, TDP1, and TDP/TOP1 ratio in GBM cell lines studied here (Table 2.23). Besides, the limitation of sequencing analysis has been addressed and the inability to predict protein levels from mRNA levels has been 
widely observed (118). Our results suggest that the TOP1, TDP1 protein and activity levels in GBM cell lines might be more relevant than mRNA level for finding GBM biomarkers to predict the outcome of IRT treatment. Our analysis indicated that TDP1/TOP1 protein ratio and to a higher degree activity ratio, rather than mRNA ratio, could be promising biomarkers for IRT treatment.

In addition, according to the results from the WT-TDP1 transfection experiment, TOP1 expression and activity levels were not affected by the 5 -fold elevation of TDP1 expressions in transfected GBM cells which are resistant to IRT treatment (Figure 2.37). We also found no inherent relationship between TOP1 and TDP1, at either the protein level or activity level, can be observed for GBM cell lines (Table 2.21). Consistent with our experimental analysis, mRNA level of TOP1 and TDP1 also does not correlate with each other for three different sets of cancer cells with data available in CellMinerCDB database (Table 2.21). Furthermore, inhibition of TOP1 with $15 \mu \mathrm{M}$ IRT did not result in any significant changes in TDP1 expression and activity in measurements at up to $22 \mathrm{~h}$ of treatment (Figure 2.35). Thus, we can conclude that the protein level as well as the activity level of TOP1 and TDP1 are independent of each other. In addition, there is no evidence supporting the existence of overlapping signaling pathways of regulation of TDP and TOP1 in GBM cells. Therefore, TOP1 and TDP1 are two independent parameters that would determine the TDP1/TOP1 ratio as a biomarker.

Furthermore, we found that the TDP1/TOP1 activity ratio is superior to TDP1/TOP1 protein ratio as a predictor for the response of GBM cell lines to IRT treatment. We also observed that TOP1 protein level does not correlate with TOP1 
activity level. Although TDP1 protein and activity have a stronger correlation than TOP1, TDP1 protein levels are still not able to represent the activity levels in GBM cell lines (Table 2.22). The result might be explained by post-translational modifications (PTMs) that modulate the activity level of proteins by phosphorylation, acetylation, ubiquitylation, PARylation, SUMOylation, or glycosylation. Numerous investigations of PTMs that may regulate TOP1 activity have been conducted. It has been demonstrated that O-GIcNAcylation on TOP1 contributed to the elevation of TOP1 activity in porcine proximal tubular epithelial cells (LLC-PK1) (119). Bromodomain-containing protein 4 (BRD4)-dependent phosphorylation of RNA polymerase II (RNAPII) stimulates TOP1 activity according to enzyme assay results, and the combination treatment of BRD4 and TOP1 inhibitors could induce more cytotoxicity in colon colorectal cell line (120). It has also been reported that the increased activity of TOP 1 by hyperphosphorylation at T268 or S506 sensitized cancer cells to CPT-induced cytotoxicity $(91,92)$. We propose that the wear correlation between TOP1 protein and activity levels in GBM cell lines might due to the PTMs in GBM cell lines. In contrast, the lesser influence of PTMs on TDP1 activity might account for the stronger correlations between TDP1 protein and its activity level. According to the previous studies, majority of the PTMs of TDP1 is associated with the TDP1 catalytic activity dispensable N-terminal domain (1-148 residue), which promote TDP1 binding at DNA lesion sites and also enhance TDP1 association with other essential repair factors such as XRCC1, without affecting its catalytic activity (72-75). Only one recently published study reported that the methylation of R261 and R586 of TDP1 at its catalytic domain (149-608) enhances 
TDP1 activity and facilitates the association of XRCC1 with TDP1 to promote cancer cell survival in response to CPT treatment in colon carcinoma cell line (HCT116), human kidney origin (HEK293), and human breast cancer cell line (MCF7) models (76). Although, our experimental results showed a relatively strong correlation between TDP1/TOP1 protein ratio with its activity ratio in GBM cell lines (Table 2.22), assay of both protein and activity levels of TOP1 and TDP1 might still be necessary in order to optimize the cancer treatment. Additionally, TDP1 possesses the versatility of precisely hydrolyzing a variety of 3' adducts from DNA. Therefore, screening of TDP1 inhibitors and combination therapy with TOP1 poisons may produce promising treatment regimens for GBM. Advances in finding predictive biomarkers for cancer cells is a paradigm shift towards personalized cancer medicine (121). Thus, research based on clinical samples will be described in the following chapter. 


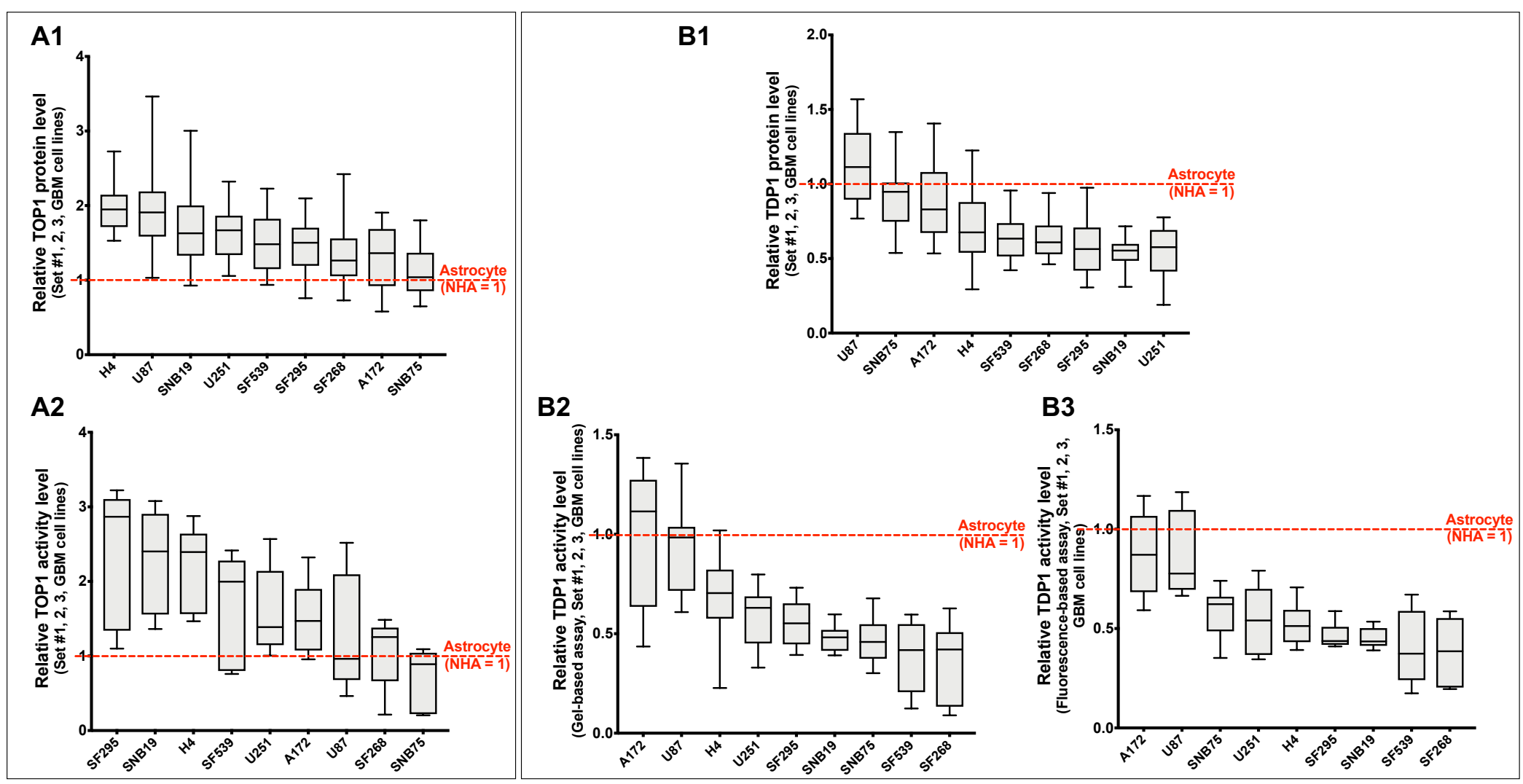

Figure 2.39. Protein expression level and activity level of TOP1 and TDP1 from all three sets of GBM cell line experiments

The box plots of (A1) TOP1 and (B1) TDP1 protein expression level from set \#1, \#2, \#3 GBM cell line experiments. The bar graphs of (A2) TOP1, (B2) gel-based TDP1, and (B3) fluorescence-based TDP1 activity level from set \#1, \#2, \#3 GBM cell line experiments. The box plots show the median of data from all three sets of experiments with minimum and maximum values at the bottom and top tail-ends. The relative levels were normalized to the levels present in NHA (red dotted line, relative ratio $=1$ ) 
Table 2.13. Correlation of experimental TOP1, TDP1, and TDP1/TOP1 ratio with experimental IC 50 of IRT in GBM cell lines

\begin{tabular}{|c|c|c|c|c|c|c|c|c|c|}
\hline \multicolumn{10}{|c|}{ Experimental IRT IC $\mathrm{C}_{50}$} \\
\hline \multirow{3}{*}{\multicolumn{2}{|c|}{ Cell type }} & \multicolumn{3}{|c|}{ vs Protein levels } & \multicolumn{5}{|c|}{ vs Activity levels } \\
\hline & & \multirow{2}{*}{ TOP1 protein } & \multirow{2}{*}{ TDP1 protein } & \multirow{2}{*}{$\begin{array}{l}\text { TDP1/TOP1 } \\
\text { protein ratio }\end{array}$} & \multirow{2}{*}{ TOP1 activity } & \multicolumn{2}{|c|}{ TDP1 activity } & \multicolumn{2}{|c|}{ TDP1/TOP1 activity ratio } \\
\hline & & & & & & Gel-based assay & FL-based assay & Gel-based assay & FL-based assay \\
\hline \multirow{4}{*}{$\begin{array}{l}\text { GBM cell } \\
\text { lines }\end{array}$} & Set \#1, GBM $(n=9)$ & $\begin{array}{c}\mathrm{R}=-0.254 ; \mathrm{P}=0.510 \\
(\mathrm{~ns})\end{array}$ & $\begin{array}{c}\mathrm{R}=0.797 ; \mathrm{P}=0.010 \\
\left({ }^{*}\right)\end{array}$ & $\begin{array}{c}\mathrm{R}=0.696 ; \mathrm{P}=0.037 \\
\left(^{*}\right)\end{array}$ & $\begin{array}{c}\mathrm{R}=-0.445 ; \mathrm{P}=0.230 \\
(\mathrm{~ns})\end{array}$ & $\begin{array}{c}\mathrm{R}=0.687 ; \mathrm{P}=0.041 \\
\left(^{*}\right)\end{array}$ & $\begin{array}{c}\mathrm{R}=0.729 ; \mathrm{P}=0.026 \\
\left(^{*}\right)\end{array}$ & $\begin{array}{c}\mathrm{R}=0.917 ; \mathrm{P}=0.0005 \\
(* * *)\end{array}$ & $\begin{array}{c}\mathrm{R}=0.922 ; \mathrm{P}=0.0004 \\
(* \star *)\end{array}$ \\
\hline & Set \#2, GBM $(n=9)$ & $\begin{array}{c}\mathrm{R}=0.139 ; \mathrm{P}=0.722 \\
\text { (ns) }\end{array}$ & $\begin{array}{c}\mathrm{R}=0.770 ; \mathrm{P}=0.015 \\
\left({ }^{*}\right)\end{array}$ & $\begin{array}{c}\mathrm{R}=0.698 ; \mathrm{P}=0.04 \\
\left(^{*}\right)\end{array}$ & $\begin{array}{c}\mathrm{R}=-0.660 ; \mathrm{P}=0.053 \\
(\mathrm{~ns})\end{array}$ & $\begin{array}{c}\mathrm{R}=0.389 ; \mathrm{P}=0.301 \\
(\mathrm{~ns})\end{array}$ & $\begin{array}{c}\mathrm{R}=0.461 ; \mathrm{P}=0.211 \\
(\mathrm{~ns})\end{array}$ & $\begin{array}{c}\mathrm{R}=0.940 ; \mathrm{P}=0.0001 \\
(* * *)\end{array}$ & $\begin{array}{c}\mathrm{R}=0.827 ; ; \mathrm{P}=0.006 \\
\left({ }^{* *}\right)\end{array}$ \\
\hline & Set \#3, GBM (n = 9) & $\begin{array}{c}\mathrm{R}=-0.294 ; \mathrm{P}=0.442 \\
(\mathrm{~ns})\end{array}$ & $\mathrm{R}=0.955 ; \mathrm{P}=5.8 \times 10^{-5}$ & $\begin{array}{c}\mathrm{R}=0.862 ; \mathrm{P}=0.003 \\
\left({ }^{\star *}\right)\end{array}$ & $\begin{array}{c}\mathrm{R}=0.464 ; \mathrm{P}=0.208 \\
(\mathrm{~ns})\end{array}$ & $\begin{array}{c}\mathrm{R}=0.565 ; \mathrm{P}=0.113 \\
(\mathrm{~ns})\end{array}$ & $\begin{array}{c}\mathrm{R}=0.841 ; \mathrm{P}=0.004 \\
\left({ }^{* *}\right)\end{array}$ & $\begin{array}{c}\mathrm{R}=0.860 ; \mathrm{P}=0.003 \\
\left({ }^{* *}\right)\end{array}$ & $\begin{array}{c}\mathrm{R}=0.953 ; \mathrm{P}=6.8 \times 10^{-5} \\
(* \star * \star)\end{array}$ \\
\hline & \begin{tabular}{|c|} 
Average of Set $\# 1$, \\
$2,3(n=9)$
\end{tabular} & $\begin{array}{c}\mathrm{R}=-0.139 ; \mathrm{P}=0.720 \\
(\mathrm{~ns})\end{array}$ & $\begin{array}{c}\mathrm{R}=0.863 ; \mathrm{P}=0.003 \\
\left({ }^{* *}\right)\end{array}$ & $\begin{array}{c}\mathrm{R}=0.744 ; \mathrm{P}=0.02 \\
\left(^{*}\right)\end{array}$ & $\begin{array}{c}\mathrm{R}=-0.665 ; \mathrm{P}=0.051 \\
(\mathrm{~ns})\end{array}$ & $\begin{array}{c}\mathrm{R}=0.585 ; \mathrm{P}=0.100 \\
(\mathrm{~ns})\end{array}$ & $\begin{array}{c}\mathrm{R}=0.829 ; \mathrm{P}=0.006 \\
\left({ }^{* *}\right)\end{array}$ & $\begin{array}{c}R=0.972 ; P=1.2 \times 10^{-5} \\
(* * * *)\end{array}$ & $\begin{array}{c}1 \\
R=0.952 ; P=7.7 \times 10^{-5} \\
(* \star * *)\end{array}$ \\
\hline
\end{tabular}

Table 2.14. Correlation of experimental TOP1, TDP1, and TDP1/TOP1 ratio with Z-score of IRT in GBM cell lines from CellMiner database

\begin{tabular}{|c|c|c|c|c|c|c|c|c|c|}
\hline \multicolumn{10}{|c|}{ Iriontecan Z-score of CellMiner } \\
\hline \multirow{3}{*}{\multicolumn{2}{|c|}{ Cell type }} & \multicolumn{3}{|c|}{ vs Protein levels } & \multicolumn{5}{|c|}{ vs Activity levels } \\
\hline & & \multirow{2}{*}{ TOP1 protein } & \multirow{2}{*}{ TDP1 protein } & \multirow{2}{*}{$\begin{array}{l}\text { TDP1/TOP1 } \\
\text { protein ratio }\end{array}$} & \multirow{2}{*}{ TOP1 activity } & \multicolumn{2}{|c|}{ TDP1 activity } & \multicolumn{2}{|c|}{ TDP1/TOP1 activity ratio } \\
\hline & & & & & & Gel-based assay & FL-based assay & Gel-based assay & FL-based assay \\
\hline \multirow{4}{*}{$\begin{array}{l}\text { GBM cell } \\
\text { lines }\end{array}$} & Set \#1, GBM $(n=9)$ & $\begin{array}{c}\mathrm{R}=0.330 ; \mathrm{P}=0.523 \\
(\mathrm{~ns})\end{array}$ & $\begin{array}{c}\mathrm{R}=-0.633 ; \mathrm{P}=0.177 \\
(\mathrm{~ns})\end{array}$ & $\begin{array}{c}\mathrm{R}=-0.620 ; \mathrm{P}=0.190 \\
(\mathrm{~ns})\end{array}$ & $\begin{array}{c}\mathrm{R}=0.174 ; \mathrm{P}=0.741 \\
(\mathrm{~ns})\end{array}$ & $\begin{array}{c}\mathrm{R}=-0.834 ; \mathrm{P}=0.039 \\
\left({ }^{*}\right)\end{array}$ & $\begin{array}{c}\mathrm{R}=-0.738 ; \mathrm{P}=0.094 \\
(\mathrm{~ns})\end{array}$ & $\begin{array}{c}\mathrm{R}=-0.916 ; \mathrm{P}=0.010 \\
\left({ }^{*}\right)\end{array}$ & $\begin{array}{c}\mathrm{R}=-0.862 ; \mathrm{P}=0.027 \\
\left({ }^{*}\right)\end{array}$ \\
\hline & Set \#2, GBM $(n=9)$ & $\begin{array}{c}\mathrm{R}=0.854 ; \mathrm{P}=0.030 \\
\left(^{*}\right)\end{array}$ & $\begin{array}{c}\mathrm{R}=-0.720 ; \mathrm{P}=0.107 \\
(\mathrm{~ns})\end{array}$ & $\begin{array}{c}\mathrm{R}=-0.788 ; \mathrm{P}=0.063 \\
(\mathrm{~ns})\end{array}$ & $\begin{array}{c}\mathrm{R}=0.422 ; \mathrm{P}=0.404 \\
(\mathrm{~ns})\end{array}$ & $\begin{array}{c}\mathrm{R}=-0.145 ; \mathrm{P}=0.783 \\
(\mathrm{~ns})\end{array}$ & $\begin{array}{c}\mathrm{R}=-0.247 ; \mathrm{P}=0.638 \\
(\mathrm{~ns})\end{array}$ & $\begin{array}{c}\mathrm{R}=-0.875 ; \mathrm{P}=0.022 \\
\left(^{*}\right)\end{array}$ & $\begin{array}{c}\mathrm{R}=-0.787 ; \mathrm{P}=0.063 \\
\text { (ns) }\end{array}$ \\
\hline & Set \#3, GBM $(n=9)$ & $\begin{array}{c}\mathrm{R}=0.604 ; \mathrm{P}=0.204 \\
\text { (ns) }\end{array}$ & $\begin{array}{c}\mathrm{R}=-0.861 ; \mathrm{P}=0.028 \\
\left(^{*}\right)\end{array}$ & $\begin{array}{c}\mathrm{R}=-0.905 ; \mathrm{P}=0.013 \\
\left(^{*}\right)\end{array}$ & $\begin{array}{c}\mathrm{R}=0.464 ; \mathrm{P}=0.352 \\
(\mathrm{~ns})\end{array}$ & $\begin{array}{c}\mathrm{R}=-0.335 ; \mathrm{P}=0.516 \\
(\mathrm{~ns})\end{array}$ & $\begin{array}{c}\mathrm{R}=-0.577 ; \mathrm{P}=0.231 \\
(\mathrm{~ns})\end{array}$ & $\begin{array}{c}\mathrm{R}=-0.640 ; \mathrm{P}=0.171 \\
(\mathrm{~ns})\end{array}$ & $\begin{array}{c}\mathrm{R}=-0.861 ; \mathrm{P}=0.028 \\
\left({ }^{*}\right)\end{array}$ \\
\hline & $\begin{array}{c}\text { Average of Set \#1, } \\
2,3(n=9)\end{array}$ & $\begin{array}{c}\mathrm{R}=0.642 ; \mathrm{P}=0.169 \\
(\mathrm{~ns})\end{array}$ & $\begin{array}{c}\mathrm{R}=-0.785 ; \mathrm{P}=0.065 \\
(\mathrm{~ns})\end{array}$ & $\begin{array}{c}\mathrm{R}=-0.740 ; \mathrm{P}=0.092 \\
(\mathrm{~ns})\end{array}$ & $\begin{array}{c}\mathrm{R}=0.447 ; \mathrm{P}=0.375 \\
(\mathrm{~ns})\end{array}$ & $\begin{array}{c}\mathrm{R}=-0.150 ; \mathrm{P}=0.777 \\
(\mathrm{~ns})\end{array}$ & $\begin{array}{c}\mathrm{R}=-0.769 ; \mathrm{P}=0.074 \\
(\mathrm{~ns})\end{array}$ & $\begin{array}{c}\mathrm{R}=-0.871 ; \mathrm{P}=0.024 \\
\left(^{*}\right)\end{array}$ & $\begin{array}{c}\mathrm{R}=-0.862 ; \mathrm{P}=0.027 \\
\left({ }^{*}\right)\end{array}$ \\
\hline
\end{tabular}


Table 2.15. Correlation of experimental TOP1, TDP1, and TDP1/TOP1 ratio with Z-score of Camptothecin in GBM cell lines from CellMiner database

\begin{tabular}{|c|c|c|c|c|c|c|c|c|c|}
\hline \multicolumn{10}{|c|}{ Camptothecin Z-score of CellMiner } \\
\hline \multirow{3}{*}{\multicolumn{2}{|c|}{ Cell type }} & \multicolumn{3}{|c|}{ vs Protein levels } & \multicolumn{5}{|c|}{ vs Activity levels } \\
\hline & & \multirow{2}{*}{ TOP1 protein } & \multirow{2}{*}{ TDP1 protein } & \multirow{2}{*}{$\begin{array}{l}\text { TDP1/TOP1 } \\
\text { protein ratio }\end{array}$} & \multirow{2}{*}{ TOP1 activity } & \multicolumn{2}{|c|}{ TDP1 activity } & \multicolumn{2}{|c|}{ TDP1/TOP1 activity ratio } \\
\hline & & & & & & Gel-based assay & FL-based assay & Gel-based assay & FL-based assay \\
\hline \multirow{4}{*}{$\begin{array}{l}\text { GBM cell } \\
\text { lines }\end{array}$} & Set \#1, GBM $(n=9)$ & $\begin{array}{c}\mathrm{R}=0.506 ; \mathrm{P}=0.306 \\
(\mathrm{~ns})\end{array}$ & $\begin{array}{c}\mathrm{R}=-0.862 ; \mathrm{P}=0.027 \\
\left.{ }^{*}\right)\end{array}$ & $\begin{array}{c}\mathrm{R}=-0.790 ; \mathrm{P}=0.061 \\
(\mathrm{~ns})\end{array}$ & $\begin{array}{c}\mathrm{R}=0.560 ; \mathrm{P}=0.248 \\
(\mathrm{~ns})\end{array}$ & $\begin{array}{c}\mathrm{R}=-0.526 ; \mathrm{P}=0.284 \\
(\mathrm{~ns})\end{array}$ & $\begin{array}{c}R=-0.465 ; P=0.353 \\
(n s)\end{array}$ & $\begin{array}{c}\mathrm{R}=-0.861 ; \mathrm{P}=0.028 \\
\left(^{*}\right)\end{array}$ & $\begin{array}{c}\mathrm{R}=-0.832 ; \mathrm{P}=0.040 \\
\left({ }^{*}\right)\end{array}$ \\
\hline & Set \#2, GBM $(n=9)$ & $\begin{array}{c}\mathrm{R}=0.950 ; \mathrm{P}=0.004 \\
\left({ }^{* *}\right)\end{array}$ & $\begin{array}{c}\mathrm{R}=-0.859 ; \mathrm{P}=0.028 \\
\left(^{*}\right)\end{array}$ & $\begin{array}{c}\mathrm{R}=-0.889 ; \mathrm{P}=0.018 \\
\left(^{*}\right)\end{array}$ & $\begin{array}{c}\mathrm{R}=0.415 ; \mathrm{P}=0.413 \\
(\mathrm{~ns})\end{array}$ & $\begin{array}{c}\mathrm{R}=-0.182 ; \mathrm{P}=0.731 \\
(\mathrm{~ns})\end{array}$ & $\begin{array}{c}\mathrm{R}=-0.174 ; \mathrm{P}=0.741 \\
(\mathrm{~ns})\end{array}$ & $\begin{array}{c}\mathrm{R}=-0.866 ; \mathrm{P}=0.026 \\
\left(^{*}\right)\end{array}$ & $\begin{array}{c}\mathrm{R}=-0.778 ; \mathrm{P}=0.068 \\
(\mathrm{~ns})\end{array}$ \\
\hline & Set \#3, GBM $(n=9)$ & $\begin{array}{c}\mathrm{R}=0.546 ; \mathrm{P}=0.263 \\
(\mathrm{~ns})\end{array}$ & $\begin{array}{c}\mathrm{R}=-0.900 ; \mathrm{P}=0.014 \\
\left(^{*}\right)\end{array}$ & $\begin{array}{c}\mathrm{R}=-0.901 ; \mathrm{P}=0.014 \\
\left(^{*}\right)\end{array}$ & $\begin{array}{c}\mathrm{R}=0.556 ; \mathrm{P}=0.252 \\
\text { (ns) }\end{array}$ & $\begin{array}{c}\mathrm{R}=-0.535 ; \mathrm{P}=0.274 \\
(\mathrm{~ns})\end{array}$ & $\begin{array}{c}\mathrm{R}=-0.498 ; \mathrm{P}=0.315 \\
(\mathrm{~ns})\end{array}$ & $\begin{array}{c}\mathrm{R}=-0.615 ; \mathrm{P}=0.194 \\
(\mathrm{~ns})\end{array}$ & $\begin{array}{c}\mathrm{R}=-0.862 ; \mathrm{P}=0.027 \\
\left(^{*}\right)\end{array}$ \\
\hline & $\begin{array}{c}\text { Average of Set \#1, } \\
2,3(n=9)\end{array}$ & $\begin{array}{c}\mathrm{R}=0.701 ; \mathrm{P}=0.120 \\
(\mathrm{~ns})\end{array}$ & $\begin{array}{c}\mathrm{R}=-0.914 ; \mathrm{P}=0.011 \\
(\mathrm{~ns})\end{array}$ & $\begin{array}{c}\mathrm{R}=-0.845 ; \mathrm{P}=0.034 \\
\left(^{*}\right)\end{array}$ & $\begin{array}{c}\mathrm{R}=0.564 ; \mathrm{P}=0.243 \\
(\mathrm{~ns})\end{array}$ & $\begin{array}{c}\mathrm{R}=-0.153 ; \mathrm{P}=0.772 \\
(\mathrm{~ns})\end{array}$ & $\begin{array}{c}\mathrm{R}=-0.594 ; \mathrm{P}=0.214 \\
(\mathrm{~ns})\end{array}$ & $\begin{array}{c}R=-0.853 ; P=0.031 \\
\left(^{*}\right)\end{array}$ & $\begin{array}{c}\mathrm{R}=-0.847 ; \mathrm{P}=0.033 \\
\left(^{*}\right)\end{array}$ \\
\hline
\end{tabular}

Table 2.16. Correlation of experimental TOP1, TDP1, and TDP1/TOP1 ratio with Z-score of Topotecan in GBM cell lines from CellMiner database

\begin{tabular}{|c|c|c|c|c|c|c|c|c|c|}
\hline \multicolumn{10}{|c|}{ Topotecan Z-score of CellMiner } \\
\hline \multirow{3}{*}{\multicolumn{2}{|c|}{ Cell type }} & \multicolumn{3}{|c|}{ vs Protein levels } & \multicolumn{5}{|c|}{ vs Activity levels } \\
\hline & & \multirow{2}{*}{ TOP1 protein } & \multirow{2}{*}{ TDP1 protein } & \multirow{2}{*}{$\begin{array}{l}\text { TDP1/TOP1 } \\
\text { protein ratio }\end{array}$} & \multirow{2}{*}{ TOP1 activity } & \multicolumn{2}{|c|}{ TDP1 activity } & \multicolumn{2}{|c|}{ TDP1/TOP1 activity ratio } \\
\hline & & & & & & Gel-based assay & FL-based assay & Gel-based assay & FL-based assay \\
\hline \multirow{4}{*}{$\begin{array}{l}\text { GBM cell } \\
\text { lines }\end{array}$} & Set \#1, GBM $(n=9)$ & $\begin{array}{c}\mathrm{R}=0.308 ; \mathrm{P}=0.553 \\
(\mathrm{~ns})\end{array}$ & $\begin{array}{c}\mathrm{R}=-0.652 ; \mathrm{P}=0.160 \\
(\mathrm{~ns})\end{array}$ & $\begin{array}{c}\mathrm{R}=-0.611 ; \mathrm{P}=0.178 \\
(\mathrm{~ns})\end{array}$ & $\begin{array}{c}\mathrm{R}=0.232 ; \mathrm{P}=0.659 \\
(\mathrm{~ns})\end{array}$ & $\begin{array}{c}\mathrm{R}=-0.702 ; \mathrm{P}=0.120 \\
(\mathrm{~ns})\end{array}$ & $\begin{array}{c}R=-0.626 ; P=0.183 \\
(n s)\end{array}$ & $\mathrm{R}=-0.837 ; \mathrm{P}=0.038$ & $\begin{array}{c}\mathrm{R}=-0.797 ; \mathrm{P}=0.058 \\
\text { (ns) }\end{array}$ \\
\hline & Set \#2, GBM $(n=9)$ & $\begin{array}{c}\mathrm{R}=0.898 ; \mathrm{P}=0.015 \\
\left(^{*}\right)\end{array}$ & $\begin{array}{c}\mathrm{R}=-0.789 ; \mathrm{P}=0.062 \\
(\mathrm{~ns})\end{array}$ & $\begin{array}{c}\mathrm{R}=-0.867 ; \mathrm{P}=0.025 \\
\left(^{\star}\right)\end{array}$ & $\begin{array}{c}\mathrm{R}=0.392 ; \mathrm{P}=0.433 \\
\text { (ns) }\end{array}$ & $\begin{array}{c}\mathrm{R}=-0.193 ; \mathrm{P}=0.714 \\
(\mathrm{~ns})\end{array}$ & $\begin{array}{c}\mathrm{R}=-0.234 ; \mathrm{P}=0.656 \\
(\mathrm{~ns})\end{array}$ & $\begin{array}{c}\mathrm{R}=-0.820 ; \mathrm{P}=0.045 \\
\left({ }^{*}\right)\end{array}$ & $\begin{array}{c}\mathrm{R}=-0.734 ; \mathrm{P}=0.096 \\
(\mathrm{~ns})\end{array}$ \\
\hline & Set \#3, GBM $(n=9)$ & $\begin{array}{c}\mathrm{R}=0.437 ; \mathrm{P}=0.387 \\
\text { (ns) }\end{array}$ & $\mathrm{R}=-0.824 ; \mathrm{P}=0.044$ & $\mathrm{R}=-0.844 ; \mathrm{P}=0.034$ & $\begin{array}{c}\mathrm{R}=0.455 ; \mathrm{P}=0.365 \\
\text { (ns) }\end{array}$ & $\begin{array}{c}\mathrm{R}=-0.478 ; \mathrm{P}=0.337 \\
(\mathrm{~ns})\end{array}$ & $\begin{array}{c}\mathrm{R}=-0.502 ; \mathrm{P}=0.310 \\
\text { (ns) }\end{array}$ & $\begin{array}{c}\mathrm{R}=-0.550 ; \mathrm{P}=0.259 \\
\text { (ns) }\end{array}$ & $\left.R=-0.881 ; P=0.05 \quad{ }^{*}\right)$ \\
\hline & $\begin{array}{c}\text { Average of Set \#1, } \\
2,3(n=9)\end{array}$ & $\begin{array}{c}\mathrm{R}=0.562 ; \mathrm{P}=0.245 \\
(\mathrm{~ns})\end{array}$ & $\begin{array}{c}\mathrm{R}=-0.786 ; \mathrm{P}=0.064 \\
(\mathrm{~ns})\end{array}$ & $\begin{array}{c}\mathrm{R}=-0.711 ; \mathrm{P}=0.113 \\
(*)\end{array}$ & $\begin{array}{c}\mathrm{R}=0.444 ; \mathrm{P}=0.377 \\
\text { (ns) }\end{array}$ & $\begin{array}{c}\mathrm{R}=-0.011 ; \mathrm{P}=0.983 \\
(\mathrm{~ns})\end{array}$ & $\begin{array}{c}\mathrm{R}=-0.661 ; \mathrm{P}=0.153 \\
(\mathrm{~ns})\end{array}$ & $\begin{array}{c}\mathrm{R}=-0.803 ; \mathrm{P}=0.068 \\
(\mathrm{~ns})\end{array}$ & $\begin{array}{c}\mathrm{R}=-0.804 ; \mathrm{P}=0.054 \\
\text { (ns) }\end{array}$ \\
\hline
\end{tabular}


Table 2.17. Correlation of experimental TOP1, TDP1, and TDP1/TOP1 ratio with Z-score of Etoposide in GBM cell lines from CellMiner database

\begin{tabular}{|c|c|c|c|c|c|c|c|c|c|}
\hline \multicolumn{10}{|c|}{ Etoposide Z-score of CellMiner } \\
\hline \multirow{3}{*}{\multicolumn{2}{|c|}{ Cell type }} & \multicolumn{3}{|c|}{ vs Protein levels } & \multicolumn{5}{|c|}{ vs Activity levels } \\
\hline & & \multirow{2}{*}{ TOP1 protein } & \multirow{2}{*}{ TDP1 protein } & \multirow{2}{*}{$\begin{array}{l}\text { TDP1/TOP1 } \\
\text { protein ratio }\end{array}$} & \multirow{2}{*}{ TOP1 activity } & \multicolumn{2}{|c|}{ TDP1 activity } & \multicolumn{2}{|c|}{ TDP1/TOP1 activity ratio } \\
\hline & & & & & & Gel-based assay & FL-based assay & Gel-based assay & FL-based assay \\
\hline \multirow{4}{*}{$\begin{array}{l}\text { GBM cell } \\
\text { lines }\end{array}$} & Set \#1, GBM $(n=9)$ & $\begin{array}{c}\mathrm{R}=0.667 ; \mathrm{P}=0.148 \\
(\mathrm{~ns})\end{array}$ & $\begin{array}{c}\mathrm{R}=-0.459 ; \mathrm{P}=0.360 \\
(\mathrm{~ns})\end{array}$ & $\begin{array}{c}\mathrm{R}=-0.643 ; \mathrm{P}=0.169 \\
(\mathrm{~ns})\end{array}$ & $\begin{array}{c}\mathrm{R}=0.032 ; \mathrm{P}=0.952 \\
\text { (ns) }\end{array}$ & $\begin{array}{c}\mathrm{R}=-0.779 ; \mathrm{P}=0.068 \\
(\mathrm{~ns})\end{array}$ & $\begin{array}{c}\mathrm{R}=-0.902 ; \mathrm{P}=0.014 \\
\left(^{\star}\right)\end{array}$ & $\begin{array}{c}\mathrm{R}=-0.687 ; \mathrm{P}=0.132 \\
(\mathrm{~ns})\end{array}$ & $\begin{array}{c}\mathrm{R}=-0.781 ; \mathrm{P}=0.067 \\
(\mathrm{~ns})\end{array}$ \\
\hline & Set \#2, GBM $(n=9)$ & $\begin{array}{c}\mathrm{R}=0.619 ; \mathrm{P}=0.190 \\
\left(^{*}\right)\end{array}$ & $\begin{array}{c}\mathrm{R}=-0.773 ; \mathrm{P}=0.071 \\
(\mathrm{~ns})\end{array}$ & $\begin{array}{c}\mathrm{R}=-0.768 ; \mathrm{P}=0.075 \\
(\mathrm{~ns})\end{array}$ & $\begin{array}{c}\mathrm{R}=0.773 ; \mathrm{P}=0.072 \\
(\mathrm{~ns})\end{array}$ & $\begin{array}{c}\mathrm{R}=-0.865 ; \mathrm{P}=0.026 \\
\left(^{*}\right)\end{array}$ & $\begin{array}{c}\mathrm{R}=-0.900 ; \mathrm{P}=0.014 \\
\left(^{*}\right)\end{array}$ & $\begin{array}{c}\mathrm{R}=-0.614 ; \mathrm{P}=0.195 \\
(\mathrm{~ns})\end{array}$ & $\begin{array}{c}\mathrm{R}=-0.763 ; \mathrm{P}=0.078 \\
(\mathrm{~ns})\end{array}$ \\
\hline & Set \#3, GBM $(n=9)$ & $\begin{array}{c}\mathrm{R}=0.074 ; \mathrm{P}=0.890 \\
\text { (ns) }\end{array}$ & $\begin{array}{c}\mathrm{R}=-0.606 ; \mathrm{P}=0.202 \\
(\mathrm{~ns})\end{array}$ & $\begin{array}{c}\mathrm{R}=-0.510 ; \mathrm{P}=0.302 \\
(\mathrm{~ns})\end{array}$ & $\begin{array}{c}\mathrm{R}=0.774 ; \mathrm{P}=0.070 \\
(\mathrm{~ns})\end{array}$ & $\begin{array}{c}\mathrm{R}=-0.745 ; \mathrm{P}=0.089 \\
(\mathrm{~ns})\end{array}$ & $\begin{array}{c}\mathrm{R}=-0.152 ; \mathrm{P}=0.774 \\
(\mathrm{~ns})\end{array}$ & $\begin{array}{c}\mathrm{R}=-0.710 ; \mathrm{P}=0.114 \\
(\mathrm{~ns})\end{array}$ & $\begin{array}{c}\mathrm{R}=-0.446 ; \mathrm{P}=0.375 \\
\left({ }^{*}\right)\end{array}$ \\
\hline & $\begin{array}{c}\text { Average of Set \#1, } \\
2,3(n=9)\end{array}$ & $\begin{array}{c}\mathrm{R}=0.688 ; \mathrm{P}=0.130 \\
(\mathrm{~ns})\end{array}$ & $\begin{array}{c}\mathrm{R}=-0.635 ; \mathrm{P}=0.176 \\
(\mathrm{~ns})\end{array}$ & $\begin{array}{c}\mathrm{R}=-0.672 ; \mathrm{P}=0.143 \\
(\mathrm{~ns})\end{array}$ & $\begin{array}{c}\mathrm{R}=0.703 ; \mathrm{P}=0.119 \\
(\mathrm{~ns})\end{array}$ & $\begin{array}{c}\mathrm{R}=-0.464 ; \mathrm{P}=0.354 \\
(\mathrm{~ns})\end{array}$ & $\begin{array}{c}\mathrm{R}=-0.116 ; \mathrm{P}=0.826 \\
(\mathrm{~ns})\end{array}$ & $\begin{array}{c}\mathrm{R}=-0.627 ; \mathrm{P}=0.183 \\
(\mathrm{~ns})\end{array}$ & $\begin{array}{c}\mathrm{R}=-0.699 ; \mathrm{P}=0.122 \\
\text { (ns) }\end{array}$ \\
\hline
\end{tabular}

Table 2.18. Correlation of experimental TOP1, TDP1, and TDP1/TOP1 ratio with Z-score of Doxorubicin in GBM cell lines from CellMiner database

\begin{tabular}{|c|c|c|c|c|c|c|c|c|c|}
\hline \multicolumn{10}{|c|}{ Doxorubicin Z-score of CellMiner } \\
\hline \multirow{3}{*}{\multicolumn{2}{|c|}{ Cell type }} & \multicolumn{3}{|c|}{ vs Protein levels } & \multicolumn{5}{|c|}{ vs Activity levels } \\
\hline & & \multirow{2}{*}{ TOP1 protein } & \multirow{2}{*}{ TDP1 protein } & \multirow{2}{*}{$\begin{array}{l}\text { TDP1/TOP1 } \\
\text { protein ratio }\end{array}$} & \multirow{2}{*}{ TOP1 activity } & \multicolumn{2}{|c|}{ TDP1 activity } & \multicolumn{2}{|c|}{ TDP1/TOP1 activity ratio } \\
\hline & & & & & & Gel-based assay & FL-based assay & Gel-based assay & FL-based assay \\
\hline \multirow{4}{*}{$\begin{array}{l}\text { GBM cell } \\
\text { lines }\end{array}$} & Set \#1, GBM $(n=9)$ & $\begin{array}{c}\mathrm{R}=0.770 ; \mathrm{P}=0.073 \\
(\mathrm{~ns})\end{array}$ & $\begin{array}{c}\mathrm{R}=-0.278 ; \mathrm{P}=0.593 \\
(\mathrm{~ns})\end{array}$ & $\begin{array}{c}\mathrm{R}=-0.464 ; \mathrm{P}=0.354 \\
(\mathrm{~ns})\end{array}$ & $\begin{array}{c}\mathrm{R}=0.254 ; \mathrm{P}=0.628 \\
(\mathrm{~ns})\end{array}$ & $\begin{array}{c}\mathrm{R}=-0.030 ; \mathrm{P}=0.954 \\
(\mathrm{~ns})\end{array}$ & $\begin{array}{c}\mathrm{R}=-0.244 ; \mathrm{P}=0.641 \\
(\mathrm{~ns})\end{array}$ & $\begin{array}{c}\mathrm{R}=-0.105 ; \mathrm{P}=0.842 \\
(\mathrm{~ns})\end{array}$ & $\begin{array}{c}\mathrm{R}=-0.255 ; \mathrm{P}=0.625 \\
\text { (ns) }\end{array}$ \\
\hline & Set \#2, GBM $(n=9)$ & $\begin{array}{c}\mathrm{R}=0.023 ; \mathrm{P}=0.966 \\
\left(^{\star}\right)\end{array}$ & $\begin{array}{c}\mathrm{R}=-0.344 ; \mathrm{P}=0.505 \\
(\mathrm{~ns})\end{array}$ & $\begin{array}{c}\mathrm{R}=-0.197 ; \mathrm{P}=0.708 \\
(\mathrm{~ns})\end{array}$ & $\begin{array}{c}\mathrm{R}=0.366 ; \mathrm{P}=0.476 \\
(\mathrm{~ns})\end{array}$ & $\begin{array}{c}\mathrm{R}=-0.746 ; \mathrm{P}=0.089 \\
(\mathrm{~ns})\end{array}$ & $\begin{array}{c}\mathrm{R}=-0.787 ; \mathrm{P}=0.081 \\
(\mathrm{~ns})\end{array}$ & $\begin{array}{c}\mathrm{R}=-0.014 ; \mathrm{P}=0.980 \\
(\mathrm{~ns})\end{array}$ & $\begin{array}{c}\mathrm{R}=-0.196 ; \mathrm{P}=0.710 \\
(\mathrm{~ns})\end{array}$ \\
\hline & Set \#3, GBM $(n=9)$ & $\begin{array}{c}\mathrm{R}=0.175 ; \mathrm{P}=0.740 \\
\text { (ns) }\end{array}$ & $\begin{array}{c}\mathrm{R}=-0.038 ; \mathrm{P}=0.944 \\
(\mathrm{~ns})\end{array}$ & $\begin{array}{c}\mathrm{R}=-0.089 ; \mathrm{P}=0.867 \\
(\mathrm{~ns})\end{array}$ & $\begin{array}{c}\mathrm{R}=0.478 ; \mathrm{P}=0.340 \\
(\mathrm{~ns})\end{array}$ & $\begin{array}{c}\mathrm{R}=-0.552 ; \mathrm{P}=0.256 \\
(\mathrm{~ns})\end{array}$ & $\begin{array}{c}\mathrm{R}=-0.706 ; \mathrm{P}=0.117 \\
(\mathrm{~ns})\end{array}$ & $\begin{array}{c}\mathrm{R}=-0.265 ; \mathrm{P}=0.611 \\
(\mathrm{~ns})\end{array}$ & $\begin{array}{c}\mathrm{R}=-0.194 ; \mathrm{P}=0.712 \\
(\mathrm{~ns})\end{array}$ \\
\hline & $\begin{array}{c}\text { Average of Set \#1, } \\
2,3(n=9)\end{array}$ & $\begin{array}{c}\mathrm{R}=0.505 ; \mathrm{P}=0.307 \\
\text { (ns) }\end{array}$ & $\begin{array}{c}\mathrm{R}=-0.247 ; \mathrm{P}=0.637 \\
(\mathrm{~ns})\end{array}$ & $\begin{array}{c}\mathrm{R}=-0.362 ; \mathrm{P}=0.480 \\
(\mathrm{~ns})\end{array}$ & $\begin{array}{c}\mathrm{R}=0.417 ; \mathrm{P}=0.411 \\
(\mathrm{~ns})\end{array}$ & $\begin{array}{c}\mathrm{R}=-0.736 ; \mathrm{P}=0.096 \\
(\mathrm{~ns})\end{array}$ & $\begin{array}{c}\mathrm{R}=-0.604 ; \mathrm{P}=0.204 \\
(\mathrm{~ns})\end{array}$ & $\begin{array}{c}\mathrm{R}=-0.029 ; \mathrm{P}=0.956 \\
(\mathrm{~ns})\end{array}$ & $\begin{array}{c}\mathrm{R}=-0.097 ; \mathrm{P}=0.856 \\
\text { (ns) }\end{array}$ \\
\hline
\end{tabular}

Table 2.19. Correlation of experimental TOP1, TDP1, and TDP1/TOP1 ratio with fold-increase in TOP1cc level at $15 \mathrm{~min}, 30 \mathrm{~min}$, and $60 \mathrm{~min}$ following $15 \mu \mathrm{M}$ IRT treatment of GBM cell lines 


\begin{tabular}{|c|c|c|c|c|c|c|c|c|c|c|}
\hline \multicolumn{11}{|c|}{ Fold-increase in TOP1cc level at $15 \mathrm{~min}$} \\
\hline \multirow{3}{*}{\multicolumn{2}{|c|}{ Cell type }} & \multicolumn{3}{|c|}{ vs Protein levels } & \multicolumn{5}{|c|}{ vs Activity levels } & \multirow{3}{*}{ vs IC $\mathrm{C}_{50}$} \\
\hline & & \multirow{2}{*}{ TOP1 protein } & \multirow{2}{*}{ TDP1 protein } & \multirow{2}{*}{$\begin{array}{l}\text { TDP1/TOP1 } \\
\text { protein ratio }\end{array}$} & \multirow{2}{*}{ TOP1 activity } & \multicolumn{2}{|c|}{ TDP1 activity } & \multicolumn{2}{|c|}{ TDP1/TOP1 activity ratio } & \\
\hline & & & & & & Gel-based assay & FL-based assay & Gel-based assay & FL-based assay & \\
\hline \multirow{4}{*}{$\begin{array}{l}\text { GBM cell } \\
\text { lines }\end{array}$} & Set \#1, GBM $(n=9)$ & $\begin{array}{c}\mathrm{R}=0.606 ; \mathrm{P}=0.278 \\
(\mathrm{~ns})\end{array}$ & $\begin{array}{c}\mathrm{R}=-0.980 ; \mathrm{P}=0.0033 \\
\left({ }^{\star *}\right)\end{array}$ & $\begin{array}{c}\mathrm{R}=-0.873 ; \mathrm{P}=0.053 \\
(\mathrm{~ns})\end{array}$ & $\begin{array}{c}\mathrm{R}=0.664 ; \mathrm{P}=0.222 \\
(\mathrm{~ns})\end{array}$ & $\begin{array}{c}\mathrm{R}=-0.750 ; \mathrm{P}=0.144 \\
(\mathrm{~ns})\end{array}$ & $\begin{array}{c}\mathrm{R}=-0.934 ; \mathrm{P}=0.020 \\
\left({ }^{*}\right)\end{array}$ & $\begin{array}{c}\mathrm{R}=-0.966 ; \mathrm{P}=0.0074 \\
\left({ }^{* *}\right)\end{array}$ & $\begin{array}{c}\mathrm{R}=-0.942 ; \mathrm{P}=0.017 \\
\left(^{*}\right)\end{array}$ & \multirow{4}{*}{$\begin{array}{c}R=-0.892 ; P=0.042 \\
\left({ }^{*}\right)\end{array}$} \\
\hline & Set \#2, GBM $(n=9)$ & $\begin{array}{c}R=0.336 ; P=0.557 \\
(n s)\end{array}$ & $\begin{array}{c}\mathrm{R}=-0.926 ; \mathrm{P}=0.024 \\
(*)\end{array}$ & $\begin{array}{c}\mathrm{R}=-0.873 ; \mathrm{P}=0.053 \\
(\mathrm{~ns})\end{array}$ & $\begin{array}{c}\mathrm{R}=0.829 ; \mathrm{P}=0.083 \\
(\mathrm{~ns})\end{array}$ & $\begin{array}{c}\mathrm{R}=-0.299 ; \mathrm{P}=0.625 \\
(\mathrm{~ns})\end{array}$ & $\begin{array}{c}\mathrm{R}=-0.307 ; \mathrm{P}=0.615 \\
(\mathrm{~ns})\end{array}$ & $\begin{array}{c}\mathrm{R}=-0.838 ; \mathrm{P}=0.076 \\
(\mathrm{~ns})\end{array}$ & $\begin{array}{c}R=-0.756 ; P=0.139 \\
(n s)\end{array}$ & \\
\hline & Set \#3, GBM $(n=9)$ & $\begin{array}{c}\mathrm{R}=0.629 ; \mathrm{P}=0.256 \\
(\mathrm{~ns})\end{array}$ & $\begin{array}{c}\mathrm{R}=-0.889 ; \mathrm{P}=0.044 \\
\left(^{*}\right)\end{array}$ & $\begin{array}{c}\mathrm{R}=-0.792 ; \mathrm{P}=0.110 \\
(\mathrm{~ns})\end{array}$ & $\begin{array}{c}\mathrm{R}=0.901 ; \mathrm{P}=0.037 \\
\left(^{*}\right)\end{array}$ & $\begin{array}{c}\mathrm{R}=-0.356 ; \mathrm{P}=0.557 \\
(\mathrm{~ns})\end{array}$ & $\begin{array}{c}\mathrm{R}=-0.754 ; \mathrm{P}=0.140 \\
(\mathrm{~ns})\end{array}$ & $\begin{array}{c}\mathrm{R}=-0.892 ; \mathrm{P}=0.047 \\
\left.{ }^{*}\right)\end{array}$ & $\begin{array}{c}\mathrm{R}=-0.926 ; \mathrm{P}=0.024 \\
\left(^{*}\right)\end{array}$ & \\
\hline & \begin{tabular}{|c|} 
Average of Set $\# 1$, \\
$2,3(n=9)$
\end{tabular} & $\begin{array}{c}\mathrm{R}=0.529 ; \mathrm{P}=0.370 \\
(\mathrm{~ns})\end{array}$ & $\begin{array}{c}\mathrm{R}=-0.994 ; \mathrm{P}=0.0006 \\
(* \star)\end{array}$ & $\begin{array}{c}\mathrm{R}=-0.111 ; \mathrm{P}=0.870 \\
(\mathrm{~ns})\end{array}$ & $\begin{array}{c}\mathrm{R}=0.417 ; \mathrm{P}=0.411 \\
(\mathrm{~ns})\end{array}$ & $\begin{array}{c}\mathrm{R}=-0.745 ; \mathrm{P}=0.149 \\
(\mathrm{~ns})\end{array}$ & $\begin{array}{c}\mathrm{R}=-0.899 ; \mathrm{P}=0.038 \\
\left({ }^{*}\right)\end{array}$ & $\begin{array}{c}\mathrm{R}=-0.932 ; \mathrm{P}=0.021 \\
\left.{ }^{*}\right)\end{array}$ & $\begin{array}{c}\mathrm{R}=-0.885 ; \mathrm{P}=0.046 \\
\left(^{*}\right)\end{array}$ & \\
\hline
\end{tabular}

\begin{tabular}{|c|c|c|c|c|c|c|c|c|c|c|}
\hline \multicolumn{11}{|c|}{ Fold-increase in TOP1cc level at $30 \mathrm{~min}$} \\
\hline \multirow{3}{*}{\multicolumn{2}{|c|}{ Cell type }} & \multicolumn{3}{|c|}{ vs Protein levels } & \multicolumn{5}{|c|}{ vs Activity levels } & \multirow{3}{*}{ vs $\mathrm{IC}_{50}$} \\
\hline & & \multirow{2}{*}{ TOP1 protein } & \multirow{2}{*}{ TDP1 protein } & \multirow{2}{*}{$\begin{array}{l}\text { TDP1/TOP1 } \\
\text { protein ratio }\end{array}$} & \multirow{2}{*}{ TOP1 activity } & \multicolumn{2}{|c|}{ TDP1 activity } & \multicolumn{2}{|c|}{ TDP1/TOP1 activity ratio } & \\
\hline & & & & & & Gel-based assay & FL-based assay & Gel-based assay & FL-based assay & \\
\hline \multirow{4}{*}{$\begin{array}{l}\text { GBM cell } \\
\text { lines }\end{array}$} & Set \#1, GBM $(n=9)$ & $\begin{array}{c}\mathrm{R}=0.491 ; \mathrm{P}=0.401 \\
(\mathrm{~ns})\end{array}$ & $\begin{array}{c}\mathrm{R}=-0.911 ; \mathrm{P}=0.031 \\
\left(^{*}\right)\end{array}$ & $\begin{array}{c}\mathrm{R}=-0.769 ; \mathrm{P}=0.129 \\
(\mathrm{~ns})\end{array}$ & $\begin{array}{c}\mathrm{R}=0.580 ; \mathrm{P}=0.306 \\
(\mathrm{~ns})\end{array}$ & $\begin{array}{c}\mathrm{R}=-0.713 ; \mathrm{P}=0.177 \\
(\mathrm{~ns})\end{array}$ & $\begin{array}{c}\mathrm{R}=-0.844 ; \mathrm{P}=0.072 \\
(\mathrm{~ns})\end{array}$ & $\begin{array}{c}\mathrm{R}=-0.913 ; \mathrm{P}=0.030 \\
\left(^{*}\right)\end{array}$ & $\begin{array}{c}\mathrm{R}=-0.867 ; \mathrm{P}=0.057 \\
(\mathrm{~ns})\end{array}$ & \multirow{4}{*}{$\begin{array}{c}\mathrm{R}=-0.877 ; \mathrm{P}=0.051 \\
\text { (ns) }\end{array}$} \\
\hline & Set \#2, GBM $(n=9)$ & $\begin{array}{c}\mathrm{R}=0.474 ; \mathrm{P}=0.420 \\
\text { (ns) }\end{array}$ & $\begin{array}{c}\mathrm{R}=-0.854 ; \mathrm{P}=0.065 \\
(\mathrm{~ns})\end{array}$ & $\begin{array}{c}\mathrm{R}=-0.936 ; \mathrm{P}=0.02 \\
\left(^{*}\right)\end{array}$ & $R=0.893 ; P=0.04$ & $\begin{array}{c}\mathrm{R}=-0.062 ; \mathrm{P}=0.921 \\
(\mathrm{~ns})\end{array}$ & $\begin{array}{c}\mathrm{R}=-0.095 ; \mathrm{P}=0.879 \\
(\mathrm{~ns})\end{array}$ & $\begin{array}{c}\mathrm{R}=-0.872 ; \mathrm{P}=0.054 \\
(\mathrm{~ns})\end{array}$ & $\begin{array}{c}\mathrm{R}=-0.825 ; \mathrm{P}=0.086 \\
(\mathrm{~ns})\end{array}$ & \\
\hline & Set \#3, GBM $(n=9)$ & $\begin{array}{c}\mathrm{R}=0.524 ; \mathrm{P}=0.364 \\
(\mathrm{~ns})\end{array}$ & $\begin{array}{c}\mathrm{R}=-0.881 ; \mathrm{P}=0.048 \\
\left(^{*}\right)\end{array}$ & $\begin{array}{c}\mathrm{R}=-0.814 ; \mathrm{P}=0.093 \\
(\mathrm{~ns})\end{array}$ & $\begin{array}{c}\mathrm{R}=0.949 ; \mathrm{P}=0.013 \\
\left(^{*}\right)\end{array}$ & $\begin{array}{c}\mathrm{R}=-0.126 ; \mathrm{P}=0.840 \\
(\mathrm{~ns})\end{array}$ & $\begin{array}{c}\mathrm{R}=-0.596 ; \mathrm{P}=0.054 \\
(\mathrm{~ns})\end{array}$ & $\begin{array}{c}\mathrm{R}=-0.751 ; \mathrm{P}=0.143 \\
(\mathrm{~ns})\end{array}$ & $\begin{array}{c}\mathrm{R}=-0.893 ; \mathrm{P}=0.042 \\
\left(^{\star}\right)\end{array}$ & \\
\hline & $\begin{array}{c}\text { Average of Set } \# 1 \\
2,3(n=9)\end{array}$ & $\begin{array}{c}\mathrm{R}=0.453 ; \mathrm{P}=0.443 \\
(\mathrm{~ns})\end{array}$ & $\begin{array}{c}\mathrm{R}=-0.930 ; \mathrm{P}=0.022 \\
\left(^{*}\right)\end{array}$ & $\begin{array}{c}\mathrm{R}=-0.784 ; \mathrm{P}=0.117 \\
(\mathrm{~ns})\end{array}$ & $\begin{array}{c}\mathrm{R}=0.928 ; \mathrm{P}=0.023 \\
\left(^{*}\right)\end{array}$ & $\begin{array}{c}\mathrm{R}=-0.198 ; \mathrm{P}=0.749 \\
(\mathrm{~ns})\end{array}$ & $\begin{array}{c}\mathrm{R}=-0.575 ; \mathrm{P}=0.311 \\
(\mathrm{~ns})\end{array}$ & $\begin{array}{c}\mathrm{R}=-0.909 ; \mathrm{P}=0.032 \\
\left(^{*}\right)\end{array}$ & $\begin{array}{c}\mathrm{R}=-0.892 ; \mathrm{P}=0.042 \\
\left(^{\star}\right)\end{array}$ & \\
\hline
\end{tabular}

\begin{tabular}{|c|c|c|c|c|c|c|c|c|c|c|}
\hline \multicolumn{11}{|c|}{ Fold-increase in TOP1cc level at $60 \mathrm{~min}$} \\
\hline \multirow{3}{*}{\multicolumn{2}{|c|}{ Cell type }} & \multicolumn{3}{|c|}{ vs Protein levels } & \multicolumn{5}{|c|}{ vs Activity levels } & \multirow{3}{*}{ vs $\mathrm{IC}_{50}$} \\
\hline & & \multirow{2}{*}{ TOP1 protein } & \multirow{2}{*}{ TDP1 protein } & \multirow{2}{*}{$\begin{array}{l}\text { TDP1/TOP1 } \\
\text { protein ratio }\end{array}$} & \multirow{2}{*}{ TOP1 activity } & \multicolumn{2}{|c|}{ TDP1 activity } & \multicolumn{2}{|c|}{ TDP1/TOP1 activity ratio } & \\
\hline & & & & & & Gel-based assay & FL-based assay & Gel-based assay & FL-based assay & \\
\hline \multirow{4}{*}{$\begin{array}{l}\text { GBM cell } \\
\text { lines }\end{array}$} & Set \#1, GBM $(n=9)$ & $\begin{array}{c}\mathrm{R}=0.077 ; \mathrm{P}=0.902 \\
\text { (ns) }\end{array}$ & $\begin{array}{c}\mathrm{R}=-0.805 ; \mathrm{P}=0.10 \\
(\mathrm{~ns})\end{array}$ & $\begin{array}{c}\mathrm{R}=-0.469 ; \mathrm{P}=0.426 \\
(\mathrm{~ns})\end{array}$ & $\begin{array}{c}\mathrm{R}=0.156 ; \mathrm{P}=0.802 \\
(\mathrm{~ns})\end{array}$ & $\begin{array}{c}\mathrm{R}=-0.945 ; \mathrm{P}=0.015 \\
\left(^{*}\right)\end{array}$ & $\begin{array}{c}\mathrm{R}=-0.886 ; \mathrm{P}=0.046 \\
\left(^{*}\right)\end{array}$ & $\begin{array}{c}\mathrm{R}=-0.705 ; \mathrm{P}=0.184 \\
(\mathrm{~ns})\end{array}$ & $\begin{array}{c}\mathrm{R}=-0.603 ; \mathrm{P}=0.281 \\
(\mathrm{~ns})\end{array}$ & \multirow{4}{*}{$\begin{array}{c}R=-0.547 ; P=0.340 \\
\text { (ns) }\end{array}$} \\
\hline & Set \#2, GBM $(n=9)$ & $\begin{array}{c}\mathrm{R}=0.008 ; \mathrm{P}=0.990 \\
(\mathrm{~ns})\end{array}$ & $\begin{array}{c}\mathrm{R}=-0.868 ; \mathrm{P}=0.056 \\
(\mathrm{~ns})\end{array}$ & $\begin{array}{c}\mathrm{R}=-0.666 ; \mathrm{P}=0.220 \\
(\mathrm{~ns})\end{array}$ & $\begin{array}{c}\mathrm{R}=0.548 ; \mathrm{P}=0338 \\
(\mathrm{~ns})\end{array}$ & $\begin{array}{c}\mathrm{R}=-0.194 ; \mathrm{P}=0.755 \\
(\mathrm{~ns})\end{array}$ & $\begin{array}{c}\mathrm{R}=-0.076 ; \mathrm{P}=0.903 \\
(\mathrm{~ns})\end{array}$ & $\begin{array}{c}\mathrm{R}=-0.530 ; \mathrm{P}=0.0359 \\
(\mathrm{~ns})\end{array}$ & $\begin{array}{c}\mathrm{R}=-0.465 ; \mathrm{P}=0.430 \\
(\mathrm{~ns})\end{array}$ & \\
\hline & Set \#3, GBM $(n=9)$ & $\begin{array}{c}\mathrm{R}=0.705 ; \mathrm{P}=0.234 \\
(\mathrm{~ns})\end{array}$ & $\begin{array}{c}R=-0.342 ; P=0.545 \\
(n s)\end{array}$ & $\begin{array}{c}R=-0.445 ; P=0.453 \\
(n s)\end{array}$ & $\begin{array}{c}R=0.693 ; P=0.194 \\
(n s)\end{array}$ & $\begin{array}{c}R=-0.256 ; P=0.677 \\
(n s)\end{array}$ & $\begin{array}{c}\mathrm{R}=-0.450 ; \mathrm{P}=0.447 \\
(\mathrm{~ns})\end{array}$ & $\begin{array}{c}R=-0.631 ; P=0.254 \\
(n s)\end{array}$ & $\begin{array}{c}R=-0.591 ; P=0.294 \\
(n s)\end{array}$ & \\
\hline & $\begin{array}{c}\text { Average of Set \#1, } \\
2,3(\mathrm{n}=9)\end{array}$ & $\begin{array}{c}\mathrm{R}=0.021 ; \mathrm{P}=0.973 \\
(\mathrm{~ns})\end{array}$ & $\begin{array}{c}\mathrm{R}=-0.780 . ; \mathrm{P}=0.120 \\
(\mathrm{~ns})\end{array}$ & $\begin{array}{c}\mathrm{R}=-0.458 ; \mathrm{P}=0.438 \\
(\mathrm{~ns})\end{array}$ & $\begin{array}{c}\mathrm{R}=0.622 ; \mathrm{P}=0.262 \\
(\mathrm{~ns})\end{array}$ & $\begin{array}{c}\mathrm{R}=-0.378 ; \mathrm{P}=0.530 \\
(\mathrm{~ns})\end{array}$ & $\begin{array}{c}\mathrm{R}=-0.514 ; \mathrm{P}=0.375 \\
(\mathrm{~ns})\end{array}$ & $\begin{array}{c}\mathrm{R}=-0.624 ; \mathrm{P}=0.261 \\
(\mathrm{~ns})\end{array}$ & $\begin{array}{c}\mathrm{R}=-0.566 ; \mathrm{P}=0.320 \\
(\mathrm{~ns})\end{array}$ & \\
\hline
\end{tabular}


Table 2.20. Comparison of TOP1, TDP1, TDP1/TOP1 levels in three sets of experiments and three different database panels

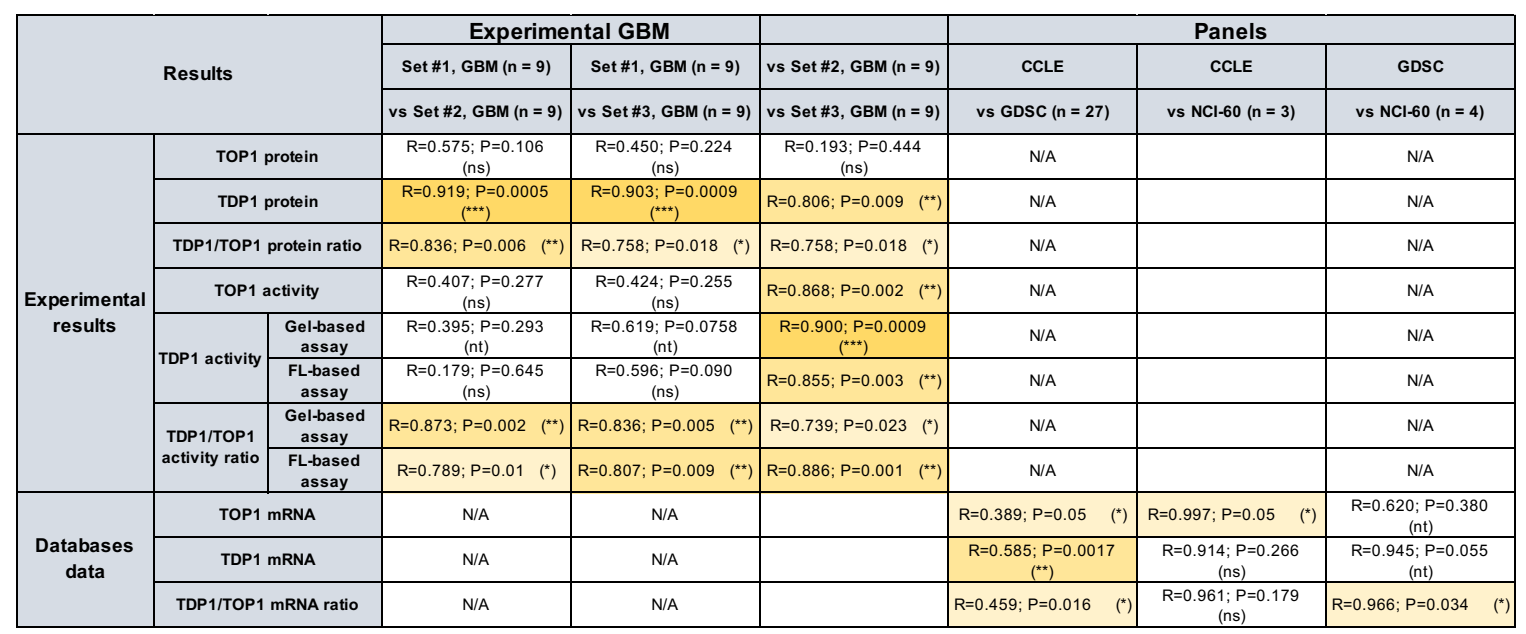

Table 2.21. Correlation of TOP1 level with TDP1 level in GBM cell lines

\begin{tabular}{|c|c|c|c|c|c|}
\hline & & \multicolumn{3}{|c|}{ Experimental results } & Database panel \\
\hline \multicolumn{2}{|c|}{ Cell type and Databases } & TOP1 protein & \multicolumn{2}{|c|}{ TOP1 activity } & TOP1 mRNA \\
\hline & & \multirow{2}{*}{ vs TDP1 protein } & \multicolumn{2}{|c|}{ vs TDP1 activity } & EC TRP1 mRNA \\
\hline & & & Gel-based assay & FL-based assay & VS IDPI MRINA \\
\hline \multirow{4}{*}{$\begin{array}{l}\text { GBM cell } \\
\text { lines }\end{array}$} & Set \#1, GBM ( $n=9)$ & $\begin{array}{c}R=-0.114 ; P=0.771 \\
(n s)\end{array}$ & $\begin{array}{c}\mathrm{R}=0.141 ; \mathrm{P}=0.717 \\
(\mathrm{~ns})\end{array}$ & $\begin{array}{c}\mathrm{R}=0.072 ; \mathrm{P}=0.854 \\
\text { (ns) }\end{array}$ & N/A \\
\hline & Set \#2, GBM (n = 9) & $\begin{array}{c}\mathrm{R}=0.475 ; \mathrm{P}=0.198 \\
(\mathrm{~ns})\end{array}$ & $\begin{array}{c}\mathrm{R}=0.266 ; \mathrm{P}=0.490 \\
\text { (ns) }\end{array}$ & $\begin{array}{c}\mathrm{R}=0.085 ; \mathrm{P}=0.829 \\
\text { (ns) }\end{array}$ & N/A \\
\hline & Set \#3, GBM $(n=9)$ & $\begin{array}{c}\mathrm{R}=-0.201 ; \mathrm{P}=0.603 \\
(\mathrm{~ns})\end{array}$ & $\begin{array}{c}\mathrm{R}=0.210 ; \mathrm{P}=0.588 \\
\text { (ns) }\end{array}$ & $\begin{array}{c}\mathrm{R}=-0.059 ; \mathrm{P}=0.881 \\
(\mathrm{~ns})\end{array}$ & N/A \\
\hline & $\begin{array}{c}\text { Average of Set \#1, 2, } \\
3(n=9)\end{array}$ & $\begin{array}{c}\mathrm{R}=0.091 ; \mathrm{P}=0.836 \\
(\mathrm{~ns})\end{array}$ & $\begin{array}{c}\mathrm{R}=0.016 ; \mathrm{P}=0.967 \\
\text { (ns) }\end{array}$ & $\begin{array}{c}\mathrm{R}=-0.298 ; \mathrm{P}=0.436 \\
\text { (ns) }\end{array}$ & N/A \\
\hline \multirow{3}{*}{$\begin{array}{l}\text { GBM cell } \\
\text { lines from } \\
\text { database }\end{array}$} & CCLE $(n=45)$ & $\mathrm{N} / \mathrm{A}$ & $\mathrm{N} / \mathrm{A}$ & $\mathrm{N} / \mathrm{A}$ & $\begin{array}{c}\mathrm{R}=0.065 ; \mathrm{P}=0.673 \\
(\mathrm{~ns})\end{array}$ \\
\hline & GDSC $(n=41)$ & $\mathrm{N} / \mathrm{A}$ & $\mathrm{N} / \mathrm{A}$ & $\mathrm{N} / \mathrm{A}$ & $\begin{array}{c}\mathrm{R}=0.234 ; \mathrm{P}=0.142 \\
\text { (ns) }\end{array}$ \\
\hline & $\mathrm{NCl}-60(n=5)$ & $\mathrm{N} / \mathrm{A}$ & $\mathrm{N} / \mathrm{A}$ & $\mathrm{N} / \mathrm{A}$ & $\begin{array}{c}\mathrm{R}=0.142 ; \mathrm{P}=0.819 \\
(\mathrm{~ns})\end{array}$ \\
\hline
\end{tabular}


Table 2.22. Comparison of protein level with activity level of TOP1 and TDP1 in GBM cell

\begin{tabular}{|c|c|c|c|c|c|c|}
\hline \multicolumn{7}{|c|}{ Experimental results } \\
\hline \multirow{3}{*}{\multicolumn{2}{|c|}{ Cell type }} & TOP1 protein & \multirow{2}{*}{\multicolumn{2}{|c|}{$\begin{array}{c}\text { TDP1 protein } \\
\text { vs TDP1 activity } \\
\end{array}$}} & \multirow{2}{*}{\multicolumn{2}{|c|}{$\begin{array}{c}\text { TDP/TOP1 protein ratio } \\
\text { vs TDP1/TOP1 activity ratio }\end{array}$}} \\
\hline & & vs TOP1 activity & & & & \\
\hline & & Western blotting & Gel-based assay & FL-based assay & Gel-based assay & FL-based assay \\
\hline \multirow{4}{*}{$\begin{array}{l}\text { GBM cell } \\
\text { lines }\end{array}$} & Set \#1, GBM ( $n=9)$ & $\begin{array}{c}\mathrm{R}=0.629 ; \mathrm{P}=0.069 \\
(\mathrm{~ns})\end{array}$ & $\begin{array}{c}\mathrm{R}=0.708 ; \mathrm{P}=0.033 \\
\left(^{*}\right)\end{array}$ & $\begin{array}{c}\mathrm{R}=0.664 ; \mathrm{P}=0.051 \\
(\mathrm{~ns})\end{array}$ & $\begin{array}{c}\mathrm{R}=0.669 ; \mathrm{P}=0.05 \\
\left(^{*}\right)\end{array}$ & $\begin{array}{c}\mathrm{R}=0.829 ; \mathrm{P}=0.0006 \\
\left({ }^{* *}\right)\end{array}$ \\
\hline & Set \#2, GBM $(n=9)$ & $\begin{array}{c}\mathrm{R}=0.182 ; \mathrm{P}=0.639 \\
(\mathrm{~ns})\end{array}$ & $\begin{array}{c}\mathrm{R}=0.495 ; \mathrm{P}=0.176 \\
\text { (ns) }\end{array}$ & $\begin{array}{c}\mathrm{R}=0.427 ; \mathrm{P}=0.251 \\
\text { (ns) }\end{array}$ & $\begin{array}{c}\mathrm{R}=0.745 ; \mathrm{P}=0.021 \\
\left(^{*}\right)\end{array}$ & $\begin{array}{c}\mathrm{R}=0.720 ; \mathrm{P}=0.029 \\
\left({ }^{*}\right)\end{array}$ \\
\hline & Set \#3, GBM $(n=9)$ & $\begin{array}{c}\mathrm{R}=0.338 ; \mathrm{P}=0.374 \\
\text { (ns) }\end{array}$ & $\begin{array}{c}\mathrm{R}=0.512 ; \mathrm{P}=0.158 \\
(\mathrm{~ns})\end{array}$ & $\begin{array}{c}\mathrm{R}=0.774 ; \mathrm{P}=0.014 \\
\left(^{*}\right)\end{array}$ & $\begin{array}{c}\mathrm{R}=0.643 ; \mathrm{P}=0.062 \\
(\mathrm{~ns})\end{array}$ & $\begin{array}{c}\mathrm{R}=0.926 ; \mathrm{P}=0.0004 \\
\left(^{* * *}\right)\end{array}$ \\
\hline & $\begin{array}{c}\text { Average of Set \#1, } 2 \text {, } \\
3(n=9)\end{array}$ & $\begin{array}{c}\mathrm{R}=0.446 ; \mathrm{P}=0.229 \\
\text { (ns) }\end{array}$ & $\begin{array}{c}\mathrm{R}=0.644 ; \mathrm{P}=0.061 \\
\text { (ns) }\end{array}$ & $\begin{array}{c}\mathrm{R}=0.812 ; \mathrm{P}=0.008 \\
\left({ }^{*}\right)\end{array}$ & $\begin{array}{c}\mathrm{R}=0.799 ; \mathrm{P}=0.01 \\
\left(^{*}\right)\end{array}$ & $\begin{array}{c}\mathrm{R}=0.827 ; \mathrm{P}=0.006 \\
\left({ }^{* *}\right)\end{array}$ \\
\hline
\end{tabular}

\section{Table 2.23. Correlation of protein level with mRNA level in GBM cell lines}

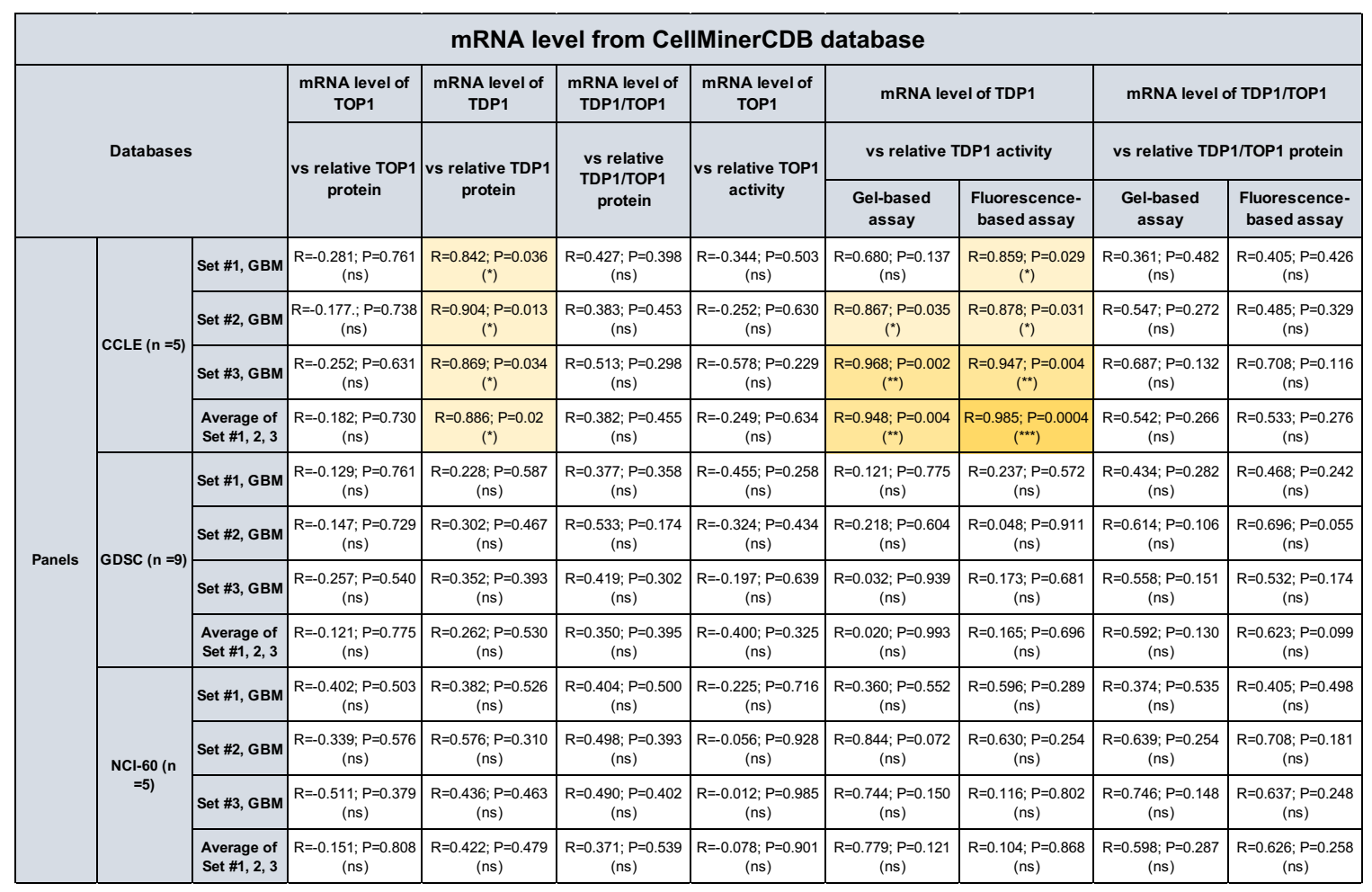




\section{CHAPTER III: STUDY OF TOP1 AND TDP1 IN GBM STEM CELLS AND GBM PATIENT TUMORS}

\section{ABSTRACT}

The TDP1/TOP1 activity ratio, shown in our previous chapter to be a predictive indicator for GBM cell lines response to IRT treatment, was further analyzed with the IRT cytotoxicity against GBM stem cell lines (GSC). We observed that IRT IC 50 S are not correlated with TOP1, TDP1, nor with TDP1/TOP1 ratios in four GSC cell lines, suggesting TDP1/TOP1 activity ratio might not be a predictive indicator for stem cells treatment.

No correlations of TOP1 or TDP1 with GBM patient age has ever been reported. The potential prognostic role of TOP1 and TDP1 in GBM patients who underwent chemotherapy remains to be explored. In our study, a total of ten patient GBM tumors were analyzed. We observed a positive correlation of TOP1 activity with patients age $(R=0.717, P=0.02)$ and also a negative correlation of TDP1/TOP1 activity with patients age at diagnosis $(R=-0.707, P=0.03)$. Because

of the significant correlation between patient age and survival from both our set of GBM patients data $(n=10, R=-0.929, P=0.023)$ and TCGA database $(n=451$, $\mathrm{R}=-0.353, \mathrm{P}=7.7 \times 10^{-17}$ ), TDP1/TOP1 activity ratio might be a potential prognosis biomarker for GBM patients. 


\section{INTRODUCTION}

The heterogeneity of GBM is one of the factors that limit the efficacy of chemotherapeutic treatment. It has been proposed that cancer stem cells (CSC) have the ability to drive tumor growth and are significantly associated with heterogeneity in GBM (122). Glioblastoma stem cells (GSC) are a subpopulation of cancer cells displaying tumorigenic and recurrent potentials and are highly resistant to chemotherapies (123). Therefore, targeting GSC has become a promising chemotherapeutic approach that has been investigated extensively (124). Studies have shown that inhibition of signaling check-point kinases might sensitize the GSC cancer cells to radiotherapy (125). A recent study has also demonstrated that inhibiting the autophagic process could make GSC more sensitive to Temozolomide (TMZ) treatment in vitro (126). Whereas lack of bone morphogenetic protein (BMP)-induced GSC differentiation suggested that BMPbased therapies may not be an effective treatment for GSC (127). Even though much efforts have been devoted to GSC studies, the drug resistance and lack of treatment efficacy remain as the main obstacles. Therefore, we analyzed the IRT sensitivity of four GSC cell lines and their levels of TOP1, TDP1 and TDP/TOP1 ratio in order to determine if promising indicators can be identified for IRT treatment of GSC.

The Cancer Genome Atlas (TCGA), also known as Genomic Data Commons (GDC) (https://portal.gdc.cancer.gov), is a valuable source of a variety of cancer genomic data platforms, including RNA sequencing, DNA sequencing, microRNA sequencing, single nucleotide polymorphism (SNP)-based platforms, array-based 
DNA methylation sequencing, and reverse-phase protein array (RPPA), which provides as a powerful tool that supports scientific investigations towards precision medicine (128). Glioblastoma was the very first cancer subject for TCGA, with data on specific characteristics that include survival analysis, promoter DNA methylation, and nucleotide aberrations (129-131). Analyses using the TCGA database have led to hypotheses which are then further investigated by scientists for increasing the likelihood of positive drug responses $(132,133)$. Here, we analyzed RNA sequencing results provided by the TCGA database to study TOP1 and TDP1 expressions and their potential correlations in cancer therapy. A small set of GBM patient tumors $(n=10)$ were also analyzed in our study to compare with the database contents. 


\section{MATERIAL AND METHODS}

All buffer compositions are listed in Appendix I.

\section{Western blot analysis}

Protein expression levels were detected with western blots. Briefly, proteins in WCE were first separated by $7.5 \%$ SDS-PAGE and then transferred to nitrocellulose membrane with transfer buffer (48 mM Tris, $39 \mathrm{mM}$ glycine, $0.4 \%$ SDS, $20 \% \mathrm{v} / \mathrm{v}$ methanol) at $100 \mathrm{~V}$ for $1 \mathrm{~h}$. The membrane was blocked with $5 \%$ BSA in $1 \times$ TBS at RT for $1 \mathrm{~h}$ followed by incubation with 1:1000 (v/v) primary antibody diluted in $1 \times \mathrm{TBST}$ at $4^{\circ} \mathrm{C}$ overnight. The membrane was washed $3 \times 5$ min by TBST and the HRP-conjugated secondary antibody 1:5000 (v/v) diluted in TBST was incubated with the membrane at RT for additional $1 \mathrm{~h}$. The membrane was then washed $3 \times 5 \mathrm{~min}$ before the signal for the target protein was developed with the SuperSignal West Pico Plus Chemiluminescent Substrate (Thermo Fisher) for 5 min in the dark. The images were obtained by C-DiGit Blot scanner (LI-COR) and the expression density for the target protein was analyzed by ImageStudio (LICORE).

\section{Glioblastoma neurosphere cell lines culture}

The adult neurosphere cell lines, GSC-11 and GSC-23, a kind gift from Frederick Lang at UT MD Anderson Cancer Center, were established from acute cell dissociation of human GBM surgical specimens. The neurosphere cell lines GBM1A and GBM1B were originally derived and characterized by Vescovi and his coworkers (134). All GSC cell lines were cultured and maintained in serum-free 
medium containing DMEM/nutrient mixture F12 (1:1, v/v) (Thermo Fisher) supplemented with $1 \%$ of Penicillin/Streptomycin (Lonza), $10 \times$ of B27 supplement (Thermo Fisher), and $20 \mathrm{ng} / \mathrm{mL}$ of both EGF and FGF (Sigma-Aldrich) according to the procedures described by Galli (134). All cell lines were grown at $37^{\circ} \mathrm{C}$ in a humidified incubator with $5 \% \mathrm{CO}_{2}$.

\section{Glioblastoma neurosphere cell collection}

To isolate proteins for analysis, cells were plated at a density of $2.5 \times 10^{5}$ cells/well in 60-mm dishes. Cells were then collected as described as following. Cells were washed twice in PBS and lysed in RIPA buffer (50 mM Tris-HCl, $\mathrm{pH} 7.4$, $150 \mathrm{mM} \mathrm{NaCl}, 5 \mathrm{mM}$ EDTA, $1 \mathrm{mM}$ EGTA. $1 \%$ NP-40, $0.1 \%$ SDS and $0.5 \%$ sodium deoxycholate) supplemented with $1 \mathrm{mM}$ PMSF, Halt Protease and Phosphatase inhibitor cocktails. Cells were incubated with gentle rocking at $4^{\circ} \mathrm{C}$ for $5 \mathrm{~min}$ and then transferred to a sterile microcentrifuge tube. After 2 min on ice, cell disruption was completed using sonication. The lysate was cleared by centrifuging at 15000 $\times \mathrm{g}$ for $15 \mathrm{~min}$ at $4^{\circ} \mathrm{C}$. Supernatant protein concentrations were measured using the Pierce BCA Assay kit.

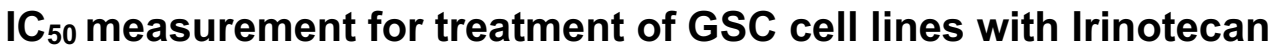

To determine the sensitivity of the GSCs lines, cells were treated with increasing concentrations $(0-10 \mu \mathrm{M})$ of IRT. GSCs were plated at $6.5 \times 10^{3}$ cells per well in black-walled, clear bottom plates (PerkinElmer), which were previously coated with $10 \mu \mathrm{g} / \mathrm{mL}$ laminin (Corning) and grown overnight. The cells were then 
treated with IRT for $72 \mathrm{~h} \mathrm{~h}$. The cells were washed three times with PBS, fixed in $4 \%$ paraformaldehyde/PBS and permeabilized with $0.2 \%$ TritonX-100/PBS. The cells were then blocked using the Licor Blocking Buffer and stained with CellTag700 stain (1:1000 dilution) for 60min at RT. The cells were then washed three times in Hank's Buffered Saline Solution (HBSS). The plate was imaged using the Odyssey CLx scanner (LI-COR) and analyzed using the Image Studio 2.0 software (LI-COR). The IC50s were collected by Dr. Dr. Arlet Maria Acanda De La Rocha from Dr. Chambers's lab and calculated using the GraphPad Prism7@ software.

\section{Collection and storage of brain tumor samples from patients}

Table 3.1 GBM Patient information

\begin{tabular}{|c|c|c|c|c|c|c|c|c|c|c|c|c|c|}
\hline $\begin{array}{l}\text { Patient } \\
\text { Code }\end{array}$ & $\begin{array}{c}\text { Tumor } \\
\text { ID }\end{array}$ & Age & Sex & Dignosed & Surgery & $\begin{array}{l}\text { Collected } \\
\text { date }\end{array}$ & Radiosurgery & CHEMO & Reccurrence & Deceased & \begin{tabular}{|c|}
$\begin{array}{c}\text { Status } \\
\text { unknown } \\
\text { after }\end{array}$ \\
\end{tabular} & $\begin{array}{c}\text { Stable } \\
\text { after }\end{array}$ & $\begin{array}{l}\text { Survival } \\
\text { Imonth }\end{array}$ \\
\hline 331475 & $\# 17$ & 78 & $\mathrm{~F}$ & 05/09/16 & $\times 1$ & $05 / 12 / 2016$ & Gammma knife x 1 & & & $08 / 2016$ & & & 3 \\
\hline 516-46837B & $\# 22$ & 92 & $\mathrm{~F}$ & & $\times 1$ & $11 / 09 / 2016$ & & Temodar & & $12 / 2016$ & & & 1 \\
\hline 758058 & $\# 29$ & 80 & $\mathrm{~F}$ & $12 / 2016$ & $\times 1$ & $12 / 19 / 2016$ & Gammma knife x 3 & Avastin & $08 / 2017$ & $01 / 2018$ & & & 12 \\
\hline 780540 & $\# 42$ & 71 & M & $03 / 2017$ & $\times 1$ & 08/30/2017 & Gammma knife $\times 3$ & \begin{tabular}{|l|} 
Temodar \\
\& Avastin \\
\end{tabular} & $08 / 2017$ & & $09 / 2017$ & & \\
\hline 782691 & $\# 44$ & 30 & $\mathrm{~F}$ & $04 / 2015$ & $\times 2$ & 09/27/2017 & Gammma knife $\times 2$ & & $09 / 2017$ & $05 / 30 / 2018$ & & & 36 \\
\hline 791171 & $\# 47$ & 60 & M & $12 / 2017$ & $\times 2$ & $12 / 22 / 2017$ & Gammma knife x 2 & \begin{tabular}{|l|} 
Temodar \\
\& Avastin \\
\end{tabular} & $07 / 2018$ & & & $12 / 2018$ & \\
\hline 792371 & $\# 49$ & 67 & M & $09 / 2017$ & $\times 1$ & 01/19/2018 & Gammma knife x 2 & & & 2018 & & & \\
\hline 795033 & $\# 50$ & 51 & $\mathrm{~F}$ & $09 / 2015$ & $\times 3$ & 02/09/2018 & Gammma knife $\times 3$ & Avastin & $\begin{array}{c}01 / 16 ; \\
06 / 16 ; 01 / 18 \\
\end{array}$ & $10 / 2018$ & & & 36 \\
\hline 763107 & $\# 62$ & 44 & M & $02 / 2017$ & $\times 1$ & $02 / 21 / 2017$ & Gammma knife x 1 & $\begin{array}{l}\text { Temodar } \\
\text { \& Avastin }\end{array}$ & & & $05 / 2017$ & & \\
\hline 772697 & \#66 & 71 & $\mathrm{~F}$ & 06/2017 & $\times 1$ & 06/09/2017 & Gammma knife x 1 & & & & 06/2017 & & \\
\hline
\end{tabular}

Glioblastoma brain tumors were collected from patients undergoing operations at Miami Neuroscience Center of Larkin Hospital according to the protocol approved by Florida International University Institutional Review Board 
(FIU IRB, No. IRB-16-0355-CR02), and snap-frozen in cryotubes which were precooled on dry ice. Samples were then sent by courier to FIU and cryopreserved in liquid nitrogen for further analysis. Information on the glioblastoma patient tumors is listed in Table 3.1.

\section{Protein extraction from GBM patient samples}

To extract proteins for analysis, Tumor tissues were carefully transferred on an ice-cooled $100 \mathrm{~mm}$ cell culture dish and sliced into small pieces. The tumor segments were then weighed, and RIPA/inhibitors lysis buffer was added at a ratio of 1:10 (v/w). Samples were then homogenized with the Dounce Homogenizer and rotated with a rotator at $4^{\circ} \mathrm{C}$ for additional $2 \mathrm{~h}$, followed by centrifugation at 15000 $\times \mathrm{g}$ for $15 \mathrm{~min}$. Protein concentration was then determined with the BioPhotometer (Eppendorf).

\section{Human TOP1 activity measurement by gel relaxation assay}

Human topoisomerase I activity measurement was carried out in a final reaction volume of $20 \mu \mathrm{L}$. Negatively supercoiled pBAD/Thio DNA (240 ng) was relaxed by a serial diluted WCE at $37^{\circ} \mathrm{C}$ for $30 \mathrm{~min}$ in $1 \times$ relaxation buffer $(10 \mathrm{mM}$ Tris- $\mathrm{HCl}, \mathrm{pH} 7.9,1 \mathrm{mM}$ EDTA, $150 \mathrm{mM} \mathrm{NaCl}, 0.1 \%$ BSA, $0.1 \mathrm{mM}$ spermidine, 5\% glycerol). Reactions were stopped by adding $4 \mu \mathrm{L}$ of $6 \times \mathrm{SDS}$ stop buffer and DNAs were then separated on $1 \%$ agarose gel electrophoresis on the basis of the topological differences. The DNA lanes were stained by $1 \mu \mathrm{g} / \mathrm{mL}$ of EtBr solution 
and analyzed by AlphaView SA (ProteinSimple) using the intensity of the supercoiled DNA fractions.

\section{Human TDP1 activity measurement by Gel-based assay}

Human tyrosyl-DNA phosphodiesterase 1 (TDP1) activity measurement by

gel-based assay was carried out in a final reaction volume of $5 \mu \mathrm{L}$. The $\mathrm{P}^{32}$-labeled $\mathrm{P} 12 \mathrm{Y}$ oligo (4 $\mathrm{ng}$ ) was cleaved by $2 \mu \mathrm{g} \mathrm{WCE}$, at $37^{\circ} \mathrm{C}$ for $30 \mathrm{~min}$ in gel-based assay reaction buffer (20 mM Tris-HCl, pH 7.5, 100 mM KCl, 10 mM EDTA, 1 mM DTT). The reaction was stopped by adding $5 \mu \mathrm{L}$ of $2 \times$ stop buffer ( $96 \%$ formamide, 20 mM EDTA, $0.03 \%$ xylene cyanol and $0.03 \%$ bromophenol blue) followed by heatinactivation at $95^{\circ} \mathrm{C}$ for $5 \mathrm{~min}$. The oligonucleotides were separated by $20 \%$ ureadenaturing sequencing gel based on the mobility difference between the $\mathrm{P} 12 \mathrm{Y}$ substrate and P12.oligonucleotide product with the 3'-tyrosyl removed from the substrate.

\section{Human TDP1 activity measurement by fluorescence-based assay}

The TDP1 activity was also measured with the fluorescence-based assay as described (101). Briefly, 25 pmol of 5'FAM-DNA-BHQ1-3' was incubated with $2 \mu \mathrm{g}$ WCE at $37^{\circ} \mathrm{C}$ in TDP1 reaction buffer $(20 \mathrm{mM}$ Tris- $\mathrm{HCl}, \mathrm{pH}$ 8.0, $100 \mathrm{mM} \mathrm{KCl}, 10$ mM EDTA, $10 \mathrm{mM}$ DTT, $0.05 \%$ TritonX-100) with a final volume of $25 \mu \mathrm{L}$. Fluorescence signal from each reaction was recorded every $30 \mathrm{~s}$ for $500 \mathrm{~min}$ by CFX96 Touch Real-Time PCR Detection System (Bio-Rad). 


\section{RESULTS AND DISCUSSION}

\section{TDP1/TOP1 activity ratio and IRT sensitivity measured for GSC cell lines}

It has been reported that the malignant progression of GBM is primarily contributed by the GBM stem cells (GSCs) which play a significant role in the recurrence of the tumors and resistance of drug treatment (123). In our study, four different GSC cell lines (GSC-11, GSC-23, GBM1A, and GBM1B) derived from two individual labs were used for analysis. GSC cell lines were treated with serial dilutions of IRT and the cell viabilities were measured with the TO-PRO3 assay (Figure 3.1, panel B). TOP1, TDP1, and TDP1/TOP1 ratio levels were analyzed for potential correlation with GSC sensitivity to IRT treatment,

From Coomassie blue staining, the proteins present in $10 \mu \mathrm{g}$ of the GSC WCEs were comparable to NHA (Figure 3.1, panel A). Results from western blot showed that relative TOP1 expression level was higher in the GSC WCEs, ranging from 2.96 to 3.78 , whereas relative TDP1 protein levels in GSC were lower in comparison to $\mathrm{NHA}$, ranging from 0.71 to 1.02 (Figure 3.1, panels $\mathrm{C} 1, \mathrm{D} 1$ ). Meanwhile, TOP1 activity was measured by the relaxation assay and TDP1 activity was measured by the fluorescence-based assay. Activities were calculated based on their standard curves as described in the previous chapter. The results showed that all of the GSC cell lines tested had a higher level of relative TOP1 activity ranging from 1.57 to 2.41 , and a lower level relative TDP1 activity ranging from 0.167 to 0.575 (Figure 3.2, panels A1, B1). Subsequently, TDP1/TOP1 protein ratio and activity level were calculated. There is a greater variety of TDP1/TOP1 activity ratio (ranging from 0.081 to 0.333 ) compared to the variation of 
TDP1/TOP1 protein ratio (ranging from 0.24 to 0.314 ) (Figure 3.3, panels A1, B1). The protein and activity levels are listed in Table 3.2.

According to our analysis above, GSC cell lines have the same trend as GBM cell lines, with relatively higher TOP1 and relatively lower TDP1 levels in comparison with NHA for both protein expression and activity levels. However, neither TOP1, TDP1 alone, nor TDP1/TOP1 ratios are significantly correlated with IRT IC 50 $_{5}$ (Figure 3.1, panels C2, D2; Figure 3.2, panels A2, B2; Figure 3.3, panels A2, B2).

Table 3.2 TOP1, TDP1, and TDP1/TOP1 ratio of GSC cell lines

\begin{tabular}{|c|c|c|c|c|c|c|c|c|c|}
\hline \multicolumn{10}{|c|}{ TOP1, TDP1, TOP1/TDP1 ratios of GSC cell lines } \\
\hline \multirow{2}{*}{$\begin{array}{l}\text { GSC cell } \\
\text { lines }\end{array}$} & \multicolumn{3}{|c|}{ Protein level } & \multicolumn{2}{|c|}{ TOP1 Activity level } & \multicolumn{2}{|c|}{ TDP1 Activity level } & \multicolumn{2}{|c|}{ TDP1/TOP1 Activity Ratio } \\
\hline & Relative TOP1 & Relative TDP1 & TDP1/TOP1 & $\begin{array}{c}\text { TOP1 activity } \\
(\mathrm{U} / \mu \mathrm{g})\end{array}$ & $\begin{array}{c}\text { Relative TOP1 } \\
\text { activity }\end{array}$ & $\begin{array}{l}\text { TDP1 activity } \\
\text { (fmol/ } / \mu \mathrm{g} \text { ) }\end{array}$ & $\begin{array}{c}\text { Relative TDP1 } \\
\text { activity }\end{array}$ & $\begin{array}{l}\text { activity ratio } \\
\text { (fmol/U) }\end{array}$ & $\begin{array}{c}\text { relative } \\
\text { activity ratio }\end{array}$ \\
\hline GBM1A & $3.408 \pm 0.764$ & $1.019 \pm 0.106$ & 0.299 & $2.201 \pm 0.130$ & $2.414 \pm 0.142$ & $1.675 \pm 0.383$ & $0.575 \pm 0.131$ & 0.761 & 0.238 \\
\hline GBM1B & $2.961 \pm 0.815$ & $0.749 \pm 0.064$ & 0.253 & $1.885 \pm 0.0206$ & $2.068 \pm 0.142$ & $0.486 \pm 0.186$ & $0.167 \pm 0.0639$ & 0.258 & 0.081 \\
\hline GSC11 & $2.994 \pm 0.195$ & $0.714 \pm 0.167$ & 0.239 & $1.433 \pm 0.050$ & $1.571 \pm 0.0545$ & $1.522 \pm 0.104$ & $0.522 \pm 0.0356$ & 1.062 & 0.332 \\
\hline GSC23 & $3.874 \pm 1.052$ & $0.869 \pm 0.235$ & 0.224 & $1.982 \pm 0.0139$ & $2.174 \pm 0.0152$ & $1.352 \pm 0.211$ & $0.464 \pm 0.0724$ & 0.682 & 0.213 \\
\hline
\end{tabular}




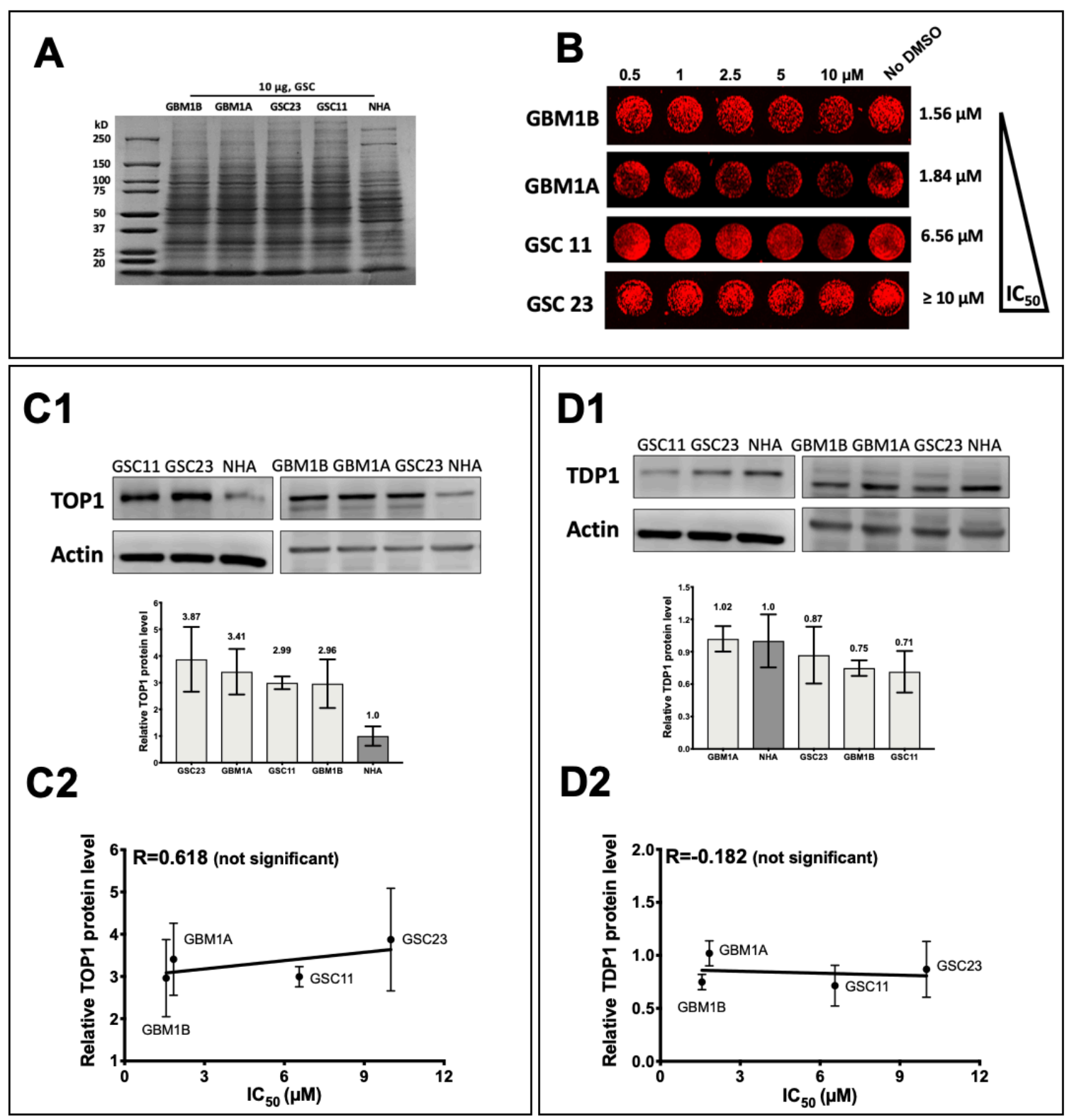

Figure 3.1. Analysis of WCE of glioblastoma stem cells

(A) Coomassie blue staining of proteins in GSC WCEs (10 $\mu \mathrm{g}$ total proteins) following SDS PAGE. (B) The cell viabilities of GSC cell lines were measured by TO-PRO3 assay following treatment with serial dilutions of IRT. DMSO treatment was used as control. The (C1) TOP1 and (D1) TDP1 expression levels in GSC cell lines were measured by western blots. The signal intensity was first normalized to actin signal to correct for loading, then divided by the NHA signal intensity for comparison. The (C2) TOP1 and (D2) TDP1 expression levels in GSC cell are not significantly correlated with IRT IC 50 S. 

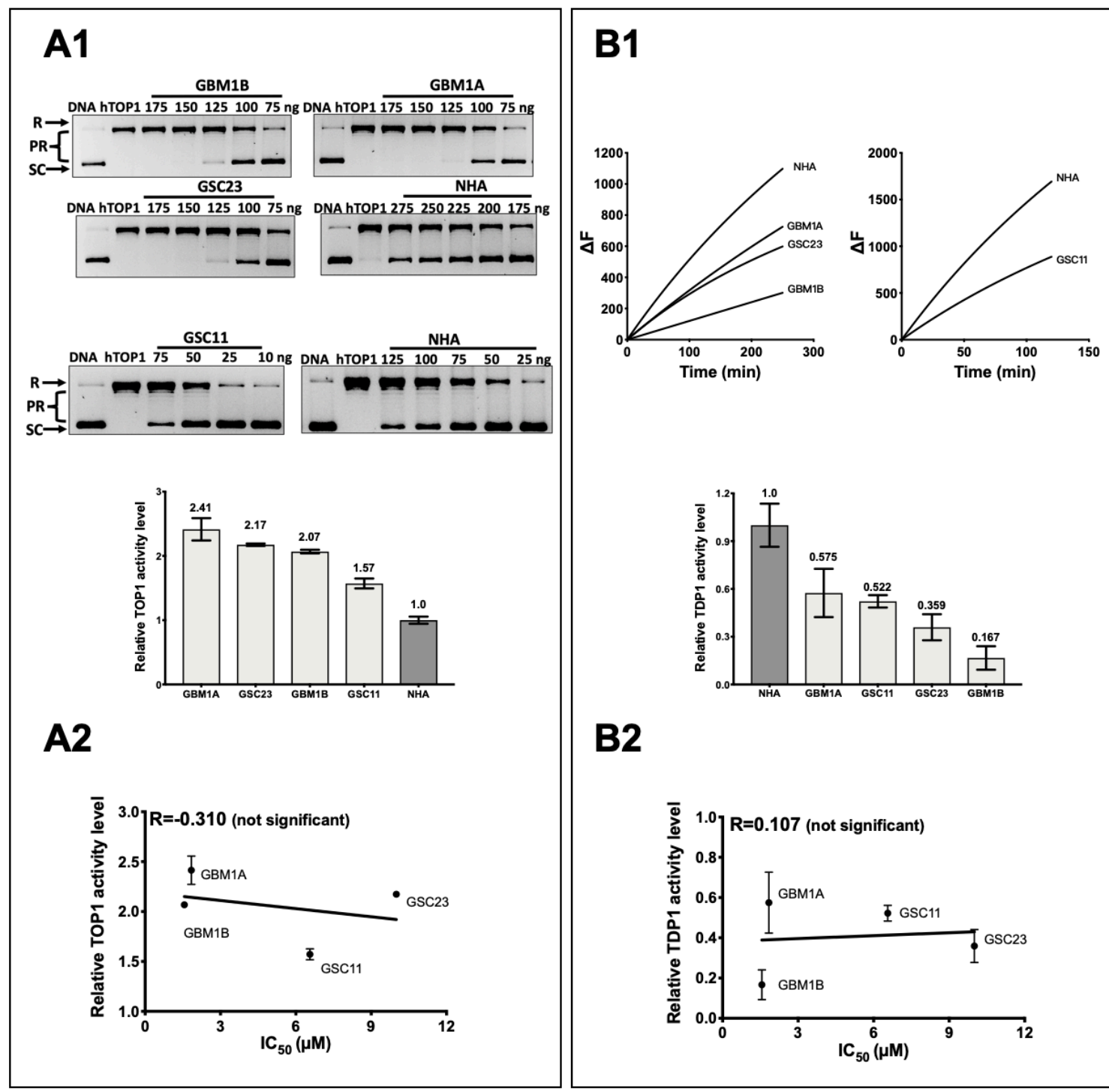

B2

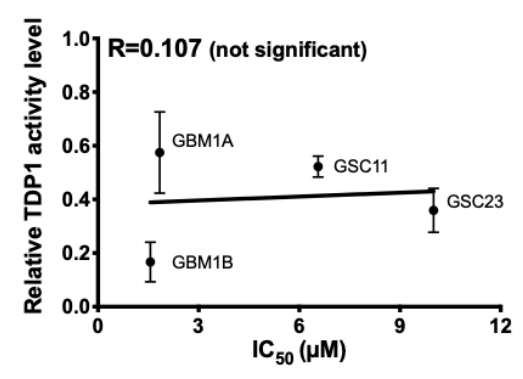

Figure 3.2. Comparison of TOP1, TDP1, and TD1P/TOP1 ratio levels in GSC cell lines with Irinotecan sensitivities

(A1) TOP1 activity of GSC was measured by relaxation assay. (B1) TDP1 activity level was measured by fluorescence-based assay. The (A2) TOP1 and (B2) TDP1 activity levels in GSC cell are not significantly correlated with IRT IC $\mathrm{C}_{50}$. 

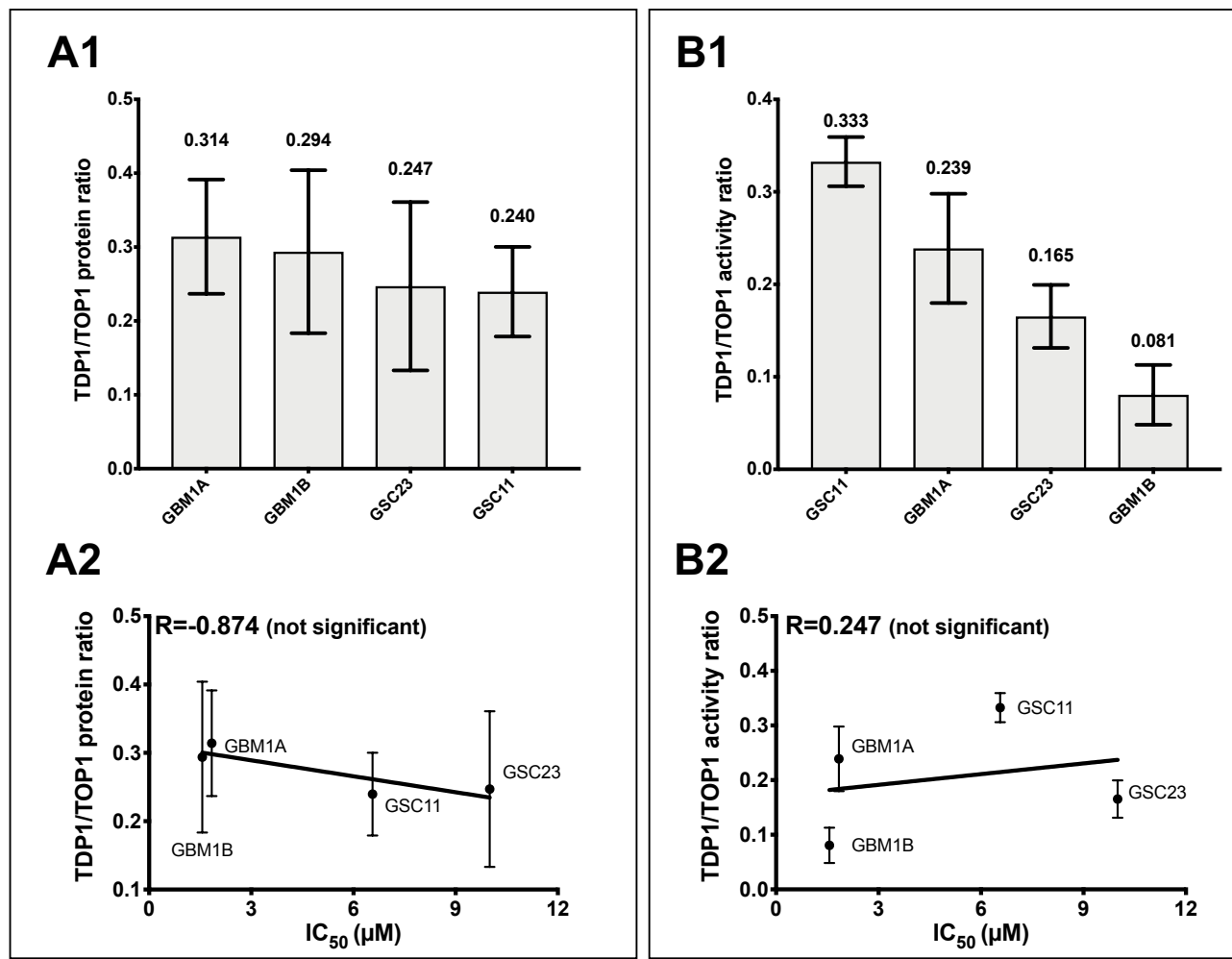

B2

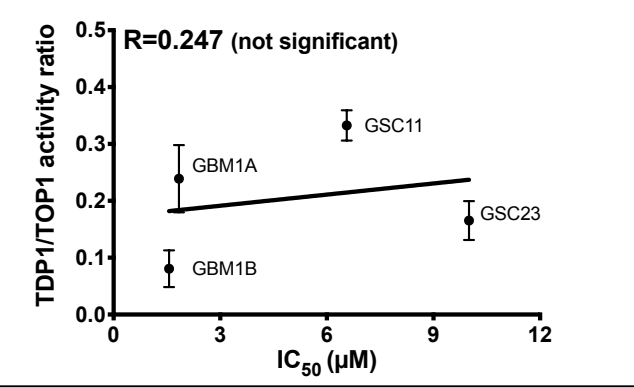

Figure 3.3.TOP1 and TDP1 levels in GBM and GSC cell lines

Bar-graph of (A1) TDP1/TOP1 protein ratio and (B1) TDP1/TOP1 activity ratio. The (A2) TDP1/TOP1 protein ratio and (B2) TDP1/TOP1 activity ratio in GSC cell are not significantly correlated with IRT IC $\mathrm{C}_{50}$ S. 


\section{The variation of TDP1/TOP1 ratios observed among GBM patient tumors}

Ten GBM tumors from patients (Table 3.1) were collected from surgery. Coomassie blue staining following SDS PAGE showed similar overall protein expression in WCEs of patient tumors (Figure 3.4, panel A). The TOP1 and TDP1 expression level of GBM tumors were much lower than GBM cell lines. Therefore $60 \mu \mathrm{g}$ WCE were used for western blotting. In order to normalized protein expression level to NHA, patient tumor (ID: \#22) with the highest expression level was used to compare with NHA. From our results, the expression level of TOP1 and TDP1 can vary up to 12.5 -fold (ranging from 0.011 to 0.138 , Figure 3.4 , panel C) and 3.4-fold (ranging from 0.14 to 0.47 , Figure 3.5 , panel B) respectively. The relative activity level of TOP1 and TDP1 can vary up to 6.5-fold (ranging from 0.133 to 0.860 , Figure 3.4 , panel B) and 13 -fold (ranging from 0.059 to 0.770 , Figure 3.5 , panel A) respectively. Additionally, TDP1/TOP1 protein and activity ratio can vary up to 12.7-fold (from 1.88 to 23.86, Figure 3.6, panel A) and 9.3-fold (from 0.223 to 2.087, Figure 3.6, panel B) differences, respectively. Relative levels of TOP1, TDP1, as well as TDP/TOP1 ratios found in GBM patient tumors are listed in Table 3.3.

On the basis of these results, there is a more considerable variation of TOP1, TDP1, as well as TDP1/TOP1 ratio levels among the patient tumors than GBM cell lines, suggesting the variation of TDP1/TOP1 activity ratios has the potential to represent as a predictive biomarker in clinical trials. The TOP1 activity in patient samples is highly correlated with TOP1 protein levels (Figure 3.4, panel D), suggesting TOP1 activity in patient tumors is most likely not as modulated by post- 
translational modifications as in GBM cell lines $(92,102,103)$. Although, the TDP1 activity in patient samples are significantly correlated with TDP1 protein levels (Figure 3.5 , panel $\mathrm{C}$ ), the TDP1/TOP1 activity ratios are still not significantly correlated with TDP1/TOP1 protein ratios (Figure 3.6, panel C), suggesting activity assays are necessary for finding rational predictive biomarkers for both GBM cell lines and patient tumors.

Among the tumors we tested, 5 out of 10 patients have the survival information (Table 3.1). Interestingly, we observed a strong correlation $(R=-0.929$, $P=0.023$ ) between patient age at diagnosis with patient survival (Figure 3.7, panel A). With the increased patient age, the survival duration time was decreased. A significant correlation $\left(R=-0.353, P=7.7 \times 10^{-17}\right)$ was also observed in GBM patient samples provided from TCGA database (Figure 3.7, panel B). TCGA is a powerful database tool with abundant genomic data from patient tumors available for analysis. The data we used from the TCGA database including 451 GBM patients who had already deceased and their survival days after diagnosis were provided (Table 3.5). Furthermore, comparison of the correlations of patient age with its survival among 26 different cancers provided by TCGA database showed that only GBM, lower grade glioma (LGG), skin cutaneous melanoma (SKCM), and breast invasive carcinoma (BRCA) are significantly as well as negatively correlated with patient age (Table 3.4). Among those, GBM patient age has the strongest correlation with survival. Furthermore, we observed a significantly positive correlation between patient age at diagnosis and TOP1 activity levels (Figure 3.8, panel A2) and a significantly negative correlation between patient age and 
TDP1/TOP1 activity ratio according to our results (Figure 3.8, panel C2), suggesting TDP1/TOP1 activity ratio might also be a prognostic indicator for GBM. Whereas, no correlation was observed between patient age and protein expression levels or mRNA expression levels of TDP1 and TOP1 (Figure 3.8, panel D). 
Table 3.3. Relative levels of TOP1, TDP1 protein and activity plus TDP1/TOP1 protein and activity ratio in GBM tumors

\begin{tabular}{|c|c|c|c|c|c|c|c|c|c|}
\hline \multicolumn{10}{|c|}{ TOP1, TDP1, TOP1/TDP1 ratios of GBM tumors } \\
\hline \multirow[b]{2}{*}{ Tumor ID } & \multicolumn{3}{|c|}{ Protein level } & \multicolumn{2}{|c|}{ TOP1 Activity level } & \multicolumn{2}{|c|}{ TDP1 Activity level } & \multicolumn{2}{|c|}{ TDP1/TOP1 Activity Ratio } \\
\hline & Relative TOP1 & Relative TDP1 & TDP1/TOP1 & $\begin{array}{l}\text { TOP1 activity } \\
(\mathrm{U} / \mu \mathrm{g})\end{array}$ & $\begin{array}{c}\text { Relative TOP1 } \\
\text { activity }\end{array}$ & $\begin{array}{l}\text { TDP1 activity } \\
\text { (fmol/ } / \mu \mathrm{g})\end{array}$ & $\begin{array}{c}\text { Relative TDP1 } \\
\text { activity }\end{array}$ & $\begin{array}{l}\text { activity ratio } \\
\text { (fmol/U) }\end{array}$ & $\begin{array}{c}\text { relative activity } \\
\text { ratio }\end{array}$ \\
\hline$\# 17$ & $0.138 \pm 0.016$ & $0.260 \pm 0.035$ & 1.884 & $0.785 \pm 0.0509$ & $0.860 \pm 0.056$ & $1.054 \pm 0.206$ & $0.427 \pm 0.0837$ & 1.343 & 0.497 \\
\hline \#22 & $0.116 \pm 0.021$ & $0.472 \pm 0.105$ & 4.075 & $0.741 \pm 0.039$ & $0.813 \pm 0.0430$ & $1.899 \pm 0.216$ & $0.770 \pm 0.0875$ & 2.563 & 0.947 \\
\hline \#29 & $0.0193 \pm 0.0039$ & $0.206 \pm 0.0683$ & 10.640 & $0.148 \pm 0.0180$ & $0.163 \pm 0.0197$ & $0.407 \pm 0.0911$ & $0.165 \pm 0.0369$ & 2.744 & 1.014 \\
\hline$\# 44$ & $0.216 \pm 0.0024$ & $0.296 \pm 0.0606$ & 13.690 & $0.127 \pm 0.0095$ & $0.139 \pm 0.0104$ & $0.717 \pm 0.113$ & $0.291 \pm 0.0460$ & 5.647 & 2.087 \\
\hline$\# 50$ & $0.0490 \pm 0.0116$ & $0.341 \pm 0.0544$ & 6.963 & $0.279 \pm 0.0186$ & $0.306 \pm 0.0204$ & $0.792 \pm 0.154$ & $0.321 \pm 0.0625$ & 2.838 & 1.049 \\
\hline$\# 66$ & $0.0283 \pm 0.0051$ & $0.144 \pm 0.0438$ & 5.100 & $0.419 \pm 0.0719$ & $0.460 \pm 0.0789$ & $0.700 \pm 0.102$ & $0.284 \pm 0.0414$ & 1.671 & 0.618 \\
\hline$\# 42$ & $0.0384 \pm 0.0103$ & $0.222 \pm 0.0628$ & 5.788 & $0.473 \pm 0.0506$ & $0.518 \pm 0.0555$ & $0.286 \pm 0.053$ & $0.116 \pm 0.0216$ & 0.605 & 0.223 \\
\hline$\# 47$ & $0.0141 \pm 0.0033$ & $0.337 \pm 0.0299$ & 23.860 & $0.121 \pm 0.0090$ & $0.133 \pm 0.0099$ & $0.424 \pm 0.0791$ & $0.172 \pm 0.0321$ & 3.501 & 1.294 \\
\hline \#49 & $0.0295 \pm 0.0018$ & $0.194 \pm 0.0332$ & 6.591 & $0.360 \pm 0.0375$ & $0.395 \pm 0.0411$ & $0.877 \pm 0.166$ & $0.356 \pm 0.0675$ & 2.437 & 0.901 \\
\hline \#62 & $0.0105 \pm 0.0022$ & $0.196 \pm 0.0380$ & 18.630 & 0.000 & 0.000 & $0.145 \pm 0.048$ & $0.0588 \pm 0.0195$ & $\mathrm{~N} / \mathrm{A}$ & $\mathrm{N} / \mathrm{A}$ \\
\hline
\end{tabular}




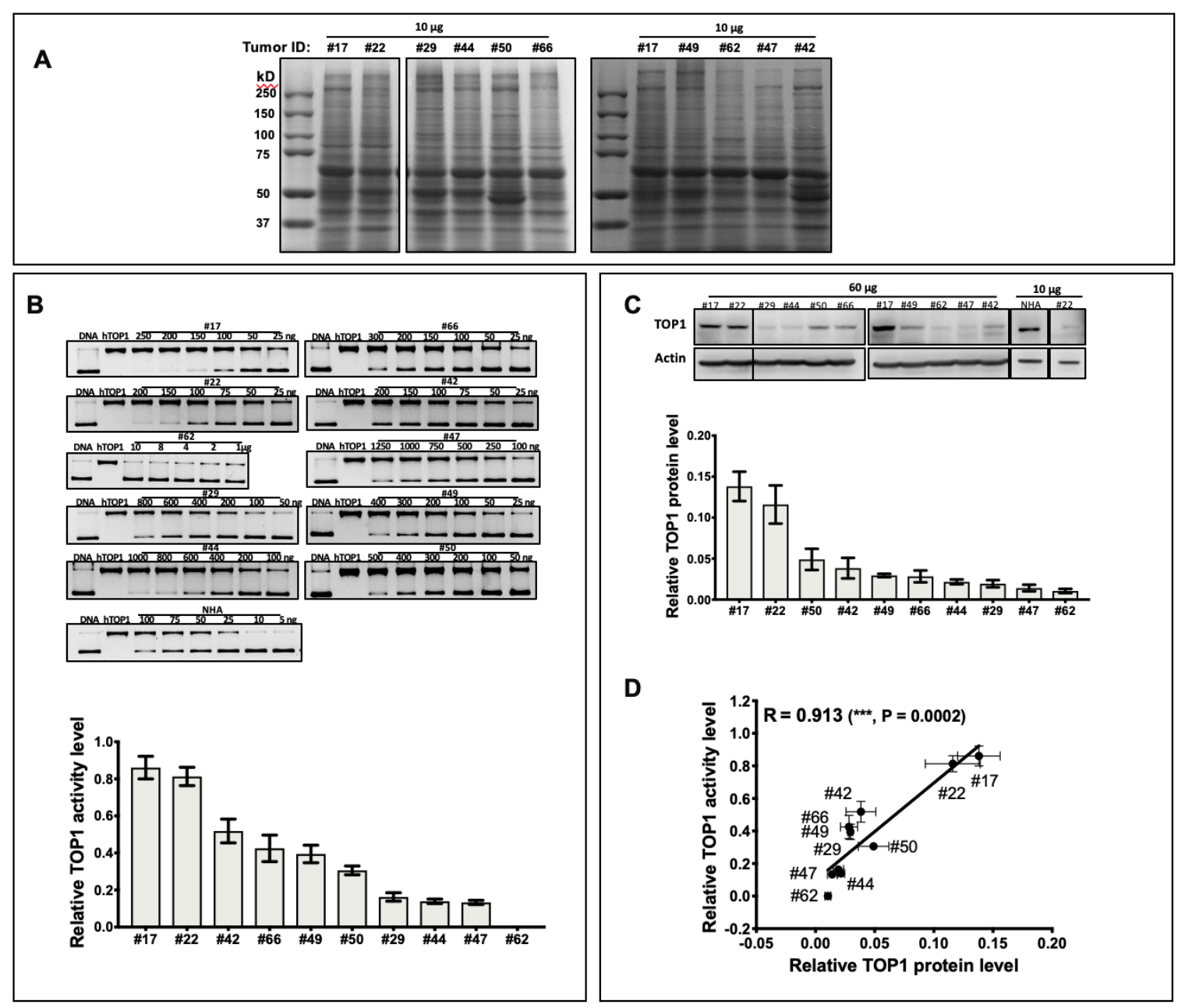

Figure 3.4. Analysis of TOP1 protein expression and activity levels of GBM patient tumors

(A) Coomassie blue staining of patient tumor WCEs (60 $\mu \mathrm{g}$ total proteins) following SDS PAGE. Tumor \#17 was included in both gels. (B) TOP1 activity of GBM patient tumors was measured by relaxation assay. (C) TOP1 expression level in GBM patient tumors was measured by western blot. The signal intensity was first normalized to actin signal to correct for loading, then divided by the NHA signal intensity for comparison. (D) TOP1 activity is significantly correlated with TOP1 protein level. 

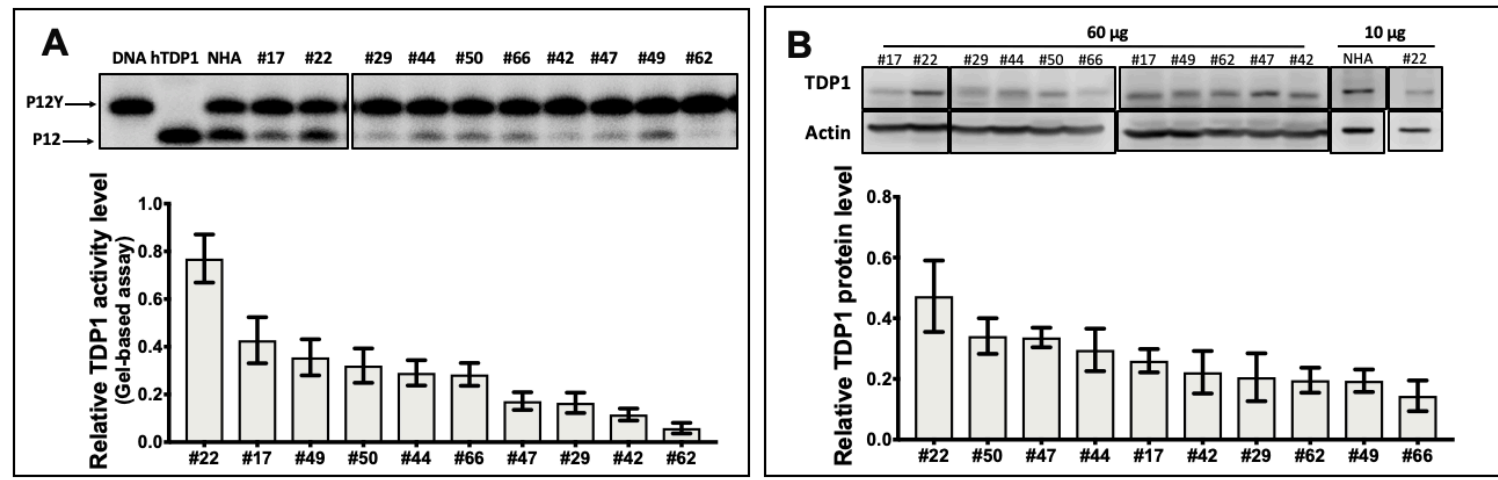

C

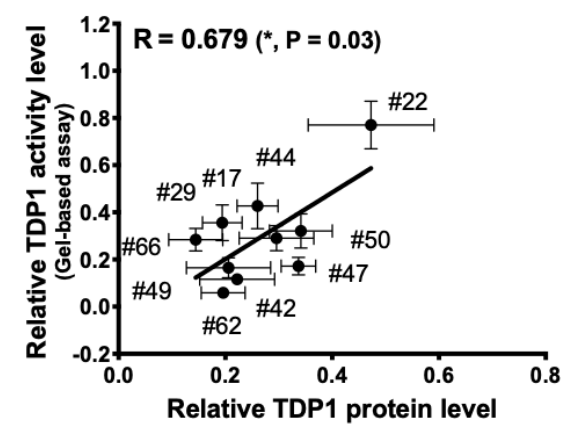

Figure 3.5. Analysis of TDP1 protein expression and activity levels of GBM patient tumors

(A) TDP1 activity of GBM patient tumors was measured by gel-based assay. (B) TOP1 expression level in GBM patient tumors was measured by western blot. The signal intensity was first normalized to actin signal to correct for loading, then divided by the NHA signal intensity for comparison. (C) TDP1 activity is significantly correlated with TDP1 protein level.

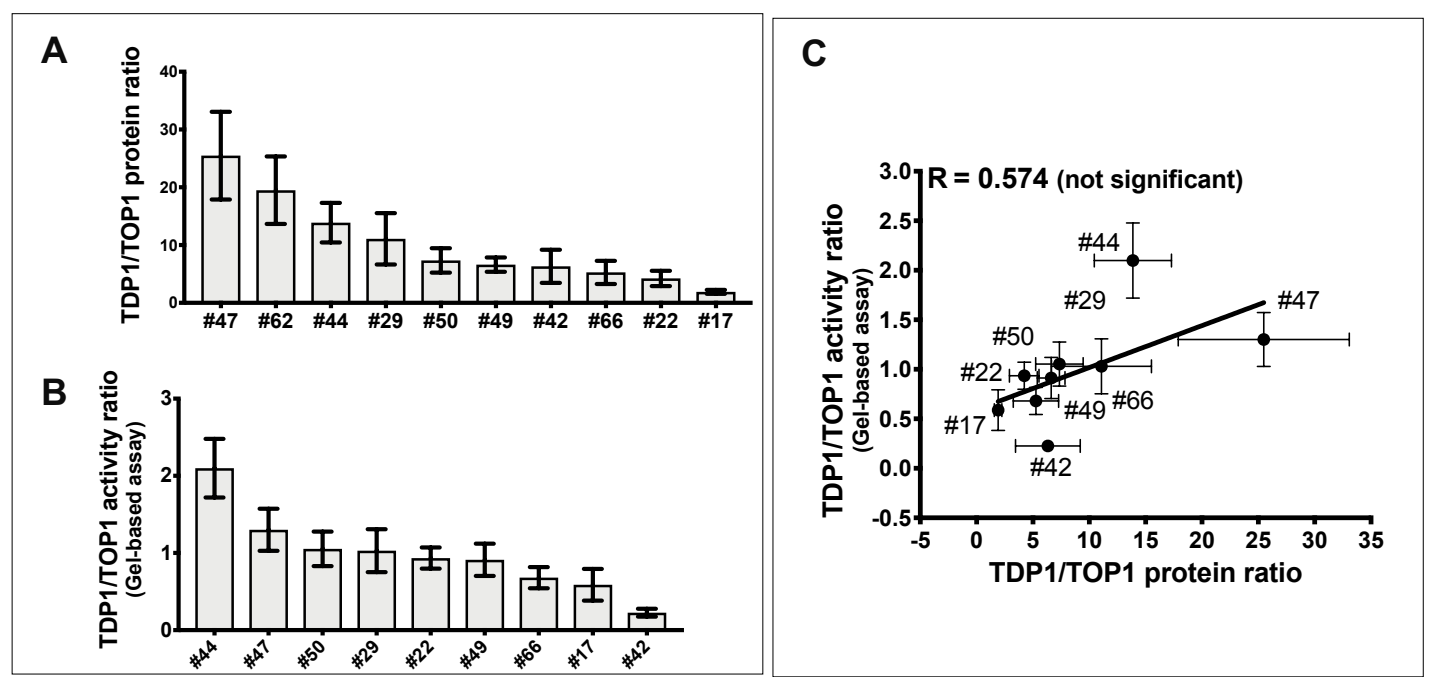

Figure 3.6. Analysis of TDP1/TOP1 ratios of GBM patient tumors 
The bar graphs of the (A) TDP1/TOP1 protein ratio and (A) TDP1/TOP1 activity ratio of GBM patient tumor. (C) TDP1/TOP1 activity ratio is not significantly correlated with TDP1/TOP1 protein ratio.

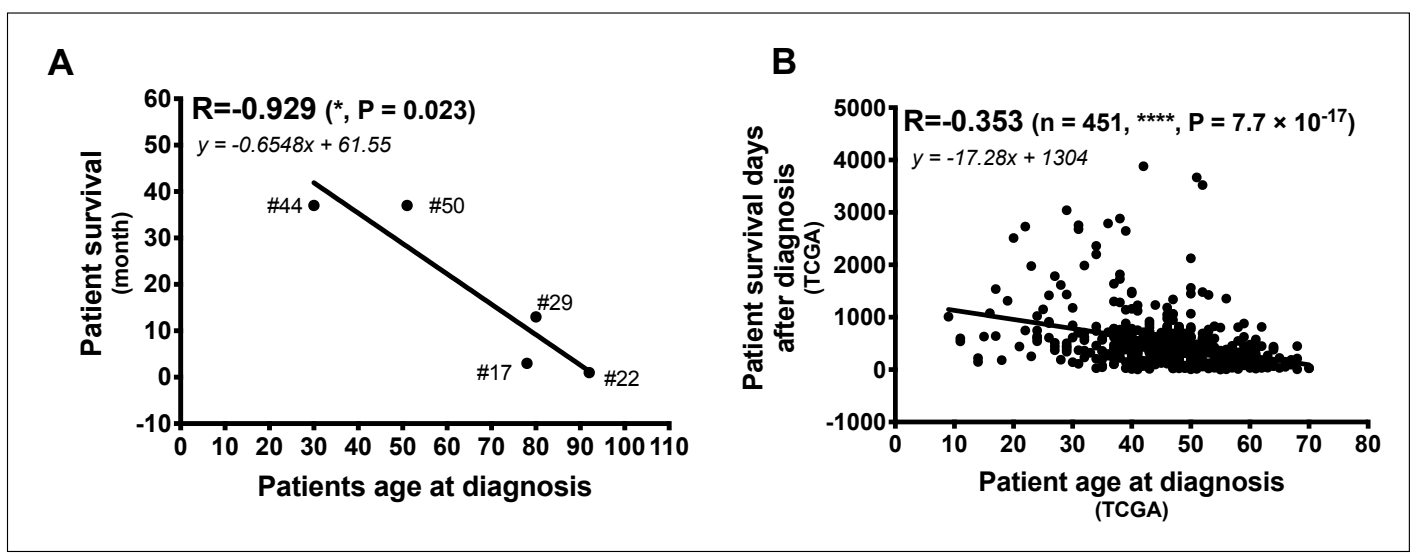

Figure 3.7. Correlations between patient age and survivals

(A) Patient age correlates strongly with patient survivals in our GBM patient cohort. (B) Correlation between patient age and patient survivals from data in the TCGA database. 
Table 3.4. Correlations of patient survival and diagnosis age among cancers from TCGA database

\begin{tabular}{|c|c|c|c|c|c|}
\hline Cancer & name & cancer & Individuals & $\mathbf{R}$ & $\mathbf{P}$ \\
\hline brain & TCGA-GBM & glioblastoma & 451 & -0.353 & $7.74 \mathrm{E}-16$ \\
\hline brain & TCGA-LGG & brain lower grade glioma & 125 & -0.526 & $3 \mathrm{E}-10$ \\
\hline skin & TCGA-SKCM & skin cutaneous melanoma & 221 & -0.301 & 5.09E-06 \\
\hline ovary & TCGA-OV & ovarian serous cystadenocarcinoma & 341 & -0.2 & 0.00019 \\
\hline kidney & TCGA-KIRP & kidney renal papillary cell carcinoma & 44 & 0.316 & 0.03657 \\
\hline breast & TCGA-BRCA & breast invasive carcinoma & 151 & -0.166 & 0.0409 \\
\hline eyes & TCGA-UVM & uveal melanoma & 23 & -0.407 & 0.0539 \\
\hline kid̋ney & TARGET-WT & wilms tumor & 114 & 0.177 & 0.05956 \\
\hline liver & TCGA-LIHC & liver hepatocellular carcinoma & 130 & 0.16 & 0.06828 \\
\hline pleura & TCGA-MESO & mesothelioma & 75 & -0.184 & 0.11407 \\
\hline colorectal & TCGA-READ & rectum adenocarcinoma & 26 & -0.289 & 0.1517 \\
\hline testic & TCGA-TGCT & testicular germ cell tumor & 4 & -0.854 & 0.16 \\
\hline bladder & TCGA-BLCA & bladder urothelial carcinoma & 180 & -0.103 & 0.17011 \\
\hline kidney & TCGA-KIRC & kidney renal clear cell carcinoma & 176 & 0.09886 & 0.19177 \\
\hline soft tissue & TCGA-SARC & sarcoma & 38 & -0.214 & 0.19702 \\
\hline liver & TCGA-CHOL & cholangiocarcinoma & 19 & -0.299 & 0.21293 \\
\hline uterus & TCGA-SARC & sarcoma & 14 & -0.33 & 0.249 \\
\hline uterus & TCGA-UCS & uterine carcinosarcoma & 35 & -0.172 & 0.32275 \\
\hline thyroid & TCGA-THCA & thyroid carcinoma & 16 & 0.177 & 0.51125 \\
\hline colorectal & TCGA-COAD & colon adenocarcinoma & 101 & 0.0573 & 0.56917 \\
\hline blood & TARGET-AML & acute myloid leukemia & 342 & -0.0305 & 0.57441 \\
\hline lung & TCGA-LUSC & lung squamous cell carcinoma & 215 & -0.03 & 0.66319 \\
\hline pancreas & TCGA-PAAD & pancreatic adenocarcinoma & 100 & -0.044 & 0.66639 \\
\hline prostate & TCGA-PRAD & prostate adenocarcinoma & 10 & 0.152 & 0.67546 \\
\hline esophagus & TCGA-ESCA & esophageal carcinoma & 76 & -0.048 & 0.68331 \\
\hline cervix & TCGA-CESC & cervical squamous cell carcinoma and endocervical & 72 & 0.0454 & 0.70502 \\
\hline adrenal gland & TCGA-ACC & adrenocortical carcinoma & 33 & -0.066 & 0.71406 \\
\hline lung & TCGA-LUAD & lung adenocarcinoma & 175 & -0.027 & 0.71963 \\
\hline stomach & TCGA-STAD & stomach adenocarcinoma & 171 & -0.25 & 0.7501 \\
\hline lymph nodes & TCGA-DLBC & lymphoid neoplasm diffuse large B-cell lymphoma & 8 & 0.123 & 0.77214 \\
\hline kidney & TARGET-RT & rhabdoid tumor & 34 & -0.049 & 0.78126 \\
\hline bone marrow & TARGET-OS & bone marrow & 100 & -0.025 & 0.80595 \\
\hline kidney & TCGA-KICH & kidney chromophobe & 12 & 0.07017 & 0.82845 \\
\hline uterus & TCGA-UCEC & uterine corpus endometrial carcinoma & 91 & 0.023 & 0.82865 \\
\hline head and & TCGA-HNSC & head and neck squamous cell carcinoma & 223 & 0.008 & 0.90486 \\
\hline thymus & TCGA-THYM & thymoma & 7 & 0.069 & 0.907 \\
\hline
\end{tabular}



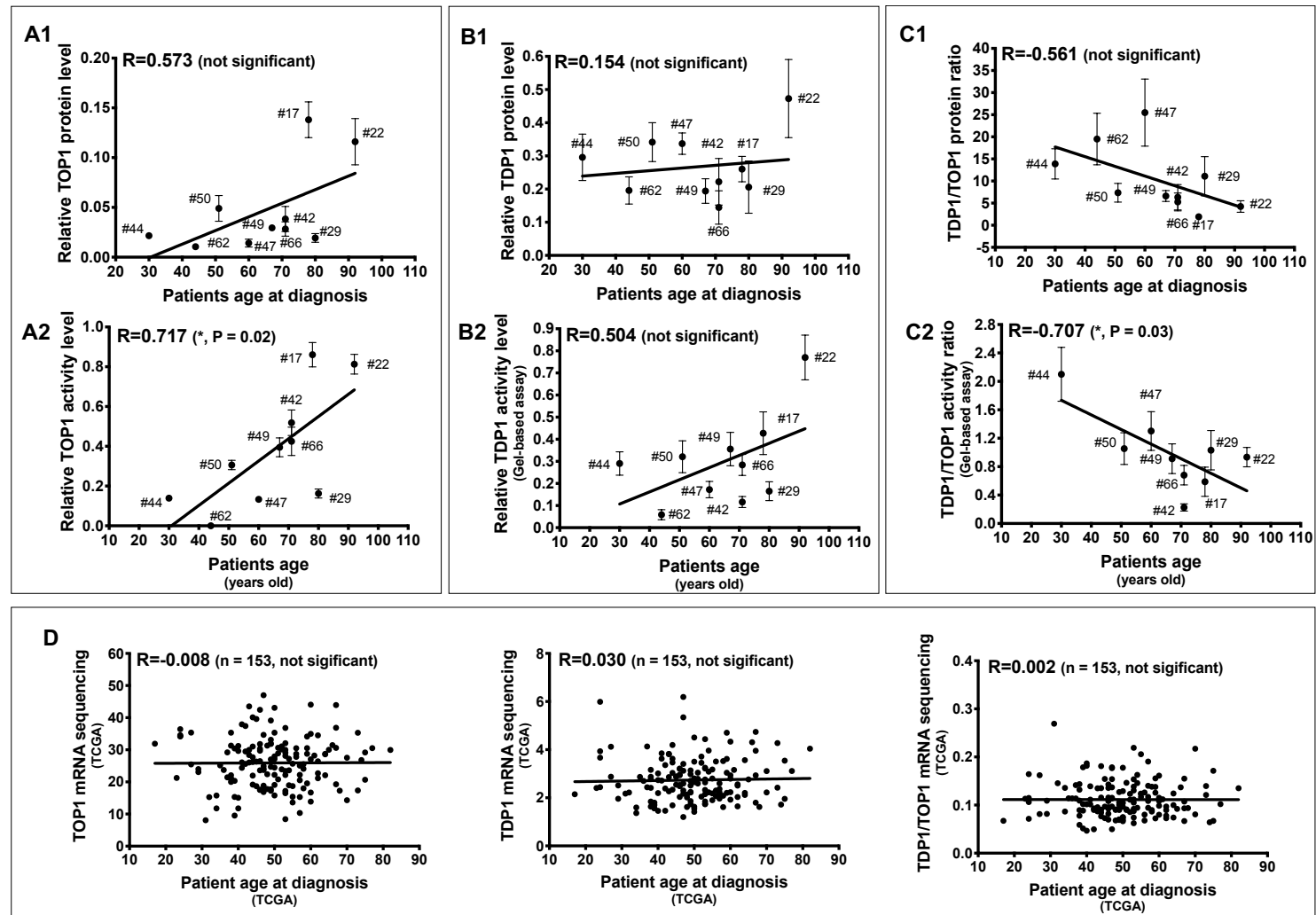

Figure 3.8. Correlations between TOP1, TDP1, TDP1/TOP1 ratio in GBM patient tumors and patient ages

Patient age at diagnosis does not correlate with (A1) TOP1 protein level, (B1) TDP1 protein, (B2) TDP1 activity, (C1) TDP1/TOP1 protein ratio, (D) TOP1 mRNA level, TDP1 mRNA level, nor TDP1/TOP1 mRNA ratio. Patient age at diagnosis is significantly correlated with (A2) TOP1 activity level and (C1) TDP1/TOP1 activity ratio. 
Table 3.5. GBM tumor information from TCGA database

\begin{tabular}{|c|c|c|c|c|c|c|}
\hline \multicolumn{7}{|c|}{ TCGA Database } \\
\hline GBM patients ID & gender & Age at diagnosis & Days to death & TOP1 mRNA & TOP1 mRNA & mRNA of TDP1/TOP1 ratio \\
\hline 4c42dc4e-66b7-40bf-9fbe-b92543248198 & male & 17 & 1537 & 31.900 & 2.145 & 0.0673 \\
\hline 2188c194-dfe4-4471-9b8b-050db1a1062c & male & 24 & 632 & 34.153 & 2.441 & 0.0715 \\
\hline bde84ea9-55c9-4d6d-be86-58fd9222c1d6 & male & 24 & 1024 & 34.554 & 3.669 & 0.1062 \\
\hline 054f472f-98cb-4559-b2e2-b5f80ofc8eef & male & 24 & 603 & 34.271 & 3.933 & 0.1148 \\
\hline 2f61ea6b-a3f2-477f-ab98-47ed07b3b2cd & female & 27 & 442 & 35.352 & 2.874 & 0.0813 \\
\hline 4776b959-d5f5-41ad-ab39-dba6031f6884 & male & 27 & 510 & 25.441 & 4.121 & 0.1620 \\
\hline bc7a0c8f-c1c1-447c-8019-389e52525081 & male & 29 & 427 & 23.066 & 2.515 & 0.1090 \\
\hline edcfac32-adb4-4fe7-86a0-309d3c6430e5 & female & 29 & 448 & 23.997 & 1.961 & 0.0817 \\
\hline 53abce1d-7e33-4ebd-832f-f3789f67377f & male & 31 & 2681 & 8.081 & 2.175 & 0.2692 \\
\hline 5bbeb8a7-3ac2-4ef1-bd48-6f83bc994a75 & male & 32 & 362 & 15.272 & 2.220 & 0.1454 \\
\hline 66bd4c9e-2ebd-4092-a2b0-69027e8af5b8 & male & 34 & 737 & 11.750 & 1.595 & 0.1358 \\
\hline 0456a66b-c9b3-4eb1-9872-424a7ea712a2 & male & 34 & 28 & 15.753 & 1.363 & 0.0865 \\
\hline 35a7e49e-747b-45ce-9a07-3a5faba0ca94 & male & 35 & 77 & 25.128 & 2.866 & 0.1140 \\
\hline eddbca7a-d668-4c5d-9843-340d7f18e30e & male & 37 & 405 & 21.413 & 2.436 & 0.1138 \\
\hline 5ef9486a-aeff-421d-b620-03ef119d85a5 & male & 37 & 333 & 29.206 & 4.132 & 0.1415 \\
\hline 5c984433-33cf-42fc-b3ba-511 efcdcab19 & male & 38 & 360 & 35.332 & 3.161 & 0.0895 \\
\hline a589e2dc-7649-492c-9569-592698acaa6f & female & 38 & 666 & 22.079 & 2.414 & 0.1093 \\
\hline 6ff96a7e-1b96-4530-b8a8-7f2e9e541955 & male & 38 & 550 & 31.292 & 1.840 & 0.0588 \\
\hline 52408d9f-2637-4952-9b90-cb607a860f23 & female & 38 & 224 & 20.977 & 1.634 & 0.0779 \\
\hline 43d98306-8b1f-4840-a1a0-146ba0c36400 & male & 38 & 360 & 20.004 & 2.872 & 0.1436 \\
\hline 456bcab3-165d-456f-94e3-f34f81a61d2e & male & 38 & 385 & 21.042 & 2.776 & 0.1319 \\
\hline 9b9654c9-5a64-4a8e-b1f0-987437e6012e & male & 39 & 29 & 20.328 & 1.796 & 0.0884 \\
\hline 9ad6c241-ccc5-4532-a6ac-098271b13b5f & male & 39 & 771 & 15.321 & 1.563 & 0.1020 \\
\hline cd73f38a-f6ff-4e7b-bd43-ec7b82dbe7df & female & 39 & 883 & 30.408 & 1.562 & 0.0514 \\
\hline cdfff14d-ed6c-419f-88f5-e7dee96fcaf6 & male & 39 & 460 & 9.536 & 1.702 & 0.1785 \\
\hline d6de8d1c-e5ff-45cd-b53e-f943d2578713 & female & 40 & 1458 & 29.639 & 3.011 & 0.1016 \\
\hline e921772f-f81a-49bc-b35e-3354c94447c0 & male & 40 & 82 & 11.761 & 2.194 & 0.1866 \\
\hline 309005a2-93a8-4566-b8d3-6b9310144266 & male & 40 & 141 & 31.190 & 1.457 & 0.0467 \\
\hline 3f960d3b-a58c-43d0-a8a4-f3555b399c9d & male & 40 & 254 & 15.046 & 2.734 & 0.1817 \\
\hline 2f4a127f-101a-4192-b3e8-f9be2c8648bc & male & 41 & 5 & 26.085 & 3.625 & 0.1390 \\
\hline 46bfebf4-0ef6-4348-81dc-d7d3cb52c08f & male & 41 & 544 & 37.923 & 3.849 & 0.1015 \\
\hline b1c4579c-72fa-4974-830c-b6a81ace45f4 & female & 41 & 532 & 24.388 & 2.715 & 0.1113 \\
\hline 987cb702-057b-4198-8ef3-9cf6a9c51989 & female & 42 & 648 & 25.617 & 2.387 & 0.0932 \\
\hline d6a48eb1-7c20-4ae3-ae35-b6b641238ef1 & female & 42 & 537 & 29.487 & 1.461 & 0.0496 \\
\hline 44ef426e-b67d-4b49-80a3-86681b9abf1a & male & 42 & 82 & 37.397 & 3.359 & 0.0898 \\
\hline 7cada85b-00b1-41e5-9924-e09eb077ad56 & male & 43 & 394 & 29.963 & 2.860 & 0.0955 \\
\hline ee3fc631-1e88-4f70-ab31-335851b38640 & male & 43 & 98 & 28.374 & 3.825 & 0.1348 \\
\hline 7cbabf1d-ec38-4048-ae1c-7doł3001691b & male & 43 & 342 & 26.044 & 2.267 & 0.0870 \\
\hline af055b98-be6a-4012-ac64-f1b6539b23d0 & female & 43 & 357 & 43.525 & 3.813 & 0.0876 \\
\hline 878584ad-e6b6-493a-977f-3e284f5d9f68 & female & 44 & 175 & 27.677 & 2.337 & 0.0844 \\
\hline 5327e899-a20d-4571-8236-98454bad574e & female & 44 & 98 & 26.212 & 3.034 & 0.1157 \\
\hline a597bfa8-8c4d-4f8e-9d85-8a9fdc2c56ff & male & 44 & 231 & 19.172 & 3.468 & 0.1809 \\
\hline 93ed7a2b-b0cb-4a84-871f-5c34a0b6a640 & male & 44 & 455 & 40.104 & 3.623 & 0.0903 \\
\hline 15e058e8-2f33-4fb4-92af-3d9dea1fa906 & male & 45 & 178 & 18.679 & 2.880 & 0.1542 \\
\hline 6e72d2e2-96fe-4fbb-9fe6-39ec28753eb6 & male & 45 & 154 & 26.335 & 2.546 & 0.0967 \\
\hline 9d1d9ae5-4640-4060-a207-c9c5b0e905e1 & male & 46 & 535 & 23.610 & 3.199 & 0.1355 \\
\hline f4fe7c02-be19-4929-8638-960e5776494c & male & 46 & 114 & 31.792 & 2.940 & 0.0925 \\
\hline a515cf2d-e918-4958-9bf6-e611b425a97e & female & 46 & 543 & 17.586 & 2.035 & 0.1157 \\
\hline bf339349-062f-4ea9-a0b2-d87d3a21099e & female & 46 & 975 & 17.514 & 2.500 & 0.1428 \\
\hline $\mathrm{c} 7 \mathrm{~b} 4 \mathrm{fd} 72-\mathrm{b} 45 \mathrm{~d}-4524-8424-983120 \mathrm{abfec} 0$ & male & 46 & 506 & 42.442 & 2.962 & 0.0698 \\
\hline 6c5154d2-af36-492f-b520-d925528824e4 & male & 46 & 468 & 26.466 & 2.530 & 0.0956 \\
\hline dd76930a-1678-4b70-9864-730534174d41 & female & 47 & 300 & 23.716 & 2.301 & 0.0970 \\
\hline c184c3ca-7ad3-4202-b108-cb9fd5f5d947 & female & 47 & 460 & 46.993 & 5.343 & 0.1137 \\
\hline 224235c1-5b6e-48d5-a5d1-777dfede0f1e & female & 47 & 598 & 17.665 & 3.124 & 0.1768 \\
\hline 386b629e-fab1-4033-b088-45d6eeb4a13e & male & 47 & 239 & 16.842 & 2.594 & 0.1540 \\
\hline
\end{tabular}




\begin{tabular}{|c|c|c|c|c|c|c|}
\hline \multicolumn{7}{|c|}{ TCGA Database } \\
\hline GBM patients ID & gender & Age at diagnosis & Days to death & TOP1 mRNA & TOP1 mRNA & mRNA of TDP1/TOP1 ratio \\
\hline 159e0318-6173-440f-be07-8d956086e99d & male & 47 & 1062 & 24.125 & 1.201 & 0.0498 \\
\hline 0389b35b-651b-4776-b12a-d315a100f47c & male & 47 & 1062 & 24.905 & 3.408 & 0.1369 \\
\hline 0078b0c4-68a9-483b-9aab-61156d263213 & female & 47 & 485 & 34.656 & 6.190 & 0.1786 \\
\hline c970240f-03e2-4395-85be-5eb81a69b710 & female & 48 & 454 & 17.792 & 1.615 & 0.0908 \\
\hline e17a6048-7a72-42c0-ad3f-97cbff02bc9f & male & 48 & 737 & 31.303 & 2.129 & 0.0680 \\
\hline ea82c1da-eada-4108-80ec-77ce891d82a7 & male & 48 & 175 & 22.394 & 2.016 & 0.0900 \\
\hline c9e4fobf-48fc-4600-9e03-314bc575273f & female & 49 & 335 & 31.834 & 2.219 & 0.0697 \\
\hline da5f6940-e8ee-4fd1-a8da-4cd68e02e59c & female & 49 & 76 & 33.123 & 2.977 & 0.0899 \\
\hline 74139255-a635-4c87-814d-3dd04ed630a8 & male & 49 & 317 & 27.020 & 2.509 & 0.0929 \\
\hline 2b82e941-1b16-444e-af41-24dbc0a7e8b5 & female & 49 & 675 & 24.694 & 3.139 & 0.1271 \\
\hline be3a7ef3-34ed-40e1-9d9c-187940596b26 & male & 49 & 480 & 39.127 & 2.705 & 0.0691 \\
\hline 30011f30-2926-47f2-a8f3-4f1b58ffa227 & male & 49 & 485 & 17.701 & 1.864 & 0.1053 \\
\hline 4b43da9d-60ee-4269-b44d-d92c034b844c & male & 49 & 313 & 17.235 & 1.731 & 0.1004 \\
\hline eae44c1c-1628-4b58-8b90-d3372e3577d5 & male & 49 & 323 & 31.890 & 2.242 & 0.0703 \\
\hline 737b35e1-d668-4fce-9b6e-76946c7952b6 & male & 50 & 489 & 43.070 & 4.505 & 0.1046 \\
\hline 5252c0b7-be05-4c0c-a8ac-afe9ad459489 & female & 50 & 772 & 27.948 & 2.694 & 0.0964 \\
\hline d558203d-3770-42d4-accb-008ace280f48 & male & 50 & 157 & 35.324 & 2.649 & 0.0750 \\
\hline 66afd908-0c76-469e-abc3-89563de338c6 & female & 50 & 6 & 22.215 & 1.542 & 0.0694 \\
\hline ea3b5da2-6a12-400c-bfof-e442f5ec1132 & female & 50 & 97 & 27.143 & 3.502 & 0.1290 \\
\hline 1f48f010-98fe-4b5a-b96a-14fb25eff23f & male & 50 & 2126 & 19.052 & 1.416 & 0.0743 \\
\hline 8da3103e-3e6c-4176-a583-d5fe5e60601e & female & 50 & 1448 & 24.462 & 1.625 & 0.0664 \\
\hline 79a68b32-29a3-47bf-9b2b-643ec7323d73 & male & 50 & 618 & 15.791 & 2.805 & 0.1776 \\
\hline 7fe37feb-e205-4524-8c98-1f9ac5fe0700 & female & 51 & 419 & 28.882 & 2.594 & 0.0898 \\
\hline 55a063b0-98ad-4700-b3ce-61bfe364fec8 & male & 51 & 133 & 20.809 & 3.045 & 0.1463 \\
\hline f19850cb-50c4-4f3a-ba80-b1464958ffa8 & male & 52 & 419 & 30.110 & 3.713 & 0.1233 \\
\hline 01a92062-967a-4900-8dc7-a5ecd3b3f8e2 & male & 52 & 399 & 23.932 & 2.046 & 0.0855 \\
\hline e876dd29-68b0-4bf1-83d1-488c40068a35 & male & 52 & 585 & 31.055 & 3.453 & 0.1112 \\
\hline f45f4a30-6b4c-4f15-9140-959d6a25a45f & male & 53 & 505 & 16.488 & 2.149 & 0.1304 \\
\hline 5613f5f6-086d-470b-8f77-6dcb7f8625b7 & male & 53 & 1426 & 17.188 & 2.639 & 0.1536 \\
\hline 25f41de3-9d70-45df-913f-4fb3e5fof7d6 & male & 53 & 22 & 8.419 & 1.844 & 0.2191 \\
\hline 1e80ccf6-ef81-4662-bf5e-392f092c1e67 & male & 53 & 406 & 28.108 & 1.747 & 0.0622 \\
\hline 8e6b9705-e9d2-4fbc-ac03-35c1a5115eef & male & 53 & 388 & 22.143 & 2.326 & 0.1051 \\
\hline 1b25795e-69ad-47fd-bb2f-94ffo910fae 1 & male & 53 & 766 & 29.979 & 2.758 & 0.0920 \\
\hline f5bc5d97-e054-4e53-992d-71b896bd97d5 & male & 53 & 375 & 36.813 & 3.217 & 0.0874 \\
\hline 8df94420-c736-4a36-b001-5dbe3dff17fo & male & 54 & 138 & 18.954 & 3.085 & 0.1627 \\
\hline 149be735-d5db-43b6-80b7-d40e3a84500b & male & 54 & 828 & 23.600 & 2.226 & 0.0943 \\
\hline a2338b30-f511-4163-af3b-1e4a40ffo0e1 & male & 54 & 68 & 27.196 & 3.962 & 0.1457 \\
\hline 5a86d9f1-d38d-4b78-9a23-c7855a20ca2d & female & 55 & 164 & 13.604 & 2.800 & 0.2058 \\
\hline e2e83064-7d1c-4dd5-993f-cc7a5ee228ed & male & 55 & 803 & 18.690 & 2.182 & 0.1168 \\
\hline 352768f9-3ce1-419c-beef-6515c78f5d7a & male & 55 & 148 & 15.385 & 1.899 & 0.1234 \\
\hline e0e1b5b3-6e3c-4b79-aa2a-32b320c3e45a & male & 55 & 232 & 25.652 & 3.174 & 0.1237 \\
\hline 752a6e21-9a91-417f-beba-bfdf331d5cac & female & 56 & 279 & 27.794 & 3.508 & 0.1262 \\
\hline d9fff27f-48e3-43fd-a8cf-3db246cf4221 & male & 56 & 343 & 28.702 & 2.302 & 0.0802 \\
\hline 652a39fo-c539-4303-bedc-f0d7f4669d9f & male & 56 & 384 & 30.496 & 2.069 & 0.0678 \\
\hline 884f867b-4a8b-4b67-8fe4-ab3f068be84e & female & 57 & 108 & 25.072 & 2.366 & 0.0944 \\
\hline d59ffef5-f39b-4627-a7c7-6920b99c2408 & male & 57 & 36 & 15.296 & 2.143 & 0.1401 \\
\hline 69d56f2d-6924-409b-9d1e-c8d69b400270 & female & 57 & 270 & 20.519 & 2.227 & 0.1085 \\
\hline de7b7cac-f094-4d59-8651-e991e34ea093 & female & 57 & 225 & 22.209 & 2.598 & 0.1170 \\
\hline 66f3с936-272e-4a1e-8567-f609af411329 & female & 58 & 64 & 18.000 & 1.614 & 0.0897 \\
\hline bc316a17-9d73-4ef3-97e9-c4ac5516b75a & male & 58 & 329 & 24.070 & 2.085 & 0.0866 \\
\hline 314d9188-c8fd-43fc-905d-b6889de542c8 & male & 58 & 548 & 25.503 & 3.524 & 0.1382 \\
\hline 72f88d18-03be-4b51-9f4a-1151521b7292 & female & 59 & 880 & 34.126 & 4.704 & 0.1378 \\
\hline cf286533-5c8a-40f3-9c69-f46264c7893b & female & 59 & 380 & 28.764 & 3.614 & 0.1256 \\
\hline 51c3409d-5d77-4720-83db-0e6de065f82c & female & 59 & 83 & 19.547 & 3.039 & 0.1555 \\
\hline c34760a2-f70e-48c4-a7c2-eb359f8aeb71 & female & 60 & 142 & 16.686 & 1.922 & 0.1152 \\
\hline
\end{tabular}




\begin{tabular}{|c|c|c|c|c|c|c|}
\hline \multicolumn{7}{|c|}{ TCGA Database } \\
\hline GBM patients ID & gender & Age at diagnosis & Days to death & TOP1 mRNA & TOP1 mRNA & mRNA of TDP1/TOP1 ratio \\
\hline c04657d2-b71b-4402-82fa-02747cce331d & female & 60 & 111 & 27.046 & 2.934 & 0.1085 \\
\hline f6b2f52b-284d-4bde-9a3d-a0f458d07f08 & female & 60 & 124 & 13.860 & 2.234 & 0.1612 \\
\hline 6c28f086-6a25-40b6-93eb-bba0014acda6 & male & 60 & 33 & 34.970 & 2.794 & 0.0799 \\
\hline 872abc8a-6c1f-4114-b993-7d0327fb38bd & male & 60 & 146 & 44.047 & 4.332 & 0.0984 \\
\hline $34 \mathrm{f} 216 \mathrm{fb}-09 \mathrm{dc}-48 \mathrm{af}-9 \mathrm{e} 09-7 \mathrm{~d} 12 \mathrm{cc} 07 \mathrm{c} 1 \mathrm{f7}$ & female & 61 & 577 & 28.215 & 3.159 & 0.1120 \\
\hline 3caf009f-d9e0-4c57-b1d9-8eb59fc833bd & male & 62 & 448 & 22.704 & 2.031 & 0.0895 \\
\hline e6e2d4c3-d37c-4de3-ac68-b301800770f0 & female & 62 & 138 & 26.404 & 2.559 & 0.0969 \\
\hline 69d0a566-5fbf-45f6-a240-649b06868e27 & female & 62 & 87 & 21.137 & 1.644 & 0.0778 \\
\hline e3251837-fff3-4dad-856f-108e20d03dad & male & 64 & 382 & 28.725 & 3.565 & 0.1241 \\
\hline 9348e446-0e43-4210-b07e-c534980cbf62 & female & 64 & 414 & 22.068 & 2.202 & 0.0998 \\
\hline ca893d12-3d6c-4e6f-b0e7-7f4eb8bb724b & male & 66 & 150 & 31.459 & 4.308 & 0.1369 \\
\hline 543c0a7d-ccd7-4b8d-98fb-eabec806231d & male & 67 & 119 & 19.262 & 1.797 & 0.0933 \\
\hline dfa3ef71-7006-4c6d-81c4-e0c0c7b75c26 & female & 67 & 94 & 43.928 & 2.932 & 0.0668 \\
\hline d88bbd87-e876-4a44-96f5-c28ceac661b8 & male & 68 & 211 & 17.257 & 1.619 & 0.0938 \\
\hline 722f462d-f939-4bc1-aae4-8778b1335a87 & male & 70 & 26 & 14.316 & 3.110 & 0.2172 \\
\hline 3a3fc890-1985-4353-861b-dc3abfb364b1 & female & 23 & & 21.251 & 2.406 & 0.1132 \\
\hline 620282f9-f932-4335-9c7d-ece53dcaf7a1 & female & 24 & & 36.425 & 5.989 & 0.1644 \\
\hline a262928c-e20a-4c02-8114-1227e05c43e1 & male & 36 & & 23.714 & 2.702 & 0.1139 \\
\hline c29d73c0-c885-4105-bf74-38e9178e71c9 & male & 44 & & 21.983 & 1.685 & 0.0767 \\
\hline a2ac9937-f351-4d78-9261-264bf6c21e0c & male & 44 & & 31.006 & 4.193 & 0.1352 \\
\hline 74ce7e7f-e214-4b6e-8551-114a153ab7fb & female & 45 & & 39.587 & 2.881 & 0.0728 \\
\hline d1547b99-3c96-4c62-8261-5111bcf860a9 & female & 46 & & 29.720 & 3.213 & 0.1081 \\
\hline 350232cb-b9ba-465b-be9a-81afbc6a92e9 & male & 46 & & 30.292 & 2.484 & 0.0820 \\
\hline 22e0c3ea-9f6d-4d73-9282-17ee4553f436 & female & 47 & & 18.827 & 2.167 & 0.1151 \\
\hline 8ff9f921-f9e9-41c1-a5d4-891fd4cfe979 & male & 51 & & 30.612 & 2.786 & 0.0910 \\
\hline c2f7f72f-13ae-4efc-9cda-69ca037b4498 & male & 53 & & 23.397 & 1.732 & 0.0740 \\
\hline b98184b9-6190-4e95-a1cf-8cffb44b9963 & male & 53 & & 29.103 & 3.247 & 0.1116 \\
\hline 521ea765-1bd1-423d-a75d-091243df37a9 & male & 53 & & 32.048 & 4.436 & 0.1384 \\
\hline 47a4161c-9c61-48f5-b9bc-a6d1acad4e5a & male & 57 & & 10.318 & 1.965 & 0.1905 \\
\hline a28b256e-e085-467d-bdba-5c39718012d7 & male & 59 & & 30.507 & 2.207 & 0.0724 \\
\hline 7a650a2c-bc3f-4e0c-820e-4f492977107b & male & 62 & & 34.485 & 2.505 & 0.0726 \\
\hline 4644a15f-3115-4f27-86b2-b092419431e1 & male & 64 & & 28.608 & 2.118 & 0.0741 \\
\hline d73ca945-b60b-4b5c-ac53-7ef2602a4951 & female & 65 & & 30.005 & 2.764 & 0.0921 \\
\hline 153c2442-ea61-4b5e-8c5c-c71d287c6055 & female & 67 & & 36.851 & 3.954 & 0.1073 \\
\hline 8d2e88d9-d8d0-4c42-8aa2-205a788dea58 & male & 67 & & 30.594 & 4.738 & 0.1549 \\
\hline 30256f61-7be9-4d47-8afd-afafa7a079c0 & female & 70 & & 27.535 & 2.221 & 0.0806 \\
\hline 7338e476-10ff-444a-a16f-429d28355f65 & male & 73 & & 17.338 & 2.420 & 0.1396 \\
\hline ba383ea6-c885-49f0-bddc-e00be0230a6b & female & 73 & & 35.299 & 4.273 & 0.1210 \\
\hline 20bad0d5-3135-49a4-a119-fa7a1e56fd1b & male & 74 & & 26.793 & 1.717 & 0.0641 \\
\hline 2c5fa2d4-8e35-42e4-8bca-9fb3371a19c8 & male & 75 & & 20.670 & 3.542 & 0.1713 \\
\hline 98e2f2ec-bdcd-490a-bf45-600e3b6c7491 & male & 75 & & 29.172 & 1.957 & 0.0671 \\
\hline aa7ad106-eadc-489e-83b2-5698652434ea & female & 77 & & 30.517 & 3.112 & 0.1020 \\
\hline 1030a6b9-0df8-4d60-b69f-2a36e630a6ad & male & 82 & & 29.943 & 4.043 & 0.1350 \\
\hline
\end{tabular}




\section{CONCLUSION}

In this chapter, we observed a greater variation of TDP1/TOP1 activity ratio levels among the patient tumors than GBM cell lines, suggesting the variation of TDP1/TOP1 activity ratios has the potential to be utilized as a predictive biomarker in clinical trials. We also observed a positive correlation of GBM patient age with TOP1 activity level and a negative correlation of patient age with TDP1/TOP1 activity ratio level, suggesting that elderly patients lacking TDP1 repair activity may benefit from chemotherapy treatment with TOP1 poisons. Combination treatment of TOP1 poisons and TDP1 inhibitors might be needed for the treatment of patients of younger age. In addition, we observed a negative correlation between patient age and survival time after diagnosis in both experimental results $(n=5)$ and TCGA database $(n=451)$, suggesting TOP1 activity and TDP1/TOP1 activity could be a potential prognosis biomarker in GBM. Patients with lower TOP1 activity and higher TDP1/TOP1 activity ratio might be more likely to have a longer survival time. As we concluded from the previous chapter, TDP1/TOP1 activity ratio might be a potential predictive biomarker of GBM response to IRT treatment, therefore TDP1/TOP1 activity ratio could also be explored as a prognosis biomarker for GBM cancers. Our hypothesis needs to be further confirmed in future studies.

GSC cell lines were also investigated in our study. However, neither TOP1, TDP1 alone, nor TDP1/TOP1 ratios are significantly correlated with IRT IC ${ }_{50}$ in GSC cell lines. The results are different from GBM cell lines as we concluded from the previous chapter that TDP1/TOP1 activity ratio is a predictive indicator for IRT 
sensitivity for GBM cell lines. Further experiments with a higher number of GSC cell lines are needed to obtain a more rational conclusion.

According to Chapter II, there is no correlation between TOP1 and TDP1 at the protein or activity levels for the GBM cell lines results as well as the GBM cell lines data in the CellMinerCDB database. Results from this chapter, also indicated that there is no correlation between TOP1 and TDP1 in GSC cell lines. In contrast, we observed a significant correlation between TOP1 mRNA and TDP1 mRNA levels for GBM patient tumors in the TCGA database. There is also a significant correlation of TOP1 activity and TDP1 activity in the ten GBM patient tumors studied here (Table 3.6). Therefore, even though TOP1 and TDP1 might be independent of each other in cell line models, the relationship between these two activities in GBM patient tumors need to be further studied.

We observed that TOP1 and TDP1 protein levels do not correlate with their activity levels for GBM cell lines, suggesting that it might be due to the PTMs in cells. In this chapter, we observed a similar pattern in GSC cell lines. However, in GBM patient tumors, TOP1 and TDP1 protein levels have stronger correlations with their activity levels (Table 3.7). The results might suggest that in clinical GBM tumors, TDP1 and TOP1 activities are not as strongly modulated by PTMs as in GBM cell line models. The TDP1/TOP1 activity ratio is not consistently correlated with TDP1/TOP1 protein ratio, suggesting activity level measurements are necessary for biomarker screenings. 
Table 3.6. Correlation between TOP1 and TDP1 levels in GBM cell lines, GSC cell lines, and GBM tumors

\begin{tabular}{|c|c|c|c|c|c|c|}
\hline \multirow{4}{*}{\multicolumn{3}{|c|}{ Cell type and Databases }} & \multicolumn{3}{|c|}{ Experimental results } & Database panel \\
\hline & & & TOP1 protein & \multirow{2}{*}{\multicolumn{2}{|c|}{$\begin{array}{c}\text { TOP1 activity } \\
\text { vs TDP1 activity }\end{array}$}} & TOP1 mRNA \\
\hline & & & \multirow{2}{*}{ vs TDP1 protein } & & & \multirow{2}{*}{ vs TDP1 mRNA } \\
\hline & & & & Gel-based assay & FL-based assay & \\
\hline \multirow{8}{*}{ Cell lines } & \multirow{4}{*}{$\begin{array}{l}\text { GBM cell } \\
\text { lines }\end{array}$} & Set \#1, GBM ( $n=9$ ) & $\begin{array}{c}\mathrm{R}=-0.114 ; \mathrm{P}=0.771 \\
(\mathrm{~ns})\end{array}$ & $\begin{array}{c}\mathrm{R}=0.141 ; \mathrm{P}=0.717 \\
(\mathrm{~ns})\end{array}$ & $\begin{array}{c}\mathrm{R}=0.072 ; \mathrm{P}=0.854 \\
\text { (ns) }\end{array}$ & $\mathrm{N} / \mathrm{A}$ \\
\hline & & Set \#2, GBM ( $n=9$ ) & $\begin{array}{c}\mathrm{R}=0.475 ; \mathrm{P}=0.198 \\
(\mathrm{~ns})\end{array}$ & $\begin{array}{c}\mathrm{R}=0.266 ; \mathrm{P}=0.490 \\
(\mathrm{~ns})\end{array}$ & $\begin{array}{c}\mathrm{R}=0.085 ; \mathrm{P}=0.829 \\
(\mathrm{~ns})\end{array}$ & $\mathrm{N} / \mathrm{A}$ \\
\hline & & Set \#3, GBM ( $n=9)$ & $\begin{array}{c}\mathrm{R}=-0.201 ; \mathrm{P}=0.603 \\
(\mathrm{~ns})\end{array}$ & $\begin{array}{c}\mathrm{R}=0.210 ; \mathrm{P}=0.588 \\
(\mathrm{~ns})\end{array}$ & $\begin{array}{c}\mathrm{R}=-0.059 ; \mathrm{P}=0.881 \\
(\mathrm{~ns})\end{array}$ & $\mathrm{N} / \mathrm{A}$ \\
\hline & & \begin{tabular}{|c|} 
Average of Set \#1, 2, \\
$3(n=9)$ \\
\end{tabular} & $\begin{array}{c}\mathrm{R}=0.091 ; \mathrm{P}=0.836 \\
\text { (ns) }\end{array}$ & $\begin{array}{c}\mathrm{R}=0.016 ; \mathrm{P}=0.967 \\
(\mathrm{~ns})\end{array}$ & $\begin{array}{c}\mathrm{R}=-0.298 ; \mathrm{P}=0.436 \\
(\mathrm{~ns})\end{array}$ & $\mathrm{N} / \mathrm{A}$ \\
\hline & \multirow{3}{*}{$\begin{array}{l}\text { GBM cell } \\
\text { lines from } \\
\text { database }\end{array}$} & $\operatorname{CCLE}(n=45)$ & $\mathrm{N} / \mathrm{A}$ & N/A & $\mathrm{N} / \mathrm{A}$ & $\begin{array}{c}\mathrm{R}=0.065 ; \mathrm{P}=0.673 \\
\text { (ns) }\end{array}$ \\
\hline & & $\operatorname{GDSC}(n=41)$ & $\mathrm{N} / \mathrm{A}$ & N/A & $\mathrm{N} / \mathrm{A}$ & $\begin{array}{c}\mathrm{R}=0.234 ; \mathrm{P}=0.142 \\
(\mathrm{~ns})\end{array}$ \\
\hline & & $\mathrm{NCl}-60(n=5)$ & $\mathrm{N} / \mathrm{A}$ & N/A & $\mathrm{N} / \mathrm{A}$ & $\begin{array}{c}\mathrm{R}=0.142 ; \mathrm{P}=0.819 \\
(\mathrm{~ns})\end{array}$ \\
\hline & $\begin{array}{l}\text { GSC cell } \\
\text { lines }\end{array}$ & $\operatorname{GSC}(n=4)$ & $\begin{array}{c}\mathrm{R}=0.595 ; \mathrm{P}=0.405 \\
\text { (ns) }\end{array}$ & $\begin{array}{c}\mathrm{R}=0.664 ; \mathrm{P}=0.336 \\
(\mathrm{~ns})\end{array}$ & $\begin{array}{c}\mathrm{R}=0.022 ; \mathrm{P}=0.978 \\
\text { (ns) }\end{array}$ & $\mathrm{N} / \mathrm{A}$ \\
\hline \multirow{2}{*}{ Tumor } & \multirow{2}{*}{ Patients } & GBM Tumors $(n=10)$ & $\begin{array}{c}\mathrm{R}=0.490 ; \mathrm{P}=0.150 \\
\text { (ns) }\end{array}$ & $\begin{array}{c}\mathrm{R}=0.606 ; \mathrm{P}=0.084 \\
(\mathrm{~ns})\end{array}$ & $\begin{array}{c}\mathrm{R}=0.729 ; \mathrm{P}=0.03 \\
\left(^{*}\right)\end{array}$ & $\mathrm{N} / \mathrm{A}$ \\
\hline & & TCGA $(n=153)$ & $\mathrm{N} / \mathrm{A}$ & $\mathrm{N} / \mathrm{A}$ & $\mathrm{N} / \mathrm{A}$ & $\begin{array}{c}\mathrm{R}=0.539 ; \mathrm{P}=6.3 \times 10^{-13} \\
\left({ }^{* * *}\right)\end{array}$ \\
\hline
\end{tabular}

Table 3.7. Correlation between protein level and activity level of TOP1, TDP1, as well as TDP1/TOP1 ratio in GBM cell lines, GSC cell lines, and GBM tumors

\begin{tabular}{|c|c|c|c|c|c|c|c|}
\hline \multicolumn{8}{|c|}{ Experimental results } \\
\hline \multirow{3}{*}{\multicolumn{3}{|c|}{ Cell type }} & TOP1 protein & \multirow{2}{*}{\multicolumn{2}{|c|}{$\begin{array}{l}\text { TDP1 protein } \\
\text { vs TDP1 activity }\end{array}$}} & \multirow{2}{*}{\multicolumn{2}{|c|}{$\begin{array}{c}\text { TDP/TOP1 protein ratio } \\
\text { vs TDP1/TOP1 activity ratio }\end{array}$}} \\
\hline & & & vs TOP1 activity & & & & \\
\hline & & & Western blotting & Gel-based assay & FL-based assay & Gel-based assay & FL-based assay \\
\hline \multirow{5}{*}{ Cell lines } & \multirow{4}{*}{$\begin{array}{l}\text { GBM cell } \\
\text { lines }\end{array}$} & Set \#1, GBM $(n=9)$ & $\begin{array}{c}\mathrm{R}=0.629 ; \mathrm{P}=0.069 \\
(\mathrm{~ns})\end{array}$ & $\begin{array}{c}\mathrm{R}=0.708 ; \mathrm{P}=0.033 \\
\left(^{\star}\right)\end{array}$ & $\begin{array}{c}\mathrm{R}=0.664 ; \mathrm{P}=0.051 \\
(\mathrm{~ns})\end{array}$ & $\begin{array}{c}\mathrm{R}=0.669 ; \mathrm{P}=0.05 \\
\left(^{*}\right)\end{array}$ & $\begin{array}{c}\mathrm{R}=0.829 ; \mathrm{P}=0.0006 \\
\left({ }^{\star *}\right)\end{array}$ \\
\hline & & Set \#2, GBM $(n=9)$ & $\begin{array}{c}\mathrm{R}=0.182 ; \mathrm{P}=0.639 \\
(\mathrm{~ns})\end{array}$ & $\begin{array}{c}\mathrm{R}=0.495 ; \mathrm{P}=0.176 \\
(\mathrm{~ns})\end{array}$ & $\begin{array}{c}\mathrm{R}=0.427 ; \mathrm{P}=0.251 \\
(\mathrm{~ns})\end{array}$ & $\begin{array}{c}\mathrm{R}=0.745 ; \mathrm{P}=0.021 \\
\left(^{*}\right)\end{array}$ & $\begin{array}{c}\mathrm{R}=0.720 ; \mathrm{P}=0.029 \\
\left({ }^{*}\right)\end{array}$ \\
\hline & & Set \#3, GBM $(n=9)$ & $\begin{array}{c}\mathrm{R}=0.338 ; \mathrm{P}=0.374 \\
(\mathrm{~ns})\end{array}$ & $\begin{array}{c}\mathrm{R}=0.512 ; \mathrm{P}=0.158 \\
(\mathrm{~ns})\end{array}$ & $\begin{array}{c}\mathrm{R}=0.774 ; \mathrm{P}=0.014 \\
\left(^{*}\right)\end{array}$ & $\begin{array}{c}\mathrm{R}=0.643 ; \mathrm{P}=0.062 \\
\text { (ns) }\end{array}$ & $\begin{array}{c}\mathrm{R}=0.926 ; \mathrm{P}=0.0004 \\
\left(^{\star * *}\right)\end{array}$ \\
\hline & & \begin{tabular}{|c|} 
Average of Set \#1, \\
$2,3(n=9)$ \\
\end{tabular} & $\begin{array}{c}\mathrm{R}=0.446 ; \mathrm{P}=0.229 \\
(\mathrm{~ns})\end{array}$ & $\begin{array}{c}\mathrm{R}=0.644 ; \mathrm{P}=0.061 \\
(\mathrm{~ns})\end{array}$ & $\begin{array}{c}\mathrm{R}=0.812 ; \mathrm{P}=0.008 \\
\left({ }^{* *}\right)\end{array}$ & $\begin{array}{c}\mathrm{R}=0.799 ; \mathrm{P}=0.01 \\
\left(^{*}\right)\end{array}$ & $\begin{array}{c}\mathrm{R}=0.827 ; \mathrm{P}=0.006 \\
(* *)\end{array}$ \\
\hline & $\begin{array}{c}\text { GSC cell } \\
\text { lines }\end{array}$ & $\operatorname{GSC}(n=4)$ & $\begin{array}{c}\mathrm{R}=0.551 ; \mathrm{P}=0.449 \\
\text { (ns) }\end{array}$ & $\begin{array}{c}\mathrm{R}=0.932 ; \mathrm{P}=0.068 \\
(\mathrm{~ns})\end{array}$ & $\begin{array}{c}\mathrm{R}=0.476 ; \mathrm{P}=0.524 \\
\text { (ns) }\end{array}$ & $\begin{array}{c}\mathrm{R}=0.092 ; \mathrm{P}=0.908 \\
(\mathrm{~ns})\end{array}$ & $\begin{array}{c}\mathrm{R}=0.082 ; \mathrm{P}=0.918 \\
(\mathrm{~ns})\end{array}$ \\
\hline Tumor & Patients & $\begin{array}{c}\text { GBM Patients }(n= \\
10)\end{array}$ & $\begin{array}{c}\mathrm{R}=0.913 ; \mathrm{P}=0.0002 \\
\left({ }^{\star \star \star}\right)\end{array}$ & $\begin{array}{c}\mathrm{R}=0.679 ; \mathrm{P}=0.031 \\
\left(^{*}\right)\end{array}$ & $\begin{array}{c}\mathrm{R}=0.798 ; \mathrm{P}=0.006 \\
\left({ }^{* *}\right)\end{array}$ & $\begin{array}{c}\mathrm{R}=0.575 ; \mathrm{P}=0.106 \\
(\mathrm{~ns})\end{array}$ & $\begin{array}{c}\mathrm{R}=0.806 ; \mathrm{P}=0.009 \\
\left({ }^{* *}\right)\end{array}$ \\
\hline
\end{tabular}




\section{CHAPTER IV: SUMMARY}

The research of this dissertation aimed to identify potential predictive biomarkers for the response of devastating glioblastoma (GBM) cancer to topoisomerase I inhibitors treatment in order to improve the efficacy of chemotherapeutic treatment for individual patients. In our study, three different models, GBM cell line, GBM stem cell line (GSC), and GBM patient tumors were used for analyzing the protein expression level and activity level of the inhibitortargeted enzyme topoisomerase I (TOP1) and the essential repair enzyme tyrosylDNA phosphodiesterase 1 (TDP1). Nine GBM cell lines (SNB75, U87, A172, U251, SF258, H4, SF295, SF539, SNB19), four GSC cell lines (GBM1A, GBM1B, GSC11, GSC23), and ten GBM patient tumors (\#17, \#22, \#29, \#42, \#44, \#47, \#49, \#50, \#62, \#66) were used for this study.

GBM cell lines and GSC cell lines were treated with increasing concentrations of Irinotecan (IRT) to obtain the $\mathrm{IC}_{50}$ values. Irinotecan sensitivities, Z-scores, of six different GBM cell lines (SF539, SF295, SF268, SNB18, U251, SNB75) were obtained from the CellMiner database. Irinotecan $\mathrm{IC}_{50}$ values of three different GBM cell lines (SF295, A172, U87) were obtained from the CancerDR database. The fold-increase in TOP1cc levels of two relatively resistant GBM cell lines (A172, SNB75) and three relatively sensitive GBM cell lines (SF295, H4, SNB19) with 15 $\mu M$ IRT treatment were determined by the RADAR assay. TOP1 and TDP1 protein levels from each cell type were determined by western blot analysis, while activity levels were ascertained by specific enzymatic assays. TOP1 activity levels were determined by the relaxation of the negatively supercoiled plasmid DNA. TDP1 
activity levels were determined by the traditional gel-based assay and an alternative fluorescence-based assay. The two assays are strongly correlated (Table 4.1), indicating both assays could be used for TDP1 activity measurement.

Table 4.1 Correlations between gel-based assay and fluorescence-based assay for the measurement of TDP1 activity

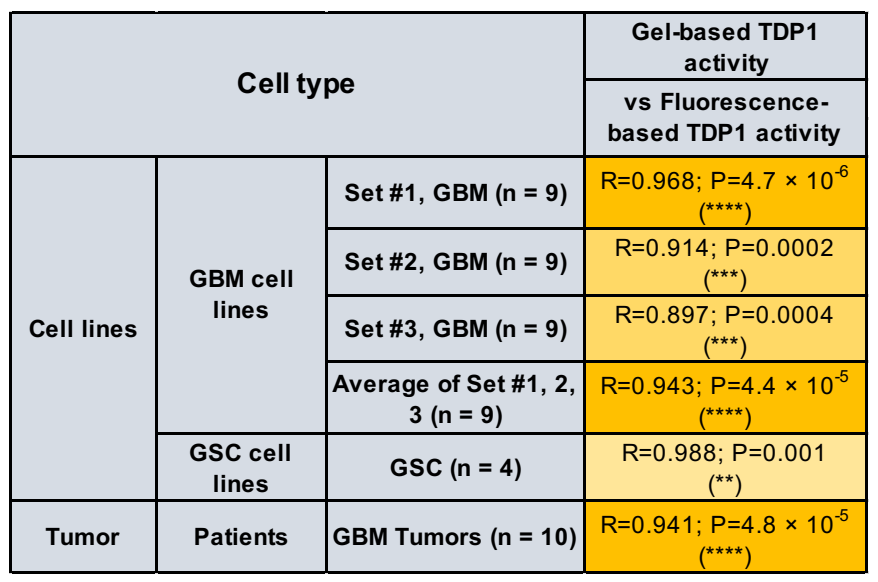

By analyzing the correlations of TOP1, TDP1, and TDP1/TOP1 ratios with IRT sensitivities of GBM cell lines, we found that the experimental IC $\mathrm{C}_{50}$ S of IRT have the highest correlations with TDP1/TOP1 activity ratios (Table 4.2, first row). In addition, the $\mathrm{IC}_{50} \mathrm{~S}$ of IRT from CancerDR database and the Z-scores of IRT from CellMiner database are also highly correlated with TDP1/TOP1 activity ratios (Table 4.2, third row and fourth row). Therefore, we suggest that TDP1/TOP1 activity ratio might be a predictive indicator for the response of GBM cell lines to IRT treatment. Our hypothesis was further proven by analyzing the fold-increase in TOP1cc levels with $15 \mathrm{~min}, 15 \mu \mathrm{M}$ IRT treatment. The lethal TOP1cc level is significantly correlated with TDP1/TOP1 activity ratios (Table 4.2, second row). This observation is consistent with a low TDP1/TOP1 activity ratio leading to 
increased TOP1cc levels and greater Irinotecan sensitivity. Interestingly, TDP1/TOP1 activity ratios are also highly correlated with the sensitivities of GBM cell lines to TOP1 inhibitors, camptothecin and topotecan (Table 4.2, row five and row six). No correlations were observed between TDP1/TOP1 activity ratio and TOP2 inhibitors, etoposide and doxorubicin (Table 4.2, row seven and row eight). The evidence further confirmed that TDP1/TOP1 activity ratio might be a potential predictive biomarker of GBM cell lines to TOP1 inhibitors treatment. Additionally, increase in TDP1 catalytic activity in the WCE from WT-TDP1 but not H263A-TDP1 was also observed along with no change in TOP1 catalytic activity, as expected. GBM cell line, H4, transfected with WT-TDP1 had significantly higher Irinotecan $\mathrm{IC}_{50}$ than $\mathrm{H} 4$ cells transfected with H236A-TDP1 clone (Figure 2.37), demonstrating the correlation between TDP1/TOP1 activity ratio and Irinotecan $\mathrm{IC}_{50}$ for GBM is significant. In addition, carboxylesterase isoform, CES2, which is able to convert IRT to the much more potent metabolite SN-38, has been found to be comparable among the nine GBM cell lines (Figure 2.36). The results further demonstrate that the relatively higher level of resistance of cell lines such as A172 and SNB75 to Irinotecan was not due to lack of CES2 activity in these cells, and Irinotecan sensitivity of SNB19 was not due to the relatively high level of CES2 being present in SNB19. The GBM cells with lower TDP1/TOP1 activity ratio would be more sensitive to TOP1 poison inhibitor is valid with the GBM CES2 activity data being taken into consideration. Therefore, we concluded that the TDP1/TOP1 activity ratio might be a potential predictive indicator for the response of GBM cell lines to the treatment of TOP1 inhibitors. 
However, by analyzing the correlations of TOP1, TDP1, and TDP1/TOP1 ratios with IRT sensitivities of the four GSC cell lines, we did not find any significant correlations between these factors and the experimental IC $\mathrm{C}_{50} \mathrm{~S}$ of IRT (Table 4.2, row nine). The TDP1/TOP1 activity ratio, which is not correlated with GSC sensitivities to IRT treatment, is acting differently from GBM cell lines, demonstrating that the differentiated progeny generated by GSC might behave differently from the established GBM cell lines (135). The results need to be further investigated in future study.

Table 4.2. Correlations between TDP1/TOP1 activity ratio and GBM sensitivities to topoisomerase inhibitors treatment

\begin{tabular}{|c|c|c|c|c|c|c|}
\hline \multirow{2}{*}{\multicolumn{5}{|c|}{ Parameters }} & \multicolumn{2}{|c|}{$\begin{array}{c}\text { Average of TDP1/TOP1 activity } \\
\text { ratio }\end{array}$} \\
\hline & & & & & Gel-based assay & FL-based assay \\
\hline \multirow{9}{*}{$\begin{array}{l}\text { Cell } \\
\text { lines }\end{array}$} & \multirow{8}{*}{$\begin{array}{c}\text { GBM } \\
\text { Cell lines }\end{array}$} & $\mathrm{IC}_{50}$ & TOP1 inhibitor & Irinotecan $(n=9)$ & $\mathrm{R}=0.972 ; \mathrm{P}=1.2 \times 10^{-5}$ & $\begin{array}{c}\mathrm{R}=0.952 ; \mathrm{P}=7.7 \times 10^{-5} \\
{ }_{(\star * \star *}\end{array}$ \\
\hline & & TOP1cc & $15 \mathrm{~min}, 15 \mu \mathrm{M}$ & Irinotecan $(n=6)$ & $\begin{array}{c}\mathrm{R}=-0.932 ; \mathrm{P}=0.021 \\
\left(^{*}\right)\end{array}$ & $\begin{array}{c}R=-0.885 ; P=0.046 \\
\left(^{*}\right)\end{array}$ \\
\hline & & $\begin{array}{l}\mathrm{IC}_{50} \\
\text { (CancerDR } \\
\text { Database) }\end{array}$ & TOP1 inhibitor & Irinotecan $(n=3)$ & $\begin{array}{c}\mathrm{R}=0.991 ; \mathrm{P}=0.0855 \\
\text { (ns) }\end{array}$ & $\begin{array}{c}\mathrm{R}=0.991 ; \mathrm{P}=0.0851 \\
\text { (ns) }\end{array}$ \\
\hline & & \multirow{5}{*}{$\begin{array}{l}\text { Z-score } \\
\text { (CellMiner } \\
\text { Database) }\end{array}$} & \multirow{3}{*}{ TOP1 inhibitor } & Irinotecan $(n=6)$ & $\begin{array}{c}\mathrm{R}=-0.871 ; \mathrm{P}=0.024 \\
\left(^{*}\right)\end{array}$ & $\begin{array}{c}\mathrm{R}=-0.862 ; \mathrm{P}=0.027 \\
\left(^{*}\right)\end{array}$ \\
\hline & & & & Camptothecin $(n=6)$ & $\begin{array}{c}\mathrm{R}=-0.853 ; \mathrm{P}=0.031 \\
\left(^{*}\right)\end{array}$ & $\begin{array}{c}\mathrm{R}=-0.847 ; \mathrm{P}=0.033 \\
\left(^{*}\right)\end{array}$ \\
\hline & & & & Topotecan $(n=6)$ & $\begin{array}{c}\mathrm{R}=-0.803 ; \mathrm{P}=0.068 \\
(\mathrm{~ns})\end{array}$ & $\begin{array}{c}\mathrm{R}=-0.804 ; \mathrm{P}=0.054 \\
(\mathrm{~ns})\end{array}$ \\
\hline & & & \multirow{2}{*}{ TOP2 inhibitor } & Etoposide $(n=6)$ & $\begin{array}{c}\mathrm{R}=-0.627 ; \mathrm{P}=0.183 \\
(\mathrm{~ns})\end{array}$ & $\begin{array}{c}\mathrm{R}=-0.699 ; \mathrm{P}=0.122 \\
(\mathrm{~ns})\end{array}$ \\
\hline & & & & Doxorubicin $(n=6)$ & $\begin{array}{c}\mathrm{R}=-0.029 ; \mathrm{P}=0.956 \\
(\mathrm{~ns})\end{array}$ & $\begin{array}{c}\mathrm{R}=-0.097 ; \mathrm{P}=0.856 \\
(\mathrm{~ns})\end{array}$ \\
\hline & $\begin{array}{l}\text { GSC cell } \\
\text { lines }\end{array}$ & $\mathrm{IC}_{50}$ & TOP1 inhibitor & Irinotecan $(n=4)$ & $\begin{array}{c}\mathrm{R}=0.469 ; \mathrm{P}=0.531 \\
(\mathrm{~ns})\end{array}$ & $\begin{array}{c}\mathrm{R}=0.247 ; \mathrm{P}=0.753 \\
(\mathrm{~ns})\end{array}$ \\
\hline
\end{tabular}


From this dissertation, we demonstrated that the TDP1/TOP1 ratio might be a predictive biomarker for GBM sensitivity to TOP1 inhibitors treatment. The GBM cell lines with relatively lower TDP1/TOP1 ratios are more sensitive to IRT or TOP1 inhibitors treatment, such as SNB19, SF539, SF295, and H4 cell lines (Figure 4.1, panels A1, A2). On the other hand, GBM cell lines with relatively higher TDP1/TOP1 ratios are most likely to be resistant to IRT or TOP1 inhibitors treatment, such as SNB75, U87, and A172 (Figure 4.1, panels A1, A2). For making chemotherapeutic treatment more specific for individual patients, we analyzed ten different GBM patient tumors which were directly collected from surgery (Table 3.1). By analyzing the TDP1/TOP1 activity ratio of the patient tumors, we found as high as ten-fold differences among these samples. The ratio might even be greater in \#62, which has undetectable TOP1 activity. The patients with relatively lower level of TDP1/TOP1 activity ratio, such as \#42, \#17, \#28, and \#66 might be benefited from IRT or other TOP1 inhibitors treatment (Figure 4.1 panels B1, B2). While, patient with relatively higher level of TDP1/TOP1 activity ratio, such as \#44, $\# 47, \# 29$, \#59 and \#62, might not respond from the treatment of TOP1 inhibitors (Figure 4.1 panels B1, B2). The patients with higher TDP1/TOP1 activity ratio probably should not be treated with TOP1 inhibitors to avoid side-effect from chemotherapy medicines that are not likely to be effective. Research on patientderived GBM xenografts in mice models is needed to confirm our hypothesis further. 

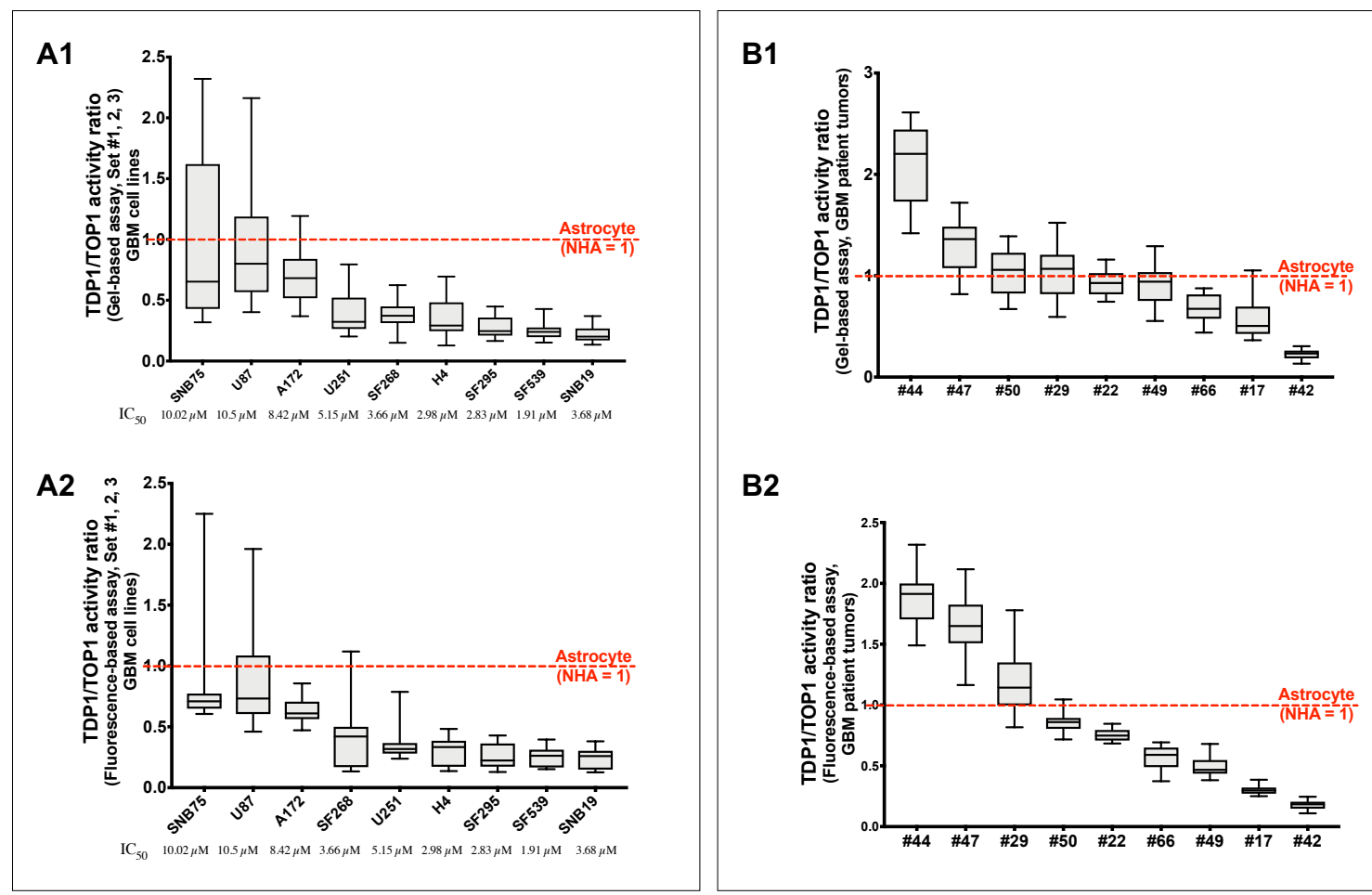

B2

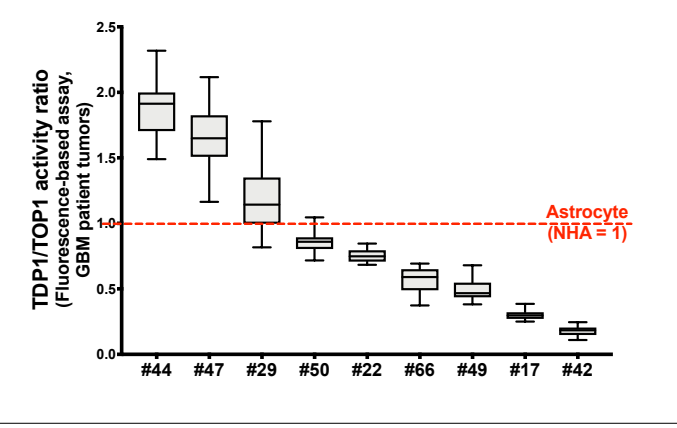

Figure 4.1. TDP1/TOP1 activity ratios of GBM cell lines and patient tumors The box plots of (A1) gel-based TDP1/TOP1 activity ratio and (A2) fluorescencebased TDP1/TOP1 activity ratio of three sets of GBM cell lines. The box plots of (B1) gel-based TDP1/TOP1 activity ratio and (B2) fluorescence-based TDP1/TOP1 activity ratio of GBM patient tumors. The box plots show the median of data from all three sets of experiments with minimum and maximum values at the bottom and top tail-ends. The relative levels were normalized to the levels present in NHA (red dotted line, relative ratio $=1$ ) 


\section{REFERENCES}

1. Louis, D.N., Perry, A., Reifenberger, G., von Deimling, A., Figarella-Branger, D., Cavenee, W.K., Ohgaki, H., Wiestler, O.D., Kleihues, P. and Ellison, D.W. (2016) The 2016 World Health Organization Classification of Tumors of the Central Nervous System: a summary. Acta Neuropathol, 131, 803820.

2. Ostrom, Q.T., Gittleman, H., Liao, P., Vecchione-Koval, T., Wolinsky, Y., Kruchko, C. and Barnholtz-Sloan, J.S. (2017) CBTRUS Statistical Report: Primary brain and other central nervous system tumors diagnosed in the United States in 2010-2014. Neuro-Oncology, 19, V1-V88.

3. Stupp, R., Mason, W.P., van den Bent, M.J., Weller, M., Fisher, B., Taphoorn, M.J., Belanger, K., Brandes, A.A., Marosi, C., Bogdahn, U. et al. (2005) Radiotherapy plus concomitant and adjuvant temozolomide for glioblastoma. N Engl J Med, 352, 987-996.

4. Brandes, A.A. (2003) State-of-the-art treatment of high-grade brain tumors. Semin Oncol, 30, 4-9.

5. Hess, K.R., Broglio, K.R. and Bondy, M.L. (2004) Adult glioma incidence trends in the United States, 1977-2000. Cancer, 101, 2293-2299.

6. Lukas, R.V., Wainwright, D.A., Ladomersky, E., Sachdev, S., Sonabend, A.M. and Stupp, R. (2019) Newly Diagnosed Glioblastoma: A Review on Clinical Management. Oncology (Williston Park), 33, 91-100.

7. Pandith, A.A., Qasim, I., Zahoor, W., Shah, P., Bhat, A.R., Sanadhya, D., Shah, Z.A. and Naikoo, N.A. (2018) Concordant association validates MGMT methylation and protein expression as favorable prognostic factors in glioma patients on alkylating chemotherapy (Temozolomide). Sci Rep, 8, 6704.

8. Hegi, M.E., Diserens, A.C., Gorlia, T., Hamou, M.F., de Tribolet, N., Weller, M., Kros, J.M., Hainfellner, J.A., Mason, W., Mariani, L. et al. (2005) MGMT gene silencing and benefit from temozolomide in glioblastoma. $N$ Engl $J$ Med, 352, 997-1003.

9. Osuka, S. and Van Meir, E.G. (2017) Overcoming therapeutic resistance in glioblastoma: the way forward. J Clin Invest, 127, 415-426.

10. Zhang, X., Zhang, W., Cao, W.D., Cheng, G. and Zhang, Y.Q. (2012) Glioblastoma multiforme: Molecular characterization and current treatment strategy (Review). Exp Ther Med, 3, 9-14. 
11. Shergalis, A., Bankhead, A., 3rd, Luesakul, U., Muangsin, N. and Neamati, N. (2018) Current Challenges and Opportunities in Treating Glioblastoma. Pharmacol Rev, 70, 412-445.

12. Harder, B.G., Blomquist, M.R., Wang, J.W., Kim, A.J., Woodworth, G.F., Winkles, J.A., Loftus, J.C. and Tran, N.L. (2018) Developments in BloodBrain Barrier Penetrance and Drug Repurposing for Improved Treatment of Glioblastoma. Frontiers in Oncology, 8.

13. Housman, G., Byler, S., Heerboth, S., Lapinska, K., Longacre, M., Snyder, N. and Sarkar, S. (2014) Drug resistance in cancer: an overview. Cancers (Basel), 6, 1769-1792.

14. Miller, K.D., Nogueira, L., Mariotto, A.B., Rowland, J.H., Yabroff, K.R., Alfano, C.M., Jemal, A., Kramer, J.L. and Siegel, R.L. (2019) Cancer treatment and survivorship statistics, 2019. CA Cancer J Clin.

15. Jue, T.R., Sena, E.S., Macleod, M.R., McDonald, K.L. and Hirst, T.C. (2018) A systematic review and meta-analysis of topoisomerase inhibition in preclinical glioma models. Oncotarget, 9, 11387-11401.

16. Han, J. and Puri, R.K. (2018) Analysis of the cancer genome atlas (TCGA) database identifies an inverse relationship between interleukin-13 receptor alpha1 and alpha2 gene expression and poor prognosis and drug resistance in subjects with glioblastoma multiforme. J Neurooncol, 136, 463-474.

17. Patel, V.N., Gokulrangan, G., Chowdhury, S.A., Chen, Y., Sloan, A.E., Koyuturk, M., Barnholtz-Sloan, J. and Chance, M.R. (2013) Network signatures of survival in glioblastoma multiforme. Plos Comput Biol, 9, e1003237.

18. Rajapakse, V.N., Luna, A., Yamade, M., Loman, L., Varma, S., Sunshine, M., Iorio, F., Sousa, F.G., Elloumi, F., Aladjem, M.I. et al. (2018) CellMinerCDB for Integrative Cross-Database Genomics and Pharmacogenomics Analyses of Cancer Cell Lines. iScience, 10, 247-264.

19. Noroxe, D.S., Poulsen, H.S. and Lassen, U. (2016) Hallmarks of glioblastoma: a systematic review. ESMO Open, 1, e000144.

20. Paolillo, M., Boselli, C. and Schinelli, S. (2018) Glioblastoma under Siege: An Overview of Current Therapeutic Strategies. Brain Sci, 8.

21. Fann, L.Y., Chen, Y., Chu, D.C., Weng, S.J., Chu, H.C., Wu, A.T.H., Lee, J.F., Ali, A.A.A., Chen, T.C., Huang, H.S. et al. (2018) Identification and preclinical evaluation of the small molecule, NSC745887, for treating 
glioblastomas via suppressing DcR3-associated signaling pathways. Oncotarget, 9, 11922-11937.

22. Wen, P.Y., Chang, S.M., Lamborn, K.R., Kuhn, J.G., Norden, A.D., Cloughesy, T.F., Robins, H.I., Lieberman, F.S., Gilbert, M.R., Mehta, M.P. et al. (2014) Phase I/II study of erlotinib and temsirolimus for patients with recurrent malignant gliomas: North American Brain Tumor Consortium trial 04-02. Neuro Oncol, 16, 567-578.

23. Vredenburgh, J.J., Desjardins, A., Herndon, J.E., 2nd, Dowell, J.M., Reardon, D.A., Quinn, J.A., Rich, J.N., Sathornsumetee, S., Gururangan, S., Wagner, M. et al. (2007) Phase II trial of bevacizumab and Irinotecan in recurrent malignant glioma. Clin Cancer Res, 13, 1253-1259.

24. Gil-Gil, M.J., Mesia, C., Rey, M. and Bruna, J. (2013) Bevacizumab for the treatment of glioblastoma. Clin Med Insights Oncol, 7, 123-135.

25. Wick, W., Chinot, O.L., Bendszus, M., Mason, W., Henriksson, R., Saran, F., Nishikawa, R., Revil, C., Kerloeguen, Y. and Cloughesy, T. (2016) Evaluation of pseudoprogression rates and tumor progression patterns in a phase III trial of bevacizumab plus radiotherapy/temozolomide for newly diagnosed glioblastoma. Neuro Oncol, 18, 1434-1441.

26. Chinot, O.L., Wick, W., Mason, W., Henriksson, R., Saran, F., Nishikawa, R., Carpentier, A.F., Hoang-Xuan, K., Kavan, P., Cernea, D. et al. (2014) Bevacizumab plus radiotherapy-temozolomide for newly diagnosed glioblastoma. N Engl J Med, 370, 709-722.

27. Vredenburgh, J.J., Desjardins, A., Herndon, J.E., 2nd, Marcello, J., Reardon, D.A., Quinn, J.A., Rich, J.N., Sathornsumetee, S., Gururangan, S., Sampson, J. et al. (2007) Bevacizumab plus Irinotecan in recurrent glioblastoma multiforme. J Clin Oncol, 25, 4722-4729.

28. Lim, M., Xia, Y., Bettegowda, C. and Weller, M. (2018) Current state of immunotherapy for glioblastoma. Nat Rev Clin Oncol, 15, 422-442.

29. McGranahan, T., Therkelsen, K.E., Ahmad, S. and Nagpal, S. (2019) Current State of Immunotherapy for Treatment of Glioblastoma. Curr Treat Options Oncol, 20, 24.

30. Khansur, E.M., Shah, A.H., Lacy, K., Kuchakulla, M. and Komotar, R.J. (2018) Novel Immunotherapeutics for the Treatment of Glioblastoma: The Last Decade of Research. Cureus, 10, e2130.

31. Keskin, D.B., Anandappa, A.J., Sun, J., Tirosh, I., Mathewson, N.D., Li, S., Oliveira, G., Giobbie-Hurder, A., Felt, K., Gjini, E. et al. (2019) Neoantigen 
vaccine generates intratumoral $\mathrm{T}$ cell responses in phase $\mathrm{lb}$ glioblastoma trial. Nature, 565, 234-239.

32. Hilf, N., Kuttruff-Coqui, S., Frenzel, K., Bukur, V., Stevanovic, S., Gouttefangeas, C., Platten, M., Tabatabai, G., Dutoit, V., van der Burg, S.H. et al. (2019) Actively personalized vaccination trial for newly diagnosed glioblastoma. Nature, 565, 240-245.

33. Ozdemir-Kaynak, E., Qutub, A.A. and Yesil-Celiktas, O. (2018) Advances in Glioblastoma Multiforme Treatment: New Models for Nanoparticle Therapy. Front Physiol, 9, 170.

34. Lieberman, F. (2017) Glioblastoma update: molecular biology, diagnosis, treatment, response assessment, and translational clinical trials. F1000Res, 6, 1892.

35. Pommier, Y., Sun, Y., Huang, S.N. and Nitiss, J.L. (2016) Roles of eukaryotic topoisomerases in transcription, replication and genomic stability. Nat Rev Mol Cell Biol, 17, 703-721.

36. Pommier, Y., Huang, S.Y., Gao, R., Das, B.B., Murai, J. and Marchand, C. (2014) Tyrosyl-DNA-phosphodiesterases (TDP1 and TDP2). DNA Repair (Amst), 19, 114-129.

37. Chen, S.H., Chan, N.L. and Hsieh, T.S. (2013) New Mechanistic and Functional Insights into DNA Topoisomerases. Annual Review of Biochemistry, Vol 82, 82, 139-+.

38. Schoeffler, A.J. and Berger, J.M. (2008) DNA topoisomerases: harnessing and constraining energy to govern chromosome topology. Q Rev Biophys, 41, 41-101.

39. Pommier, Y., Barcelo, J.M., Rao, V.A., Sordet, O., Jobson, A.G., Thibaut, L., Miao, Z.H., Seiler, J.A., Zhang, H., Marchand, C. et al. (2006) Repair of topoisomerase I-mediated DNA damage. Prog Nucleic Acid Res Mol Biol, 81, 179-229.

40. Sordet, O., Khan, Q.A. and Pommier, Y. (2004) Apoptotic topoisomerase IDNA complexes induced by oxygen radicals and mitochondrial dysfunction. Cell Cycle, 3, 1095-1097.

41. King, I.F., Yandava, C.N., Mabb, A.M., Hsiao, J.S., Huang, H.S., Pearson, B.L., Calabrese, J.M., Starmer, J., Parker, J.S., Magnuson, T. et al. (2013) Topoisomerases facilitate transcription of long genes linked to autism. Nature, 501, 58-+. 
42. Morham, S.G., Kluckman, K.D., Voulomanos, N. and Smithies, O. (1996) Targeted disruption of the mouse topoisomerase I gene by camptothecin selection. Mol Cell Biol, 16, 6804-6809.

43. Sordet, O., Khan, Q.A., Plo, I., Pourquier, P., Urasaki, Y., Yoshida, A., Antony, S., Kohlhagen, G., Solary, E., Saparbaev, M. et al. (2004) Apoptotic topoisomerase I-DNA complexes induced by staurosporine-mediated oxygen radicals. J Biol Chem, 279, 50499-50504.

44. Pommier, Y. (2006) Topoisomerase I inhibitors: camptothecins and beyond. Nat Rev Cancer, 6, 789-802.

45. Lanza, A., Tornaletti, S., Rodolfo, C., Scanavini, M.C. and Pedrini, A.M. (1996) Human DNA topoisomerase I-mediated cleavages stimulated by ultraviolet light-induced DNA damage. J Biol Chem, 271, 6978-6986.

46. Pourquier, P., Waltman, J.L., Urasaki, Y., Loktionova, N.A., Pegg, A.E., Nitiss, J.L. and Pommier, Y. (2001) Topoisomerase I-mediated cytotoxicity of $\mathrm{N}$-methyl-N'-nitro-N-nitrosoguanidine: trapping of topoisomerase I by the O6-methylguanine. Cancer Res, 61, 53-58.

47. Pourquier, P., Ueng, L.M., Kohlhagen, G., Mazumder, A., Gupta, M., Kohn, K.W. and Pommier, Y. (1997) Effects of uracil incorporation, DNA mismatches, and abasic sites on cleavage and religation activities of mammalian topoisomerase I. J Biol Chem, 272, 7792-7796.

48. Norbury, C.J. and Zhivotovsky, B. (2004) DNA damage-induced apoptosis. Oncogene, 23, 2797-2808.

49. Pommier, Y., Barcelo, J.A., Rao, V.A., Sordet, O., Jobson, A.G., Thibaut, L., Miao, Z.H., Seiler, J.A., Zhang, H., Marchand, C. et al. (2006) Repair of topoisomerase I - Mediated DNA damage. Progress in Nucleic Acid Research and Molecular Biology, Vol 81, 81, 179-+.

50. Cuya, S.M., Bjornsti, M.A. and van Waardenburg, R. (2017) DNA topoisomerase-targeting chemotherapeutics: what's new? Cancer Chemother Pharmacol, 80, 1-14.

51. Pommier, Y. (2013) Drugging Topoisomerases: Lessons and Challenges. Acs Chem Biol, 8, 82-95.

52. Hevener, K., Verstak, T.A., Lutat, K.E., Riggsbee, D.L. and Mooney, J.W. (2018) Recent developments in topoisomerase-targeted cancer chemotherapy. Acta Pharm Sin B, 8, 844-861.

53. Pommier, Y. (2009) DNA topoisomerase I inhibitors: chemistry, biology, and interfacial inhibition. Chem Rev, 109, 2894-2902. 
54. Xu, Y. and Her, C. (2015) Inhibition of Topoisomerase (DNA) I (TOP1): DNA Damage Repair and Anticancer Therapy. Biomolecules, 5, 1652-1670.

55. Pommier, Y., Leo, E., Zhang, H.L. and Marchand, C. (2010) DNA Topoisomerases and Their Poisoning by Anticancer and Antibacterial Drugs. Chem Biol, 17, 421-433.

56. Sehouli, J., Stengel, D., Harter, P., Kurzeder, C., Belau, A., Bogenrieder, T., Markmann, S., Mahner, S., Mueller, L., Lorenz, R. et al. (2011) Topotecan Weekly Versus Conventional 5-Day Schedule in Patients With PlatinumResistant Ovarian Cancer: a randomized multicenter phase II trial of the North-Eastern German Society of Gynecological Oncology Ovarian Cancer Study Group. J Clin Oncol, 29, 242-248.

57. ten Bokkel Huinink, W., Lane, S.R., Ross, G.A. and International Topotecan Study, G. (2004) Long-term survival in a phase III, randomised study of topotecan versus paclitaxel in advanced epithelial ovarian carcinoma. Ann Oncol, 15, 100-103.

58. Ardizzoni, A. (2004) Topotecan in the treatment of recurrent small cell lung cancer: an update. Oncologist, 9 Suppl 6, 4-13.

59. Horita, N., Yamamoto, M., Sato, T., Tsukahara, T., Nagakura, H., Tashiro, K., Shibata, Y., Watanabe, H., Nagai, K., Inoue, M. et al. (2015) Topotecan for Relapsed Small-cell Lung Cancer: Systematic Review and MetaAnalysis of 1347 Patients. Sci Rep, 5, 15437.

60. Fuchs, C., Mitchell, E.P. and Hoff, P.M. (2006) Irinotecan in the treatment of colorectal cancer. Cancer Treat Rev, 32, 491-503.

61. Vanhoefer, U., Harstrick, A., Achterrath, W., Cao, S., Seeber, S. and Rustum, Y.M. (2001) Irinotecan in the treatment of colorectal cancer: clinical overview. J Clin Oncol, 19, 1501-1518.

62. Yang, M., Hsu, C.T., Ting, C.Y., Liu, L.F. and Hwang, J. (2006) Assembly of a polymeric chain of SUMO1 on human topoisomerase I in vitro. J Biol Chem, 281, 8264-8274.

63. Ando, K., Shah, A.K., Sachdev, V., Kleinstiver, B.P., Taylor-Parker, J., Welch, M.M., Hu, Y., Salgia, R., White, F.M., Parvin, J.D. et al. (2017) Camptothecin resistance is determined by the regulation of topoisomerase I degradation mediated by ubiquitin proteasome pathway. Oncotarget, 8, 43733-43751.

64. Kummar, S., Chen, A., Ji, J., Zhang, Y., Reid, J.M., Ames, M., Jia, L., Weil, M., Speranza, G., Murgo, A.J. et al. (2011) Phase I study of PARP inhibitor 
ABT-888 in combination with topotecan in adults with refractory solid tumors and lymphomas. Cancer Res, 71, 5626-5634.

65. Thomas, A., Redon, C.E., Sciuto, L., Padiernos, E., Ji, J., Lee, M.J., Yuno, A., Lee, S., Zhang, Y., Tran, L. et al. (2018) Phase I Study of ATR Inhibitor M6620 in Combination With Topotecan in Patients With Advanced Solid Tumors. J Clin Oncol, 36, 1594-1602.

66. Meisenberg, C., Ashour, M.E., El-Shafie, L., Liao, C.Y., Hodgson, A., Pilborough, A., Khurram, S.A., Downs, J.A., Ward, S.E. and El-Khamisy, S.F. (2017) Epigenetic changes in histone acetylation underpin resistance to the topoisomerase I inhibitor Irinotecan. Nucleic Acids Research, 45, 1159-1176.

67. Wang, W. and Tse-Dinh, Y.C. (2019) Recent Advances in Use of Topoisomerase Inhibitors in Combination Cancer Therapy. Curr Top Med Chem.

68. Nitiss, K.C., Malik, M., He, X., White, S.W. and Nitiss, J.L. (2006) TyrosylDNA phosphodiesterase (Tdp1) participates in the repair of Top2-mediated DNA damage. Proc Natl Acad Sci U S A, 103, 8953-8958.

69. Kawale, A.S. and Povirk, L.F. (2018) Tyrosyl-DNA phosphodiesterases: rescuing the genome from the risks of relaxation. Nucleic Acids Research, 46, 520-537.

70. Borda, M.A., Palmitelli, M., Veron, G., Gonzalez-Cid, M. and de Campos Nebel, M. (2015) Tyrosyl-DNA-phosphodiesterase I (TDP1) participates in the removal and repair of stabilized-Top2alpha cleavage complexes in human cells. Mutat Res, 781, 37-48.

71. Ashour, M.E., Atteya, R. and El-Khamisy, S.F. (2015) Topoisomerasemediated chromosomal break repair: an emerging player in many games. Nat Rev Cancer, 15, 137-151.

72. Das, B.B., Huang, S.Y., Murai, J., Rehman, I., Ame, J.C., Sengupta, S., Das, S.K., Majumdar, P., Zhang, H., Biard, D. et al. (2014) PARP1-TDP1 coupling for the repair of topoisomerase I-induced DNA damage. Nucleic Acids Res, 42, 4435-4449.

73. Das, B.B., Antony, S., Gupta, S., Dexheimer, T.S., Redon, C.E., Garfield, S., Shiloh, Y. and Pommier, Y. (2009) Optimal function of the DNA repair enzyme TDP1 requires its phosphorylation by ATM and/or DNA-PK. EMBO J, 28, 3667-3680. 
74. Chiang, S.C., Carroll, J. and El-Khamisy, S.F. (2010) TDP1 serine 81 promotes interaction with DNA ligase Illalpha and facilitates cell survival following DNA damage. Cell Cycle, 9, 588-595.

75. Hudson, J.J.R., Chiang, S.C., Wells, O.S., Rookyard, C. and El-Khamisy, S.F. (2012) SUMO modification of the neuroprotective protein TDP1 facilitates chromosomal single-strand break repair. Nat Commun, 3.

76. Rehman, I., Basu, S.M., Das, S.K., Bhattacharjee, S., Ghosh, A., Pommier, Y. and Das, B.B. (2018) PRMT5-mediated arginine methylation of TDP1 for the repair of topoisomerase I covalent complexes. Nucleic Acids Res, 46, 5601-5617.

77. El-Khamisy, S.F., Saifi, G.M., Weinfeld, M., Johansson, F., Helleday, T., Lupski, J.R. and Caldecott, K.W. (2005) Defective DNA single-strand break repair in spinocerebellar ataxia with axonal neuropathy-1. Nature, 434, 108113.

78. Takashima, H., Boerkoel, C.F., John, J., Saifi, G.M., Salih, M.A., Armstrong, D., Mao, Y., Quiocho, F.A., Roa, B.B., Nakagawa, M. et al. (2002) Mutation of TDP1, encoding a topoisomerase I-dependent DNA damage repair enzyme, in spinocerebellar ataxia with axonal neuropathy. Nat Genet, 32, 267-272.

79. Interthal, H., Chen, H.J., Kehl-Fie, T.E., Zotzmann, J., Leppard, J.B. and Champoux, J.J. (2005) SCAN1 mutant Tdp1 accumulates the enzyme-DNA intermediate and causes camptothecin hypersensitivity. EMBO J, 24, 2224-2233.

80. Alagoz, M., Wells, O.S. and El-Khamisy, S.F. (2014) TDP1 deficiency sensitizes human cells to base damage via distinct topoisomerase I and PARP mechanisms with potential applications for cancer therapy. Nucleic Acids Res, 42, 3089-3103.

81. Quinn, J.A., Jiang, S.X., Reardon, D.A., Desjardins, A., Vredenburgh, J.J., Friedman, A.H., Sampson, J.H., McLendon, R.E., Herndon, J.E., 2nd and Friedman, H.S. (2009) Phase II trial of temozolomide (TMZ) plus Irinotecan (CPT-11) in adults with newly diagnosed glioblastoma multiforme before radiotherapy. J Neurooncol, 95, 393-400.

82. Vredenburgh, J.J., Desjardins, A., Reardon, D.A. and Friedman, H.S. (2009) Experience with Irinotecan for the treatment of malignant glioma. Neuro Oncol, 11, 80-91.

83. Nonnenmacher, L., Westhoff, M.A., Fulda, S., Karpel-Massler, G., Halatsch, M.E., Engelke, J., Simmet, T., Corbacioglu, S. and Debatin, K.M. (2015) 
RIST: a potent new combination therapy for glioblastoma. Int J Cancer, 136, E173-187.

84. Adamson, C., Kanu, O.O., Mehta, A.I., Di, C., Lin, N., Mattox, A.K. and Bigner, D.D. (2009) Glioblastoma multiforme: a review of where we have been and where we are going. Expert Opin Investig Drugs, 18, 1061-1083.

85. Kumar, R., Chaudhary, K., Gupta, S., Singh, H., Kumar, S., Gautam, A., Kapoor, P. and Raghava, G.P. (2013) CancerDR: cancer drug resistance database. Sci Rep, 3, 1445.

86. Shankavaram, U.T., Varma, S., Kane, D., Sunshine, M., Chary, K.K., Reinhold, W.C., Pommier, Y. and Weinstein, J.N. (2009) CellMiner: a relational database and query tool for the $\mathrm{NCl}-60$ cancer cell lines. $\mathrm{Bmc}$ Genomics, 10, 277.

87. Wang, S., Gribskov, M., Hazbun, T.R. and Pascuzzi, P.E. (2016) CellMiner Companion: an interactive web application to explore CellMiner $\mathrm{NCl}-60$ data. Bioinformatics, 32, 2399-2401.

88. Meisenberg, C., Ward, S.E., Schmid, P. and El-Khamisy, S.F. (2014) TDP1/TOP1 Ratio as a Promising Indicator for the Response of Small Cell Lung Cancer to Topotecan. J Cancer Sci Ther, 6, 258-267.

89. Barthelmes, H.U., Habermeyer, M., Christensen, M.O., Mielke, C., Interthal, H., Pouliot, J.J., Boege, F. and Marko, D. (2004) TDP1 overexpression in human cells counteracts DNA damage mediated by topoisomerases I and II. J Biol Chem, 279, 55618-55625.

90. Gomez-Manzano, C., Alonso, M.M., Yung, W.K., McCormick, F., Curiel, D.T., Lang, F.F., Jiang, H., Bekele, B.N., Zhou, X., Alemany, R. et al. (2006) Delta-24 increases the expression and activity of topoisomerase $\mathrm{I}$ and enhances the antiglioma effect of Irinotecan. Clin Cancer Res, 12, 556-562.

91. Bandyopadhyay, K., Li, P. and Gjerset, R.A. (2012) CK2-mediated hyperphosphorylation of topoisomerase I targets serine 506, enhances topoisomerase I-DNA binding, and increases cellular camptothecin sensitivity. PLoS One, 7, e50427.

92. Yu, D., Khan, E., Khaleque, M.A., Lee, J., Laco, G., Kohlhagen, G., Kharbanda, S., Cheng, Y.C., Pommier, Y. and Bharti, A. (2004) Phosphorylation of DNA topoisomerase I by the c-Abl tyrosine kinase confers camptothecin sensitivity. J Biol Chem, 279, 51851-51861. 
93. Liu, C., Zhou, S., Begum, S., Sidransky, D., Westra, W.H., Brock, M. and Califano, J.A. (2007) Increased expression and activity of repair genes TDP1 and XPF in non-small cell lung cancer. Lung Cancer, 55, 303-311.

94. Wang, D., Zou, L., Jin, Q., Hou, J., Ge, G. and Yang, L. (2018) Human carboxylesterases: a comprehensive review. Acta Pharm $\operatorname{Sin}$ B, 8, 699-712.

95. Wang, W., Ghandi, A., Liebes, L., Louie, S.G., Hofman, F.M., Schonthal, A.H. and Chen, T.C. (2011) Effective conversion of Irinotecan to SN-38 after intratumoral drug delivery to an intracranial murine glioma model in vivo. Laboratory investigation. J Neurosurg, 114, 689-694.

96. Shaojun, C., Li, H., Haixin, H. and Guisheng, L. (2018) Expression of Topoisomerase 1 and carboxylesterase 2 correlates with Irinotecan treatment response in metastatic colorectal cancer. Cancer Biol Ther, 19, 153-159.

97. Simplicio, A.L., Coroadinha, A.S., Gilmer, J.F. and Lamego, J. (2013) A methodology for detection and quantification of esterase activity. Methods Mol Biol, 984, 309-319.

98. Kiianitsa, K. and Maizels, N. (2013) A rapid and sensitive assay for DNAprotein covalent complexes in living cells. Nucleic Acids Res, 41, e104.

99. Interthal, H., Pouliott, J.J. and Champoux, J.J. (2001) The tyrosyl-DNA phosphodiesterase Tdp1 is a member of the phospholipase $D$ superfamily. P Natl Acad Sci USA, 98, 12009-12014.

100. Antony, S., Marchand, C., Stephen, A.G., Thibaut, L., Agama, K.K., Fisher, R.J. and Pommier, Y. (2007) Novel high-throughput electrochemiluminescent assay for identification of human tyrosyl-DNA phosphodiesterase (Tdp1) inhibitors and characterization of furamidine (NSC 305831) as an inhibitor of Tdp1. Nucleic Acids Res, 35, 4474-4484.

101. Jensen, P.W., Falconi, M., Kristoffersen, E.L., Simonsen, A.T., Cifuentes, J.B., Marcussen, L.B., Frohlich, R., Vagner, J., Harmsen, C., Juul, S. et al. (2013) Real-time detection of TDP1 activity using a fluorophore-quencher coupled DNA-biosensor. Biosens Bioelectron, 48, 230-237.

102. Wright, C.M., van der Merwe, M., DeBrot, A.H. and Bjornsti, M.A. (2015) DNA Topoisomerase I Domain Interactions Impact Enzyme Activity and Sensitivity to Camptothecin. Journal of Biological Chemistry, 290, 1206812078. 
103. Pommier, Y., Kerrigan, D., Hartman, K.D. and Glazer, R.I. (1990) Phosphorylation of Mammalian DNA Topoisomerase-I and Activation by Protein Kinase-C. Journal of Biological Chemistry, 265, 9418-9422.

104. Raymond, A.C., Staker, B.L. and Burgin, A.B., Jr. (2005) Substrate specificity of tyrosyl-DNA phosphodiesterase I (Tdp1). J Biol Chem, 280, 22029-22035.

105. Capello, M., Lee, M., Wang, H., Babel, I., Katz, M.H., Fleming, J.B., Maitra, A., Wang, H.M., Tian, W.H., Taguchi, A. et al. (2015) Carboxylesterase 2 as a Determinant of Response to Irinotecan and Neoadjuvant FOLFIRINOX Therapy in Pancreatic Ductal Adenocarcinoma. Jnci-J Natl Cancer I, 107.

106. Quinney, S.K., Sanghani, S.P., Davis, W.I., Hurley, T.D., Sun, Z., Murry, D.J. and Bosron, W.F. (2005) Hydrolysis of capecitabine to 5'-deoxy-5fluorocytidine by human carboxylesterases and inhibition by loperamide. $J$ Pharmacol Exp Ther, 313, 1011-1016.

107. Hristova, V.A. and Chan, D.W. (2019) Cancer biomarker discovery and translation: proteomics and beyond. Expert Rev Proteomics, 16, 93-103.

108. Sasmita, A.O., Wong, Y.P. and Ling, A.P.K. (2018) Biomarkers and therapeutic advances in glioblastoma multiforme. Asia Pac J Clin Oncol, 14, 40-51.

109. Perez-Gracia, J.L., Sanmamed, M.F., Bosch, A., Patino-Garcia, A., Schalper, K.A., Segura, V., Bellmunt, J., Tabernero, J., Sweeney, C.J., Choueiri, T.K. et al. (2017) Strategies to design clinical studies to identify predictive biomarkers in cancer research. Cancer Treat Rev, 53, 79-97.

110. Interthal, H. and Champoux, J.J. (2011) Effects of DNA and protein size on substrate cleavage by human tyrosyl-DNA phosphodiesterase 1. Biochem $J, 436,559-566$.

111. Stingele, J., Schwarz, M.S., Bloemeke, N., Wolf, P.G. and Jentsch, S. (2014) A DNA-dependent protease involved in DNA-protein crosslink repair. Cell, 158, 327-338.

112. Sordet, O., Goldman, A., Redon, C., Solier, S., Rao, V.A. and Pommier, Y. (2008) Topoisomerase I requirement for death receptor-induced apoptotic nuclear fission. J Biol Chem, 283, 23200-23208.

113. Huang, X., Traganos, F. and Darzynkiewicz, Z. (2003) DNA damage induced by DNA topoisomerase I- and topoisomerase II-inhibitors detected by histone $\mathrm{H} 2 \mathrm{AX}$ phosphorylation in relation to the cell cycle phase and apoptosis. Cell Cycle, 2, 614-619. 
114. Sordet, O., Khan, Q.A., Kohn, K.W. and Pommier, Y. (2003) Apoptosis induced by topoisomerase inhibitors. Curr Med Chem Anticancer Agents, 3, 271-290.

115. Meisenberg, C., Gilbert, D.C., Chalmers, A., Haley, V., Gollins, S., Ward, S.E. and El-Khamisy, S.F. (2015) Clinical and cellular roles for TDP1 and TOP1 in modulating colorectal cancer response to Irinotecan. Mol Cancer Ther, 14, 575-585.

116. Pavillard, V., Charasson, V., Laroche-Clary, A., Soubeyran, I. and Robert, J. (2004) Cellular parameters predictive of the clinical response of colorectal cancers to Irinotecan. A preliminary study. Anticancer Research, 24, 579585.

117. Proszek, J., Roy, A., Jakobsen, A.K., Frohlich, R., Knudsen, B.R. and Stougaard, M. (2014) Topoisomerase I as a Biomarker: Detection of Activity at the Single Molecule Level. Sensors-Basel, 14, 1195-1207.

118. Payne, S.H. (2015) The utility of protein and mRNA correlation. Trends Biochem Sci, 40, 1-3.

119. Noach, N., Segev, Y., Levi, I., Segal, S. and Priel, E. (2007) Modification of topoisomerase I activity by glucose and by O-GlcNAcylation of the enzyme protein. Glycobiology, 17, 1357-1364.

120. Baranello, L., Wojtowicz, D., Cui, K.R., Devaiah, B.N., Chung, H.J., ChanSalis, K.Y., Guha, R., Wilson, K., Zhang, X.H., Zhang, H.L. et al. (2016) RNA Polymerase II Regulates Topoisomerase 1 Activity to Favor Efficient Transcription. Cell, 165, 357-371.

121. La Thangue, N.B. and Kerr, D.J. (2011) Predictive biomarkers: a paradigm shift towards personalized cancer medicine. Nat Rev Clin Oncol, 8, 587-596.

122. Dirkse, A., Golebiewska, A., Buder, T., Nazarov, P.V., Muller, A., Poovathingal, S., Brons, N.H.C., Leite, S., Sauvageot, N., Sarkisjan, D. et al. (2019) Stem cell-associated heterogeneity in Glioblastoma results from intrinsic tumor plasticity shaped by the microenvironment. Nat Commun, 10, 1787.

123. Jackson, M., Hassiotou, F. and Nowak, A. (2015) Glioblastoma stem-like cells: at the root of tumor recurrence and a therapeutic target. Carcinogenesis, 36, 177-185.

124. Kalkan, R. (2015) Glioblastoma Stem Cells as a New Therapeutic Target for Glioblastoma. Clin Med Insights Oncol, 9, 95-103. 
125. Huang, Z., Cheng, L., Guryanova, O.A., Wu, Q. and Bao, S. (2010) Cancer stem cells in glioblastoma--molecular signaling and therapeutic targeting. Protein Cell, 1, 638-655.

126. Buccarelli, M., Marconi, M., Pacioni, S., De Pascalis, I., D'Alessandris, Q.G., Martini, M., Ascione, B., Malorni, W., Larocca, L.M., Pallini, R. et al. (2018) Inhibition of autophagy increases susceptibility of glioblastoma stem cells to temozolomide by igniting ferroptosis. Cell Death Dis, 9, 841.

127. Caren, H., Stricker, S.H., Bulstrode, H., Gagrica, S., Johnstone, E., Bartlett, T.E., Feber, A., Wilson, G., Teschendorff, A.E., Bertone, P. et al. (2015) Glioblastoma Stem Cells Respond to Differentiation Cues but Fail to Undergo Commitment and Terminal Cell-Cycle Arrest. Stem Cell Reports, 5, 829-842.

128. Tomczak, K., Czerwinska, P. and Wiznerowicz, M. (2015) The Cancer Genome Atlas (TCGA): an immeasurable source of knowledge. Contemp Oncol (Pozn), 19, A68-77.

129. Cancer Genome Atlas Research, N. (2008) Comprehensive genomic characterization defines human glioblastoma genes and core pathways. Nature, 455, 1061-1068.

130. Noushmehr, H., Weisenberger, D.J., Diefes, K., Phillips, H.S., Pujara, K., Berman, B.P., Pan, F., Pelloski, C.E., Sulman, E.P., Bhat, K.P. et al. (2010) Identification of a CpG island methylator phenotype that defines a distinct subgroup of glioma. Cancer Cell, 17, 510-522.

131. Brennan, C.W., Verhaak, R.G., McKenna, A., Campos, B., Noushmehr, H., Salama, S.R., Zheng, S., Chakravarty, D., Sanborn, J.Z., Berman, S.H. et al. (2013) The somatic genomic landscape of glioblastoma. Cell, 155, 462477.

132. Ying, H., Zheng, H., Scott, K., Wiedemeyer, R., Yan, H., Lim, C., Huang, J., Dhakal, S., Ivanova, E., Xiao, Y. et al. (2010) Mig-6 controls EGFR trafficking and suppresses gliomagenesis. Proc Natl Acad Sci U S A, 107, 6912-6917.

133. Kim, H., Huang, W., Jiang, X., Pennicooke, B., Park, P.J. and Johnson, M.D. (2010) Integrative genome analysis reveals an oncomir/oncogene cluster regulating glioblastoma survivorship. Proc Natl Acad Sci U S A, 107, 21832188.

134. Galli, R., Binda, E., Orfanelli, U., Cipelletti, B., Gritti, A., De Vitis, S., Fiocco, R., Foroni, C., Dimeco, F. and Vescovi, A. (2004) Isolation and 
characterization of tumorigenic, stem-like neural precursors from human glioblastoma. Cancer Res, 64, 7011-7021.

135. Lathia, J.D., Mack, S.C., Mulkearns-Hubert, E.E., Valentim, C.L. and Rich, J.N. (2015) Cancer stem cells in glioblastoma. Genes Dev, 29, 1203-1217. 


\section{APPENDIX}

\section{Appendix I: Buffer Preparation}

\section{Part 1: Reaction buffer}

\section{$10 \times$ HTOP1 relaxation buffer (TopoGen)}

$100 \mathrm{mM}$ Tris- $\mathrm{HCl}$ (pH 7.9), $10 \mathrm{mM}$ EDTA (pH 7.9), $1.5 \mathrm{M} \mathrm{NaCl}, 1 \mathrm{mM}$ spermidine, $1 \%(10 \mathrm{mg} / \mathrm{ml} \mathrm{BSA}), 50 \%$ glycerol

\begin{tabular}{|c|c|c|}
\hline & Reagent needed & Volume \\
\hline \multirow{7}{*}{$\begin{array}{l}10 \times \text { HTOP1 } \\
\text { relaxation } \\
\text { buffer }\end{array}$} & $2 \mathrm{M}$ Tris- $\mathrm{HCl}(\mathrm{pH} 7.9)$ & $0.5 \mathrm{~mL}$ \\
\hline & $0.5 \mathrm{M}$ EDTA $(\mathrm{pH} 7.9)$ & $0.2 \mathrm{~mL}$ \\
\hline & $5 \mathrm{M} \mathrm{NaCl}$ & $3 \mathrm{~mL}$ \\
\hline & $0.5 \mathrm{M}$, Spermidine & $0.02 \mathrm{~mL}$ \\
\hline & $100 \mathrm{mg} / \mathrm{mL}$ BSA & $1 \mathrm{~mL}$ \\
\hline & $100 \%$ Glycerol & $5 \mathrm{~mL}$ \\
\hline & Water & $0.28 \mathrm{~mL}$ \\
\hline
\end{tabular}

\section{5 x HTDP1 gel-based assay buffer (TopoGen)}

$100 \mathrm{mM}$ Tris- $\mathrm{HCl}(\mathrm{pH} 7.5) 500 \mathrm{mM} \mathrm{KCl}, 50 \mathrm{mM}$ EDTA, 5 mM DTT

\begin{tabular}{|c|c|c|}
\hline & Reagent needed & Volume \\
\hline \multirow{3}{*}{$5 \times$ HTdp1 } & $2 \mathrm{M}$ Tris- $\mathrm{HCl}(\mathrm{pH} 7.5)$ & $0.5 \mathrm{~mL}$ \\
\cline { 2 - 3 } reaction buffer & $0.5 \mathrm{M} \mathrm{EDTA}(\mathrm{pH} 7.5)$ & $1 \mathrm{~mL}$ \\
\cline { 2 - 3 } (gel-based) & $2 \mathrm{M} \mathrm{KCl}$ & $1.25 \mathrm{~mL}$ \\
\cline { 2 - 3 } & $1 \mathrm{M} \mathrm{DTT}$ & $0.05 \mathrm{~mL}$ \\
\cline { 2 - 3 } & Water & $7.2 \mathrm{~mL}$ \\
\hline
\end{tabular}

$10 \times$ HTDP1 FL-based assay partial buffer

$200 \mathrm{mM}$ Tris- $\mathrm{HCl}(\mathrm{pH} 8.0), 1 \mathrm{M} \mathrm{KCl}, 100 \mathrm{mM}$ EDTA, 0.5\% TritonX-100

\begin{tabular}{|c|c|c|}
\hline & Reagent needed & Volume \\
\hline \multirow{2}{*}{$\begin{array}{c}10 \times \mathrm{HTdp} 1 \\
\text { partial reaction }\end{array}$} & $2 \mathrm{M}$ Tris- $\mathrm{HCl}(\mathrm{pH} 8.0)$ & $20 \mathrm{~mL}$ \\
\cline { 2 - 3 } buffer (FL- & $0.5 \mathrm{M} \mathrm{EDTA}(\mathrm{pH} 7.5)$ & $40 \mathrm{~mL}$ \\
\cline { 2 - 3 } based) & $2 \mathrm{M} \mathrm{KCl}$ & $100 \mathrm{~mL}$ \\
\cline { 2 - 3 } & $100 \%$ TritonX-100 & $1 \mathrm{~mL}$ \\
\hline \multicolumn{2}{|r|}{ Storage 10 $\mathrm{Add}$ HT water to } & $200 \mathrm{~mL}$ \\
\hline \multicolumn{2}{|c|}{ St partial buffer at RT } \\
\hline
\end{tabular}

\section{$5 \times$ HTDP1 FL-based assay buffer}

$100 \mathrm{mM}$ Tris- $\mathrm{HCl}$ (pH 8.0), $500 \mathrm{mM} \mathrm{KCl,} 50 \mathrm{mM}$ EDTA, $50 \mathrm{mM}$ DTT, $0.25 \%$ TritonX-10

\begin{tabular}{|c|c|c|}
\hline & Reagent needed & Volume \\
\hline 5x HTdp1 & $10 \times$ FL partial buffer & $10 \mathrm{~mL}$ \\
\cline { 2 - 3 } reaction buffer & $1 \mathrm{M} \mathrm{DTT}$ & $1 \mathrm{~mL}$ \\
\cline { 2 - 3 } (FL-based) & Water & $9 \mathrm{~mL}$ \\
\hline
\end{tabular}




\section{Part 2: Dilution buffer}

\section{1 x HTOP1 dilution buffer (TopoGen)}

$20 \mathrm{mM} \mathrm{KH}_{2} \mathrm{PO} 4$ (pH 7.4), 1 mM EDTA (pH 7.4), $300 \mathrm{mM} \mathrm{NaCl}$

\begin{tabular}{|c|c|c|}
\hline & Reagent needed & Volume \\
\hline & $1 \mathrm{M} \mathrm{KH}_{2} \mathrm{PO}_{4}(\mathrm{pH} 7.4)$ & $0.2 \mathrm{~mL}$ \\
\cline { 2 - 3 } 1 x HTOP1 & $2 \mathrm{M} \mathrm{NaCl}$ & $1.5 \mathrm{~mL}$ \\
\cline { 2 - 3 } Dilution buffer & $0.5 \mathrm{M} \mathrm{EDTA}(\mathrm{pH} 7.4)$ & $0.02 \mathrm{~mL}$ \\
\cline { 2 - 3 } & Water & $8.28 \mathrm{~mL}$ \\
\hline
\end{tabular}

\section{Part 3. Storage buffer}

\section{$1 \times$ HTOP1 Storage buffer (TopoGen)}

$20 \mathrm{mM} \mathrm{NaH}_{2} \mathrm{PO}_{4}(\mathrm{pH} 7.4), 300 \mathrm{mM} \mathrm{NaCl}, 50 \mu \mathrm{g} / \mathrm{mL}$ BSA, $50 \%$ Glycerol, $50 \mathrm{mM}$ Imidazole

\begin{tabular}{|c|c|c|}
\hline & Reagent needed & Volume \\
\hline \multirow{4}{*}{$\begin{array}{c}\text { 1 } \\
\text { Storage buffer }\end{array}$} & $1 \mathrm{M} \mathrm{NaH}_{2} \mathrm{PO} 4(\mathrm{pH} 7.4)$ & $20 \mathrm{~mL}$ \\
\cline { 2 - 3 } & $5 \mathrm{M} \mathrm{NaCl}$ & $60 \mathrm{~mL}$ \\
\cline { 2 - 3 } & $10 \%(100 \mathrm{mg} / \mathrm{mL}) \mathrm{BSA}$ & $0.5 \mathrm{~mL}$ \\
\cline { 2 - 3 } & $1 \mathrm{M} \mathrm{Imidazole}$ & $50 \mathrm{~mL}$ \\
\cline { 2 - 3 } & Water & To $1 \mathrm{~L}$ \\
\hline
\end{tabular}

\section{$1 \times$ HTDP1 storage buffer (Dr. Pommier)}

$20 \mathrm{mM}$ HEPES, pH 7.3,50 mM KCl, $20 \mathrm{mM}$ DTT, $1 \mathrm{mM}$ EDTA, 50\% glycerol

\begin{tabular}{|c|c|c|}
\hline & Reagent needed & Volume \\
\hline \multirow{4}{*}{ 1 x HTdp1 } & $1 \mathrm{M} \mathrm{HEPES}(\mathrm{pH} 7.3)$ & $0.2 \mathrm{~mL}$ \\
\cline { 2 - 3 } Storage buffer & $0.5 \mathrm{M} \mathrm{EDTA}(\mathrm{pH} 7.3)$ & $0.02 \mathrm{~mL}$ \\
\cline { 2 - 3 } & $2 \mathrm{M} \mathrm{KCl}$ & $0.25 \mathrm{~mL}$ \\
\cline { 2 - 3 } & $1 \mathrm{M} \mathrm{DTT}$ & $0.2 \mathrm{~mL}$ \\
\cline { 2 - 3 } & $100 \%$ Glycerol & $5 \mathrm{~mL}$ \\
\cline { 2 - 3 } & Water & $4.33 \mathrm{~mL}$ \\
\hline
\end{tabular}

\section{Part 4. Stop solutions}

\section{$2 \times$ gel-based assay stop solution (TopoGen):}

$96 \%$ formamide, $20 \mathrm{mM}$ EDTA, $0.03 \%$ xylene cyanol and $0.03 \%$ bromophenol blue

\begin{tabular}{|c|c|c|}
\hline & Reagent needed & Volume \\
\hline \multirow{3}{*}{$2 \times$ Stop Buffer } & $100 \%$ formamide & $9.6 \mathrm{~mL}$ \\
\cline { 2 - 3 } & $0.5 \mathrm{M} \mathrm{EDTA}(\mathrm{pH} 8.0)$ & $0.4 \mathrm{~mL}$ \\
\cline { 2 - 3 } & Bromophenol blue & $3 \mathrm{mg}$ \\
\cline { 2 - 3 } & Xylene cyanol & $3 \mathrm{mg}$ \\
\hline
\end{tabular}

\section{$6 \times$ SDS stop solution:}

$6 \%$ SDS, $0.6 \%$ bromophenol blue, $40 \%$ glycerol

\begin{tabular}{|c|c|c|}
\hline & Reagent needed & Volume \\
\hline \multirow{2}{*}{$\begin{array}{c}6 \times \text { SDS Stop } \\
\text { Buffer }\end{array}$} & $10 \%$ SDS & $6 \mathrm{~mL}$ \\
\cline { 2 - 3 } & Bromophenol blue & $60 \mathrm{mg}$ \\
\cline { 2 - 3 } & $100 \%$ Glycerol & $4 \mathrm{~mL}$ \\
\hline
\end{tabular}




\section{$4 \times$ SDS protein loading buffer}

\begin{tabular}{|c|c|c|}
\hline & Reagent needed & Volume \\
\hline \multirow{5}{*}{$\begin{array}{c}\text { Partial } 4 x \\
\text { SDS protein } \\
\text { loading buffer }\end{array}$} & $0.5 \mathrm{M}$ Tris- $\mathrm{HCl}(\mathrm{pH} 6.8)$ & $0.5 \mathrm{~mL}$ \\
\hline & SDS $($ solid/g) & $0.8 \mathrm{~g}$ \\
\hline & $100 \%$ glycerol & $4 \mathrm{~mL}$ \\
\hline & Bromophenol blue & $40 \mathrm{mg}$ \\
\hline & Add water to & $9.5 \mathrm{~mL}$ \\
\hline
\end{tabular}

\section{Part 5: Other assay buffers}

\section{$1 \times$ Coomassie Brilliant Blue G-250 Staining}

\begin{tabular}{|c|c|c|}
\hline $35 \mathrm{mM}(0.11 \%) \mathrm{HCl}, 0.6 \%-0.8 \%$ & $\mathrm{CBB} \mathrm{G}-250$ \\
\hline $1 \times$ Coomassie & Reagent needed & Volume \\
\cline { 2 - 3 } & $\mathrm{G}-250$ & $6-8 \mathrm{~g}$ \\
\cline { 2 - 3 } brilliant blue & $12.1 \mathrm{M} \mathrm{HCl}(37.5 \%)$ & $2.9 \mathrm{~mL}$ \\
\hline 250 Staining & Add water to & $1 \mathrm{~L}$ \\
\hline \multicolumn{3}{|c|}{ Stir 2-3 h, brown bottle, RT } \\
\hline
\end{tabular}

\section{$1 \times$ SDS running buffer}

$25 \mathrm{mM}$ Tris- $\mathrm{HCl}, 192 \mathrm{mM}$ glycine, $0.1 \%$ SDS

\begin{tabular}{|c|c|c|}
\hline & Reagent needed & Volume \\
\hline \multirow{3}{*}{$\begin{array}{c}\text { SD sunning } \\
\text { buffer }\end{array}$} & Tris base (solid/g) & $3.03 \mathrm{~mL}$ \\
\cline { 2 - 3 } & Glycine (solid/g) & $14.4 \mathrm{~g}$ \\
\cline { 2 - 3 } & $10 \%$ SDS & $10 \mathrm{~mL}$ \\
\cline { 2 - 3 } & Add water to & $1 \mathrm{~L}$ \\
\hline
\end{tabular}

\section{$1 \times$ Tank blotting buffer (Bjerrum Schafer-Nielsen buffer)}

$48 \mathrm{mM}$ Tris (pH 9.2), $39 \mathrm{mM}$ glycine, $20 \%$ methanol, $0.1 \%-0.4 \%$ SDS (alternative)

\begin{tabular}{|c|c|c|}
\hline & Reagent needed & Volume \\
\hline \multirow{4}{*}{$\begin{array}{c}\text { 1 } \\
\text { buffer }\end{array}$} & Tris base & $5.82 \mathrm{~g}$ \\
\cline { 2 - 3 } & Glycine & $2.93 \mathrm{~g}$ \\
\cline { 2 - 3 } & Methanol & $200 \mathrm{~mL}$ \\
\cline { 2 - 3 } & $10 \%$ SDS(Alternative) & $4 \mathrm{~mL}$ \\
\cline { 2 - 3 } & Add water to & $1 \mathrm{~L}$ \\
\hline \multicolumn{2}{|c|}{ ICE Bag, stir bar, cold room, 100 V transfer $1 \mathrm{~h}$} \\
\hline
\end{tabular}

\section{$50 \times \operatorname{TAE}(\mathrm{pH} 8.5)$}

\begin{tabular}{|c|c|c|}
\hline 2 M Tris, $50 \mathrm{mM}$ EDTA, $1 \mathrm{M}$ acetic acid \\
\hline \multirow{3}{*}{$50 \times$ TAE } & Reagent needed & Weight/Volum \\
\cline { 2 - 3 } & Tris & $242 \mathrm{~g}$ \\
\cline { 2 - 3 } & $0.5 \mathrm{M}$ EDTA $(\mathrm{pH} 8.0)$ & $100 \mathrm{~mL}$ \\
\cline { 2 - 3 } & $100 \%$ Acetic acid & $57.1 \mathrm{~mL}$ \\
\hline
\end{tabular}




\section{$10 \times$ TBE ( pH 8.3)}

$0.89 \mathrm{M}$ Trizma-Boric acid (pH 8.3), $0.02 \mathrm{M}$ EDTA

\begin{tabular}{|c|c|c|}
\hline & Reagent needed & Volume \\
\hline \multirow{3}{*}{$10 \times$ TBE } & Tris base & $108 \mathrm{~g}$ \\
\cline { 2 - 3 } & $0.5 \mathrm{M} \mathrm{EDTA}(\mathrm{pH} 8.0)$ & $40 \mathrm{~mL}$ \\
\cline { 2 - 3 } & Boric acid & $55 \mathrm{~g}$ \\
\cline { 2 - 3 } & Add water to & $1 \mathrm{~L}$ \\
\hline
\end{tabular}

\section{$10 \times$ TBS (Tris-Buffered Saline)}

$200 \mathrm{mM}$ Tris- $\mathrm{HCl}(\mathrm{pH} 7.5), 1.5 \mathrm{M} \mathrm{NaCl}$

\begin{tabular}{|c|c|c|}
\hline & Reagent needed & Volume \\
\hline \multirow{3}{*}{$10 \times$ TBS } & Tris base- $\mathrm{HCl}(\mathrm{pH}$ to 7.5$)$ & $12.114 \mathrm{~g}$ \\
\cline { 2 - 3 } & $\mathrm{NaCl}$ & $43.83 \mathrm{~g}$ \\
\cline { 2 - 3 } & Add water to & $500 \mathrm{~mL}$ \\
\hline
\end{tabular}

\section{$1 \times$ TBST}

$20 \mathrm{mM}$ Tris- $\mathrm{HCl}(\mathrm{pH} 7.5), 150 \mathrm{mM} \mathrm{NaCl}, 0.1 \%$ Tween 20

\begin{tabular}{|c|c|c|}
\hline & Reagent needed & Volume \\
\hline \multirow{3}{*}{$1 \times$ TBST } & $10 \times$ TBS & $100 \mathrm{~mL}$ \\
\cline { 2 - 3 } & Tween 20 & $1 \mathrm{~mL}$ \\
\cline { 2 - 3 } & Add water to & $1 \mathrm{~L}$ \\
\hline
\end{tabular}

\section{$1 \times T E(p H 8.0)$}

$10 \mathrm{mM}$ Tris-HC (pH 8.0), 1 mM EDTA (pH 8.0)

\begin{tabular}{|c|c|c|}
\hline & Reagent needed & Weight/Volum \\
\hline \multirow{3}{*}{$1 \times \mathrm{TE}$} & $1 \mathrm{M}$ Tris- $\mathrm{HCl}(\mathrm{pH} 8.0)$ & $20 \mathrm{~mL}$ \\
\cline { 2 - 3 } & $0.5 \mathrm{M} \mathrm{EDTA}(\mathrm{pH} 8.0)$ & $4 \mathrm{~mL}$ \\
\cline { 2 - 3 } & Water & To $2 \mathrm{~L}$ \\
\hline
\end{tabular}

\section{$1 \times \mathrm{TE}-\mathrm{NaCl}(\mathrm{pH} \mathrm{8.0)}$}

$10 \mathrm{mM}$ Tris-HC (pH 8.0), 1 mM EDTA (pH 8.0), $200 \mathrm{mM} \mathrm{NaCl}$

\begin{tabular}{|c|c|c|}
\hline & Reagent needed & Volume \\
\hline \multirow{3}{*}{$1 \times \mathrm{TE} \mathrm{NaCl}$} & $1 \mathrm{M}$ Tris- $\mathrm{HCl}(\mathrm{pH} 8.0)$ & $40 \mathrm{~mL}$ \\
\cline { 2 - 3 } & $0.5 \mathrm{M} \mathrm{EDTA}(\mathrm{pH} 8.0)$ & $8 \mathrm{~mL}$ \\
\cline { 2 - 3 } & $1 \mathrm{M} \mathrm{NaCl}$ & $400 \mathrm{~mL}$ \\
\cline { 2 - 3 } & Water & To $4 \mathrm{~L}$ \\
\hline
\end{tabular}


VITA

WENJIE WANG

2007-2011

B.S., Bioengineering

Hebei University of Technology City Institute

Tianjin, China

2011-2014

M.S., Physical Chemistry

Capital Normal University

Beijing, China

2014-2019

Ph.D., Chemistry

Florida International University

Miami, FL

PRESENTATIONS \& PUBLICATIONS \& PATENTS \& HONORS

Worlds Ahead Graduate

Florida International University, Miami, Florida

Dissertation Year Fellowship

Florida International University, Miami, Florida
2019 Summer Commencement

January 2019 - July 2019

Wang, W., Silva, M., Rocha, A., Wolf, A., Lai, Y., Liu, Y., Reinhold, W., Pommier, Y., Chambers, J., Tse-Dinh, Y.C. Tyrosyl-DNA phosphodiesterase 1 and topoisomerase I activity as predictive indicators for glioblastoma susceptibility to genotoxic agents. In preparation

Wang, W., Tse-Dinh, Y.C. Recent advances in use of topoisomerase inhibitors in combination cancer Therapy. Current topics in medicinal chemistry (2019). doi: 10.2174/1568026619666190401113350. [Epub ahead of print]

Garcia, P.K., Annamalai, T., Wang, W., Bell, R.S., Le, D., Pancorbo, P.M., Sikandar, S., Seddek, A., Yu, X., Sun, D. and Uhlemann, A.C., Leng, F., Tse-Dinh, Y.C. (2019) Mechanism and resistance for antimycobacterial activity of a fluoroquinophenoxazine compound. PLoS ONE, 14(2), p.e0207733.

Gupta, R., Felix, C.R., Akerman, M.P., Akerman, K.J., Slabber, C.A., Wang, W., Adams, J., Shaw, L.N., Tse-Dinh, Y.C., Munro, O.Q. and Rohde, K.H. (2018). Evidence for inhibition of topoisomerase $1 \mathrm{~A}$ by gold (III) macrocycles and chelates targeting Mycobacterium tuberculosis and Mycobacterium abscessus. Antimicrobial agents and chemotherapy, 62(5), e01696-17.

Wang, W., Silva, M., Chambers, J., Pommier, Y., Tse-Dinh, Y.C. TDP1/TOP1 activity ratio as a predictive indicator for the response of glioblastoma cancer cells 
to Irinotecan treatment. Poster presentation at DNA Topoisomerases in Biology and Medicine, Gordon Research Conference (GRC) meeting, July $29^{\text {th }}$ to August $3^{\text {rd }}, 2018$, South Hadley, MA

Wang, W., Silva, M., Chambers, J., Pommier, Y., Tse-Dinh, Y.C. TDP1/TOP1 activity ratio as a predictive indicator for the response of glioblastoma cancer cells to Irinotecan treatment. DNA Topoisomerases in Biology and Medicine, Gordon Research Seminar (GRS) meeting, July $28^{\text {th }}$ to $29^{\text {th }}, 2018$, South Hadley, MA

Wang, W., Silva, M., Chambers, J., Tse-Dinh, Y.C. TDP1/TOP1 ratio as a predictive indicator for the response of glioblastoma cancer cells to Irinotecan treatment. 9th Annual Biomedical \& Comparative Immunology Symposium (BCl), Florida International University, March $31^{\text {st }}, 2017$, Miami, FL

Wang, W., Silva, M., Chambers, J., Tse-Dinh, Y.C. TDP1/TOP1 ratio as a predictive indicator for the response of glioblastoma cancer cells to Irinotecan treatment. $22^{\text {nd }}$ Society for Neuro-Oncology (SNO) annual meeting, November 17th, 2017, San Francisco, CA

Wang, W., Ding, X., Xu, Q., Wang, J., Wang, L., and Lou, X. (2016). Zeta-potential data reliability of gold nanoparticle biomolecular conjugates and its application in sensitive quantification of surface absorbed protein. Colloids and Surfaces B: Biointerfaces, 148, 541-548.

Wang, W., Ding, X., He, M., Wang, J., and Lou, X. (2014). Kinetic adsorption profile and conformation evolution at the DNA-gold nanoparticle interface probed by dynamic light scattering. Analytical Chemistry, 86(20), 10186-10192.

Lou, X., Wang, W., and Ding, X. A method for measuring the conformation evolution of the thiolated linear DNA and aptamers at the DNA-gold nanoparticle interface. China patent, No. 20140171224.9

Lou, X., Zou, R., Zhang, Y., and Wang, W. A method for improving PCR reaction. China patent, No. 201310043855.8

Wang, W., Wang, J., and Lou, X. In Situ Monitoring of the Immobilization Process of Protein and DNAs on Gold Nanoparticles and Protein-Aptamer Binding vis Zetapotential Measurements. $6^{\text {th }}$ Shanghai International Symposium on Analytical Chemistry, October $17^{\text {th }}, 2012$, Shanghai, China

Zou, R., Lou, X., Ou, H., Zhang, Y., Wang, W., Yuan, M., Guan, M., Luo, Z., and Liu, Y. (2012). Highly specific triple-fragment aptamer for optical detection of cocaine. RSC Advances, 2(11), 4636-4638. 